\title{
Genetical Aspects of Bone Stability in Laying Hens Differing in Phylogeny and Performance Level
}

\author{
Dissertation \\ to attain the doctoral degree (Dr. sc. agr.) \\ of the Faculty of Agricultural Sciences, \\ Georg-August-Universität Göttingen
}

Submitted by

Simon Jansen

born in Cloppenburg

Göttingen, June 2021 
This thesis was carried out at the Institute of Farm Animal Genetics, Friedrich-Loeffler-Institut, Federal Research Institute for Animal Health, 31535 Neustadt, Germany.

1st Referee: Dr. Ahamd Reza Sharifi

Animal Breeding and Genetics Group

University of Göttingen

2nd Referee: Prof. Dr. Armin Otto Schmitt

Breeding Informatics Group

University of Göttingen

3rd Referee: apl. Prof. Dr. Steffen Weigend

Institute of Farm Animal Genetics

Friedrich-Loeffler-Institut

4th Referee: Prof. Dr. Georg Thaller

Institute for Animal Breeding and Husbandry

Christian-Albrechts-University Kiel

Date of oral examination: 10 September 2021 


\section{Table of Contents}

Summary . . . . . . . . . . . . . . . . . . . . . . 5

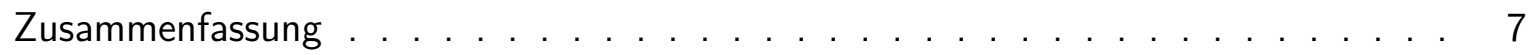

1 General Introduction $\quad 9$

1.1 A Brief History of Layer Breeding . . . . . . . . . . . . . . . . . . . . . . . . 9

1.2 Fundamentals on Avian Bone Biology . . . . . . . . . . . . . . . . . . . . . . 10

1.3 Skeletal Disorders in Laying Hens . . . . . . . . . . . . . . . . . . . . . . . . 13

1.4 Genetics — An Integral Part of Bone Stability . . . . . . . . . . . . . . . . . 15

1.5 Environmental Factors Influencing Bone Stability . . . . . . . . . . . . . . . 19

1.6 Thesis Aim and Objectives . . . . . . . . . . . . . . . . . . . . . . . . . . . . 20

1.7 References . . . . . . . . . . . . . . . . . . . . . . 21

2 Relationship between Bone Stability and Egg Production in Genetically Divergent Chicken Layer Lines

3 Bone Health or Performance? Adaptation Response of Genetically Divergent Chicken Layer Lines to a Nutritive Calcium Depletion

4 Identification and Functional Annotation of Genes Related to Bone Stability in Laying Hens Using Genome-wide Association Analyses

5 General Discussion

5.1 Phylogenetic Origin and Egg Production Level - Two Main Determinants? . . 121

5.2 Potential of Genetics to Improve Bone Stability . . . . . . . . . . . . . . 126

5.3 General Conclusions . . . . . . . . . . . . . . . . . . . . . . . . . . 129

5.4 References . . . . . . . . . . . . . . . . . . . . . . . . . 130

6 Appendix 135

6.1 Corrigendum . . . . . . . . . . . . . . . . . . . . . . . . 136

6.2 Acknowledgements . . . . . . . . . . . . . . . . . . . . . . . . . 141

6.3 Declarations . . . . . . . . . . . . . . . . . . . . . . . . . . . . . . 142 



\section{Summary}

Skeletal disorders in laying hens is one of the most serious problems facing the egg production industry and is gaining increasing attention due to changes in husbandry systems and overall increased public concern about hen welfare. There are a high number of hens in commercial flocks suffering from bone weakness and fractures due to osteoporosis, which has serious animal welfare implications. Genetics have been found to substantially affect skeletal integrity, although little is yet known about the exact mechanisms. Therefore, the aim of this thesis was to further characterise the influence of genetics on the differentiation of bone stability and to evaluate its potential for improving bone health in laying hens. The experimental part of this work involves three studies, in which an animal model was applied comprising four purebred layer lines differing in their phylogenetic origin (brown vs. white-egg) and egg production level (high vs. moderate performing).

In the first study (Chapter 2), we aimed at analysing the relationship between bone stability and egg production using the four-line animal model. Besides basic characterisation of skeletal traits in these lines, multifactorial models and regression analyses were employed to identify factors determining the bone breaking strength (BBS) and bone mineral density (BMD) of the tibiotarsus and humerus. While the morphometry of the bones had limited effects on their BBS, the BMD was found to be a decisive factor accounting for a high amount of the observed variance in BBS. Strong phylogenetic effects were only observed in relation to bone dimensions, in that the bones of the brown-egg lines were larger and heavier and had a higher BMD than those of the white-egg ones. Although both high performing lines were superior to the moderate performing ones in terms of production traits and inferior in terms of BMD, there was no effect of total eggshell production on BBS or BMD within the lines studied. Contrary to what was suspected, the results did not provide evidence for a negative association between egg production and bone health and we concluded that a high egg number does not necessarily pose a risk for bone weakness. Finally, genetic parameter estimations implied an inherited component of BBS and BMD, supporting the role of genetics in skeletal traits.

The aim of the second study (Chapter 3) was to examine skeletal traits under the metabolically challenging situation of repeated dietary calcium restrictions. Within and among the four chicken lines of our animal model, the hens' adaptation response was characterised with regard to the effects of phylogeny and performance level. Calcium depletions led to a decrease in egg number and eggshell quality in all lines, but recovery occurred after reconversion to adequate supply. Substantial bone demineralisation was observed post mortem. These results may reflect the attempt to maintain reproductive performance at the expense of skeletal integrity. It turned out that the performance level influenced the adaptation response less than phylogeny. In this regard, the white-egg lines showed a more pronounced response whereas the brown-egg ones seemed to be less sensitive towards reduced calcium levels. The latter was explained by a more favourable body constitution of these lines, where higher amounts of calcium could be provided by the skeletal system without severely compromising bone health. 
In the third study (Chapter 4), the BBS and BMD measurements obtained in the first experiment were examined from a genomic perspective to see whether genomic regions associated with bone stability could be identified. To this end, the four layer lines were combined to one set. Two alternate approaches were applied for single nucleotide polymorphisms (SNP) selection including single-locus mixed linear model analysis and machine learning-based Random Forests classification. The latter method seem more robust in terms of population stratification bias. Sixteen potential candidate genes located in close proximity to the SNPs were identified by subsequent functional analyses. These genes are supposed to be functionally related to the skeleton in chickens or humans. Moreover, gene set enrichment analysis showed that some of these candidate genes are involved in the same metabolic pathways critical for bone metabolism. The results met our expectations in that they suggest that multiple genes, each of which has a rather small effect size given the calculated SNP effect estimates, determine bone stability. Though the candidates presented in this study are putative and causality has yet to be proven, they are promising in terms of bone biology.

Overall, this work identified genetics as a major determinant of bone stability in laying hens. However, the performance level of the hens does not seem to play a decisive role, as no correlations between hen productivity and bone stability were observed. In contrast, a phylogenetic effect is to be assumed which, according to current knowledge, is most likely based on an advantageous physical constitution of the brown-egg lines. Given moderate inheritance of bone traits, there is the possibility of genetic selection for improved skeletal health. Since multiple genes regulate bone stability, genetic improvement should be achievable through the increased use of genomic information. 


\section{Zusammenfassung}

Knochenschäden stellen eines der größten Probleme in der Legehennenzucht dar und die Thematik rückt durch veränderte Haltungssysteme sowie ein insgesamt gestiegenes Bewusstsein für den Tierschutz zunehmend in den Fokus der Öffentlichkeit. Der Anteil der kommerziellen Hennen, die an Knochenschwäche und Frakturen aufgrund von Osteoporose leiden, ist hoch, was schwerwiegende Auswirkungen auf das Wohlergehen der Tiere hat. Obwohl die Genetik als einer der entscheidenden Einflussfaktoren für die Knochenstabilität identifiziert wurde, ist bisher nur wenig über die genauen genetischen Mechanismen bekannt. Daher war das Ziel dieser Arbeit, die nähere Charakterisierung des Einflusses der Genetik auf die Differenzierung der Knochenstabilität sowie die Abschätzung ihres Potentials zur Verbesserung der Knochengesundheit bei Legehennen. Der experimentelle Teil der Arbeit umfasst drei Studien, in denen ein Tiermodell verwendet wurde, welches vier Reinzuchtlegelinien beinhaltet. Diese Linien unterscheiden sich hinsichtlich ihrer phylogenetischen Abstammung (Braun- vs. Weißleger) und Legeleistung (hoch- vs. minderleistend).

Das Ziel der ersten Studie (Kapitel 2) war es, den Zusammenhang zwischen Knochenstabilität und Eiproduktion anhand des Vier-Linien-Tiermodells zu analysieren. Neben der grundlegenden Beschreibung von Knochenmerkmalen dieser Linien wurden multifaktorielle Modelle und Regressionsanalysen eingesetzt, um Faktoren zu identifizieren, welche die Knochenbruchfestigkeit (BBS) und die Knochenmineraldichte (BMD) des Tibiotarsus und Humerus beeinflussen. Während die Knochenmaße nur begrenzte Auswirkungen auf die BBS hatten, erwies sich die BMD als entscheidender Faktor, der einen großen Teil der beobachteten Varianz in der BBS erklärte. Deutliche phylogenetische Effekte wurden nur in Bezug auf die Knochenmaße beobachtet, wobei die Knochen der Braunleger größer und schwerer waren und eine höhere BMD aufwiesen als die der Weißleger. Obwohl die beiden Hochleistungslinien den minderleistenden in Bezug auf die Produktionsmerkmale überlegen und in Bezug auf die BMD unterlegen waren, gab es innerhalb der untersuchten Linien keinen Einfluss der Gesamtschalenproduktion auf die BBS oder BMD. Anders als vermutet, lieferten die Ergebnisse keine Hinweise auf einen negativen Zusammenhang zwischen Legeleistung und Knochengesundheit. Wir kamen zu dem Schluss, dass eine hohe Legeleistung nicht zwangsläufig ein Risiko für Knochenschwäche darstellt.

Das Ziel der zweiten Studie (Kapitel 3) war die Untersuchung von Skelettmerkmalen unter den metabolisch herausfordernden Bedingungen einer wiederholten diätetischen Kalziumrestriktion. Innerhalb und zwischen den vier Linien unseres Tiermodells wurde die Adaptationsreaktion der Hennen im Hinblick auf mögliche Effekte von Phylogenie und Leistungsniveau charakterisiert. Die Kalziumrestriktionen führten bei allen Linien zu einer Abnahme der Eizahl und der Schalenqualität, jedoch setzte nach Umstellung auf eine adäquate Versorgung eine Erholung ein. Post mortem wurde eine erhebliche Demineralisierung des Knochens festgestellt. Diese Ergebnisse spiegeln möglicherweise den Versuch wider, die Reproduktionsleistung auf Kosten der Skelettintegrität zu erhalten. Es zeigte sich, dass das Leistungsniveau die Anpassungsreaktion weniger stark beeinflusste als die Phylogenie. Hierbei zeigten die Weißleger eine stärkere Reaktion, während die Braunleger 
weniger empfindlich auf den reduzierten Kalziumgehalt zu reagieren schienen. Letzteres wurde mit einer vorteilhafteren Körperkonstitution dieser Linien erklärt, bei der höhere Mengen an Kalzium vom Skelettsystem bereitgestellt werden konnten, ohne die Knochengesundheit stark zu beeinträchtigen.

In der dritten Studie (Kapitel 4) wurden die im ersten Experiment erhobenen Messungen der BBS und BMD aus genomischer Perspektive untersucht, um zu prüfen, ob genomische Regionen identifiziert werden können, die mit Knochenstabilität assoziiert sind. Hierzu wurden die Daten der vier Linien zusammengefasst. Zwei unterschiedliche Verfahren wurden zur Identifikation von Single Nucleotide Polymorphisms (SNP) angewendet, darunter eine Single-Locus Mixed Linear Model Analyse sowie die auf maschinellem Lernen basierende Methode der Random Forests Klassifikation. Letztere Methode scheint robuster in Bezug auf Populationsstratifikation zu sein. Sechzehn potenzielle Kandidatengene, die sich in unmittelbarer Nähe der SNPs befinden, wurden durch anschließende Funktionsanalysen identifiziert. Diese Gene sind mutmaßlich funktionell mit dem Skelett bei Hühnern oder Menschen assoziiert. Darüber hinaus hat das Gene Set Enrichment gezeigt, dass einige dieser Kandidatengene an Stoffwechselwegen beteiligt sind, die für den Knochenmetabolismus von Bedeutung sind. Unsere Ergebnisse deuten erwartungsgemäß darauf hin, dass die Knochenstabilität durch eine Vielzahl von Genen reguliert wird, von denen jedes einen eher geringen Effekt auf das Merkmal hat. Die hier vorgestellten Kandidatengene sind aus knochenbiologischer Sicht sehr vielversprechend, kausale Beziehungen müssen jedoch noch nachgewiesen werden.

Zusammenfassend lässt sich sagen, dass in dieser Arbeit die Genetik als maßgeblicher Bestimmungsfaktor für die Knochenstabilität bei Legehennen identifiziert wurde. Das Leistungsniveau der Hennen scheint allerdings keine entscheidende Rolle zu spielen, da keinerlei Korrelationen zwischen der Produktivität der Hennen und der Knochenstabilität beobachtet wurden. Im Gegensatz dazu ist von einem phylogenetischen Effekt auszugehen, der nach heutigem Kenntnisstand am ehesten auf einer vorteilhaften körperlichen Konstitution der Braunleger beruht. Angesichts der moderaten Erblichkeit der Knochenmerkmale besteht die Möglichkeit einer genetischen Verbesserung der Skelettgesundheit. Da zahlreiche Gene an der Regulation der Knochenstabilität beteiligt sind, erscheint eine verstärkte Nutzung genomischer Informationen als sinnvoll. 


\section{General Introduction}

\subsection{A Brief History of Layer Breeding}

The domestic chicken (Gallus gallus domesticus) descends from the red junglefowl (Gallus gallus) and, although to a much lesser extent, from the grey junglefowl (Gallus sonneratii) [1]. Its domestication took place at several sites in the Asian region between 2,500 and 6,000 years BCE [2, 3], from which the chicken migrated to Europe along two main trading routes [1]. Archaeological findings suggest that chickens were originally kept for leisure purposes such as cockfighting, whereas the first adoption as food source is attributed to the Romans $[4,5]$. An intensive diversification of chicken breeds took place during migration, leading to a broad variety of populations. In China and Europe, traditional breeds were initially formed by selecting for preferred morphological traits, the subgroups of which in turn served as the foundation for standardised breeds [1]. In this way, the founder stocks of today's commercial chicken lines were established and both maintained as purebred populations and used for crossbreeding [6]. While many of the standardised breeds may still be considered dual purpose breeds today, intensive selection for either egg or meat production soon led to the emergence of two specialised chicken types $[1,7,8]$. However, intensive selection also led to a decline in genetic diversity, especially in laying hens. Malomane et al. [6] recently showed that brown-egg layer and broiler lines cluster together with regard to their phylogenetic relationship, while white-egg layer lines form a separate cluster. This represents both domestication and selection effects, as brown and white-egg lines evolved independently during breed history [6,9] and all white-egg lines have descended from the White Leghorn breed. In contrast, today's brown-egg lines originate from a number of breeds including Rhode Island Red, New Hampshire, Light Sussex and Barred Plymouth Rock $[10,11]$. For this reason, there have been completely separate breeding populations for white and brown-shelled eggs since the beginning of commercial layer breeding [12].

Starting in the U.S., chicken breeding developed very rapidly from the 1940 s onwards and after a few years, there were a large number of professional poultry breeders, some of whom cooperated with each other, e.g. by swapping stocks to create crossbreeds or attending random sample testing [12-14]. The following decades were marked by the introduction of quantitative genetic principles and concepts such as inbreeding, hybrid vigour and reciprocal recurrent selection $[11,13]$. With the increasing professionalisation of layer breeding, the number of primary breeders declined significantly and today there are only two major global players and a few others $[14,15]$.

Meat and egg-type chicken breeding basically follow the same hybridisation scheme: Commercial breeders maintain some number of pure lines, intensively selected for various performance and behavioural traits and crossed in specific combinations to produce the parent 
generation, from which individuals are in turn crossed to deliver the end product. Today, fourway crossing is commonly used for the production of laying hybrids $[12,14,16]$. Field results and information from genetic markers are combined in order to improve both the pure and cross lines [17]. Current selection indexes include a multitude of production and functional traits weighted according to hereditary and economic aspects [16]. Intensive selection for laying performance led to an earlier start of laying as well as to an increased clutch length due to persistent ovulation, which has resulted in an enormous increase in lifetime egg production per hen in the last decades $[12,18,19]$. Another trait that has been massively optimised over the last 20 years is the feed efficiency, which is now around $2 \mathrm{~kg}$ of feed per $1 \mathrm{~kg}$ of egg mass. This has been achieved through selection for higher egg mass and smaller body size $[12,16]$. Continuous improvement in the number of saleable eggs per hen will remain the most important objective. However, this can only be achieved by increasing laying persistency, i.e. extending clutch length $[16,17]$, as the biological limit of one egg per day is reached at peak production [20]. Recent studies point to the future goal of an extended production period of 100 weeks with 500 saleable eggs [17, 20]. In this regard, Fernyhough et al. [15] caution that an extending cycle length has to go alongside with an improved robustness to ensure that hens can cope with the challenges of a longer laying period. Finally, behaviour and welfare-related traits including those related to suitability for alternative housing systems are gaining more importance in the selection index and complement traditional performance traits $[15,17]$. This also applies to parameters of skeletal integrity [16], which are addressed in detail in the following chapters.

\subsection{Fundamentals on Avian Bone Biology}

\section{Bone Development and Remodelling}

The skeleton fulfils a number of important functions. In addition to its protective function for internal organs and its function as an attachment site for muscles, it also serves as a mineral reservoir and contributes to the regulation of calcium homeostasis, both of which are considered particularly important for laying hens [21]. Two major processes are involved in bone growth and development [22]. These are endochondral ossification, which describes the formation of bone on a mineralised cartilage scaffold, and intramembranous ossification, in which bone is formed without the mediation of a cartilage phase [23-26]. The process of ossification is the deposition of a type I collagen matrix by osteoblasts [25], which is subsequently mineralised by the formation of hydroxyapatite crystals in and between the collagen fibres [27].

Once formed, bone undergoes continuous remodelling. This is the process of bone resorption by osteoclast cells followed by the subsequent formation and mineralisation of new bone tissue by osteoblast cells [21, 28, 29]. During ossification, calcium minerals circulating in the blood are fixed [30], while during resorption, calcium is released from the bone into the bloodstream [29]. A balance between osteoclastic and osteoblastic activities is considered crucial for maintaining bone health, including the ability of bone to repair micro-damage and adapt to mechanical loads [31, 32]. An imbalance, on the other hand, can lead to a net loss of bone material $[28,33]$. 


\section{Bone Types in Laying Hens}

There are three distinct bone types in laying hens. These include the cortical and cancellous bone, which are together referred to as structural bone, and the medullary bone [23].

Cortical bone tissue is found in the bones of the appendicular skeleton and forms a compact tightly packed outer layer that is adjacent to the periosteum on the inside (Figure 1.1) [21, 22, 34]. The cancellous bone, on the other hand, is predominantly located in the axial skeleton as well as at the epiphyses of the long bones. It has a reticular three-dimensional structure, which is why it is synonymously called trabecular bone $[21,35,36]$. The cortical layer contributes most to the structural integrity of the bone, followed by the cancellous tissue, which was shown to be less calcified and is primarily a site of metabolic activity [21, 22, 28]. Recently, RodriguezNavarro et al. [37] observed that it is not the degree of mineralisation, but rather the thickness of the cortical bone that has the greatest contribution to the mechanical bone properties.

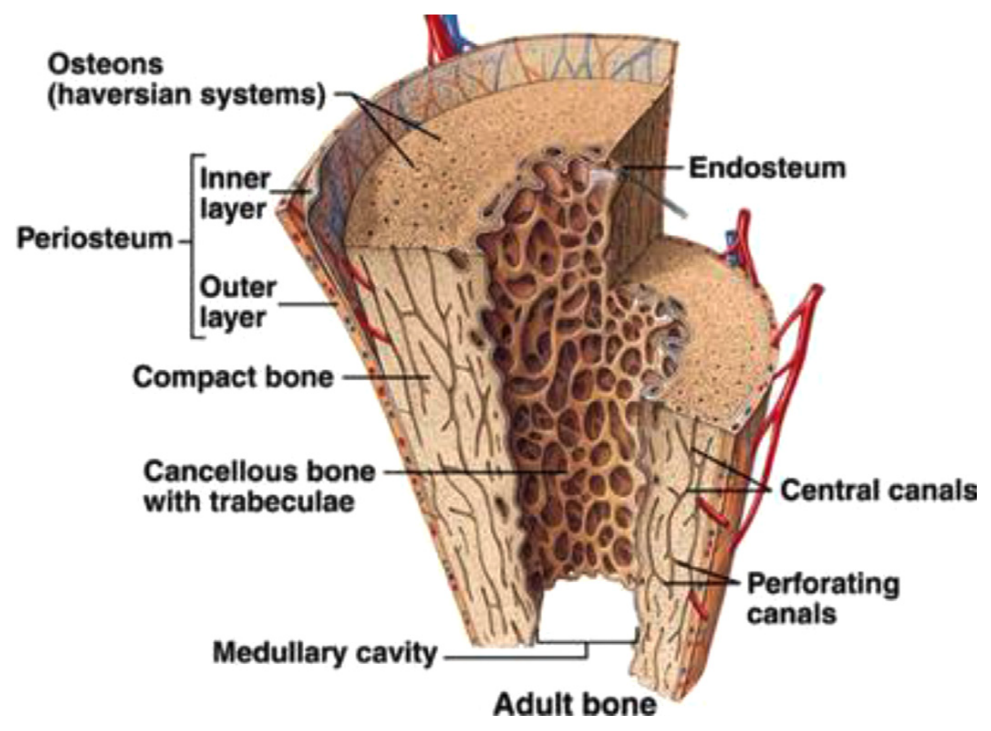

Figure 1.1: Schematic illustration of a long bone cross-section in laying hens showing various types of bone tissue. Reprinted from Toscano [22], with permission from Elsevier.

The medullary bone is the third bone type in the chicken, which, unlike the structural bone found in mammals and male birds alike, is only present in adult female birds and has been detected in dinosaur fossils as well $[23,38,39]$. Medullary bone is a highly labile woven bone [36] located in the medullary cavity and lining the endosteal surface of the structural bone $[23,40,41]$. Its spicules grow from the endosteal surface towards the centre of the bone and can fill the medullary cavities completely $[23,42]$. Medullary bone is found mainly in the diaphysis of long bones, including the tibiotarsus, femur and, to varying degrees, humerus, as well as in the keel bone [23, 29, 42-44]. Intrinsic strength of the medullary bone is lower than that of the cortical and cancellous bone [45, 46], due to the irregular arrangement of its collagen fibres and the fact that much of it is present in isolated spicules [23, 29]. Nevertheless, medullary bone contributes to overall bone strength and can increase fracture resistance $[37,43]$. Medullary bone formation starts with the initiation of ovarian follicle maturation, i.e. about two weeks before hens first come into lay, and is stimulated by the synergistic effect of oestrogens and androgens $[39,42,47]$. It acts as a labile calcium reservoir for eggshell calcification and represents about $12 \%$ of total bone calcium [48]. Medullary 
bone is characterised by intense calcification and a high remodelling rate $[42,49,50]$. This is reflected in a constant alternation between osteoclast-mediated resorption during periods of eggshell formation and osteoblast-mediated remineralisation after eggshell formation is completed [23, 36, 41]. Dacke et al. [42] concluded that only the degree of calcification of the medullary bone varies with the egg-laying cycle, but not its volume. After completion of the laying sequence, the follicle-mediated oestrogen level decreases, causing the medullary bone to gradually disappear and the remodelling of the cortical bone to be initiated $[28,51]$.

\section{Bone Resorption in Favour of Egg Production}

Commercial laying hens have been selected for high laying performance, resulting in a virtually daily egg production for a 52-week period $[19,39]$. Within the 24-hour laying cycle, eggshell formation takes place in three successive stages in the uterus, which is also referred to as the eggshell gland, and lasts about 19 hours [20,48]. With a standard lighting programme of $14 \mathrm{~h}$ light : $10 \mathrm{~h}$ dark, half the time of eggshell formation falls in the dark period [20]. Calcium carbonate $\left(\mathrm{CaCO}_{3}\right)$ is the main component of eggshells and for shell formation its ionic precursors, ionised calcium $\left(\mathrm{Ca}^{2+}\right)$ and bicarbonate $\left(\mathrm{HCO}_{3}{ }^{-}\right)$, are supplied in large quantities through the blood [39]. There is a wide variation in egg size and up to three grams of calcium are needed each day for eggshell formation [52], which is $10 \%$ of the hen's total body calcium [48]. The amount of calcium deposited in the eggshells throughout a 52-week laying sequence can be 20 to 30 times the body mass of the hens $[12,53]$. This places very high demands on their calcium homeostasis and activates efficient mechanisms for $\mathrm{Ca}^{2+}$ transfer $[47,54]$. During shell calcification, there is a large calcium flow towards the eggshell gland, resulting in a temporarily decreasing plasma $\mathrm{Ca}^{2+}$ level, which in turn stimulates the secretion of a number of calcium-regulating hormones, including parathyroid hormone (PTH) and 1,25-dihydroxyvitamin D3 $\left(1,25-(\mathrm{OH})_{2} \mathrm{D}_{3}\right)$, also referred to as calcitriol $[47,48]$. These lead to increased intestinal mineral absorption and reduced renal excretion [33].

Part of the calcium needed for eggshell formation derives from the feed and passes into the blood via intestinal absorption [33]. Hens show a specific appetite for calcium in the hours before shell formation $[48,55]$. However, despite increased feed intake and exceled absorption rates, dietary calcium supply only covers $60-75 \%$ of the demand due to limited bioavailability (see chapter 1.5) [23, 33, 56]. Furthermore, external calcium supply is limited because the larger part of eggshell formation takes place during the night, when there is no feed intake and at most a small amount of feed remains in the gastrointestinal tract $[20,33,57]$.

Besides enhancement of external supply, resorption of medullary bone is another mechanism intended to increase plasma $\mathrm{Ca}^{2+}$ levels for eggshell formation [47]. It is mobilised to provide the remainder of the minerals needed for shell calcification. This proportion is about 20$40 \%$, but varies with the dietary calcium content $[48,56]$. Degradation of medullary bone is mediated by $1,25-(\mathrm{OH})_{2} \mathrm{D}_{3}$, which stimulates bone resorption by osteoclasts in the presence of PTH $[33,47]$. Medullary bone remodelling is directly coupled to the calcification process, so that osteoblasts and osteoclasts periodically change their morphology and function depending on the position of the egg in the eggshell gland [29,39]. This includes certain restoration of the medullary bone in the short period between two eggs, i.e. between oviposition and the beginning of the subsequent eggshell formation, during which feeding takes place [20, 33]. It should be noted, however, that the ability of hens to store calcium in the skeleton 
decreases with age [58]. In principle, calcium supply from this labile source is an effective and natural mechanism, but medullary bone resorption is not without consequences. Degradation of medullary bone is associated with cancellous and cortical bone loss, as osteoclasts are not specific to medullary bone $[23,36]$. Furthermore, medullary bone formation coincides with the cessation of structural bone development, which is challenging in terms of maintaining bone health $[23,28,59,60]$. As a result, the amount of cortical and cancellous bone gradually decreases once medullary bone formation has started, which can lead to considerable skeletal weakening in laying hens, given their long and continuous laying activity [23, 61, 62].

\subsection{Skeletal Disorders in Laying Hens}

\section{Characteristics and Pathogenesis}

Skeletal disorders can occur as a result of impaired bone growth and/or bone metabolism [62]. While the former is more relevant for meat-type chickens, the latter is of particular relevance for laying hens, where bone fragility due to metabolic disorders is a common problem [63]. Osteomalacia and osteoporosis are two distinct severe metabolic skeletal diseases, both of which cause a loss of bone minerals $[49,64]$.

Osteomalacia, the adult pendant to rickets, is caused by inadequate or disrupted mineralisation of the organic fraction in mature bone, resulting in sparsely mineralised bone matrix $[28,65]$. It occurs mainly in response to a disturbance of the vitamin D metabolism [65] or due to a nutritional deficiency of vitamin D, calcium or phosphorus [63].

Osteoporosis, on the other hand, is a more complex disease principally weakening the whole skeleton [28, 66]. Osteoporosis is defined as a systemic progressive loss of fully mineralised structural bone [28, 63], manifested in decreased bone volume and cortical thickness, less well-connected trabeculae and increased skeletal porosity $[12,28,61]$. All this leads to increased bone fragility and high fracture susceptibility $[12,23,28]$. Hence measurements of bone breaking strength $[36,67-70]$ and bone mineral density [36, 70-72] are commonly performed for bone health assessment. The severity of osteoporosis varies, with milder forms sometimes referred to as osteopenia $[63,65]$, although this is rather vague as osteopenic bone can occur for reasons other than metabolic [66]. In its most extreme form, structural bone loss can lead to cage layer fatigue, a condition described by Couch [73] after the introduction of battery cage housing, which can lead to bone fractures, paralysis as well as emaciation and sudden death [28, 73, 74]. However, this problem could be reduced through nutritional interventions and generally osteoporosis is not that severe as to result in cage layer fatigue $[64,75]$. Nevertheless, osteoporosis is the most widespread skeletal disorder causing bone loss and virtually all modern layer lines are prone to it, even when mineral supply is adequate $[63,64]$.

The pathogenesis of osteoporosis is multifactorial and includes a strong genetic component as well as external environmental factors [28], both of which are discussed in the following chapters. The main mechanism by which osteoporosis develops is an imbalance in bone remodelling that leads to a net resorption of bone material $[28,31]$. This negative balance results from continuous bone degradation, leading to bone loss culminating in osteoporosis $[23,63]$. Structural bone loss was shown to begin soon after the onset of laying 
and increase subsequently, with the main period of erosion lying between weeks 30 and 50 $[28,61]$. Given this obvious link to egg-laying activity, the prevailing view is that the hens' physiological adaptations to high productivity made them susceptible to osteoporosis $[23,76]$.

Keel bone damage represents another form of skeletal disorder, which is indirectly related to osteoporosis. The term includes both fractures and deviations, i.e. unnatural bends, of the keel bone, which is very susceptible to these disorders due to its prominent anatomical position $[77,78]$. The occurrence of these damages is primarily determined by environmental factors $[77,79]$ (see chapter 1.5 ), but the gradual but sustained loss of structural bone tissue is assumed as a predisposing factor $[66,70]$. This means that the keel bone is weakened by osteoporosis, but the actual fracture or deformity is secondary to trauma such as a collision [66, 80, 81].

\section{Prevalence and Implications}

The prevalence of skeletal disorders due to bone weakness in laying hens is extremely high. However, this is by no means a new development, as the first reports of it date far back into the last century $[73,82]$. In 1989 , one third of battery hens sampled before slaughter were found to have broken bones [83]. Considering a variety of bones of the appendicular and axial skeleton, Budgell and Silversides [84] reported an overall fracture prevalence of $11.1 \%$ and $11.7 \%$, respectively, in high performing ISA-Brown and Babcock B300 end-of-lay hens. In a comparison of different genetic strains carried out by Clark et al. [85], an average of $11.2 \%$ of the hens in all six lines had at least one fracture, with a maximum value of almost $30 \%$. Larger ranges were reported by the Farm Animal Welfare Council [86] and Sandilands [87], who found fracture prevalence to be $23-44 \%$ and $26-53 \%$, respectively. In recent years, increased attention has been paid to the occurrence of keel bone damages. In this regard, Wilkins et al. [88] determined a fracture prevalence of $36-86 \%$ covering different housing systems. Considering surveys from several European countries, Canada and the United Kingdom, Toscano et al. [66] recently put the range of hens affected by keel bone fractures at $20-96 \%$. With proportions between 3 and $88 \%$, a similar situation arises with regard to keel bone damage in organic production systems [89].

Skeletal disorders, and in particular fractures, have serious animal welfare implications due to pain, behavioural changes, and mortality [90]. Although the ability of birds to perceive pain is not yet conclusively understood, the fact that they have the necessary anatomical structures, e.g. nociceptors in the bone tissue, is an indication that the painfulness of bone fractures in chickens is similar to that of mammals [86, 90-92]. This includes both acute and chronic pain $[90,92,93]$. Evidence arises from studies in Lohmann Brown (LB) laying hens in which the administration of analgesics after keel bone fracture led to increased mobility [93, 94]. Behavioural changes may occur in response to the pain, including protecting the fracture site from movement by crouching and immobility [77, 90, 95]. Hens with keel bone fractures were observed to spend more time sleeping on the floor and resting in nest boxes [77]. Casey-Trott and Widowski [96] studied the spontaneous behaviour of Lohmann Selected Leghorn (LSL) hens in furnished cages and found that keel bone fracture severity influenced the birds' sitting, standing and resting behaviour, likely representing coping strategies to compensate for pain. 
Armstrong et al. [97] concluded that fractures could lead to a depressive-like state in laying hens. Although rare, the most serious welfare impact is the death of the chicken resulting from severe internal injuries due to fractures or from culling for welfare reasons [88, 98-100]. Finally, skeletal disorders are also associated with economic losses mainly resulting from decline in hen productivity due to physiological stress $[12,36,101]$. In this context, egg production, egg weight and egg quality were compromised in hens suffering from keel bone fractures [77, 102]. In a study by Cransberg et al. [61] the laying performance of a group of severely osteoporotic LB hens was reduced by $18 \%$ at week 30 . A correlation was observed between egg production, the severity of keel bone fractures and age, i.e. fractures caused a higher drop in performance with increasing age of the hens [101]. However, egg quality was not affected by fracture severity.

\subsection{Genetics - An Integral Part of Bone Stability}

In addition to the external environmental factors of nutrition and husbandry, there is a strong genetic component in skeletal integrity and osteoporosis [12, 46, 64, 103]. The level of genetic determination of bone stability is considered high, as large individual variations have been observed, with some hens maintaining both high productivity and good bone quality at the end of the laying period [12, 23, 28, 104, 105].

It is assumed that bone quality traits are highly polygenic and thus are not regulated by a few major genes, but rather determined by several functional genes acting conjointly [106, 107]. With all the genetic progress obtained in the egg production traits, modern laying hybrids have experienced substantial genetic and phenotypic changes [7]. Due to genetic correlations and linkage of genes, co-selection of undesirable side effects may have occurred in the course of decades of targeted genetic selection for high laying performance. These side effects are likely caused by pleiotropy and epistasis, influencing traits, which were not selected for by the breeding program [7, 108, 109]. In terms of calcium homeostasis, this may have led to an imbalanced allocation of limited mineral resources, with calcium being prioritised in favour of eggshell formation and to the detriment of bone health [8, 110-112]. Compromised skeletal integrity may therefore have been caused by genes that were inadvertently co-selected by genetic hitchhiking during directed selection for efficient egg production, resulting in tradeoffs in resource allocation [109, 113].

Inspired by the work of Johnsson [62], this chapter considers (i) findings from comparisons of different breeds and lines, (ii) insights from selection experiments and estimates of genetic parameters, and (iii) genetic regions associated with bone stability.

\section{Findings from Breed and Line Comparisons}

Research comparing different chicken breeds or lines kept under similar conditions to show genetic differences probably constitutes the majority of the literature on bone stability in laying hens [62]. There are a number of studies indicating strong breed and line effects on skeletal traits. These findings suggest a genetic potential for bone health in that some lines have better bones than others [85, 103, 114-119]. 
A large part of the work involved studies comparing brown and white-egg laying hens to draw conclusions about the effects of phylogenetic differences on skeletal traits. According to Riczu et al. [115], phylogenetic differences appear obvious, as they are also observed in parameters of egg production and quality, i.e. in a complex that is presumably closely related to susceptibility to bone weakness. Habig and Distl [120] examined the bone characteristics of the tibiotarsus and humerus in LB (brown-egg line) and LSL (white-eggs line) hens over four consecutive trials. For both bone types, significantly higher breaking strengths were observed in the LB hens. In contrast, LB hens showed a significantly higher prevalence of severe keel bone deformities compared with the LSL hens. Vits et al. [121] previously observed the same phylogenetic effects on breaking strengths of the tibiotarsus and humerus in these lines. Riczu et al. [115] investigated bone stability traits in end-of-lay hens of two phylogenetically divergent lines. They found that although there were only marginal differences in bone mineral density, the bone breaking strength of the brown-egg Shaver 579 line was significantly higher in the humerus $(+18 \%)$ and femur $(+22 \%)$ compared to the white-egg Shaver 2000 line. Rayan et al. [122] examined bone quality traits in two layer parent stocks, white-egg Hy-Line W-36 and brown-egg Hy-Line Brown, at the end of the production cycle and observed a 33\% higher breaking strength of the tibiotarsus in the brown-egg line. Recently, Sharma et al. [123] performed X-ray microtomography in laying hybrids from the same two lines examined by Rayan et al. [122] and observed higher femoral cortical bone density in W-36 hens. Ali et al. [124] compared two white-egg lines (Hy-Line W36, DeKalb White) and two brown-egg lines (Hy-Line Brown, Bovans Brown) in relation to keel bone damage. Both white-egg lines were found to have a higher probability of keel fractures than hens of the brown strains. The authors explained this in part with different degrees of genetic predisposition and thus confirmed the results of other studies on a phylogenetic effect $[81,116,125,126]$. All these findings are supportive of a strong phylogenetic divergence between brown and white-egg layer lines.

Another group of studies looked at comparing lines of different performance level or selection intensity. Budgell and Silversides [84] determined the prevalence of bone fractures in commercial Babcock B300 and ISA Brown hens in comparison to a Brown Leghorn line that has been maintained without selection since 1965. High prevalences were observed in both laying hybrids, while the unselected line had a significantly lower prevalence. The authors argued that these differences may be due to the intensive selection that took place in the commercial lines [84]. Rennie et al. [127] compared the bone volume of the proximal tarsometatarsus and free thoracic vertebra of the modern hybrid line Hisex Brown and the Brown Leghorn J-line, which has been maintained at the Roslin Institute for decades without selection. They detected a lower percentage of trabecular bone in the Hisex hens, the majority of which were classified as osteoporotic, in contrast to the J-line hens. Habig et al. [128] performed bone quality measurements in four purebred lines differing in phylogenetic origin and performance level. Within both phylogenetic groups, they observed lower bone strength and mineral density values for the tibiotarsus in the lines selected for high laying performance. It was concluded that there might be an impact of egg-laying performance on bone stability within each phylogenetic group [128]. Hocking et al. [113] studied the genetic variation for skeletal traits between 12 commercial and 13 traditional layer lines. There was moderate genetic variation among and within the lines for bone stability traits. Bones from the traditional lines showed an increased 
breaking strength, mineral density and cortical bone dimensions, while the commercial lines showed a lower overall bone stability. These differences were attributed to the maintenance of eggshell quality at the expense of bone health in the lines selected for laying performance [113]. In a subsequent study, these observations were supported by showing that the lines did not differ in bone characteristics until the onset of laying, but diverged thereafter [129]. Given these findings, it is reasonable to assume that the selection of commercial laying hens for increased egg production may have negatively influenced bone stability $[23,36,113,126,130]$. However, this assumption is seen critically, as recent findings point to a less straightforward relationship between egg number and osteoporosis [66, 105, 131, 132].

\section{Insights from Selection Experiments and Estimates of Genetic Parameters}

As early as 1937, the study by Warren [82] gave indications that the tendency to develop keel bone damage might be hereditary. Previously, divergent selection was carried out in White Leghorn chickens from 1926 to 1935, selecting for the presence or absence of keel bone deformities. Both strains developed clearly differently depending on what they had been selected for. One of the most highly regarded selection experiments on bone stability in layers is certainly the one carried out by Bishop et al. [133], in which the inheritance of bone characteristics was studied over five generations in purebred White Leghorn hens. While the first generation served as the base generation, the hens of the following ones were selected divergently on high and low bone stability traits combined in a bone index. This index included the radiographic density of the keel bone as well as the bone breaking strengths of the humerus and tibiotarsus. Body weight was also considered in the index to prevent its increase. As a result, the lines differed significantly and diverged in the desired direction from the third generation onwards. Finally, the high and low bone index lines differed in keel bone density by $19 \%$ and in bone breaking strength by $13 \%$ (humerus) and $19 \%$ (tibiotarsus), respectively, which was reflected in a significantly lower fracture prevalence in the high bone index line. The authors concluded that bone traits responded quickly, so improving bone health through conventional selection techniques could be promising [133]. After the initial description by Bishop et al. [133], the low and high bone index lines were subjected to a number of follow-up studies including those characterising the bone material composition of these lines in more detail [37, 46, 134]. Furthermore, a higher keel bone mineral density and reduced prevalence of keel bone damage was observed in following generations of the high bone index line $[130,135]$. It was also found that there were no differences between the lines in egg production and quality, suggesting that selection for increased bone stability is possible without compromising hen performance $[46,64]$.

In general, skeletal traits in laying hens are considered weakly to moderately heritable [62, 64]. Preisinger [16] reported a heritability of bone stability, without further specification, of $\mathrm{h}^{2}=0.1$ to $\mathrm{h}^{2}=0.15$. Dunn et al. [132] recently studied bone quality traits in White Leghorn and Rhode Island Red hens. The heritability estimates for the bone breaking strength of the tibiotarsus and humerus were $h^{2}=0.24$ and $h^{2}=0.30$ in the White Leghorn and $h^{2}=0.51$ and $\mathrm{h}^{2}=0.47$ in the Rhode Island Red chickens. The corresponding genetic correlations between these traits were $r_{\mathrm{g}}=0.76$ and $r_{\mathrm{g}}=0.81$, respectively. In the study from Bishop et al. 
[133], humerus and tibiotarsus breaking strength were moderately heritable at $h^{2}=0.30$ and $\mathrm{h}^{2}=0.45$, respectively, and keel bone density at $\mathrm{h}^{2}=0.39$. The heritability of the bone index mentioned was $h^{2}=0.40$. The medullary and cancellous bone volume, on the other hand, proved to be rather poorly heritable, with estimates of $h^{2}=0.19$ and $h^{2}=0.0$, respectively. The genetic correlation estimates indicate a rather close relationship between the radiographic density of the keel bone and the breaking strength of the tibiotarsus $\left(r_{\mathrm{g}}=0.66\right)$ and humerus $\left(r_{\mathrm{g}}=0.49\right)$, as well as the breaking strengths of humerus and tibiotarsus $\left(r_{\mathrm{g}}=0.77\right)$ [133]. With a value of $r_{g}=0.75$, Hocking et al. [113] reported a similarly close genetic relationship between these long bones. Andersson et al. [136] estimated the heritability of keel bone deviations assessed via palpation and genetic correlations with production parameters in two White Leghorn breeding lines that differed significantly in terms of keel bone damages, showing prevalences of $15 \%$ and $75 \%$, respectively. The heritability estimates were $h^{2}=0.30$ (line A) and $h^{2}=0.15$ (line B). They observed that early egg production would be affected by selection on increased keel bone health in these lines, as the corresponding genetic correlations were $r_{\mathrm{g}}=-0.24$ (line A) and $r_{\mathrm{g}}=-0.54$ (line B).

\section{Genomic Regions Associated with Skeletal Traits}

The last part of this chapter addresses the question of which genes are related to skeletal integrity in laying hens. To date, a number of quantitative trait loci (QTL), i.e. genomic regions with a significant effect on a quantitative trait [7], have been mapped to bone phenotypes and some plausible candidates have been identified [62]. While in the beginning, mapping studies were performed at low-density marker level using microsatellite markers [137-140], technical advances in genotyping and the introduction of modern association analyses enhanced the knowledge about genetic architecture of bone stability in laying hens $[106,107,141]$. Since a comprehensive presentation of candidate genes for osteoporosis will be given in the fourth chapter of this thesis, only a few recent studies are cited here. Guo et al. [106] conducted a genome-wide association study (GWAS) on bone mineral density measures of the femur and identified a novel locus that might be related to bone stability. They confirmed some genes known to be associated with osteoporosis in humans. Raymond et al. [107] performed a GWAS on bone breaking strength measures in LSL hens. They identified five distinct and novel QTLs and the genes located within these QTLs, some of which are known to have functions in bone metabolism. One of the first significant QTL for bone stability in poultry was discovered on chromosome 1 by Dunn et al. [104] using microsatellite markers. The experiment was performed using the aforementioned population of White Leghorn chickens that have been divergently selected for bone stability [133]. De Koning et al. [142] recently performed fine-mapping of this QTL and additional functional studies, which lead to the identification of a gene that may affect the crosslinking of bone collagen matrix. Despite the conciseness of this overview, it is obvious that a number of promising candidate regions have already been discovered. It should be noted, however, that all of these genomic regions are still putative, as none of them has yet been proven to be functionally causal [62]. 


\subsection{Environmental Factors Influencing Bone Stability}

Bone stability is also influenced externally by nutrition and housing system, which affect the hens' predisposition to skeletal problems $[75,127,143]$. Calcium is considered the most important mineral in terms of skeletal integrity [143]. Already during the rearing phase, adequate supply is crucial for skeletal development and serves to minimise structural bone loss once medullary bone formation has commenced $[52,144]$. Due to their longer retention time in the gastrointestinal tract $[33,127,145,146]$, coarse calcium particles in layer diets are beneficial for bone stability, especially at night when there is no feed intake, but eggshell formation is taking place $[147,148]$. Increasing the dietary calcium content leads to improved bone strength [149-152]. However, the calcium bioavailability is limited by the intestinal transit time and absorption rate, which is $40-70 \%$ [57, 153, 154]. Furthermore, a too high calcium level can interfere with the digestion of other nutrients [155, 156]. Phosphorus is another mineral essential for bone strength [49, 52, 144] as, together with calcium, it makes up the largest part of the bone mineral structure $[157,158]$. The literature is rather contradictory regarding the benefit of additional phosphorus administration on bone stability, however, the bioavailability of dietary phosphorus can be increased by the addition of microbial phytases $[143,144,157]$. Vitamin $D$ is by far the most important vitamin for bone stability [143] and is routinely added as part of premixes to layer diets [150]. However, beneficial effects of vitamin $D$ supplementation beyond the basic requirements remain controversial. There are rather few findings that indicate a positive effect $[60,159,160]$ and most studies negate such an effect $[117,150,161-163]$. Adequate vitamin D supply during skeletal development at the pullet stage is considered important, as dietary interventions during the laying period have rather limited effects on bone stability $[60,144,160]$.

The effect of different housing systems on bone health has been intensively studied. There is a consensus that chickens from non-cage systems, i.e. aviary as well as floor and free range systems, have a higher bone stability, which is mainly attributed to the beneficial effects of physical exercise that these systems provide [123,126, 128, 135, 164-169]. Non-caged hens show stimulated bone metabolic activity, a higher turnover rate and better adaptation to mechanical loads, whereas prolonged exercise restriction in caged hens results in bone resorption and adverse structural remodelling [37, 170,171]. In summary, physical activity has a positive effect on bones' mechanical properties and can thus influence the occurrence and severity of skeletal disorders in laying hens $[172,173]$. This also applies to pullets and it is assumed that the positive effect of physical activity carried out during rearing lasts into the laying period, provided that the opportunity for exercise is maintained [169, 174-176]. However, the positive effect of non-cage systems is somewhat diminished by the fact that several authors found a high prevalence of keel bone damages in these systems, mainly involving keel bone fractures $[88,131,177-181]$. This issue, known as the "welfare paradox", is explained by the fact that as the space and internal complexity of a housing system increases, the hens have more opportunity to experience harmful accidents [28, 135, 182, 183]. In this context, the aviary design, including furnishing items such as perches has received particular attention in research, as they influence the hens' risk of falls and collisions when moving throughout the system [80, 183-185]. 


\subsection{Thesis Aim and Objectives}

Skeletal integrity in laying hens is an issue of particular relevance. The high incidence of birds suffering from osteoporosis has serious implications for animal welfare and requires urgent intervention. To do this, however, the causative and determining factors of bone stability must be identified. In addition to environmental factors including nutrition and husbandry, there is evidence of a significant contribution of genetics to bone stability.

The overarching aim of this dissertation is to further characterise the influence of genetics on the differentiation of bone stability and to evaluate its potential for improving bone health in laying hens. Different studies were conducted applying an animal model comprising four purebred chicken layer lines (Figure 1.2). This four-line animal model includes two brown (BLA, L68) and two white-egg lines (WLA, R11). Within these phylogenetic groups, both lines differ with regard to their egg-laying performance. The two high performing lines (WLA, BLA) originate from a commercial layer breeding program, whereas their moderate performing counterparts (R11, L68) have been kept as unselected resource populations for more than 25 generations. This two-dimensional divergence not only covers a broad spectrum of laying hen genetics, but is also intended to allow discrimination between effects of performance level and phylogenetic origin. A more detailed description of the layer lines is given in the following chapters.

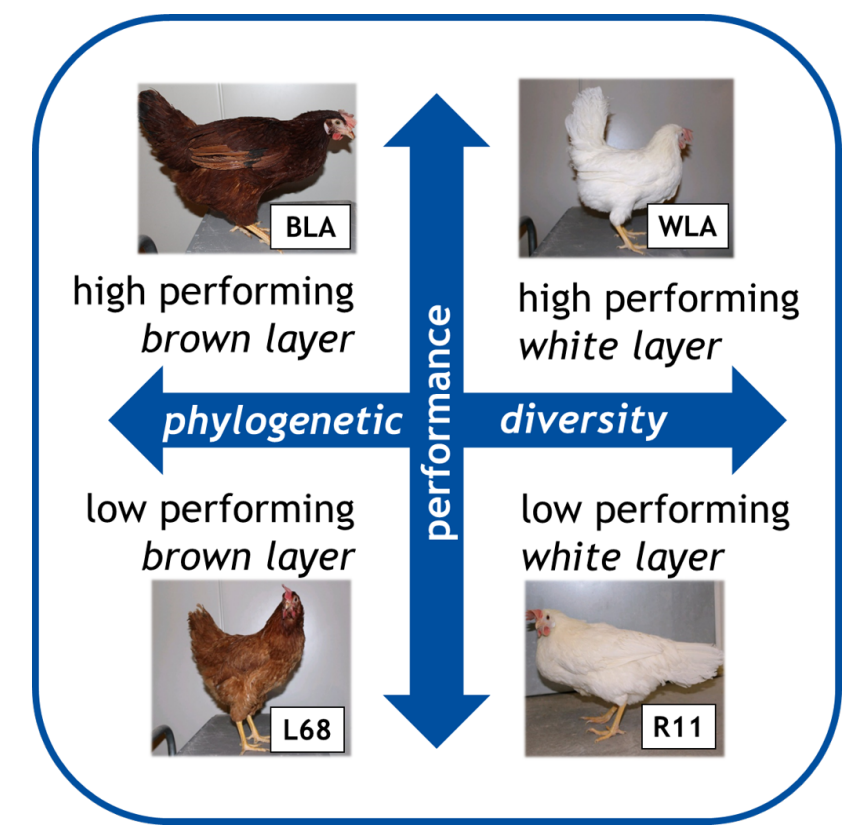

Figure 1.2: Schematic illustration of the four-line animal model comprising four purebred chicken layer lines differing in their phylogenetic origin and egg-laying performance. Modified from Lieboldt et al. [186].

The first objective is to investigate to what extent the factors of phylogeny and egg production level determine bone stability. This is studied in hens under two different metabolic conditions: the normal state and the state challenged by calcium reduction. First, Chapter 2 analyses the relationship between egg production and bone strength in metabolically normal hens with respect to the main factors of phylogeny and performance level. Besides characterising skeletal traits of the four layer lines, the question of whether bone weakness can 
be attributed to selection for high laying performance is addressed. In the following Chapter 3, the role of the two main factors on bone properties under the metabolically challenging situation of a nutritive calcium depletion is examined. Repeated administration of a low-calcium diet are employed to investigate whether there are differences in the resilience of the four layer lines in terms of skeletal integrity.

The second objective of this thesis focuses on the potential of genetics to alleviate bone disorders in laying hens. This is based on heritability and genetic correlation estimates for the bone traits given in Chapter 2, and on the results from a genomic study carried out in Chapter 4. For the latter, the four layer lines are combined to identify and functionally annotate candidate genes associated with bones traits in laying hens.

\subsection{References}

[1] Tixier-Boichard, M., Weigend, S. The origin and domestication of poultry species in Advances in poultry genetics and genomics. (Eds.: Aggrey, S. E., Zhou, H., Tixier-Boichard, M., Rhoads, D. D.). Burleigh Dodds Science Publishing. Cambridge, UK. 2020, pp. 3-40.

[2] Zeuner, F. E. A History of Domesticated Animals. Hutchinson \& Co. London, UK. 1963.

[3] West, B., Zhou, B.-X. Did chickens go North? New evidence for domestication. J. Archaeol. Sci. 1988. 15, 515-533.

[4] Crawford, R. D. Origin and history of poultry species in Poultry Breeding and Genetics. (Ed.: Crawford, R. D.). Elsevier. San Diego, CA, USA. 1990, pp. 1-42.

[5] Tixier-Boichard, M., Bed'hom, B., Rognon, X. Chicken domestication: From archeology to genomics. C. R. Biol. 2011. 334, 197-204.

[6] Malomane, D. K., Simianer, H., Weigend, A., Reimer, C., Schmitt, A. O., Weigend, S. The SYNBREED chicken diversity panel: a global resource to assess chicken diversity at high genomic resolution. BMC Genomics 2019. 20, 345.

[7] Jensen, P., Andersson, L. Genomics meets ethology: a new route to understanding domestication, behavior, and sustainability in animal breeding. Ambio 2005. 34, 320-324.

[8] Siegel, P. B., Honaker, C. F., Rauw, W. M. Selection for high production in poultry in Resource allocation theory applied to farm animal production. (Ed.: Rauw, W. M.). CABI Publishing. Wallingford, Oxfordshire, UK. 2008, pp. 230-242.

[9] Lyimo, C. M., Weigend, A., Msoffe, P. L., Eding, H., Simianer, H., Weigend, S. Global diversity and genetic contributions of chicken populations from African, Asian and European regions. Anim. Genet. 2014. 45, 836-848.

[10] Al-Nasser, A., Al-Khalaifa, H., Al-Saffar, A., Khalil, F., Albahouh, M., Ragheb, G., Al-Haddad, A., Mashaly, M. Overview of chicken taxonomy and domestication. Worlds Poult. Sci. J. 2007. 63, 285-300.

[11] Tixier-Boichard, M., Leenstra, F., Flock, D. K., Hocking, P. M., Weigend, S. A century of poultry genetics. Worlds Poult. Sci. J. 2012. 68, 307-321.

[12] Thiruvenkadan, A. K., Panneerselvam, S., Prabakaran, R. Layer breeding strategies: an overview. Worlds Poult. Sci. J. 2010. 66, 477-502.

[13] Hunton, P. 100 Years of poultry genetics. Worlds Poult. Sci. J. 2006. 62, 417-428.

[14] Leenstra, F., Sambeek, F. Breeding of laying hens. LowlnputBreeds technical note 4.1. https: //www.lowinputbreeds.org/publications/lib-technical-notes.html. Accessed on 26 May 2021. 
[15] Fernyhough, M., Nicol, C. J., Braak, T. van de, Toscano, M. J., Tønnessen, M. The Ethics of Laying Hen Genetics. J. Agric. Environ. Ethics. 2019. 33, 15-36.

[16] Preisinger, R. Kommerzielle Legehennenzucht: Rückblick und Ausblick. Züchtungskunde 2021. 93, 210-228.

[17] Preisinger, R. Innovative layer genetics to handle global challenges in egg production. $\mathrm{Br}$. Poult. Sci. 2018. 59, 1-6.

[18] Mignon-Grasteau, S., Boissy, A., Bouix, J., Faure, J.-M., Fisher, A. D., Hinch, G. N., Jensen, P., Le Neindre, P., Mormède, P., Prunet, P., et al. Genetics of adaptation and domestication in livestock. Livest. Prod. Sci. 2005. 93, 3-14.

[19] Johnson, P. A., Stephens, C. S., Giles, J. R. The domestic chicken: Causes and consequences of an egg a day. Poult. Sci. 2015. 94, 816-820.

[20] Bain, M. M., Nys, Y., Dunn, I. C. Increasing persistency in lay and stabilising egg quality in longer laying cycles. What are the challenges? Br. Poult. Sci. 2016. 57, 330-338.

[21] Loveridge, N. Bone: more than a stick. J. Anim. Sci. 1999. 77 Suppl 2, 190-196.

[22] Toscano, M. Skeletal problems in contemporary commercial laying hens in Advances in Poultry Welfare. (Ed.: Mench, J. A.). Woodhead Publishing. Cambridge, UK. 2018, pp. 151-173.

[23] Whitehead, C. C. Overview of bone biology in the egg-laying hen. Poult. Sci. 2004. 83, 193-199.

[24] Mackie, E. J., Ahmed, Y. A., Tatarczuch, L., Chen, K. S., Mirams, M. Endochondral ossification: how cartilage is converted into bone in the developing skeleton. Int. J. Biochem. Cell Biol. 2008. 40, 46-62.

[25] Shapiro, F. Bone development and its relation to fracture repair. The role of mesenchymal osteoblasts and surface osteoblasts. Eur. Cell. Mater. 2008. 15, 53-76.

[26] Pines, M., Reshef, R. Poultry bone development and bone disorders in Sturkie's Avian Physiology. (Ed.: Scanes, C. G.). Academic Press. San Diego, CA, USA. 2015, pp. 367-377.

[27] Nudelman, F., Lausch, A. J., Sommerdijk, N. A., Sone, E. D. In vitro models of collagen biomineralization. J. Struct. Biol. 2013. 183, 258-269.

[28] Whitehead, C. C., Fleming, R. H. Osteoporosis in cage layers. Poult. Sci. 2000. 79, 1033-1041.

[29] Kerschnitzki, M., Zander, T., Zaslansky, P., Fratzl, P., Shahar, R., Wagermaier, W. Rapid alterations of avian medullary bone material during the daily egg-laying cycle. Bone 2014. 69, 109-117.

[30] Burch, J., Rice, S., Yang, H., Neilson, A., Stirk, L., Francis, R., Holloway, P., Selby, P., Craig, D. Systematic review of the use of bone turnover markers for monitoring the response to osteoporosis treatment: the secondary prevention of fractures, and primary prevention of fractures in high-risk groups. Health Technol. Assess. 2014. 18.

[31] Beck, M. M., Hansen, K. K. Role of estrogen in avian osteoporosis. Poult. Sci. 2004. 83, 200-206.

[32] Gunton, J. E., Girgis, C. M., Baldock, P. A., Lips, P. Bone muscle interactions and vitamin D. Bone 2015. 80, 89-94.

[33] De Vries, S., Kwakkel, R. P., Dijkstra, J. Dynamics of calcium and phosphorus metabolism in laying hens in Phosphorus and calcium utilization requirements in farm animals. (Eds.: Vitti, D. M. S. S., Kebreab, E.). CABI Publishing. Wallingford, Oxfordshire, UK. 2010, pp. 133-150.

[34] Rath, N. C., Huff, G. R., Huff, W. E., Balog, J. M. Factors regulating bone maturity and strength in poultry. Poult. Sci. 2000. 79, 1024-1032. 
[35] Odgaard, A. Three-dimensional methods for quantification of cancellous bone architecture. Bone 1997. 20, 315-328.

[36] Kim, W. K., Bloomfield, S. A., Sugiyama, T., Ricke, S. C. Concepts and methods for understanding bone metabolism in laying hens. Worlds Poult. Sci. J. 2012. 68, 71-82.

[37] Rodriguez-Navarro, A. B., McCormack, H. M., Fleming, R. H., Alvarez-Lloret, P., RomeroPastor, J., Dominguez-Gasca, N., Prozorov, T., Dunn, I. C. Influence of physical activity on tibial bone material properties in laying hens. J. Struct. Biol. 2018. 201, 36-45.

[38] Schweitzer, M. H., Wittmeyer, J. L., Horner, J. R. Gender-specific reproductive tissue in ratites and Tyrannosaurus rex. Science 2005. 308, 1456.

[39] Dacke, C. G., Sugiyama, T., Gay, C. V. The role of hormones in the regulation of bone turnover and eggshell calcification in Sturkie's Avian Physiology. (Ed.: Scanes, C. G.). Academic Press. San Diego, CA, USA. 2015, pp. 549-575.

[40] Bonucci, E., Gherardi, G. Histochemical and electron microscopy investigations on medullary bone. Cell Tissue Res. 1975. 163, 81-97.

[41] Van de Velde, J. P., Vermeiden, J. P., Touw, J. J., Veldhuijzen, J. P. Changes in activity of chicken medullary bone cell populations in relation to the egg-laying cycle. Metab. Bone Dis. Relat. Res. 1984. 5, 191-193.

[42] Dacke, C. G., Arkle, S., Cook, D. J., Wormstone, I. M., Jones, S., Zaidi, M., Bascal, Z. A. Medullary bone and avian calcium regulation. J. Exp. Biol. 1993. 184, 63-88.

[43] Fleming, R. H., McCormack, H. A., McTeir, L., Whitehead, C. C. Medullary bone and humeral breaking strength in laying hens. Res. Vet. Sci. 1998. 64, 63-67.

[44] Fleming, R. H., McCormack, H. A., McTeir, L., Whitehead, C. C. Incidence, pathology and prevention of keel bone deformities in the laying hen. Br. Poult. Sci. 2004. 45, 320-330.

[45] Knott, L., Whitehead, C. C., Fleming, R. H., Bailey, A. J. Biochemical changes in the collagenous matrix of osteoporotic avian bone. Biochem. J. 1995. 310, 1045-1051.

[46] Fleming, R. H., McCormack, H. A., McTeir, L., Whitehead, C. C. Relationships between genetic, environmental and nutritional factors influencing osteoporosis in laying hens. $\mathrm{Br}$. Poult. Sci. 2006. 47, 742-755.

[47] Bar, A. Calcium homeostasis and vitamin D metabolism and expression in strongly calcifying laying birds. Comp. Biochem. Physiol. 2008. 151A, 477-490.

[48] Nys, Y., Le Roy, N. Calcium homeostasis and eggshell biomineralization in female chicken in Vitamin D, Volume 1: Biochemistry, Physiology and Diagnostics. (Ed.: Feldman, D.). Academic Press. San Diego, CA, USA. 2018, pp. 361-382.

[49] Wilson, S., Duff, S. R. Effects of vitamin or mineral deficiency on the morphology of medullary bone in laying hens. Res. Vet. Sci. 1991. 50, 216-221.

[50] Dominguez-Gasca, N., Benavides-Reyes, C., Sánchez-Rodríguez, E., Rodríguez-Navarro, A. B. Changes in avian cortical and medullary bone mineral composition and organization during acid-induced demineralization. Eur. J. Mineral. 2019. 31, 209-216.

[51] Johnson, A. L. Reproduction in the female in Sturkie's Avian Physiology. (Ed.: Scanes, C. G.). Academic Press. San Diego, CA, USA. 2015, pp. 635-665.

[52] Roberts, J. R. Factors affecting egg internal quality and egg shell quality in laying hens. J. Poult. Sci. 2004. 41, 161-177.

[53] Elaroussi, M. A., Forte, L. R., Eber, S. L., Biellier, H. V. Calcium homeostasis in the laying hen.: 1. age and dietary calcium effects. Poult. Sci. 1994. 73, 1581-1589.

[54] Jonchère, V., Brionne, A., Gautron, J., Nys, Y. Identification of uterine ion transporters for mineralisation precursors of the avian eggshell. BMC Physiol. 2012. 12, 10. 
[55] Wilkinson, S. J., Selle, P. H., Bedford, M. R., Cowieson, A. J. Exploiting calcium-specific appetite in poultry nutrition. Worlds Poult. Sci. J. 2011. 67, 587-598.

[56] Bar, A. Calcium transport in strongly calcifying laying birds: Mechanisms and regulation. Comp. Biochem. Physiol. 2009. 152A, 447-469.

[57] Carrillo, L., Bernad, M.-J., Monroy-Barreto, M., Coello, C. L., Sumano, H., Gutiérrez, L. Higher bioavailability of calcium in chickens with a novel in-feed pharmaceutical formulation. Front. Vet. Sci. 2020. 7, 343-343.

[58] Wistedt, A., Ridderstråle, Y., Wall, H., Holm, L. Age-related changes in the shell gland and duodenum in relation to shell quality and bone strength in commercial laying hen hybrids. Acta Vet. Scand. 2019. 61, 14.

[59] Wilson, S., Thorp, B. H. Estrogen and cancellous bone loss in the fowl. Calcif. Tissue Int. 1998. 62, 506-511.

[60] Chen, C., Turner, B., Applegate, T. J., Litta, G., Kim, W. K. Role of long-term supplementation of 25-hydroxyvitamin D3 on laying hen bone 3-dimensional structural development. Poult. Sci. 2020. 99, 5771-5782.

[61] Cransberg, P. H., Parkinson, G. B., Wilson, S., Thorp, B. H. Sequential studies of skeletal calcium reserves and structural bone volume in a commercial layer flock. Br. Poult. Sci. 2001. 42, 260-265.

[62] Johnsson, M. Genetics and genomics of skeletal traits in Advances in poultry genetics and genomics. (Eds.: Aggrey, S. E., Zhou, H., Tixier-Boichard, M., Rhoads, D. D.). Burleigh Dodds Science Publishing. Cambridge, UK. 2020, pp. 307-323.

[63] Thorp, B. H. Skeletal disorders in the fowl: a review. Avian Pathol. 1994. 23, 203-236.

[64] Whitehead, C. C., Fleming, R. H., Julian, R. J., Sørensen, P. Skeletal problems associated with selection for increased production in Poultry Genetics, Breeding and Biotechnology. (Eds.: Muir, W. M., Aggrey, S. E.). CABI Publishing. Wallingford, Oxfordshire, UK. 2003, pp. 29-52.

[65] Crenshaw, A. H., Jr. Osteopenia is not a diagnosis. Curr. Orthop. Pract. 2018. 29, 93.

[66] Toscano, M. J., Dunn, I. C., Christensen, J.-P., Petow, S., Kittelsen, K., Ulrich, R. Explanations for keel bone fractures in laying hens: Are there explanations in addition to elevated egg production? Poult. Sci. 2020. 99, 4183-4194.

[67] Crenshaw, T. D., Peo, E. R., J., Lewis, A. J., Moser, B. D. Bone strength as a trait for assessing mineralization in swine: A critical review of techniques involved. J. Anim. Sci. 1981. 53, 827-835.

[68] Ammann, P., Rizzoli, R. Bone strength and its determinants. Osteoporos. Int. 2003. 14, $13-18$.

[69] Kim, W. K., Donalson, L. M., Herrera, P., Woodward, C. L., Kubena, L. F., Nisbet, D. J., Ricke, S. C. Effects of different bone preparation methods (fresh, dry, and fat-free dry) on bone parameters and the correlations between bone breaking strength and the other bone parameters. Poult. Sci. 2004. 83, 1663-1666.

[70] Campbell, D. L. M. Skeletal health of layers across all housing systems and future research directions for Australia. Anim. Prod. Sci. 2020, AN19578.

[71] Schreiweis, M. A., Orban, J. I., Ledur, M. C., Hester, P. Y. The use of densitometry to detect differences in bone mineral density and content of live White Leghorns fed varying levels of dietary calcium. Poult. Sci. 2003. 82, 1292-1301.

[72] Almeida Paz, I. C. L., Bruno, L. D. G. Bone mineral density: Review. Rev. Bras. Cienc. Avic. 2006. 8, 69-73. 
[73] Couch, J. R. Cage layer fatigue. Feed Age 1955. 5, 55-57.

[74] Urist, M. R., Deutsch, N. M. Osteoporosis in the laying hen. Endocrinology 1960. 66, 377-391.

[75] Widowski, T., Casey-Trott, T., Hunniford, M., Morrissey, K. Welfare of laying hens: an overview in Achieving sustainable production of eggs Volume 2 - Animal welfare and sustainability. (Ed.: Roberts, J. R.). Burleigh Dodds Science Publishing. San Diego, CA, USA. 2017, pp. 57-84.

[76] Dunn, I. C., Andersson, B., Fleming, R. H., De Koning, D. J., McCormack, H. M., RodriguezNavarro, A. B., Schmutz, M., Wilson, P. W. Quality of the laying hen skeleton; insights and solutions from genetics in Proceedings of The 17th International Conference on Production Diseases in Farm Animals. (Eds.: Bruckmaier, R. M., Gross, J. J.). Bern University. Bern, Switzerland. 2019, p. 50.

[77] Nasr, M. A. F., Murrell, J., Wilkins, L. J., Nicol, C. J. The effect of keel fractures on eggproduction parameters, mobility and behaviour in individual laying hens. Anim. Welfare 2012. $21,127-135$.

[78] Casey-Trott, T., Heerkens, J. L., Petrik, M., Regmi, P., Schrader, L., Toscano, M. J., Widowski, T. Methods for assessment of keel bone damage in poultry. Poult. Sci. 2015. 94, 2339-2350.

[79] Gebhardt-Henrich, S. G., Pfulg, A., Fröhlich, E. K. F., Käppeli, S., Guggisberg, D., Liesegang, A., Stoffel, M. H. Limited associations between keel bone damage and bone properties measured with computer tomography, three-point bending test, and analysis of minerals in Swiss laying hens. Front. Vet. Sci. 2017. 4.

[80] Harlander-Matauschek, A., Rodenburg, T. B., Sandilands, V., Tobalske, B. W., Toscano, M. J. Causes of keel bone damage and their solutions in laying hens. Worlds Poult. Sci. J. 2015. $71,461-472$.

[81] Heerkens, J. L., Delezie, E., Ampe, B., Rodenburg, T. B., Tuyttens, F. A. Ramps and hybrid effects on keel bone and foot pad disorders in modified aviaries for laying hens. Poult. Sci. 2016. 95, 2479-2488.

[82] Warren, D. C. Physiologic and genetic studies of crooked keels in chickens. Kansas Agricultural Experiment Station Technical Bulletin 1937. 44, 5-32.

[83] Gregory, N. G., Wilkins, L. J. Broken bones in domestic fowl: handling and processing damage in end-of-lay battery hens. Br. Poult. Sci. 1989. 30, 555-562.

[84] Budgell, K. L., Silversides, F. G. Bone breakage in three strains of end-of-lay hens. Can. J. Anim. Sci. 2004. 84, 745-747.

[85] Clark, W. D., Cox, W. R., Silversides, F. G. Bone fracture incidence in end-of-lay highproducing, noncommercial laying hens identified using radiographs. Poult. Sci. 2008. 87, 1964-1970.

[86] Farm Animal Welfare Council. Opinion on osteoporosis and bone fractures in laying hens. https://gov.uk/government/publications/fawc-opinion-on-osteoporosis-and-bone-fracturesin-laying-hens. 2010.

[87] Sandilands, V. The laying hen and bone fractures. Vet. Rec. 2011. 169, 411.

[88] Wilkins, L. J., McKinstry, J. L., Avery, N. C., Knowles, T. G., Brown, S. N., Tarlton, J., Nicol, C. J. Influence of housing system and design on bone strength and keel bone fractures in laying hens. Vet. Rec. 2011. 169, 414.

[89] Jung, L., Niebuhr, K., Hinrichsen, L. K., Gunnarsson, S., Brenninkmeyer, C., Bestman, M., Heerkens, J., Ferrari, P., Knierim, U. Possible risk factors for keel bone damage in organic laying hens. Animal 2019. 13, 2356-2364. 
[90] Webster, A. B. Welfare implications of avian osteoporosis. Poult. Sci. 2004. 83, 184-192.

[91] McKeegan, D. E. F. Mechano-chemical nociceptors in the avian trigeminal mucosa. Brain Res. Rev. 2004. 46, 146-154.

[92] Gentle, M. J. Pain issues in poultry. Appl. Anim. Behav. Sci. 2011. 135, 252-258.

[93] Nasr, M. A. F., Nicol, C. J., Murrell, J. C. Do laying hens with keel bone fractures experience pain? PLoS One 2012. 7, e42420.

[94] Nasr, M. A. F., Nicol, C. J., Wilkins, L., Murrell, J. C. The effects of two non-steroidal antiinflammatory drugs on the mobility of laying hens with keel bone fractures. Vet. Anaesth. Analg. 2015. 42, 197-204.

[95] Riber, A. B., Casey-Trott, T. M., Herskin, M. S. The influence of keel bone damage on welfare of laying hens. Front. Vet. Sci. 2018. 5, 6.

[96] Casey-Trott, T. M., Widowski, T. M. Behavioral differences of laying hens with fractured keel bones within furnished cages. Front. Vet. Sci. 2016. 3, 42.

[97] Armstrong, E. A., Rufener, C., Toscano, M. J., Eastham, J. E., Guy, J. H., Sandilands, V., Boswell, T., Smulders, T. V. Keel bone fractures induce a depressive-like state in laying hens. Sci. Rep. 2020. 10, 3007.

[98] Roland, D. A., Rao, S. K. Nutritional and management factors related to osteopenia in laying hens in Bone biology and skeletal disorders in poultry. (Ed.: Whitehead, C. C.). Carfax Publishing Co. Abingdon, UK. 1992, pp. 281-295.

[99] McCoy, M. A., Reilly, G. A. C., Kilpatrick, D. J. Density and breaking strength of bones of mortalities among caged layers. Res. Vet. Sci. 1996. 60, 185-186.

[100] Julian, R. J. Production and growth related disorders and other metabolic diseases of poultry - a review. Vet. J. 2005. 169, 350-369.

[101] Rufener, C., Baur, S., Stratmann, A., Toscano, M. J. Keel bone fractures affect egg laying performance but not egg quality in laying hens housed in a commercial aviary system. Poult. Sci. 2019. 98, 1589-1600.

[102] Nasr, M. A. F., Murrell, J., Nicol, C. J. The effect of keel fractures on egg production, feed and water consumption in individual laying hens. Br. Poult. Sci. 2013. 54, 165-170.

[103] Candelotto, L., Stratmann, A., Gebhardt-Henrich, S. G., Rufener, C., Braak, T. van de, Toscano, M. J. Susceptibility to keel bone fractures in laying hens and the role of genetic variation. Poult. Sci. 2017. 96, 3517-3528.

[104] Dunn, I. C., Fleming, R. H., McCormack, H. A., Morrice, D., Burt, D. W., Preisinger, R., Whitehead, C. C. A QTL for osteoporosis detected in an F2 population derived from White Leghorn chicken lines divergently selected for bone index. Anim. Genet. 2007. 38, 45-49.

[105] Alfonso-Carrillo, C., Benavides-Reyes, C., Mozos, J. de los, Dominguez-Gasca, N., SanchezRodríguez, E., Garcia-Ruiz, A. I., Rodriguez-Navarro, A. B. Relationship between bone quality, egg production and eggshell quality in laying hens at the end of an extended production cycle (105 weeks). Animals 2021. 11, 623.

[106] Guo, J., Sun, C., Qu, L., Shen, M., Dou, T., Ma, M., Wang, K., Yang, N. Genetic architecture of bone quality variation in layer chickens revealed by a genome-wide association study. Sci. Rep. 2017. 7, 45317.

[107] Raymond, B., Johansson, A. M., McCormack, H. A., Fleming, R. H., Schmutz, M., Dunn, I. C., De Koning, D. J. Genome-wide association study for bone strength in laying hens. J. Anim. Sci. 2018. 96, 2525-2535.

[108] Rauw, W. M., Kanis, E., Noordhuizen-Stassen, E. N., Grommers, F. J. Undesirable side effects of selection for high production efficiency in farm animals: a review. Livest. Prod. Sci. 1998. $56,15-33$. 
[109] Hocking, P. M. Unexpected consequences of genetic selection in broilers and turkeys: problems and solutions. Br. Poult. Sci. 2014. 55, 1-12.

[110] Van der Waaij, E. H. A resource allocation model describing consequences of artificial selection under metabolic stress. J. Anim. Sci. 2004. 82, 973-981.

[111] Glazier, D. S. Resource allocation patterns in Resource allocation theory applied to farm animal production. (Ed.: Rauw, W. M.). CABI Publishing. Wallingford, Oxfordshire, UK. 2008, pp. 22-43.

[112] Mirkena, T., Duguma, G., Haile, A., Tibbo, M., Okeyo, A. M., Wurzinger, M., Sölkner, J. Genetics of adaptation in domestic farm animals: A review. Livest. Sci. 2010. 132, 1-12.

[113] Hocking, P. M., Bain, M., Channing, C. E., Fleming, R., Wilson, S. Genetic variation for egg production, egg quality and bone strength in selected and traditional breeds of laying fowl. Br. Poult. Sci. 2003. 44, 365-373.

[114] Rowland, L. O., Fry, J. L., Christmas, R. B., O'Steen, A. W., Harms, R. H. Differences in tibia strength and bone ash among strains of layers. Poult. Sci. 1972. 51, 1612-1615.

[115] Riczu, C. M., Saunders-Blades, J. L., Yngvesson, A. K., Robinson, F. E., Korver, D. R. Endof-cycle bone quality in white- and brown-egg laying hens. Poult. Sci. 2004. 83, 375-383.

[116] Silversides, F. G., Korver, D. R., Budgell, K. L. Effect of strain of layer and age at photostimulation on egg production, egg quality, and bone strength. Poult. Sci. 2006. 85, $1136-1144$.

[117] Käppeli, S., Gebhardt-Henrich, S. G., Fröhlich, E., Pfulg, A., Schäublin, H., Stoffel, M. H. Effects of housing, perches, genetics, and 25-hydroxycholecalciferol on keel bone deformities in laying hens. Poult. Sci. 2011. 90, 1637-1644.

[118] Candelotto, L., Stadelmann, M., Gebhardt-Henrich, S. G., Stratmann, A., Braak, T. G. H. van de, Guggisberg, D., Zysset, P., Toscano, M. J. Genetic variation of keel and long bone skeletal properties for 5 lines of laying hens. J. Appl. Poult. Res. 2020. 29, 937-946.

[119] Nolte, T., Jansen, S., Halle, I., Scholz, A. M., Simianer, H., Sharifi, A. R., Weigend, S. Egg production and bone stability of local chicken breeds and their crosses fed with faba beans. Animals 2020. 10, 1480.

[120] Habig, C., Distl, O. Evaluation of bone strength, keel bone status, plumage condition and egg quality of two layer lines kept in small group housing systems. Br. Poult. Sci. 2013. 54, $413-424$.

[121] Vits, A., Weitzenbürger, D., Hamann, H., Distl, O. Production, egg quality, bone strength, claw length, and keel bone deformities of laying hens housed in furnished cages with different group sizes. Poult. Sci. 2005. 84, 1511-1519.

[122] Rayan, G. N., El-Attar, A. H., Fathi, M. M. Eggshell and bone quality in two different genetic groups of aged layer breeders. Braz. J. Poultry Sci. 2020. 22, 1-7.

[123] Sharma, M. K., White, D., Chen, C., Kim, W. K., Adhikari, P. Effects of the housing environment and laying hen strain on tibia and femur bone properties of different laying phases of Hy-Line hens. Poult. Sci. 2021. 100, 100933.

[124] Ali, A. B. A., Campbell, D. L. M., Siegford, J. M. A risk assessment of health, production, and resource occupancy for 4 laying hen strains across the lay cycle in a commercial-style aviary system. Poult. Sci. 2020. 99, 4672-4684.

[125] Wahlström, A., Tauson, R., Elwinger, K. Plumage condition and health of aviary-kept hens fed mash or crumbled pellets. Poult. Sci. 2001. 80, 266-271.

[126] Silversides, F. G., Singh, R., Cheng, K. M., Korver, D. R. Comparison of bones of 4 strains of laying hens kept in conventional cages and floor pens. Poult. Sci. 2012. 91, 1-7. 
[127] Rennie, J. S., Fleming, R. H., McCormack, H. A., McCorquodale, C. C., Whitehead, C. C. Studies on effects of nutritional factors on bone structure and osteoporosis in laying hens. Br. Poult. Sci. 1997. 38, 417-424.

[128] Habig, C., Baulain, U., Henning, M., Scholz, A. M., Sharifi, A. R., Janisch, S., Simianer, H., Weigend, S. How bone stability in laying hens is affected by phylogenetic background and performance level. Eur. Poult. Sci. 2017. 81.

[129] Hocking, P. M., Sandercock, D. A., Wilson, S., Fleming, R. H. Quantifying genetic (co)variation and effects of genetic selection on tibial bone morphology and quality in 37 lines of broiler, layer and traditional chickens. Br. Poult. Sci. 2009. 50, 443-450.

[130] Stratmann, A., Frohlich, E. K., Gebhardt-Henrich, S. G., Harlander-Matauschek, A., Wurbel, H., Toscano, M. J. Genetic selection to increase bone strength affects prevalence of keel bone damage and egg parameters in commercially housed laying hens. Poult. Sci. 2016. 95, 975-984.

[131] Käppeli, S., Gebhardt-Henrich, S. G., Fröhlich, E., Pfulg, A., Stoffel, M. H. Prevalence of keel bone deformities in Swiss laying hens. Br. Poult. Sci. 2011. 52, 531-536.

[132] Dunn, I. C., De Koning, D.-J., McCormack, H. A., Fleming, R. H., Wilson, P. W., Andersson, B., Schmutz, M., Benavides, C., Dominguez-Gasca, N., Sanchez-Rodriguez, E., et al. No evidence that selection for egg production persistency causes loss of bone quality in laying hens. Genet. Sel. Evol. 2021. 53, 11.

[133] Bishop, S. C., Fleming, R. H., McCormack, H. A., Flock, D. K., Whitehead, C. C. Inheritance of bone characteristics affecting osteoporosis in laying hens. Br. Poult. Sci. 2000. 41, 33-40.

[134] Sparke, A. J., Sims, T. J., Avery, N. C., Bailey, A. J., Fleming, R. H., Whitehead, C. C. Differences in composition of avian bone collagen following genetic selection for resistance to osteoporosis. Br. Poult. Sci. 2002. 43, 127-134.

[135] Fleming, R. H., Whitehead, C. C., Alvey, D., Gregory, N. G., Wilkins, L. J. Bone structure and breaking strength in laying hens housed in different husbandry systems. Br. Poult. Sci. 1994. 35, 651-662.

[136] Andersson, B., Icken, W., Kaufmann, F., Schmutz, M. Genetic aspects of keel bone deformities and fractures determined by palpation in laying hens. Lohmann Information 2017. $51,36-41$.

[137] Schreiweis, M. A., Hester, P. Y., Moody, D. E. Identification of quantitative trait loci associated with bone traits and body weight in an F2 resource population of chickens. Genet. Sel. Evol. 2005. 37, 677.

[138] Sharman, P. W. A., Morrice, D. R., Law, A. S., Burt, D. W., Hocking, P. M. Quantitative trait loci for bone traits segregating independently of those for growth in an F-2 broiler $\times$ layer cross. Cytogenet. Genome Res. 2007. 117, 296-304.

[139] Zhou, H., Deeb, N., Evock-Clover, C. M., Mitchell, A. D., Ashwell, C. M., Lamont, S. J. Genome-wide linkage analysis to identify chromosomal regions affecting phenotypic traits in the chicken. III. Skeletal integrity. Poult. Sci. 2007. 86, 255-266.

[140] Podisi, B. K., Knott, S. A., Dunn, I. C., Burt, D. W., Hocking, P. M. Bone mineral density QTL at sexual maturity and end of lay. Br. Poult. Sci. 2012. 53, 763-769.

[141] Johnsson, M., Jonsson, K. B., Andersson, L., Jensen, P., Wright, D. Genetic regulation of bone metabolism in the chicken: Similarities and differences to ammalian systems. PLoS Genetics 2015. 11, e1005250.

[142] De Koning, D.-J., Dominguez-Gasca, N., Fleming, R. H., Gill, A., Kurian, D., Law, A., McCormack, H. A., Morrice, D., Sanchez-Rodriguez, E., Rodriguez-Navarro, A. B., et al. An eQTL in the cystathionine beta synthase gene is linked to osteoporosis in laying hens. Genet. Sel. Evol. 2020. 52, 13. 
[143] Olgun, O., Aygun, A. Nutritional factors affecting the breaking strength of bone in laying hens. Worlds Poult. Sci. J. 2016. 72, 821-832.

[144] Fleming, R. H. Nutritional factors affecting poultry bone health: Symposium on 'Diet and bone health'. Proc. Nutr. Soc. 2008. 67, 177-183.

[145] Guinotte, F., Nys, Y. Effects of particle size and origin of calcium sources on eggshell quality and bone mineralization in egg laying hens. Poult. Sci. 1991. 70, 583-592.

[146] Oliveira, A. N., Freitas, E. R., Filgueira, T. M. B., Cruz, C. E. B., Nascimento, G. A. Limestone particle size and artificial light for laying hens in the second laying cycle. Rev. Bras. Zootec. 2013. 42, 481-488.

[147] Roland, D. A., Harms, R. H. Calcium metabolism in the laying hen: 5. Effect of various sources and sizes of calcium carbonate on shell quality. Poult. Sci. 1973. 52, 369-372.

[148] Farmer, M., Roland, D. A., Clark, A. J. Influence of dietary calcium on bone calcium utilization. Poult. Sci. 1986. 65, 337-344.

[149] Koutoulis, K. C., Kyriazakis, I., Perry, G. C., Lewis, P. D. Effect of different calcium sources and calcium intake on shell quality and bone characteristics of laying hens at sexual maturity and end of lay. Int. J. Poult. Sci. 2009. 8, 342-348.

[150] Nascimento, G. R., Murakami, A. E., Guerra, A. F. Q. M., Ospinas-Rojas, I. C., Ferreira, M. F. Z., Fanhani, J. C. Effect of different vitamin D sources and calcium levels in the diet of layers in the second laying cycle. Braz. J. Poult. Sci. 2014. 16, 37-42.

[151] Swiatkiewicz, S., Arczewska-Wlosek, A., Jozefiak, D. Bone quality, selected blood variables and mineral retention in laying hens fed with different dietary concentrations and sources of calcium. Livest. Sci. 2015. 181, 194-199.

[152] Khanal, T., Widowski, T., Bédécarrats, G., Kiarie, E. Effects of pre-lay dietary calcium (2.5 vs. $4.0 \%$ ) and pullet strain (Lohmann Brown vs. Selected Leghorn LSL-Lite) on calcium utilization and femur quality at 1st through to the 50th egg. Poult. Sci. 2019. 98, 4919-4928.

[153] Hurwitz, S., Bar, A. Calcium depletion and repletion in laying hens: 1. Effect on calcium in various bone segments, in egg shells and in blood plasma, and on calcium balance. Poult. Sci. 1966. 45, 345-352.

[154] Herrera, J., Saldaña, B., Cámara, L., Berrocoso, J. D., Mateos, G. G. Influence of grinding size of the main cereal of the diet on egg production and eggs quality of brown egg laying hens from 33 to 65 weeks of age. Poult. Sci. 2018. 97, 2506-2515.

[155] Simpson, C. J., Wise, A. Binding of zinc and calcium to inositol phosphates (phytate) in vitro. Br. J. Nutr. 1990. 64, 225-232.

[156] Plumstead, P. W., Leytem, A. B., Maguire, R. O., Spears, J. W., Kwanyuen, P., Brake, J. Interaction of calcium and phytate in broiler diets. 1. Effects on apparent prececal digestibility and retention of phosphorus. Poult. Sci. 2008. 87, 449-458.

[157] Nys, Y. Laying hen nutrition: Optimising hen performance and health, bone and eggshell quality in Achieving sustainable production of eggs Volume 2 - Animal welfare and sustainability. (Ed.: Roberts, J. R.). Burleigh Dodds Science Publishing. San Diego, CA, USA. 2017, pp. 29-56.

[158] Muszyński, S., Tomaszewska, E., Dobrowolski, P., Kwiecień, M., Wiącek, D., Świetlicka, I., Skibińska, M., Szymańska-Chargot, M., Orzeł, J., Świetlicki, M., et al. Analysis of bone osteometry, mineralization, mechanical and histomorphometrical properties of tibiotarsus in broiler chickens demonstrates a influence of dietary chickpea seeds (Cicer arietinum L.) inclusion as a primary protein source. PLoS One 2018. 13, e0208921. 
[159] Mattila, P. H., Valkonen, E., Valaja, J. Effect of different vitamin D supplementations in poultry feed on vitamin D content of eggs and chicken meat. J. Agric. Food Chem. 2011. $59,8298-8303$.

[160] Wen, J., Livingston, K. A., Persia, M. E. Effect of high concentrations of dietary vitamin D3 on pullet and laying hen performance, skeleton health, eggshell quality, and yolk vitamin D3 content when fed to W36 laying hens from day of hatch until 68 wk of age. Poult. Sci. 2019. 98, 6713-6720.

[161] Ameenuddin, S., Sunde, M. L., DeLuca, H. F., Cook, M. E. Excessive cholecalciferol in a layers diet: decline in some aspects of reproductive performance and increased bone mineralisation of progeny. Br. Poult. Sci. 1986. 27, 671-677.

[162] Persia, M. E., Higgins, M., Wang, T., Trample, D., Bobeck, E. A. Effects of long-term supplementation of laying hens with high concentrations of cholecalciferol on performance and egg quality. Poult. Sci. 2013. 92, 2930-2937.

[163] Adhikari, R., White, D., House, J. D., Kim, W. K. Effects of additional dosage of vitamin D3, vitamin D2, and 25-hydroxyvitamin D3 on calcium and phosphorus utilization, egg quality and bone mineralization in laying hens. Poult. Sci. 2020. 99, 364-373.

[164] Rowland, L. O., Harms, R. H. Time required to develop bone fragility in laying hens. Poult. Sci. 1972. 51, 1339-1341.

[165] Wabeck, C. J., Littlefield, L. H. Bone strength of broilers reared in floor pens and in cages having different bottoms. Poult. Sci. 1972. 51, 897-899.

[166] Wilson, S., Duff, S. R., Whitehead, C. C. Effects of age, sex and housing on the trabecular bone of laying strain domestic fowl. Res. Vet. Sci. 1992. 53, 52-58.

[167] Leyendecker, M., Hamann, H., Hartung, J., Kamphues, J., Neumann, U., Sürie, C., Distl, O. Keeping laying hens in furnished cages and an aviary housing system enhances their bone stability. Br. Poult. Sci. 2005. 46, 536-544.

[168] Jendral, M. J., Korver, D. R., Church, J. S., Feddes, J. J. R. Bone mineral density and breaking strength of White Leghorns housed in conventional, modified, and commercially available colony battery cages. Poult. Sci. 2008. 87, 828-837.

[169] Regmi, P., Smith, N., Nelson, N., Haut, R. C., Orth, M. W., Karcher, D. M. Housing conditions alter properties of the tibia and humerus during the laying phase in Lohmann white Leghorn hens. Poult. Sci. 2016. 95, 198-206.

[170] Shipov, A., Sharir, A., Zelzer, E., Milgram, J., Monsonego-Ornan, E., Shahar, R. The influence of severe prolonged exercise restriction on the mechanical and structural properties of bone in an avian model. Vet. J. 2010. 183, 153-160.

[171] Aguado, E., Pascaretti-Grizon, F., Goyenvalle, E., Audran, M., Chappard, D. Bone mass and bone quality are altered by hypoactivity in the chicken. PLoS One 2015. 10, e0116763.

[172] Lanyon, L. E. Functional load-bearing as a controlling influence for fracture resistance in the skeleton in Bone biology and skeletal disorders in poultry. (Ed.: Whitehead, C. C.). Carfax Publishing Co. Abingdon, UK. 1992, pp. 61-66.

[173] Newman, S., Leeson, S. Effect of housing birds in cages or an aviary system on bone characteristics. Poult. Sci. 1998. 77, 1492-1496.

[174] Regmi, P., Deland, T. S., Steibel, J. P., Robison, C. I., Haut, R. C., Orth, M. W., Karcher, D. M. Effect of rearing environment on bone growth of pullets. Poult. Sci. 2015. 94, 502-511.

[175] Neijat, M., Casey-Trott, T. M., Robinson, S., Widowski, T. M., Kiarie, E. Effects of rearing and adult laying housing systems on medullary, pneumatic and radius bone attributes in 73-wk old Lohmann LSL lite hens. Poult. Sci. 2019. 98, 2840-2845. 
[176] Khanal, T., Bédécarrats, G. Y., Widowski, T., Kiarie, E. G. Rearing cage type and dietary limestone particle size: I, effects on growth, apparent retention of calcium, and long bones attributes in Lohmann selected Leghorn-Lite pullets1. Poult. Sci. 2020. 99, 4454-4465.

[177] Gregory, N. G., Wilkins, L. J., Eleperuma, S. D., Ballantyne, A. J., Overfield, N. D. Broken bones in domestic fowls: Effect of husbandry system and stunning method in end-of-lay hens. Br. Poult. Sci. 1990. 31, 59-69.

[178] Sherwin, C. M., Richards, G. J., Nicol, C. J. Comparison of the welfare of layer hens in 4 housing systems in the UK. Br. Poult. Sci. 2010. 51, 488-499.

[179] Petrik, M. T., Guerin, M. T., Widowski, T. M. On-farm comparison of keel fracture prevalence and other welfare indicators in conventional cage and floor-housed laying hens in Ontario, Canada. Poult. Sci. 2015. 94, 579-585.

[180] Regmi, P., Nelson, N., Steibel, J. P., Anderson, K. E., Karcher, D. M. Comparisons of bone properties and keel deformities between strains and housing systems in end-of-lay hens. Poult. Sci. 2016. 95, 2225-2234.

[181] Saraiva, S., Esteves, A., Stilwell, G. Influence of different housing systems on prevalence of keel bone lesions in laying hens. Avian Pathol. 2019. 48, 454-459.

[182] Sandilands, V., Moinard, C., Sparks, N. H. C. Providing laying hens with perches: fulfilling behavioural needs but causing injury? Br. Poult. Sci. 2009. 50, 395-406.

[183] Lay, D. C., Fulton, R. M., Hester, P. Y., Karcher, D. M., Kjaer, J. B., Mench, J. A., Mullens, B. A., Newberry, R. C., Nicol, C. J., O'Sullivan, N. P., et al. Hen welfare in different housing systems. Poult. Sci. 2011. 90, 278-294.

[184] Stratmann, A., Fröhlich, E. K. F., Gebhardt-Henrich, S. G., Harlander-Matauschek, A., Würbel, H., Toscano, M. J. Modification of aviary design reduces incidence of falls, collisions and keel bone damage in laying hens. Appl. Anim. Behav. Sci. 2015. 165, 112-123.

[185] Stratmann, A., Fröhlich, E. K. F., Harlander-Matauschek, A., Schrader, L., Toscano, M. J., Würbel, H., Gebhardt-Henrich, S. G. Soft perches in an aviary system reduce incidence of keel bone damage in laying hens. PLoS One 2015. 10, e0122568.

[186] Lieboldt, M.-A., Halle, I., Frahm, J., Schrader, L., Baulain, U., Henning, M., Preisinger, R., Dänicke, S., Weigend, S. Phylogenic versus selection effects on growth development, egg laying and egg quality in purebred laying hens. Eur. Poult. Sci. 2015. 79. 



\title{
2 Relationship between Bone Stability and Egg Production in Genetically Divergent Chicken Layer Lines
}

\author{
Simon Jansen ${ }^{1}$, Ulrich Baulain ${ }^{1}$, Christin Habig ${ }^{1}$, Annett Weigend ${ }^{1}$, \\ Ingrid Halle ${ }^{2}$, Armin M. Scholz ${ }^{3}$, Henner Simianer ${ }^{4,5}$, A. Reza Sharifi ${ }^{4,5}$ \\ and Steffen Weigend ${ }^{1,5}$
}

1 Institute of Farm Animal Genetics, Friedrich-Loeffler-Institut, 31535 Neustadt, Germany.

2 Institute of Animal Nutrition, Friedrich-Loeffler-Institut, 38116 Braunschweig, Germany.

3 Livestock Center of the Faculty of Veterinary Medicine, Ludwig-Maximilians-University Munich, 85764 Oberschleißheim, Germany.

4 Animal Breeding and Genetics Group, Department of Animal Sciences, University of Göttingen, 37075 Göttingen, Germany.

5 Center for Integrated Breeding Research, University of Göttingen, 37075 Göttingen, Germany.

Published in Animals 2020, 10 (5): 850

https: //doi.org/10.3390/ani10050850

Notice: After publication, it was noticed that a typographic error had been made. However, the data presented are correct and the changes do not alter their interpretation. The published corrigendum is included in the appendix of this thesis (Chapter 6). 


\section{Simple Summary}

Brittle or fractured bones due to continuous demineralisation cause major welfare and economic problems in laying hens. Bone weakness in laying hens is frequently attributed to long-term selection for increased egg production, but this is controversially discussed in the scientific literature. We aimed at characterizing factors influencing the bone breaking strength of laying hens, focusing mainly on the effect of eggshell production. By examining four different chicken layer lines separately, a genetically diverse spectrum of laying hen origins was included in our study. It was shown that bone strength is primarily influenced by bone mineral density. A strong association between bone strength and eggshell production was not observed within each of the lines studied. This applied to all layer lines. Our results suggest that a high egg number does not generally impair bone stability within layer lines. Findings from this study contribute to the discussion on the improvement of bone stability in poultry breeding programs and thus lead to increased animal welfare in egg production.

\section{Abstract}

Impaired animal welfare due to skeletal disorders is likely one of the greatest issues currently facing the egg production industry. Reduced bone stability in laying hens is frequently attributed to long-term selection for increased egg production. The present study sought to analyse the relationship between bone stability traits and egg production. The study comprised four purebred layer lines, differing in their phylogenetic origin and performance level, providing extended insight into the phenotypic variability in bone characteristics in laying hens. Data collection included basic production parameters, bone morphometry, bone mineral density (BMD) and bone breaking strength (BBS) of the tibiotarsus and humerus. Using a multifactorial model and regression analyses, BMD proved to be of outstanding importance for bone stability. Only for the tibiotarsus were morphometric parameters and the bone weight associated with BBS. Within the chicken lines, no effect of total eggshell production on BBS or BMD could be detected, suggesting that a high egg yield itself is not necessarily a risk for poor bone health. Considering the complexity of osteoporosis, the estimated genetic parameters confirmed the importance of genetics in addressing the challenge of improving bone strength in layers.

Keywords: animal welfare; bone mineral density; bone breaking strength; fractures; laying hens; laying performance; osteoporosis; phylogeny 


\section{Introduction}

Although the consideration of functional traits in selection programs to improve animal health has become increasingly important in recent years, the number of saleable eggs and extended persistency of laying are still the main goals in the breeding of laying hens [1]. Since up to three grams of calcium per egg are required for eggshell formation [2], laying more than 300 eggs in 12 months in highly selected commercial hens is an immense challenge for the calcium homeostasis, and as part of it, the skeletal system of the bird. During eggshell calcification, laying hens cover, partially, the temporarily high demand of calcium with increased mobilisation from the bones [3]. In avian species, medullary bone serves as a labile calcium source and its formation increases with the onset of sexual maturity [4, 5]. However, this is accompanied by a decrease of cancellous bone volume under the influence of oestrogen [6-8]. Continuous demineralisation leads to osteoporosis, a pathological condition of progressive loss of structural bone tissue, resulting in brittle and fragile bones being susceptible to fractures [3, 9].

High incidences of birds suffering from osteoporotic or fractured bones have been reported [10-12]. Riber et al. [13] concluded that hens suffering from bone fractures show marked atypical behavioural differences compared to those with healthy bones, suggesting that osteoporosis has serious animal welfare implications. Nasr et al. [14] proved that hens with keel bone fractures do experience pain. Bone weakness can also be a cause of mortality, as shown in a study by McCoy et al. [15], in which it accounted for up to $35 \%$ of the deaths. Fracture-associated decline in performance adds an economic dimension to the implications of skeletal disorders $[8,16,17]$.

In addition to the important factors of nutrition and husbandry, genetics are considered a decisive factor for bone health $[3,18,19]$. Skeletal problems in layers are frequently attributed to selection for increased egg production, suggesting a negative association between laying performance and bone stability [8, 20-24]. As bone quality traits are supposed to be highly polygenic [18], genetic correlations might lead to an accompaniment of selection for high laying performance by undesirable "co-selectional" side effects [25-27]. In the case of calcium homeostasis, this may have resulted in a prioritization of calcium resources in favour of reproduction and to the disadvantage of bone health [28, 29].

Targeted genetic selection certainly makes the main contribution to changes in performance potential and may be associated with undesirable associated effects on bone stability. However, differences may also be due to the phylogenetic origin of these lines, whose distinct breeding history may have influenced the genetic characteristics before selection for high performance began. Since white and brown-egg laying chicken lines evolved separately after domestication from red jungle fowl several thousands of years ago and underwent genomic changes [30, 31], phylogenetic origin has potential implications for bone characteristic differences [32]. Therefore, in addition to the comparison of genetic lines, it is necessary to assess the association within the genetic lines.

This study is part of a multidisciplinary collaboration initiated at the Friedrich-LoefflerInstitut to investigate the effects of selection on performance efficiency in terms of adaptability to changing environmental conditions in laying hens. The animal model used comprised four chicken lines, two white and two brown-egg layers, which are phylogenetically distant and evolved independently during breed history [31]. Within each phylogenetic group, the two lines differed in performance level, since one of them originated from a contemporary 
commercial egg layer breeding line ("high performing"), whereas its counterpart was based on a conservation flock without any selection for many generations ("moderate performing") [33]. Within the framework of these research activities, the phenotypic data on bone stability and egg production were used for genetic analyses in the present study, which were collected from laying hens with complete pedigree in two consecutive generations of four chicken-layer lines. The animals were supplied with different amounts of vitamin D3 (cholecalciferol). The dietary vitamin D3 content was varied in tests, since a relationship between bone stability and vitamin D3 was assumed [4, 9]. We aimed at analysing the relationship between bone stability traits and egg production within the genetically divergent layer lines used in this model. Based on the frequently stated negative association between bone stability and egg production, we hypothesized that the two high performing layer lines show deficits in bone stability compared to their moderately performing counterparts, and that within lines the level of eggshell production significantly contributes to the variation of bone breaking strength (BBS) in humerus and tibiotarsus.

\section{Materials and Methods}

\subsection{Ethical Note}

The present experiment was performed in accordance with the German Animal Welfare Law and approved by the Lower Saxony State Office for Consumer Protection and Food Safety (LAVES) (33.19-42502-04-15/1988).

\subsection{Animals and Housing}

The study included four purebred chicken layer lines (Gallus gallus domesticus), which differed in respect to their phylogenetic origins and performance levels. Lines WLA and BLA originated from a commercial breeding program of the Lohmann Tierzucht GmbH (Cuxhaven, Germany) selected for high laying performance. These lines have been maintained in a sire rotation program since 2012 and achieve a laying rate of about 320 eggs per year. In contrast, lines L68 and R11 have been maintained as non-selected resource populations at the Institute of Farm Animal Genetics, Friedrich-Loeffler-Institut (Neustadt, Germany) for more than 25 generations, R11 even for more than 50 generations. Their laying performance is about 200 eggs per year [33]. In addition to performance differences, the animal model considered a phylogenetic component, since white-egg layer lines WLA and R11 (both originating from White Leghorn) are phylogenetically closely related, but distinct from brown-egg layer lines BLA and L68. BLA originates from Rhode Island Red, while L68 descends from New Hampshire, a breed that has been developed from Rhode Island Red chickens [31].

The experiment was conducted in two consecutive generations with 576 hens in total (72 hens per layer line and generation). All chicks of a respective replicate were hatched on the same day and were reared in floor pens of $24 \mathrm{~m}^{2}$ until the 16th week of age. Information on the light program and the mean climatic conditions is given in the Supplementary Material (Table S2.1). Usual feeding stuff for chicks (until 6 weeks of age) and pullets (from 7 to 16 weeks of age), which had sufficient content of phosphorus, calcium and vitamin D3, was 
offered ad libitum. The nutrient compositions of these diets are listed in the Supplementary Material (Table S2.2).

After birds were transferred to the layer facility at the 16th week of age, they were kept in individual cages. The cage dimensions were $50 \mathrm{~cm} \times 48 \mathrm{~cm}$, which equals $2400 \mathrm{~cm}^{2}$ of total floor space, and it was equipped with a plastic perch of $3 \mathrm{~cm}$ diameter. At the beginning of the 17th week of age, two customary wheat-soya-based diets for layers were fed ad libitum. The diets' compositions and their nutrient contents are detailed in the Supplementary Material (Table S2.3). The two diets differed in content of vitamin D3: $300 \mathrm{IU}$, according to the recommendations of the German Society of Nutrition Physiology [34], or 3000 IU, displaying the maximum content according to the regulation (EC) number 1831/2003 of the European Parliament and of the Council [35]. It turned out, however, that no significant differences were found in terms of this difference in the vitamin D3 content for the traits studied (Table S2.4). It is possible that the difference between 300 and $3000 \mathrm{IU}$ of vitamin D3 was not sufficient to elicit a response reflected in the observed characteristics, as both contents were within the range of what is considered to be adequate for chickens [36]. The results could indicate that laying hens may tolerate a wide range of dietary vitamin D3 supply. However, the present study cannot provide deeper insights into this. With regard to the genetic analysis presented here, data from both vitamin D3 groups were combined.

\subsection{Experimental Procedure}

The experimental setup, including data collection, is shown in Figure 2.1 and was identical in both generations. The experimental trial lasted 52 weeks from the 18th to the 69th week of age. The individual egg number was recorded daily during weeks 18 to 68; i.e., over 51 laying weeks. Egg weight data (g) were collected every two weeks over four consecutive days each, resulting in a mean egg weight value per individual (based on an average of 78.6 eggs per individual). Eggshell weight (g) was determined six times, at week 28, 36, 44, 52, 60 and 68, on four consecutive days each. For this, the eggs were emptied and shells were dried for $30 \mathrm{~s}$ in a microwave (800 watt). A digital table scale with a weighing accuracy of $0.01 \mathrm{~g}$ (Type 3709, Sartorius, Göttingen, Germany) was used for egg and eggshell weight determination. Eggshell proportion was calculated as the ratio between eggshell and egg weight. For the eggshell characteristics, mean values were calculated the same way as for the egg weight (based on an average of 18.6 eggs per individual). Total eggshell production was calculated by multiplying the mean eggshell weight and the total egg number. Feed consumption ( $\mathrm{g}$ ) was determined weekly on individual basis by back weighing the remaining feed using a table scale with a weighing accuracy of $20 \mathrm{~g}$ (Dexal 3, Epel Industrial, Sant Boi de Llobregat, Spain). Based on this, daily feed consumption ( $\mathrm{g}$ ) was calculated. Feed-to-egg conversion rate was calculated by dividing total feed consumption by the product of mean egg weight and total number of eggs. Feed-to-eggshell conversion rate was calculated analogously. Body weight (g) was measured at hatch and during the experimental period (at week 21, 25, 35 and 69) using a digital table scale (CPA 16001S, Sartorius, Göttingen, Germany) with a weighing accuracy of $0.1 \mathrm{~g}$.

The hens were euthanized by carbon dioxide inhalation after 69 weeks of age. The left tibiotarsus and humerus were extracted and the adherent tissue removed. Bone weight $(\mathrm{g})$, length $(\mathrm{mm})$ and thickness $(\mathrm{mm})$ were recorded, and bone mineral density $(B M D)\left(\mathrm{g} / \mathrm{cm}^{2}\right)$ was examined by dual energy X-ray absorptiometry (DXA) (GE Lunar iDXA scanner, GE 
Healthcare, Solingen, Germany). The bones were scanned and analysed by using the small animal mode within the enCore ${ }^{\circledR}$ software version 17 (GE Healthcare, Solingen, Germany). A standardised rice pack positioned between dual energy $\mathrm{X}$-ray source and bones served as the soft tissue standard. All bones were stored, transported and scanned under vacuum conditions in special plastic bags individually for each hen. Manually defined regions of interest helped to analyse the bones separately after the scan. Individual results were stored using the PDF and the DICOM file formats. BBS values $(\mathrm{N})$ of the tibiotarsus and humerus were assessed at the mid-diaphyseal region via three-point bending test (Instron Materials Testing System, Instron Corporation, Canton, MA, USA). Thereby a $5 \mathrm{kN}$ load cell was used and the span length was $40 \mathrm{~mm}$ (humerus) or $80 \mathrm{~mm}$ (tibiotarsus).

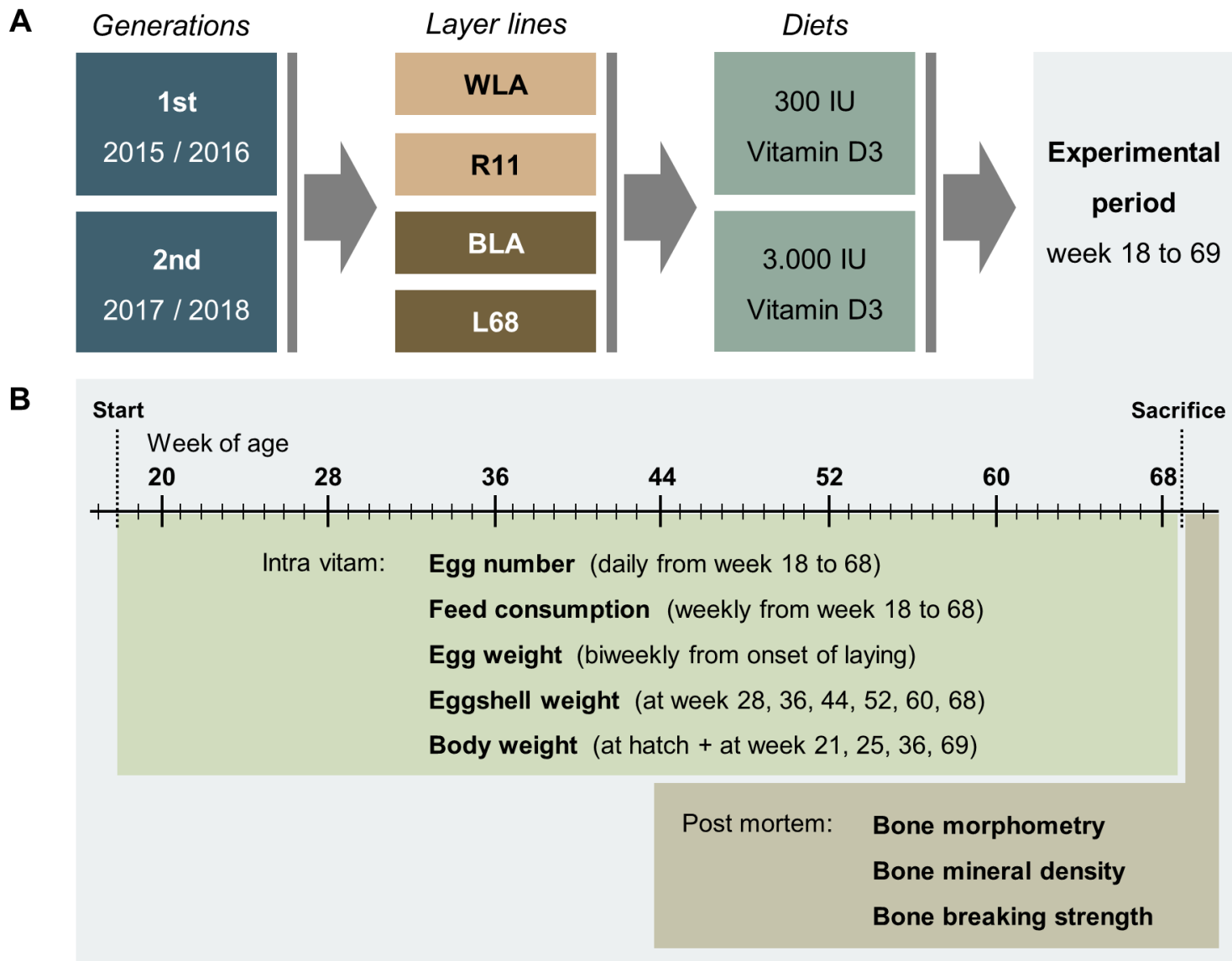

Figure 2.1: Schematic illustration of the experimental setup (A) and related data collection (B). In two consecutive generations, four chicken layer lines were allocated to a diet containing either 300 or 3000 IU of vitamin D3. During the experimental period, data on egg number, egg quality, feed consumption and body weight were collected as indicated. Post mortem, bone morphometry, bone mineral density and bone breaking strength were assessed. 


\subsection{Statistical Analysis}

As bones are supposed to differ noticeably depending on the reproductive status in female birds, exclusion of non-reproducing hens was required [18]. Individuals whose total egg numbers were outside the line specific threefold interquartile range (IQR) $\left(<X_{0.25}-3 \times I Q R\right.$; $\left.>X_{0.75}+3 \times I Q R\right)$ and who did not lay an egg during the last three consecutive experimental weeks were considered as outliers. After filtering, a total number of 524 animals remained for analyses (WLA: $n=129$; R11: $n=134$; BLA: $n=133$; L68: $n=128$ ). The sample size for the statistical analysis varied for the different variables between 125 and 134 observations per layer line (130 observations on average) and was based either on individual records, or, as in the case of egg quality traits, on average values calculated over different points in time as described above. A detailed list of sample sizes separated by genotype for all variables is given in the Supplementary Material (Table S2.5).

The impacts of layer line, generation and their interaction on production parameters, body weight and bone traits were analysed using the GLIMMIX procedure of SAS 9.4 (SAS Institute Inc. Cary, NC, USA, 2017) according to the following model:

$$
\gamma_{i j k l}=\mu+L L_{i}+G_{j}+L L \times G_{i j}+S_{k}+\varepsilon_{i j k l}
$$

where $\gamma_{i j k l}$ is the observation for a production parameter, body weight or bone trait; $\mu$ is the general mean; $L L_{i}$ is the fixed effect of layer line ( $i=1$ to 4 ); $G_{j}$ is the fixed effect of generation $(j=1,2) ; L L \times G_{i j}$ is the fixed effect of interaction between layer line and generation; $S_{k}$ is the random effect of sire ( $k=1$ to 145$)$; and $\varepsilon_{i j k l}$ is the random error variance. Tukey's HSD (honestly significant difference) test was performed for multiple comparisons of means. Statistical significance was set at $p<0.05$.

To determine the association between the bone characteristics, Pearson's correlation coefficients $\left(r_{p}\right)$ were estimated using the CORR (correlation) procedure from SAS (SAS Institute Inc. Cary, NC, USA, 2017). Results description followed recommendations by Asuero et al. [37].

An analysis of covariance was applied to study the variation of BBS considering bone morphometry, BMD and total eggshell production as covariate terms and the fixed effects of layer line, generation and significant interactions between main factors and the covariates [38]. In a backward elimination approach, the Wald F-statistics were used to determine the significance of fixed effects [39], resulting in the following model:

$$
\begin{gathered}
\gamma_{i j k l m n o p q}=\mu+L L_{i}+G_{j}+L L \times G_{i j}+B M D_{k}+L L \times B M D_{i k}+G \times B M D_{j k} \\
+L L \times G \times B M D_{i j k}+W_{l}+T_{m}+L_{n}+T E P_{o}+S_{p}+\varepsilon_{i j k l m n o p q}
\end{gathered}
$$

where $\gamma_{i j k l m n o p q}$ is the observation of BBS; $\mu$ is the general mean; $L L_{i}$ is the fixed effect of layer line $(i=1$ to 4$) ; G_{j}$ is the fixed effect of generation $(j=1,2) ; L L \times G_{i j}$ is the fixed effect of interaction between layer line and generation; $B M D_{k}$ is the effect of BMD; $L L \times B M D_{i k}$ is the effect of interaction between layer line and BMD; $G \times B M D_{j k}$ is the effect of the interaction between generation and BMD; $L L \times G \times B M D_{i j k}$ is the effect of the interaction between layer line, generation and BMD; $W_{l}$ is the effect of bone weight; $T_{m}$ is the effect of bone thickness; $L_{n}$ is the effect of bone length; $T E P_{o}$ is the effect of total egg number; $S_{p}$ is the random effect of sire ( $p=1$ to 145$)$; and $\varepsilon_{i j k l m n o p q}$ is the random 
error variance.

The bone data were converted to standardised z-scores to have a standard deviation of 1.0 and a mean of 0.0 . Univariate regression analyses were performed using the MIXED procedure from SAS (SAS Institute Inc. Cary, NC, USA, 2017) according to the following model:

$$
\gamma_{i}=\beta_{0}+\beta_{1} x_{i}+\varepsilon_{i}
$$

where $\gamma_{i}$ is the BBS or the BMD; $\beta_{0}$ is the intercept; $\beta_{1}$ is the slope; $x_{i}$ is a morphometric parameter (in case of BBS analysis) or total eggshell production (in case of BMD analysis); and $\varepsilon_{i}$ is the random error variance.

Genetic parameters were estimated using ASReml 4.1 [40] according to the following animal model:

$$
\gamma_{i j}=\mu+A_{i}+G_{j}+\varepsilon_{i j}
$$

where $\gamma_{i j}$ is the BBS or the BMD; $\mu$ is the general mean; $A_{i}$ is the random direct genetic effect of the hen; $G_{j}$ is the fixed effect of the generation $(j=1,2)$; and $\varepsilon_{i j}$ is the error term. Within lines, univariate analyses were conducted to estimate the heritability of BMD and BBS. Bivariate analyses were used for estimation of genetic correlations between these traits.

\section{Results}

\subsection{Basic Production Parameters}

Table 2.1 summarises the least squares means and the significance of layer line, generation and their interaction for various basic production parameters. For all traits, a highly significant effect of the layer line was observed. With exception of total egg number and feed-toegg conversion rate, the generation was also identified as a significant explanatory variable. However, only in respect to egg- and eggshell weight, the effect of layer line by generation interaction proved to be significant. Here, in line WLA heavier eggs were observed in the second generation, whereas in R11, BLA and L68, slightly higher eggshell weights were seen in the first generation. With the first eggs being laid at 20.56 (WLA) and 20.69 (BLA) weeks of age, in both high performing lines the onset of laying was significantly earlier than in their moderate performing counterparts, as L68 and R11 reached laying maturity only at 23.12 and 24.66 weeks of age, respectively. Within the 357 days lasting laying period, lines WLA and BLA achieved laying performances of 316.34 and 317.32 eggs respectively, and differed significantly from lines R11 (average of 226.25 eggs) and L68 (average of 215.94 eggs). In terms of egg weight, eggshell weight and proportion of the eggshell, the high performing genotypes showed significantly higher values than their corresponding moderate performing lines. This pattern continued for the total eggshell production. However, there was a clear ranking of genotypes, with WLA producing the largest amount of eggshell, followed by BLA, R11 and L68. The mean difference in total eggshell production within the phylogenetic groups was $821.94 \mathrm{~g}$ between the white-egg lines, and $812.63 \mathrm{~g}$ between the brown-egg lines. Despite significantly higher daily feed consumption of both high performing lines, the feed-to-egg and feed-toeggshell conversion rates were about one third lower in both BLA and WLA hens than in their counterparts. Results on body weight development are shown in the Supplementary Material 
(Table S2.6). The fact that WLA and BLA hens were heavier at hatch reversed during rearing. The brown-egg lines were both significantly heavier during the following measurements, and at final weighing in, week 69 , line L68 had the highest average body weight.

\subsection{Bone Characteristics}

The least squares means and the significance level for layer line, generation and their interaction for the examined traits of tibiotarsus and humerus are shown in Table 2.2. The layer line had a highly significant effect on all bone traits studied. With exception of weight and thickness in tibiotarsus, the same applies to the generation effect. The layer line by generation interaction was significant for the weight of tibiotarsus. However, post-hoc comparison did not detect any significant deviation between the two generations within lines. Hens from the brown-egg lines displayed a higher humerus BBS than the white-egg strains. For the tibiotarsus, line L68 was characterised by a high BBS, whereas the other lines differ only slightly amongst each other. Mean BMD of both bone types was significantly higher in the brown-egg lines BLA and L68, while hens of line WLA showed the lowest values. It turns out that BLA and L68 do have significantly heavier, thicker and longer bones than their white-egg-laying counterparts. Line L68 especially stands out in relation to the tibiotarsus, being the line with the highest values for all traits.

Figure 2.2 shows the Pearson's correlation coefficients $\left(r_{p}\right)$ between the bone traits examined in the tibiotarsus and humerus of the genetic lines WLA (Figure 2.2A), R11 (Figure 2.2B), $\mathrm{BLA}$ (Figure 2.2C) and L68 (Figure 2.2D). With values varying from $r_{p}=0.43$ (Figure 2.2C) to $r_{p}=0.70$ (Figure 2.2D), BBS and BMD were moderately correlated for the tibiotarsus. Slightly weaker correlations ranging from $r_{p}=0.33$ (Figure 2.2A) to $r_{p}=0.66$ (Figure 2.2B) were observed between these traits for the humerus. Except for moderate correlations between BBS and weight in the tibiotarsus of WLA $\left(r_{p}=0.68\right.$, Figure 2.2A) and L68 $\left(r_{p}=0.62\right.$, Figure 2.2D), rather low and non-significant correlations were observed regarding BBS and morphometric traits. The same applies to the relationship between BMD and morphometry in the tibiotarsus. In both bone types, BMD and weight were moderately to strongly associated. With values from $r_{p}=0.64$ (Figure $2.2 C$ ) up to $r_{p}=0.86$ (Figure 2.2B), the lengths of the two different bone types were strongly associated. While the correlation of the thicknesses of the two bone types varied only between $r_{p}=0.38$ (Figure 2.2B,C) and $r_{p}=0.43$ (Figure 2.2D), it differed considerably for the weight. However, a general pattern of correlating characteristics that applies to all lines and/or to phylogenetic groups could not be identified. 
Table 2.1: Least squares means \pm standard errors for production parameters for the effect of layer line (LL), generation (Gen) and their interaction, and the significance levels of the effects.

\begin{tabular}{|c|c|c|c|c|c|c|c|c|c|}
\hline Effect & $\begin{array}{l}\text { Laying Maturity } \\
\text { (Weeks) }\end{array}$ & $\begin{array}{l}\text { Total Number } \\
\text { of Eggs }{ }^{1}\end{array}$ & $\begin{array}{l}\text { Egg Weight } \\
\text { (g) }{ }^{2}\end{array}$ & $\begin{array}{c}\text { Eggshell } \\
\text { Weight (g) }{ }^{2}\end{array}$ & $\begin{array}{c}\text { Eggshell } \\
\text { Proportion }(\%)^{2}\end{array}$ & $\begin{array}{l}\text { Total Eggshell } \\
\text { Production }(\mathrm{g})^{3}\end{array}$ & $\begin{array}{c}\text { Daily Feed } \\
\text { Consumption (g) }\end{array}$ & $\begin{array}{l}\text { Feed-to-Egg } \\
\text { Conversion Rate }\end{array}$ & $\begin{array}{l}\text { Feed-to-Eggshell } \\
\text { Conversion Rate }\end{array}$ \\
\hline Layer line (LL) & $<0.0001$ & $<0.0001$ & $<0.0001$ & $<0.0001$ & $<0.0001$ & $<0.0001$ & $<0.0001$ & $<0.0001$ & $<0.0001$ \\
\hline WLA & $20.56 \pm 0.15^{c}$ & $316.34 \pm 2.57^{a}$ & $57.63 \pm 0.41^{b}$ & $6.38 \pm 0.04^{a}$ & $11.10 \pm 0.06^{a}$ & $2019.89 \pm 16.23^{a}$ & $93.82 \pm 0.97^{b}$ & $1.84 \pm 0.02^{c}$ & $16.64 \pm 0.29 \mathrm{~d}$ \\
\hline R11 & $24.66 \pm 0.15^{a}$ & $226.25 \pm 2.53^{b}$ & $51.54 \pm 0.41^{c}$ & $5.29 \pm 0.04^{c}$ & $10.28 \pm 0.06^{b}$ & $1197.95 \pm 16.00^{c}$ & $79.58 \pm 0.96^{c}$ & $2.47 \pm 0.02^{b}$ & $24.14 \pm 0.29^{b}$ \\
\hline BLA & $20.69 \pm 0.15^{c}$ & $317.32 \pm 2.55^{a}$ & $60.09 \pm 0.41^{a}$ & $6.14 \pm 0.04^{b}$ & $10.25 \pm 0.06^{b}$ & $1950.23 \pm 16.08^{b}$ & $102.46 \pm 0.98^{a}$ & $1.92 \pm 0.02^{c}$ & $18.80 \pm 0.29^{c}$ \\
\hline L68 & $23.12 \pm 0.15^{b}$ & $215.94 \pm 2.57^{c}$ & $53.05 \pm 0.41^{c}$ & $5.29 \pm 0.04^{c}$ & $9.95 \pm 0.06^{c}$ & $1137.60 \pm 16.27^{d}$ & $91.32 \pm 0.98^{b}$ & $2.88 \pm 0.02^{a}$ & $29.04 \pm 0.29^{a}$ \\
\hline Generation (Gen) & $<0.0001$ & 0.8384 & 0.0032 & $<0.0001$ & $<0.0001$ & $<0.0001$ & 0.0017 & 0.3673 & $<0.0001$ \\
\hline Gen1 & $21.81 \pm 0.11$ & $269.23 \pm 1.82$ & $54.97 \pm 0.29$ & $5.94 \pm 0.03$ & $10.80 \pm 0.05$ & $1619.31 \pm 11.53$ & $90.25 \pm 0.69$ & $2.27 \pm 0.02$ & $21.14 \pm 0.21$ \\
\hline Gen2 & $22.70 \pm 0.11$ & $268.70 \pm 1.79$ & $56.19 \pm 0.29$ & $5.62 \pm 0.03$ & $9.99 \pm 0.05$ & $1533.53 \pm 11.30$ & $93.33 \pm 0.68$ & $2.29 \pm 0.02$ & $23.17 \pm 0.20$ \\
\hline LL $\times$ Gen & 0.4859 & 0.2202 & 0.0470 & 0.0028 & 0.4750 & 0.1823 & 0.6130 & 0.9523 & 0.2921 \\
\hline WLA $\times$ Gen 1 & $20.01 \pm 0.22$ & $319.87 \pm 3.64$ & $56.16 \pm 0.59^{b}$ & $6.41 \pm 0.06^{a}$ & $11.42 \pm 0.09$ & $2048.99 \pm 22.99$ & $91.57 \pm 1.38$ & $1.82 \pm 0.03$ & $16.00 \pm 0.41$ \\
\hline WLA $\times$ Gen2 & $21.10 \pm 0.22$ & $312.80 \pm 3.63$ & $59.11 \pm 0.58^{a}$ & $6.37 \pm 0.06^{a}$ & $10.78 \pm 0.09$ & $1990.80 \pm 22.91$ & $96.06 \pm 1.37$ & $1.86 \pm 0.03$ & $17.27 \pm 0.41$ \\
\hline R11 × Gen 1 & $24.42 \pm 0.21$ & $224.59 \pm 3.58$ & $51.44 \pm 0.58^{c}$ & $5.51 \pm 0.06^{c}$ & $10.71 \pm 0.09$ & $1237.57 \pm 22.66$ & $78.85 \pm 1.36$ & $2.47 \pm 0.03$ & $23.09 \pm 0.41$ \\
\hline $\mathrm{R} 11 \times$ Gen2 & $24.90 \pm 0.22$ & $227.92 \pm 3.64$ & $51.64 \pm 0.58^{c}$ & $5.08 \pm 0.06^{d}$ & $9.84 \pm 0.09$ & $1158.33 \pm 22.58$ & $80.30 \pm 1.37$ & $2.47 \pm 0.03$ & $25.20 \pm 0.41$ \\
\hline $\mathrm{BLA} \times \mathrm{Gen} 1$ & $20.20 \pm 0.22$ & $319.53 \pm 3.65$ & $59.28 \pm 0.59^{a}$ & $6.33 \pm 0.06^{a}$ & $10.70 \pm 0.09$ & $2023.14 \pm 23.10$ & $101.39 \pm 1.41$ & $1.91 \pm 0.04$ & $17.85 \pm 0.42$ \\
\hline BLA $\times$ Gen2 & $21.19 \pm 0.21$ & $315.12 \pm 3.56$ & $60.91 \pm 0.58^{a}$ & $5.95 \pm 0.06^{b}$ & $9.80 \pm 0.09$ & $1877.31 \pm 22.38$ & $103.53 \pm 1.35$ & $1.93 \pm 0.03$ & $19.74 \pm 0.40$ \\
\hline L68 × Gen1 & $22.62 \pm 0.22$ & $212.90 \pm 3.70$ & $53.00 \pm 0.59^{c}$ & $5.49 \pm 0.06^{c}$ & $10.37 \pm 0.09$ & $1167.53 \pm 23.45$ & $89.21 \pm 1.41$ & $2.86 \pm 0.04$ & $27.62 \pm 0.42$ \\
\hline L68 $\times$ Gen2 & $23.62 \pm 0.22$ & $218.99 \pm 3.58$ & $53.10 \pm 0.58^{c}$ & $5.06 \pm 0.06^{d}$ & $9.54 \pm 0.09$ & $1107.67 \pm 22.56$ & $93.43 \pm 1.36$ & $2.89 \pm 0.03$ & $30.46 \pm 0.40$ \\
\hline
\end{tabular}

a,b,c,d Means with different letters within an effect differ significantly (Tukey's HSD-test, $p<0.05$ ). ${ }^{1}$ Laid between weeks 18 and 68 (357 days). ${ }^{2}$ Mean value of the eggs laid from 18 to 68 weeks of age. ${ }^{3}$ Product of total number of eggs and mean eggshell weight. 
Table 2.2: Least squares means \pm standard errors for characteristics of tibiotarsus and humerus for the effect of layer line (LL), generation (Gen) and their interaction and the significance levels for the effects.

\begin{tabular}{|c|c|c|c|c|c|c|c|c|c|c|}
\hline \multirow[b]{2}{*}{ Effect } & \multicolumn{5}{|c|}{ Tibiotarsus } & \multicolumn{5}{|c|}{ Humerus } \\
\hline & $\begin{array}{l}\text { Bone } \\
\text { Breaking } \\
\text { Strength } \\
\text { (N) }\end{array}$ & $\begin{array}{l}\text { Bone } \\
\text { Mineral } \\
\text { Density } \\
\left(\mathrm{g} / \mathrm{cm}^{2}\right)\end{array}$ & $\begin{array}{l}\text { Weight } \\
\text { (g) }\end{array}$ & $\begin{array}{l}\text { Length } \\
(\mathrm{mm})\end{array}$ & $\begin{array}{c}\text { Thickness } \\
(\mathbf{m m})\end{array}$ & $\begin{array}{l}\text { Bone } \\
\text { Breaking } \\
\text { Strength } \\
\text { (N) }\end{array}$ & $\begin{array}{l}\text { Bone } \\
\text { Mineral } \\
\text { Density } \\
\left(\mathrm{g} / \mathrm{cm}^{2}\right)\end{array}$ & $\begin{array}{l}\text { Weight } \\
\text { (g) }\end{array}$ & $\begin{array}{l}\text { Length } \\
(\mathrm{mm})\end{array}$ & $\begin{array}{l}\text { Thickness } \\
(\mathbf{m m})\end{array}$ \\
\hline $\begin{array}{l}\text { Layer line } \\
\text { (LL) }\end{array}$ & $<0.0001$ & $<0.0001$ & $<0.0001$ & $<0.0001$ & $<0.0001$ & $<0.0001$ & $<0.0001$ & $<0.0001$ & $<0.0001$ & $<0.0001$ \\
\hline WLA & $137.34 \pm 3.62^{b, c}$ & $0.211 \pm 0.005^{d}$ & $8.12 \pm 0.11^{c}$ & $116.78 \pm 0.44^{c}$ & $5.27 \pm 0.04^{c}$ & $90.81 \pm 3.43^{c}$ & $0.136 \pm 0.003^{d}$ & $3.76 \pm 0.10^{c}$ & $75.81 \pm 0.25^{c}$ & $5.33 \pm 0.03^{c}$ \\
\hline R11 & $149.40 \pm 3.54^{b}$ & $0.231 \pm 0.005^{c}$ & $8.23 \pm 0.11^{c}$ & $116.63 \pm 0.44^{c}$ & $5.17 \pm 0.04^{c}$ & $109.94 \pm 3.40^{b}$ & $0.156 \pm 0.003^{c}$ & $4.07 \pm 0.10^{c}$ & $75.38 \pm 0.25^{c}$ & $5.19 \pm 0.03^{d}$ \\
\hline BLA & $124.23 \pm 3.58^{c}$ & $0.265 \pm 0.005^{b}$ & $10.90 \pm 0.11^{b}$ & $119.41 \pm 0.44^{b}$ & $5.94 \pm 0.04^{b}$ & $138.64 \pm 3.40^{a}$ & $0.197 \pm 0.003^{a}$ & $6.53 \pm 0.10^{a}$ & $79.69 \pm 0.25^{a}$ & $5.59 \pm 0.03^{b}$ \\
\hline L68 & $211.57 \pm 3.61^{a}$ & $0.327 \pm 0.005^{a}$ & $12.03 \pm 0.11^{a}$ & $121.37 \pm 0.44^{a}$ & $6.19 \pm 0.04{ }^{a}$ & $146.02 \pm 3.45^{a}$ & $0.180 \pm 0.003^{b}$ & $4.93 \pm 0.10^{b}$ & $76.85 \pm 0.25^{b}$ & $5.71 \pm 0.03 \mathrm{a}$ \\
\hline $\begin{array}{l}\text { Generation } \\
\text { (Gen) }\end{array}$ & $<0.0001$ & 0.0369 & 0.7077 & 0.0002 & 0.1231 & $<0.0001$ & $<0.0001$ & $<0.0001$ & 0.0021 & 0.0327 \\
\hline Gen 1 & $139.23 \pm 2.55$ & $0.264 \pm 0.004$ & $9.80 \pm 0.08$ & $117.74 \pm 0.31$ & $5.61 \pm 0.03$ & $111.27 \pm 2.43$ & $0.174 \pm 0.002$ & $5.60 \pm 0.07$ & $76.54 \pm 0.18$ & $5.42 \pm 0.02$ \\
\hline Gen 2 & $172.04 \pm 2.53$ & $0.253 \pm 0.004$ & $9.84 \pm 0.07$ & $119.36 \pm 0.31$ & $5.67 \pm 0.03$ & $131.43 \pm 2.40$ & $0.161 \pm 0.002$ & $4.05 \pm 0.07$ & $77.32 \pm 0.18$ & $5.49 \pm 0.02$ \\
\hline $\mathbf{L L} \times \mathbf{G e n}$ & 0.0925 & 0.1725 & 0.0155 & 0.0892 & 0.4924 & 0.5249 & 0.8472 & 0.5376 & 0.2413 & 0.0665 \\
\hline WLA $\times$ Gen 1 & $113.51 \pm 5.10$ & $0.210 \pm 0.007$ & $7.84 \pm 0.15^{c}$ & $115.03 \pm 0.62$ & $5.20 \pm 0.05$ & $77.13 \pm 4.85$ & $0.142 \pm 0.004$ & $4.51 \pm 0.15$ & $75.00 \pm 0.36$ & $5.27 \pm 0.04$ \\
\hline WLA $\times$ Gen 2 & $161.16 \pm 5.15$ & $0.214 \pm 0.007$ & $8.40 \pm 0.15^{c}$ & $118.54 \pm 0.62$ & $5.35 \pm 0.05$ & $104.48 \pm 4.85$ & $0.131 \pm 0.004$ & $3.02 \pm 0.15$ & $76.61 \pm 0.36$ & $5.40 \pm 0.04$ \\
\hline $\mathrm{R} 11 \times \mathrm{Gen} 1$ & $132.92 \pm 5.02$ & $0.233 \pm 0.007$ & $8.25 \pm 0.15^{c}$ & $116.22 \pm 0.61$ & $5.15 \pm 0.05$ & $103.33 \pm 4.78$ & $0.162 \pm 0.004$ & $4.89 \pm 0.15$ & $74.99 \pm 0.35$ & $5.21 \pm 0.04$ \\
\hline $\mathrm{R} 11 \times$ Gen2 & $165.87 \pm 5.01$ & $0.229 \pm 0.007$ & $8.21 \pm 0.15^{c}$ & $117.05 \pm 0.62$ & $5.20 \pm 0.05$ & $116.55 \pm 4.83$ & $0.151 \pm 0.004$ & $3.24 \pm 0.14$ & $75.77 \pm 0.35$ & $5.18 \pm 0.04$ \\
\hline BLA $\times$ Gen 1 & $112.38 \pm 5.12$ & $0.275 \pm 0.007$ & $11.10 \pm 0.15^{b}$ & $119.07 \pm 0.63$ & $5.93 \pm 0.05$ & $127.87 \pm 4.89$ & $0.205 \pm 0.004$ & $7.20 \pm 0.15$ & $79.44 \pm 0.36$ & $5.59 \pm 0.04$ \\
\hline $\mathrm{BLA} \times \mathrm{Gen} 2$ & $136.07 \pm 5.01$ & $0.255 \pm 0.007$ & $10.71 \pm 0.15^{b}$ & $119.75 \pm 0.61$ & $5.94 \pm 0.05$ & $149.40 \pm 4.72$ & $0.190 \pm 0.004$ & $5.86 \pm 0.14$ & $79.94 \pm 0.35$ & $5.59 \pm 0.04$ \\
\hline L68 $\times$ Gen 1 & $198.11 \pm 5.20$ & $0.338 \pm 0.007$ & $12.02 \pm 0.15^{a}$ & $120.62 \pm 0.63$ & $6.18 \pm 0.05$ & $136.75 \pm 4.94$ & $0.188 \pm 0.004$ & $5.79 \pm 0.15$ & $76.74 \pm 0.36$ & $5.62 \pm 0.04$ \\
\hline L68 × Gen2 & $225.03 \pm 5.03$ & $0.315 \pm 0.007$ & $12.04 \pm 0.15^{a}$ & $122.12 \pm 0.62$ & $6.20 \pm 0.05$ & $155.29 \pm 4.83$ & $0.171 \pm 0.004$ & $4.07 \pm 0.14$ & $76.97 \pm 0.35$ & $5.79 \pm 0.04$ \\
\hline
\end{tabular}

a,b,c,d Means with different letters within an effect differ significantly (Tukey's HSD-test, $p<0.05$ ). 
A

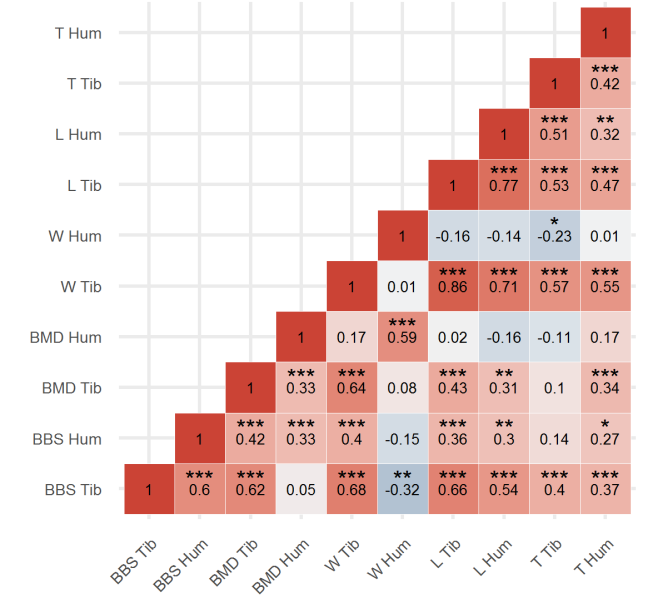

C

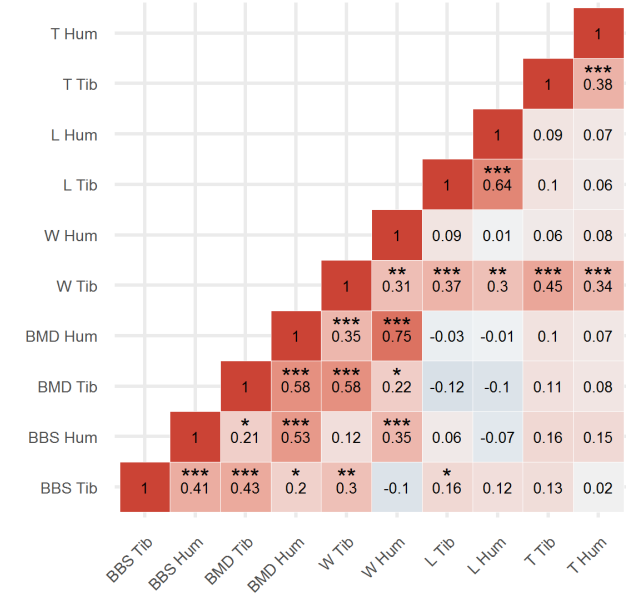

B

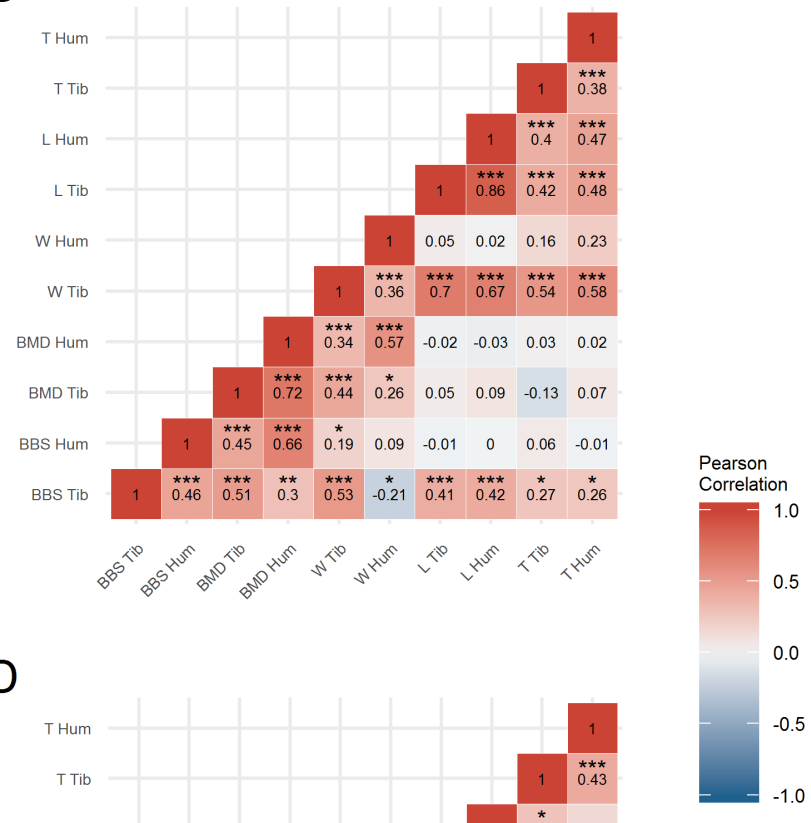

Figure 2.2: Heatmap of Pearson's correlation coefficients between bone traits (BBS, bone breaking strength; BMD, bone mineral density; $\mathrm{W}$, bone weight; $\mathrm{L}$, bone length; $\mathrm{T}$, bone thickness) of the tibiotarsus (Tib) and humerus (Hum) in laying hens of the genetic lines WLA (A), R11 (B), BLA (C) and L68 (D). Red indicates a positive correlation; white represents no correlation and blue represents a negative correlation. Significant correlation coefficients are marked with asterisks $\left({ }^{*} p<0.05 ; * *<0.01\right.$; $* * * p<0.001)$.

\subsection{Factors Affecting Bone Strength}

Table 2.3 shows the effects of the main factors and covariates, and significant interactions on the BBS of tibiotarsus and humerus. As an extension of the basic statistical model (1), which is shown in Table 2.2, in model (2) different covariates are considered additionally to assessing the effects of bone morphometry and total eggshell production on BBS. The bone types studied were influenced by the layer line and the generation. However, the interaction of layer line and generation was only significant for the humerus. The analysis revealed that a high amount of the observed variance in the hens' BBS is attributable to its BMD, as indicated by comparatively high F values being 243.50 (tibiotarsus) and 281.92 (humerus), respectively. The bone types differed with regard to the influence of morphometry on fracture strength, as an effect of bone thickness and length was only observed for the 
tibiotarsus, while bone weight did not play a role at all. Within lines, an effect of total eggshell production on the BBS was also not detectable, leading to the assumption that this variable does not contribute to the variance in BBS within the lines studied.

Table 2.3: The effects of layer line (LL), generation (Gen), bone mineral density (BMD), bone weight, bone thickness, bone length, total eggshell production and significant interactions on bone breaking strengths of the tibiotarsus and humerus in laying hens.

\begin{tabular}{|c|c|c|c|c|}
\hline \multirow[b]{2}{*}{ Effect } & \multicolumn{2}{|c|}{ Tibiotarsus } & \multicolumn{2}{|c|}{ Humerus } \\
\hline & F Value & $p$-Value & F Value & $p$-Value \\
\hline Layer line (LL) & 9.10 & $<0.0001$ & 8.13 & $<0.0001$ \\
\hline Generation (Gen) & 13.22 & 0.0003 & 8.92 & 0.0030 \\
\hline $\mathrm{LL} \times \mathrm{Gen}$ & 1.75 & 0.1568 & 5.58 & 0.0009 \\
\hline Bone mineral density (BMD) & 243.50 & $<0.0001$ & 281.92 & $<0.0001$ \\
\hline $\mathrm{BMD} \times \mathrm{LL}$ & 24.71 & $<0.0001$ & 10.53 & $<0.0001$ \\
\hline $\mathrm{BMD} \times \mathrm{Gen}$ & 33.96 & $<0.0001$ & 26.59 & $<0.0001$ \\
\hline $\mathrm{BMD} \times \mathrm{LL} \times \mathrm{Gen}$ & 2.08 & 0.1025 & 7.23 & $<0.0001$ \\
\hline Weight & 0.00 & 0.9927 & 3.42 & 0.0654 \\
\hline Thickness & 23.33 & $<0.0001$ & 0.62 & 0.4319 \\
\hline Length & 10.90 & 0.0011 & 0.09 & 0.7660 \\
\hline Total eggshell production ${ }^{1}$ & 0.13 & 0.7196 & 0.07 & 0.7879 \\
\hline
\end{tabular}

${ }^{1}$ Total eggshell production $=$ number of eggs $\times$ eggshell weight.

Figure 2.3 shows the regression coefficients $(\beta)$ between standardised bone traits; i.e., between $\mathrm{BBS}$ and $\mathrm{BMD}$ or $\mathrm{BBS}$ and morphometric traits. Highly significant regression coefficients varying from $\beta=0.53$ (WLA) to $\beta=0.76$ (L68) among the layer lines illustrate that the BMD is strongly associated with the variability of the tibiotarsal BBS (Figure 2.3A). On average across lines, a change in BMD by one standard deviation results in a 0.64 standard deviation increase in BBS. For the humerus, regression coefficients between BBS and BMD were proved to be significant and BMD was detected as primary explanatory variable of the BBS, although coefficients widely ranged from $\beta=0.43$ (WLA) to $\beta=0.84$ (R11) among the lines (Figure 2.3B). Line R11 stands out in this regard, while the average coefficient among the layer lines was $\beta=0.61$. If bone weight is considered as an explanatory variable, the analysis attributed a relatively large and highly significant effect on BBS, at least for the tibiotarsus, where the average coefficient was $\beta=0.53$. In contrast, the coefficients vary greatly in the case of the humerus, resulting in an average value of $\beta=0.22$. A significant effect of bone weight on humeral BBS was only seen in the brown-egg lines BLA and L68. With average values of $\beta=0.31$ and $\beta=0.25$ respectively, the length and thickness of the tibiotarsus were only weakly correlated with BBS. However, these correlations were significant for the majority of lines. For the length $(\beta=0.04)$ and thickness $(\beta=0.09)$ of the humerus, a rather weak influence was observed, it being only occasionally significant.

Figure 2.4 shows the regression coefficients $(\beta)$ of the total eggshell production in relation to the BMD of the tibiotarsus (Figure 2.4A) and humerus (Figure 2.4B). Overall, rather low negative regression coefficients were obtained for the two bone types, averaging $\beta=-3.5 \times 10^{-5}$ (tibiotarsus) and $\beta=-1.7 \times 10^{-5}$ (humerus) respectively. In both bone types, regression coefficients were only significant in the low performing white-egg line R11. However, other significant relationships between BMD and eggshell production, could not be 
observed. Figure 2.4C (tibiotarsus) and Figure 2.4D (humerus) show the trend of BMD with increasing total eggshell production within the chicken lines studied. Considering the range of variation in BMD (see Table 2.2), an increase of total eggshell production appears to have only limited effects on BMD, especially for hens of layer lines WLA, BLA and L68.

A

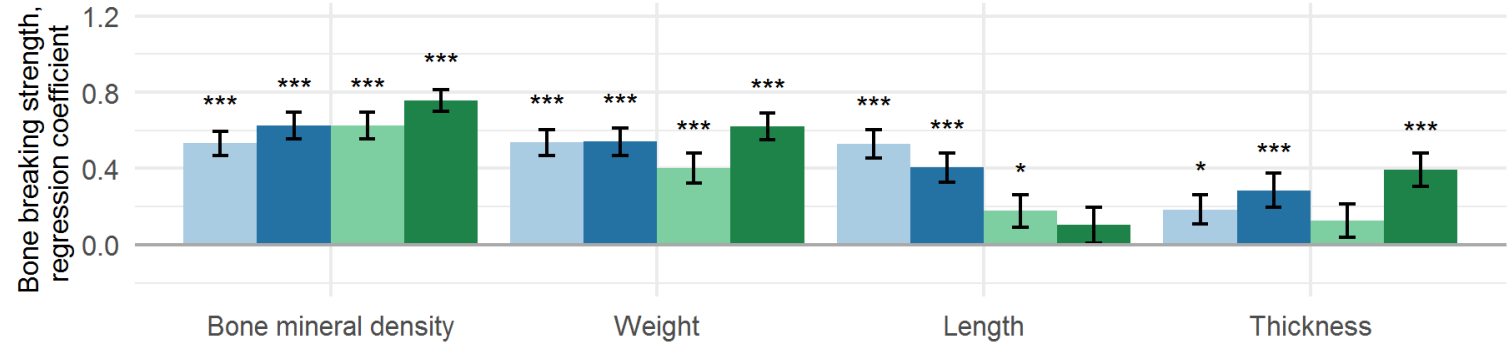

$\mathrm{B}$

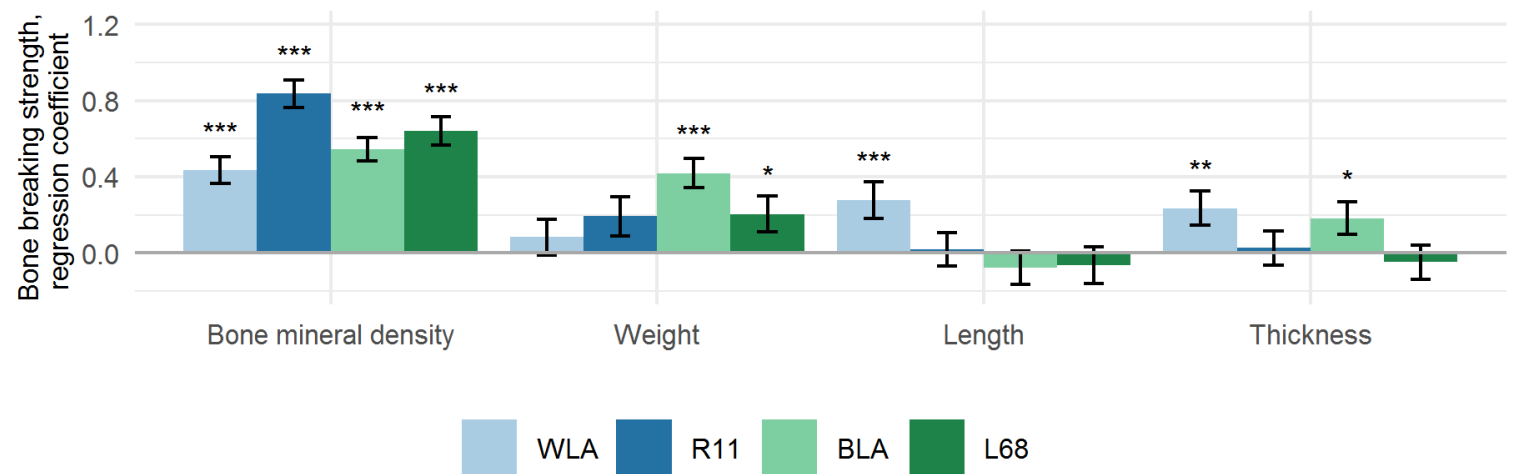

Figure 2.3: Standardised regression coefficients $(\beta) \pm$ standard errors of regression of bone mineral density, bone weight, bone length and bone thickness pertaining univariately to the bone breaking strengths of the tibiotarsus $(\mathbf{A})$ and humerus $(\mathbf{B})$ in four different chicken layer lines (WLA, R11, BLA, L68). Significant regression coefficients are marked with asterisks (* $p<0.05$; ** $p<0.01$; *** $p<0.001)$. 
A

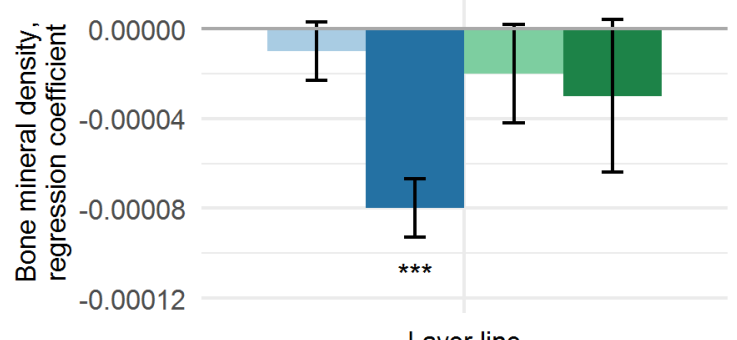

Layer line

C

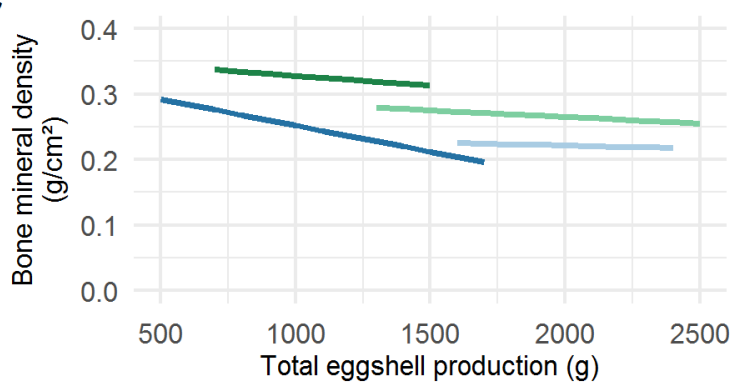

WLA R11
B

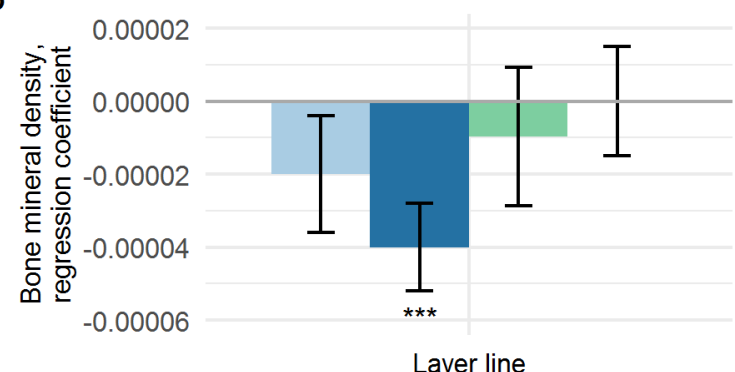

D

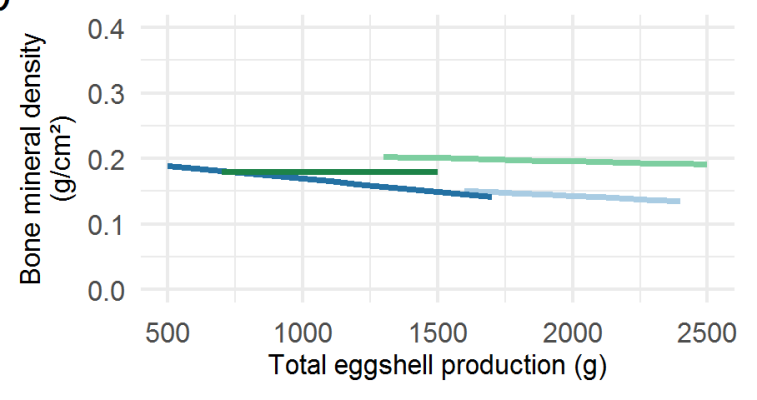

Figure 2.4: Regression coefficients $(\beta) \pm$ standard errors of regression of total eggshell production pertaining to the bone mineral densities of the tibiotarsus (A) and humerus (B), and the effect of total eggshell production on the bone mineral densities of the tibiotarsus (C) and humerus (D) in four different chicken layer lines (WLA, R11, BLA, L68). Significant regression coefficients are marked with asterisks $\left({ }^{*} p<0.05 ; * * p<0.01\right.$; $* * * p<0.001)$.

\subsection{Genetic Parameters}

Results of heritability $\left(h^{2}\right)$ estimates for BBS and BMD and the genetic correlations $\left(r_{g}\right)$ between these traits are shown in Table 2.4. Due to the lack of convergence of the model, no $\mathrm{h}^{2}$ estimations were possible for the BMD of the tibiotarsus of line R11 and for the humerus of the WLA line. Accordingly, the genetic correlation coefficients could not be estimated in these cases. The $h^{2}$ values estimated for BBS vary rather strongly among lines. In case of the tibiotarsus, for example, they vary from $h^{2}=0.17$ (BLA) to $h^{2}=0.58$ (WLA). A similar situation was found for the humerus, for which the values range from $h^{2}=0.26$ (WLA) to $h^{2}=0.50$ (BLA). The $h^{2}$ estimation for the BMD values of the tibiotarsus and humerus resulted in similarly fluctuating values, among which the line WLA stands out at $h^{2}=0.75$ for the tibiotarsus and $h^{2}=0.73$ for the humerus. Estimated $r_{g}$ coefficients suggest a moderate to close genetic relationship between BBS and BMD, except for the tibiotarsus of the BLA line, where it was estimated to be only $r_{\mathrm{g}}=0.16$. 
Table 2.4: Heritability $\left(\mathrm{h}^{2} ; \pm\right.$ standard error) and genetic correlation $\left(\mathrm{r}_{\mathrm{g}} ; \pm\right.$ standard error) estimated for bone breaking strength (BBS) and bone mineral density (BMD) of tibiotarsus and humerus in four chicken layer lines.

\begin{tabular}{lccccccc}
\hline & \multicolumn{3}{c}{ Tibiotarsus } & & \multicolumn{3}{c}{ Humerus } \\
\cline { 2 - 4 } \cline { 7 - 8 } Layer Line & $\mathbf{h}^{\mathbf{2}}$ BBS & $\mathbf{h}^{\mathbf{2}}$ BMD & $\mathbf{r}_{\mathbf{g}}$ & & $\mathbf{h}^{\mathbf{2}}$ BBS & $\mathbf{h}^{\mathbf{2}}$ BMD & $\mathbf{r}_{\mathbf{g}}$ \\
\hline WLA & $0.58 \pm 0.23$ & $0.75 \pm 0.23$ & $0.93 \pm 0.23$ & & $0.26 \pm 0.22$ & N.A. & N.A. \\
R11 & $0.29 \pm 0.22$ & N.A. & N.A. & & $0.40 \pm 0.20$ & $0.73 \pm 0.21$ & $0.81 \pm 0.18$ \\
BLA & $0.17 \pm 0.19$ & $0.55 \pm 0.20$ & $0.16 \pm 0.37$ & & $0.50 \pm 0.26$ & $0.25 \pm 0.17$ & $0.54 \pm 0.30$ \\
L68 & $0.46 \pm 0.23$ & $0.51 \pm 0.23$ & $0.74 \pm 0.17$ & & $0.44 \pm 0.21$ & $0.46 \pm 0.25$ & $0.79 \pm 0.18$ \\
\hline
\end{tabular}

N.A., not analysable.

\section{Discussion}

The aim of the current study was to analyse the relationship among bone stability traits and egg production in four phylogenetically divergent layer lines differing in their performance levels. The phylogenetic divergence provides insights into the impacts of different breeding histories, which may have affected bone stability before commercial poultry breeding began; the difference in performance level may provide a hint as to the effect of selection for high egg yield within groups of brown and white-egg layer lines.

\subsection{Phenotypic Characterization}

We observed significant differences among the layer lines regarding all examined production parameters, which are consistent with previous reports [21, 33]. Both high performing lines were superior to their counterparts, which was expected, as commercial lines have long been selected for age at laying maturity, peak production and laying persistency [41, 42]. The results on body weight and feed efficiency clearly reflect the efforts made toward improving feed conversion $[1,42]$. Our results indicated significantly higher amounts of calcium required for eggshell formation in the high performing genotypes that can compensate for this by stimulated bone resorption and/or better intestinal calcium absorption. The latter should probably be reflected in an increased expression of epithelial calcium transporting proteins [43]. However, further assumptions on this require a detailed investigation of calcium homeostasis, which could be addressed in further studies.

In accordance with Riczu et al. [44] and Habig et al. [21] our results on bone measurements revealed a strong phylogenetic divergence between brown and white-egg layer lines. Consistent performance-related differences were only found for the BMD, as within the phylogenetic groups the moderate performers possessed a significantly higher BMD. With regard to the BBS, we observed rather inconsistent results. Nevertheless, our results confirmed the tendency for the two high performing genotypes to have lower bone stability [21]. Contrary to the findings of Bishop et al. [19], we did not observe a strong correlation between the tibiotarsal and the humeral BBS, which was evident across all lines. Rather, the correlation varied depending on the layer line. Taken together, the results on the production parameters and bone characteristics reflect remarkably phenotypic differences among the layer lines. 


\subsection{Determinants of Bone Stability}

The analyses clearly turned out that the BMD significantly contributes to the variation in BBS, which is consistent with an earlier study on White Leghorn hens [45]. According to our observations, this can probably be extended to laying hens in general. Our findings are in line with those from others who have associated BMD with biomechanical strength, which is why it plays an important role in osteoporosis [4, 46]. A histological differentiation of cortical and medullary bone tissue, e.g., by means of quantitative computed tomography [47], would be helpful for a more detailed insight into the components affecting bone stability.

Since the bone stability and the whole bone properties are inseparably linked by the bone's architecture and geometry [48, 49], morphometric bone traits were considered as covariates of the BBS. Only in the tibiotarsus, could a rather small effect of morphometry on fracture strength be accounted. However, this is marginal, given the tremendous influence of the BMD. Contrary to our assumption, bone weight did not contribute to the variance in BBS at all. This could be because BMD is already considered in the statistical model and is strongly correlated with bone weight and/or because BMD indirectly integrates bone dimensions as it relates to the scanned bone area [50].

Interestingly, the total eggshell production had no significant effect on BBS or BMD of tibiotarsus and humerus. This was not expected, because although this assumption is controversially discussed, the level of egg production is frequently claimed to be detrimental [51]. Considering our findings and those from other studies that have reported an absence of relationship between bone stability and egg production [47, 51-54], evidence for a strong association within chicken lines seems rather questionable. However, if we only compare lines differing in performance level, our results would suggest that osteoporosis is mainly caused by a high laying rate, supporting earlier conclusions that differences of bone quality characteristics between genotypes should not be oversimplified [54].

We observed individuals that produced high amounts of eggshells and at the same time had high BBS values, which may indicate that high laying rate and good bone quality are not mutually exclusive. However, some studies pointed to the laying persistency causing continuous degradation of structural bone tissue, rather than the precise number of eggs [4, $7,54]$. This likely applies to our moderately performing lines, since their reduced egg number necessarily involved periods of laying inactivity, during which they were able to regenerate. An adverse effect of a premature onset of laying, at which the ossification is possibly not yet sufficiently complete, was also suggested $[3,53]$. Possibly, these two factors will ultimately have a combined effect.

\subsection{Genetic Perspectives}

The results regarding genetic parameters indicate a rather close genetic relationship between BBS and BMD in all layer lines, completing our findings from the phenotypic analyses. With an average $h^{2}$ estimate of 0.39 , we can confirm the moderate inheritance of BBS [19]. However, the $h^{2}$ estimates were quite variable and considerable differences among lines were observed. This might reflect diverse genetic composition or distinct breeding history of the lines studied [30, 31]. Given the large individual variation in bone characteristics and the implied inherited component of susceptibility to osteoporosis, the problem of skeletal damage is assumed to be alleviated by genetic selection [18, 19, 22, 54]. Our results support this assumption based on the $h^{2}$ estimates of the BBS presented. The current study emphasizes the great importance of animal breeding, offering promising possibilities to counteract the loss of bone strength. At that, the eggshell quality must continue to be considered in the selection index to improve bone stability without compromising eggshell quality. 


\section{Conclusions}

In this study, we analysed the variation of bone breaking strength (BBS) within phylogenetically divergent chicken layer lines, differing in their levels of egg production. The current results support earlier findings that bone mineral density (BMD) is of particular importance for the BBS. Results do not provide evidence of a strong association between the total eggshell production and bone stability traits within the genetic lines studied. Finally, the estimation of genetic parameters revealed an inherited component of BBS and BMD. A rather weak correlation between laying performance and bone stability was observed, opening up the possibility to select for improved bone stability without adverse effects on laying performance. Due to the line specificity in the various phenotypic characteristics, generalised statements about a possible superiority of a certain phylogenetic group or performance level are not justified.

Author Contributions: Conceptualization, S.J., A.R.S. and S.W.; formal analysis, S.J., U.B. and A.R.S.; funding acquisition, S.W.; investigation, S.J., C.H. and A.W.; project administration, C.H. and S.W.; resources, I.H., A.M.S. and H.S.; supervision, A.R.S. and S.W; writing - original draft preparation, S.J.; writing - review and editing, S.J., U.B., C.H., A.W., I.H., A.M.S., H.S., A.R.S. and S.W. All authors have read and agreed to the published version of the manuscript.

Funding: This research received no external funding.

Acknowledgments: The authors like to thank the experimental research station of the Friedrich-Loeffler-Institut for taking care of the animals and Daniel Mörlein (Chair Quality of Animal Products, University of Göttingen) for providing of measuring devices. The assistance in data collection by the technical staff of the abovementioned institutes is greatly appreciated.

Conflicts of Interest: The authors declare no conflict of interest.

\section{References}

[1] Preisinger, R. Innovative layer genetics to handle global challenges in egg production. $\mathrm{Br}$. Poult. Sci. 2018. 59, 1-6.

[2] Roberts, J. R. Factors affecting egg internal quality and egg shell quality in laying hens. J. Poult. Sci. 2004. 41, 161-177.

[3] Fleming, R. H., McCormack, H. A., McTeir, L., Whitehead, C. C. Relationships between genetic, environmental and nutritional factors influencing osteoporosis in laying hens. $\mathrm{Br}$. Poult. Sci. 2006. 47, 742-755.

[4] Whitehead, C. C. Overview of bone biology in the egg-laying hen. Poult. Sci. 2004. 83, 193-199.

[5] Dacke, C. G., Arkle, S., Cook, D. J., Wormstone, I. M., Jones, S., Zaidi, M., Bascal, Z. A. Medullary bone and avian calcium regulation. J. Exp. Biol. 1993. 184, 63-88.

[6] Wilson, S., Thorp, B. H. Estrogen and cancellous bone loss in the fowl. Calcif. Tissue Int. 1998. 62, 506-511.

[7] Whitehead, C. C., Fleming, R. H. Osteoporosis in cage layers. Poult. Sci. 2000. 79, 1033-1041.

[8] Cransberg, P. H., Parkinson, G. B., Wilson, S., Thorp, B. H. Sequential studies of skeletal calcium reserves and structural bone volume in a commercial layer flock. Br. Poult. Sci. 2001. 42, 260-265. 
[9] Webster, A. B. Welfare implications of avian osteoporosis. Poult. Sci. 2004. 83, 184-192.

[10] Sandilands, V. The laying hen and bone fractures. Vet. Rec. 2011. 169, 411.

[11] Gregory, N. G., Wilkins, L. J. Broken bones in domestic fowl: handling and processing damage in end-of-lay battery hens. Br. Poult. Sci. 1989. 30, 555-562.

[12] Petrik, M. T., Guerin, M. T., Widowski, T. M. On-farm comparison of keel fracture prevalence and other welfare indicators in conventional cage and floor-housed laying hens in Ontario, Canada. Poult. Sci. 2015. 94, 579-585.

[13] Riber, A. B., Casey-Trott, T. M., Herskin, M. S. The influence of keel bone damage on welfare of laying hens. Front. Vet. Sci. 2018. 5, 6.

[14] Nasr, M. A. F., Nicol, C. J., Murrell, J. C. Do laying hens with keel bone fractures experience pain? PLoS One 2012. 7, e42420.

[15] McCoy, M. A., Reilly, G. A. C., Kilpatrick, D. J. Density and breaking strength of bones of mortalities among caged layers. Res. Vet. Sci. 1996. 60, 185-186.

[16] Nasr, M. A. F., Murrell, J., Nicol, C. J. The effect of keel fractures on egg production, feed and water consumption in individual laying hens. Br. Poult. Sci. 2013. 54, 165-170.

[17] Candelotto, L., Stratmann, A., Gebhardt-Henrich, S. G., Rufener, C., Braak, T. van de, Toscano, M. J. Susceptibility to keel bone fractures in laying hens and the role of genetic variation. Poult. Sci. 2017. 96, 3517-3528.

[18] Raymond, B., Johansson, A. M., McCormack, H. A., Fleming, R. H., Schmutz, M., Dunn, I. C., De Koning, D. J. Genome-wide association study for bone strength in laying hens. J. Anim. Sci. 2018. 96, 2525-2535.

[19] Bishop, S. C., Fleming, R. H., McCormack, H. A., Flock, D. K., Whitehead, C. C. Inheritance of bone characteristics affecting osteoporosis in laying hens. Br. Poult. Sci. 2000. 41, 33-40.

[20] Rufener, C., Baur, S., Stratmann, A., Toscano, M. J. Keel bone fractures affect egg laying performance but not egg quality in laying hens housed in a commercial aviary system. Poult. Sci. 2019. 98, 1589-1600.

[21] Habig, C., Baulain, U., Henning, M., Scholz, A. M., Sharifi, A. R., Janisch, S., Simianer, H., Weigend, S. How bone stability in laying hens is affected by phylogenetic background and performance level. Eur. Poult. Sci. 2017. 81.

[22] Hocking, P. M., Bain, M., Channing, C. E., Fleming, R., Wilson, S. Genetic variation for egg production, egg quality and bone strength in selected and traditional breeds of laying fowl. Br. Poult. Sci. 2003. 44, 365-373.

[23] Thorp, B. H. Skeletal disorders in the fowl: a review. Avian Pathol. 1994. 23, 203-236.

[24] Eusemann, B. K., Patt, A., Schrader, L., Weigend, S., Thöne-Reineke, C., Petow, S. The role of egg production in the etiology of keel bone damage in laying hens. Front. Vet. Sci. 2020. 7, 81.

[25] Rauw, W. M., Kanis, E., Noordhuizen-Stassen, E. N., Grommers, F. J. Undesirable side effects of selection for high production efficiency in farm animals: a review. Livest. Prod. Sci. 1998. $56,15-33$.

[26] Jensen, P., Andersson, L. Genomics meets ethology: a new route to understanding domestication, behavior, and sustainability in animal breeding. Ambio 2005. 34, 320-324.

[27] Hocking, P. M. Unexpected consequences of genetic selection in broilers and turkeys: problems and solutions. Br. Poult. Sci. 2014. 55, 1-12.

[28] Mirkena, T., Duguma, G., Haile, A., Tibbo, M., Okeyo, A. M., Wurzinger, M., Sölkner, J. Genetics of adaptation in domestic farm animals: A review. Livest. Sci. 2010. 132, 1-12. 
[29] Van der Waaij, E. H. A resource allocation model describing consequences of artificial selection under metabolic stress. J. Anim. Sci. 2004. 82, 973-981.

[30] Tixier-Boichard, M., Bed'hom, B., Rognon, X. Chicken domestication: From archeology to genomics. C. R. Biol. 2011. 334, 197-204.

[31] Malomane, D. K., Simianer, H., Weigend, A., Reimer, C., Schmitt, A. O., Weigend, S. The SYNBREED chicken diversity panel: a global resource to assess chicken diversity at high genomic resolution. BMC Genomics 2019. 20, 345.

[32] Eusemann, B. K., Baulain, U., Schrader, L., Thöne-Reineke, C., Patt, A., Petow, S. Radiographic examination of keel bone damage in living laying hens of different strains kept in two housing systems. PLoS One 2018. 13, e0194974.

[33] Lieboldt, M.-A., Halle, I., Frahm, J., Schrader, L., Baulain, U., Henning, M., Preisinger, R., Dänicke, S., Weigend, S. Phylogenic versus selection effects on growth development, egg laying and egg quality in purebred laying hens. Eur. Poult. Sci. 2015. 79.

[34] GfE. Empfehlungen zur Energie- und Nährstoffversorgung der Legehennen und Broiler des Ausschuss für Bedarfsnormen der Gesellschaft für Ernährungsphysiologie. DLG-Verlag. Frankfurt am Main, Germany. 1999.

[35] European Union. Regulation (EC) No 1831/2003 of the European Parliament and of the Council of 22 September 2003 on additives for use in animal nutrition. Off. J. Eur. Commun. 2003. L268, 29-43.

[36] EFSA Panel on Additives Products or Substances used in Animal Feed. Scientific opinion on the safety and efficacy of vitamin D3 (cholecalciferol) as a feed additive for all animal species or categories based on a dossier submitted by Lohmann Animal Health GmbH. EFSA Journal 2014. 12, 3568.

[37] Asuero, A. G., Sayago, A., González, A. G. The correlation coefficient: an overview. Crit. Rev. Anal. Chem. 2006. 36, 41-59.

[38] Littell, R. C., Milliken, G. A., Stroup, W. W., Wolfinger, R. D., Schabenberger, O. SAS for Mixed Models. 2nd Ed. SAS Institute Inc. Cary, NC, USA. 2006.

[39] SAS Institute Inc. Chapter 47: The GLMSELECT Procedure in SAS/STAT 13.1 User's Guide. SAS Institute Inc. Cary, NC, USA. 2013, pp. 3751-3752.

[40] Gilmour, A. R., Gogel, B. J., Cullis, B. R., Welham, S. J., Thompson, R. ASRem/ User Guide Release 4.1 Structural Specication. VSN International Ltd. Hemel Hempstead, UK. 2015.

[41] Bain, M. M., Nys, Y., Dunn, I. C. Increasing persistency in lay and stabilising egg quality in longer laying cycles. What are the challenges? Br. Poult. Sci. 2016. 57, 330-338.

[42] Thiruvenkadan, A. K., Panneerselvam, S., Prabakaran, R. Layer breeding strategies: an overview. Worlds Poult. Sci. J. 2010. 66, 477-502.

[43] Sugiyama, T., Kikuchi, H., Hiyama, S., Nishizawa, K., Kusuhara, S. Expression and localisation of calbindin D28k in all intestinal segments of the laying hen. Br. Poult. Sci. 2007. 48, 233-238.

[44] Riczu, C. M., Saunders-Blades, J. L., Yngvesson, A. K., Robinson, F. E., Korver, D. R. Endof-cycle bone quality in white- and brown-egg laying hens. Poult. Sci. 2004. 83, 375-383.

[45] Schreiweis, M. A., Orban, J. I., Ledur, M. C., Hester, P. Y. The use of densitometry to detect differences in bone mineral density and content of live White Leghorns fed varying levels of dietary calcium. Poult. Sci. 2003. 82, 1292-1301.

[46] Whitehead, C. C., Fleming, R. H., Julian, R. J., Sørensen, P. Skeletal problems associated with selection for increased production in Poultry Genetics, Breeding and Biotechnology. (Eds.: Muir, W. M., Aggrey, S. E.). CABI Publishing. Wallingford, Oxfordshire, UK. 2003, pp. 29-52. 
[47] Jendral, M. J., Korver, D. R., Church, J. S., Feddes, J. J. R. Bone mineral density and breaking strength of White Leghorns housed in conventional, modified, and commercially available colony battery cages. Poult. Sci. 2008. 87, 828-837.

[48] Currey, J. D. Bone strength: what are we trying to measure? Calcif. Tissue Int. 2001. 68, 205-210.

[49] Zhang, B., Coon, C. N. The relationship of various tibia bone measurements in hens. Poult. Sci. 1997. 76, 1698-1701.

[50] Ammann, P., Rizzoli, R. Bone strength and its determinants. Osteoporos. Int. 2003. 14, 13-18.

[51] Dunn, I. C., Andersson, B., Fleming, R. H., De Koning, D. J., McCormack, H. M., RodriguezNavarro, A. B., Schmutz, M., Wilson, P. W. Quality of the laying hen skeleton; insights and solutions from genetics in Proceedings of The 17th International Conference on Production Diseases in Farm Animals. (Eds.: Bruckmaier, R. M., Gross, J. J.). Bern University. Bern, Switzerland. 2019, p. 50.

[52] Clark, W. D., Cox, W. R., Silversides, F. G. Bone fracture incidence in end-of-lay highproducing, noncommercial laying hens identified using radiographs. Poult. Sci. 2008. 87, 1964-1970.

[53] Gebhardt-Henrich, S. G., Fröhlich, E. K. Early onset of laying and bumblefoot favor keel bone fractures. Animals 2015. 5, 1192-1206.

[54] Rennie, J. S., Fleming, R. H., McCormack, H. A., McCorquodale, C. C., Whitehead, C. C. Studies on effects of nutritional factors on bone structure and osteoporosis in laying hens. Br. Poult. Sci. 1997. 38, 417-424. 


\section{Supplementary Materials}

Table S2.1: Light program and mean climatic conditions.

\begin{tabular}{ccccccc}
\hline $\begin{array}{c}\text { Week of } \\
\text { age }\end{array}$ & $\begin{array}{c}\text { Start } \\
\text { Time }\end{array}$ & End & $\begin{array}{c}\text { Day length } \\
(\mathbf{h})\end{array}$ & $\begin{array}{c}\text { Light intensity } \\
(\text { Lux })\end{array}$ & $\begin{array}{c}\text { Temperature } \\
\left({ }^{\circ} \mathbf{C}\right)\end{array}$ & $\begin{array}{c}\text { Relative humidity } \\
(\mathbf{\%})\end{array}$ \\
\hline Day 1 & - & - & 24.0 & 20.0 & 27.0 & 66.0 \\
1 & $4: 00 \mathrm{am}$ & $7: 00 \mathrm{pm}$ & 15.0 & 20.0 & 27.6 & 64.8 \\
2 & $4: 30 \mathrm{am}$ & $7: 00 \mathrm{pm}$ & 14.5 & 20.0 & 26.4 & 67.9 \\
3 & $5: 30 \mathrm{am}$ & $7: 00 \mathrm{pm}$ & 13.5 & 20.0 & 24.5 & 66.8 \\
4 & $6: 00 \mathrm{am}$ & $7: 00 \mathrm{pm}$ & 13.0 & 20.0 & 22.1 & 68.5 \\
5 & $7: 00 \mathrm{am}$ & $7: 00 \mathrm{pm}$ & 12.0 & 20.0 & 19.4 & 69.0 \\
6 & $7: 00 \mathrm{am}$ & $6: 00 \mathrm{pm}$ & 11.0 & 10.0 & 18.2 & 75.3 \\
7 & $7: 00 \mathrm{am}$ & $5: 00 \mathrm{pm}$ & 10.0 & 10.0 & 18.8 & 77.8 \\
8 & $7: 30 \mathrm{am}$ & $4: 30 \mathrm{pm}$ & 9.0 & 10.0 & 18.4 & 73.1 \\
9 & $7: 30 \mathrm{am}$ & $3: 30 \mathrm{pm}$ & 8.0 & 10.0 & 18.2 & 76.1 \\
10 & $7: 30 \mathrm{am}$ & $3: 30 \mathrm{pm}$ & 8.0 & 10.0 & 18.0 & 75.6 \\
11 & $7: 30 \mathrm{am}$ & $3: 30 \mathrm{pm}$ & 8.0 & 10.0 & 18.2 & 76.4 \\
12 & $7: 30 \mathrm{am}$ & $3: 30 \mathrm{pm}$ & 8.0 & 10.0 & 18.2 & 77.4 \\
13 & $7: 30 \mathrm{am}$ & $3: 30 \mathrm{pm}$ & 8.0 & 10.0 & 18.8 & 78.7 \\
14 & $7: 30 \mathrm{am}$ & $3: 30 \mathrm{pm}$ & 8.0 & 10.0 & 18.7 & 78.6 \\
15 & $7: 30 \mathrm{am}$ & $3: 30 \mathrm{pm}$ & 8.0 & 10.0 & 18.1 & 78.8 \\
16 & $7: 30 \mathrm{am}$ & $3: 30 \mathrm{pm}$ & 8.0 & 10.0 & 18.3 & 53.1 \\
17 & $7: 00 \mathrm{am}$ & $3: 30 \mathrm{pm}$ & 8.5 & 10.0 & 18.1 & 54.0 \\
18 & $6: 30 \mathrm{am}$ & $3: 30 \mathrm{pm}$ & 9.0 & 10.0 & 17.5 & 63.7 \\
19 & $6: 30 \mathrm{am}$ & $4: 00 \mathrm{pm}$ & 9.5 & 10.0 & 17.8 & 54.8 \\
20 & $5: 30 \mathrm{am}$ & $4: 00 \mathrm{pm}$ & 10.5 & 10.0 & 18.3 & 61.2 \\
21 & $4: 30 \mathrm{am}$ & $4: 00 \mathrm{pm}$ & 11.5 & 10.0 & 18.0 & 62.6 \\
22 & $4: 00 \mathrm{am}$ & $4: 30 \mathrm{pm}$ & 12.5 & 10.0 & 17.8 & 62.3 \\
23 & $3: 30 \mathrm{am}$ & $5: 00 \mathrm{pm}$ & 13.5 & 10.0 & 17.8 & 58.9 \\
$24-69$ & $3: 30 \mathrm{am}$ & $5: 30 \mathrm{pm}$ & 14.0 & 10.0 & - & - \\
\hline & & & & & &
\end{tabular}

Table S2.2: Calculated nutrient compositions of the diets fed to the chicks during the first and second generations, respectively, and of the diet fed to the pullets during both generations.

\begin{tabular}{lcccc}
\hline \multicolumn{1}{c}{ Diet } & \multicolumn{2}{c}{ Chicks } & & Pullets \\
\cline { 2 - 3 } Generation & 1 & 2 & & $1+2$ \\
\hline Crude protein (\%) & 21.00 & 21.00 & & 15.50 \\
Crude fat (\%) & 4.00 & 4.00 & & 4.00 \\
Crude fibre (\%) & 3.20 & 3.50 & & 4.50 \\
Crude ash (\%) & 6.00 & 6.00 & & 5.00 \\
ME/kg DM (MJ) & 11.80 & 11.80 & & 11.40 \\
Calcium (\%) & 1.00 & 0.95 & & 0.85 \\
Phosphorus (\%) & 0.70 & 0.65 & \\
Natrium (\%) & 0.15 & 0.15 & 0.15 \\
Lysine (\%) & 1.20 & 1.20 & 0.65 \\
Methionine (\%) & 0.48 & 0.48 & 0.34 \\
Vitamin D3 (IU/kg) & 3000.00 & 3000.00 & 1950.00 \\
\hline
\end{tabular}


Table S2.3: Ingredients and analysed nutrient compositions of the experimental layer diets of the first and second generations.

\begin{tabular}{|c|c|c|c|c|}
\hline \multirow[b]{2}{*}{ Generation } & \multicolumn{2}{|c|}{$\begin{array}{c}\text { Layers } \\
300 \text { IU Vit D3 }\end{array}$} & \multicolumn{2}{|c|}{$\begin{array}{c}\text { Layers } \\
3000 \text { IU Vit D3 }\end{array}$} \\
\hline & 1 & 2 & 1 & 2 \\
\hline \multicolumn{5}{|l|}{ Ingredients (\%) } \\
\hline Wheat & 39.80 & 39.74 & 39.80 & 39.74 \\
\hline Corn & 20.00 & 20.00 & 20.00 & 20.00 \\
\hline Soybean, toasted & 10.63 & 10.63 & 10.63 & 10.63 \\
\hline Soybean meal, toasted & 8.00 & 8.00 & 8.00 & 8.00 \\
\hline High protein soybean meal, toasted & 5.00 & 5.00 & 5.00 & 5.00 \\
\hline Lucerne pellets & 2.44 & 2.44 & 2.44 & 2.44 \\
\hline Soybean oil & 2.00 & 2.00 & 2.00 & 2.00 \\
\hline Calcium phosphate & 2.16 & 2.46 & 2.16 & 2.46 \\
\hline Calcium carbonate & 7.53 & 8.15 & 7.53 & 8.15 \\
\hline Sodium chloride & 0.29 & 0.42 & 0.29 & 0.42 \\
\hline DL-Methionine & 0.15 & 0.16 & 0.15 & 0.16 \\
\hline Silica (Sipernat ${ }^{\circledR}$ ) & 1.00 & - & 1.00 & - \\
\hline Premix 74237 & 1.00 & 1.00 & - & - \\
\hline Premix 74118 & - & - & 1.00 & 1.00 \\
\hline \multicolumn{5}{|l|}{ Nutrient composition } \\
\hline Crude protein (\%) & 15.90 & 16.80 & 15.80 & 17.10 \\
\hline Crude fat $(\%)$ & 5.60 & 6.20 & 6.20 & 6.20 \\
\hline Starch (\%) & 40.70 & 38.40 & 38.90 & 38.00 \\
\hline Sucrose $(\%)$ & 3.60 & 3.00 & 4.00 & 3.40 \\
\hline ME/kg DM (MJ) & 11.60 & 11.50 & 11.60 & 11.60 \\
\hline Vitamin D3 (IU/kg) & 430.00 & 2000.00 & 2240.0 & 3400.00 \\
\hline Calcium (\%) & & & 3.38 & \\
\hline Phosphorus (\%) & & & 0.65 & \\
\hline Natrium (\%) & & & 0.26 & \\
\hline
\end{tabular}


Table S2.4: The effects of layer line, diet and their interaction on the observed bone traits and basic production parameters calculated within generations.

\begin{tabular}{|c|c|c|c|c|c|c|}
\hline & \multicolumn{2}{|c|}{ Layer Line } & \multicolumn{2}{|c|}{ Diet } & \multicolumn{2}{|c|}{ Layer Line $\times$ Diet } \\
\hline & F Value & $p$-Value & F Value & $p$-Value & F Value & $p$-Value \\
\hline \multicolumn{7}{|l|}{ Generation 1} \\
\hline Laying maturity & 169.42 & $<0.0001$ & 1.20 & 0.2743 & 0.39 & 0.7618 \\
\hline Total number of eggs & 346.92 & $<0.0001$ & 3.39 & 0.0669 & 0.55 & 0.6509 \\
\hline Egg weight & 69.00 & $<0.0001$ & 0.68 & 0.4112 & 0.31 & 0.8152 \\
\hline Eggshell weight & 95.23 & $<0.0001$ & 0.50 & 0.4816 & 0.59 & 0.6203 \\
\hline Eggshell proportion & 36.18 & $<0.0001$ & 3.22 & 0.0740 & 0.30 & 0.8250 \\
\hline Total eggshell production & 516.80 & $<0.0001$ & 3.22 & 0.0739 & 0.33 & 0.8041 \\
\hline Daily feed consumption & 76.43 & $<0.0001$ & 0.24 & 0.6248 & 0.58 & 0.6308 \\
\hline Feed-to-egg conversion rate & 234.46 & $<0.0001$ & 0.73 & 0.3933 & 0.58 & 0.6271 \\
\hline Feed-to-eggshell conversion rate & 245.59 & $<0.0001$ & 2.78 & 0.0967 & 0.39 & 0.7589 \\
\hline Bone breaking strength Tibiotarsus & 120.59 & $<0.0001$ & 0.27 & 0.6054 & 1.60 & 0.1909 \\
\hline Bone mineral density Tibiotarsus & 87.07 & $<0.0001$ & 0.25 & 0.6155 & 2.86 & 0.0376 \\
\hline Weight Tibiotarsus & 305.57 & $<0.0001$ & 0.05 & 0.8319 & 0.33 & 0.8005 \\
\hline Length Tibiotarsus & 38.36 & $<0.0001$ & 0.47 & 0.4949 & 0.56 & 0.6442 \\
\hline Thickness Tibiotarsus & 197.36 & $<0.0001$ & 0.00 & 0.9924 & 0.28 & 0.8416 \\
\hline Bone breaking strength Humerus & 55.72 & $<0.0001$ & 1.66 & 0.1986 & 0.79 & 0.4994 \\
\hline Bone mineral density Humerus & 43.75 & $<0.0001$ & 2.50 & 0.1148 & 0.29 & 0.8315 \\
\hline Weight Humerus & 63.97 & $<0.0001$ & 0.03 & 0.8599 & 0.28 & 0.8417 \\
\hline Length Humerus & 62.34 & $<0.0001$ & 0.02 & 0.8808 & 2.02 & 0.1112 \\
\hline Thickness Humerus & 40.52 & $<0.0001$ & 1.03 & 0.3112 & 0.70 & 0.5538 \\
\hline Body weight 69 th week of age & 151.27 & $<0.0001$ & 0.03 & 0.8624 & 1.52 & 0.2097 \\
\hline \multicolumn{7}{|l|}{ Generation 2} \\
\hline Laying maturity & 159.93 & $<0.0001$ & 1.50 & 0.2211 & 0.10 & 0.9611 \\
\hline Total number of eggs & 461.62 & $<0.0001$ & 0.16 & 0.6909 & 0.51 & 0.6781 \\
\hline Egg weight & 119.07 & $<0.0001$ & 0.74 & 0.3890 & 0.43 & 0.7298 \\
\hline Eggshell weight & 217.06 & $<0.0001$ & 1.05 & 0.3061 & 1.88 & 0.1341 \\
\hline Eggshell proportion & 55.17 & $<0.0001$ & 0.03 & 0.8526 & 0.53 & 0.6613 \\
\hline Total eggshell production & 826.22 & $<0.0001$ & 1.32 & 0.2524 & 2.07 & 0.1049 \\
\hline Daily feed consumption & 109.61 & $<0.0001$ & 1.52 & 0.2181 & 0.99 & 0.3997 \\
\hline Feed-to-egg conversion rate & 278.68 & $<0.0001$ & 0.28 & 0.5960 & 3.35 & 0.0197 \\
\hline Feed-to-eggshell conversion rate & 259.92 & $<0.0001$ & 0.56 & 0.4538 & 2.37 & 0.0708 \\
\hline Bone breaking strength Tibiotarsus & 70.35 & $<0.0001$ & 0.03 & 0.8692 & 1.37 & 0.2536 \\
\hline Bone mineral density Tibiotarsus & 94.81 & $<0.0001$ & 0.13 & 0.7201 & 1.69 & 0.1706 \\
\hline Weight Tibiotarsus & 291.45 & $<0.0001$ & 0.19 & 0.6649 & 0.52 & 0.6672 \\
\hline Length Tibiotarsus & 21.25 & $<0.0001$ & 0.02 & 0.8904 & 0.08 & 0.9717 \\
\hline Thickness Tibiotarsus & 179.68 & $<0.0001$ & 0.04 & 0.8395 & 0.08 & 0.9711 \\
\hline Bone breaking strength Humerus & 32.15 & $<0.0001$ & 0.08 & 0.7807 & 1.30 & 0.2744 \\
\hline Bone mineral density Humerus & 56.76 & $<0.0001$ & 1.44 & 0.2315 & 0.19 & 0.9033 \\
\hline Weight Humerus & 99.83 & $<0.0001$ & 0.03 & 0.8528 & 0.21 & 0.8864 \\
\hline Length Humerus & 49.52 & $<0.0001$ & 0.01 & 0.9390 & 0.37 & 0.7765 \\
\hline Thickness Humerus & 60.71 & $<0.0001$ & 0.53 & 0.4689 & 0.61 & 0.6062 \\
\hline Body weight 69 th week of age & 137.20 & $<0.0001$ & 1.82 & 0.1786 & 2.13 & 0.0963 \\
\hline
\end{tabular}


Table S2.5: Sample sizes for the analysis.

\begin{tabular}{|c|c|c|c|c|c|}
\hline \multirow{2}{*}{ Variable } & \multirow{2}{*}{ Total } & \multicolumn{4}{|c|}{ Layer Line } \\
\hline & & WLA & R11 & BLA & L68 \\
\hline Laying maturity & 524 & 129 & 134 & 133 & 128 \\
\hline Total number of eggs & 524 & 129 & 134 & 133 & 128 \\
\hline Egg weight & 524 & 129 & 134 & 133 & 128 \\
\hline Eggshell weight & 524 & 129 & 134 & 133 & 128 \\
\hline Eggshell proportion & 524 & 129 & 134 & 133 & 128 \\
\hline Total eggshell production & 524 & 129 & 134 & 133 & 128 \\
\hline Daily feed consumption & 513 & 128 & 131 & 129 & 125 \\
\hline Feed-to-egg conversion rate & 513 & 128 & 131 & 129 & 125 \\
\hline Feed-to-eggshell conversion rate & 513 & 128 & 131 & 129 & 125 \\
\hline Bone breaking strength Tibiotarsus & 518 & 126 & 134 & 131 & 127 \\
\hline Bone mineral density Tibiotarsus & 524 & 129 & 134 & 133 & 128 \\
\hline Weight Tibiotarsus & 524 & 129 & 134 & 133 & 128 \\
\hline Length Tibiotarsus & 524 & 129 & 134 & 133 & 128 \\
\hline Thickness Tibiotarsus & 524 & 129 & 134 & 133 & 128 \\
\hline Bone breaking strength Humerus & 516 & 128 & 131 & 132 & 125 \\
\hline Bone mineral density Humerus & 519 & 129 & 134 & 128 & 128 \\
\hline Weight Humerus & 521 & 127 & 134 & 132 & 128 \\
\hline Length Humerus & 523 & 129 & 134 & 132 & 128 \\
\hline Thickness Humerus & 524 & 129 & 134 & 133 & 128 \\
\hline Body weight at hatch & 523 & 129 & 133 & 133 & 128 \\
\hline Body weight at week 21 & 524 & 129 & 134 & 133 & 128 \\
\hline Body weight at week 25 & 524 & 129 & 134 & 133 & 128 \\
\hline Body weight at week 35 & 524 & 129 & 134 & 133 & 128 \\
\hline Body weight at week 69 & 524 & 129 & 134 & 133 & 128 \\
\hline
\end{tabular}

Table S2.6: Least squares means \pm standard errors and level of significance for body weight measured at hatching, and different weeks of age under the effect of layer line (LL), generation (Gen), and their interaction.

\begin{tabular}{|c|c|c|c|c|c|}
\hline \multirow{2}{*}{ Effect } & \multicolumn{5}{|c|}{ Body weight(g) } \\
\hline & Hatch & Week 21 & Week 25 & Week 35 & Week 69 \\
\hline \multicolumn{6}{|l|}{ Layer line (LL) } \\
\hline WLA & $38.35 \pm 0.37^{a}$ & $1420.02 \pm 15.79^{b}$ & $1468.38 \pm 16.19^{b}$ & $1497.54 \pm 20.46^{b}$ & $1504.23 \pm 22.26^{c}$ \\
\hline $\mathrm{R} 11$ & $33.17 \pm 0.36^{c}$ & $1040.84 \pm 15.60^{c}$ & $1236.40 \pm 15.99^{c}$ & $1309.28 \pm 20.21^{c}$ & $1362.79 \pm 21.99^{d}$ \\
\hline BLA & $39.35 \pm 0.37^{a}$ & $1584.15 \pm 15.71^{a}$ & $1663.55 \pm 16.11^{a}$ & $1821.81 \pm 20.34^{a}$ & $1838.10 \pm 22.13^{b}$ \\
\hline L68 & $34.84 \pm 0.37^{b}$ & $1568.91 \pm 15.81^{a}$ & $1714.92 \pm 16.21^{a}$ & $1837.91 \pm 20.48^{a}$ & $1923.44 \pm 22.29^{a}$ \\
\hline \multicolumn{6}{|c|}{ Generation (Gen) } \\
\hline Gen 1 & $35.86 \pm 0.26$ & $1379.01 \pm 11.17$ & $1485.67 \pm 11.45$ & $1567.49 \pm 14.47$ & $1616.21 \pm 15.76$ \\
\hline Gen 2 & $37.00 \pm 0.26$ & $1427.95 \pm 11.07$ & $1555.96 \pm 11.36$ & $1665.79 \pm 14.34$ & $1698.07 \pm 15.59$ \\
\hline \multicolumn{6}{|l|}{$\mathbf{L L} \times \mathbf{G e n}$} \\
\hline WLA $\times$ Gen 1 & $37.77 \pm 0.52$ & $1376.72 \pm 22.36$ & $1415.84 \pm 22.91$ & $1460.33 \pm 28.96$ & $1443.48 \pm 31.51$ \\
\hline WLA $\times$ Gen 2 & $38.93 \pm 0.52$ & $1463.31 \pm 22.32$ & $1520.93 \pm 22.88$ & $1534.75 \pm 28.91$ & $1564.98 \pm 31.45$ \\
\hline $\mathrm{R} 11 \times$ Gen 1 & $32.64 \pm 0.51$ & $1027.33 \pm 21.99$ & $1222.77 \pm 22.53$ & $1284.20 \pm 28.49$ & $1338.12 \pm 31.02$ \\
\hline $\mathrm{R} 11 \times$ Gen 2 & $33.69 \pm 0.52$ & $1054.36 \pm 22.14$ & $1250.04 \pm 22.71$ & $1334.37 \pm 28.66$ & $1387.45 \pm 31.17$ \\
\hline BLA $\times$ Gen 1 & $38.84 \pm 0.52$ & $1549.66 \pm 22.41$ & $1627.91 \pm 22.97$ & $1767.90 \pm 29.03$ & $1804.33 \pm 31.60$ \\
\hline BLA $\times$ Gen2 & $39.87 \pm 0.51$ & $1618.63 \pm 22.02$ & $1699.19 \pm 22.59$ & $1875.73 \pm 28.50$ & $1871.86 \pm 30.98$ \\
\hline L68 × Gen1 & $34.18 \pm 0.52$ & $1562.32 \pm 22.61$ & $1676.16 \pm 23.16$ & $1757.53 \pm 29.31$ & $1878.89 \pm 31.92$ \\
\hline L68 $\times$ Gen 2 & $35.51 \pm 0.51$ & $1575.50 \pm 22.11$ & $1753.67 \pm 22.68$ & $1918.30 \pm 28.62$ & $1968.00 \pm 31.12$ \\
\hline \multicolumn{6}{|c|}{ ANOVA significance level ( $p$ value) } \\
\hline & \multicolumn{2}{|c|}{ Layer line } & Generation & \multicolumn{2}{|c|}{$\mathrm{LL} \times \mathrm{Gen}$} \\
\hline Hatch & \multicolumn{2}{|c|}{$<0.0001$} & 0.0019 & \multicolumn{2}{|c|}{0.9908} \\
\hline Week 21 & \multicolumn{2}{|c|}{$<0.0001$} & 0.0020 & \multicolumn{2}{|c|}{0.3097} \\
\hline Week 25 & \multicolumn{2}{|c|}{$<0.0001$} & $<0.0001$ & \multicolumn{2}{|c|}{0.3907} \\
\hline Week 35 & \multicolumn{2}{|c|}{$<0.0001$} & $<0.0001$ & \multicolumn{2}{|c|}{0.2486} \\
\hline Week 69 & \multicolumn{2}{|c|}{0.0003} & $<0.0001$ & \multicolumn{2}{|c|}{0.6892} \\
\hline
\end{tabular}

Means within a column with different letters differ significantly (Tukey's HSD-Test, $p<0.05$ ). 



\section{Bone Health or Performance? Adaptation Response of Genetically Divergent Chicken Layer Lines to a Nutritive Calcium Depletion}

Simon Jansen ${ }^{1, *}$, Mara Bues ${ }^{2, *}$, Ulrich Baulain ${ }^{1}$, Christin Habig ${ }^{1}$, Ingrid Halle ${ }^{3}$, Stefanie Petow ${ }^{4}$, A. Reza Sharifi ${ }^{5,6}$, Annett Weigend ${ }^{1}$, Mirja R. Wilkens ${ }^{2}$ and Steffen Weigend ${ }^{1,6}$

* These authors contributed equally to this work.

1 Institute of Farm Animal Genetics, Friedrich-Loeffler-Institut, 31535 Neustadt, Germany.

2 Institute of Physiology and Cell Biology, University of Veterinary Medicine Hannover, Foundation, 30173 Hannover, Germany.

3 Institute of Animal Nutrition, Friedrich-Loeffler-Institut, 38116 Braunschweig, Germany.

4 Institute of Animal Welfare and Animal Husbandry, Friedrich-Loeffler-Institut, 29223 Celle, Germany.

5 Animal Breeding and Genetics Group, Department of Animal Sciences, University of Göttingen, 37075 Göttingen, Germany.

6 Center for Integrated Breeding Research, University of Göttingen, 37075 Göttingen, Germany.

Published in Animals 2020, 10 (9): 1645

https: //doi.org/10.3390/ani10091645 


\section{Simple Summary}

Selection for high egg production in laying hens has led to an increased calcium requirement and consequently to an intensified calcium mobilization from the bones. However, excessive demineralization can lead to osteoporosis, which is manifested by a high incidence of bonedamaged hens. In this study, we characterized the adaptation response of laying hens to a repeated dietary calcium restriction $(1.09 \%$ instead of $4.26 \%$ calcium) by means of egg production, eggshell quality, body weight and bone stability. The animal model included four layer lines differing in performance level (high vs. moderately performing lines) and phylogenetic origin (white-egg vs. brown-egg layers). We assumed that the high performing lines would respond by maintaining egg production level at the expense of eggshell quality and bone health. Egg production and eggshell quality declined considerably and bone demineralization occurred in all lines. Contrary to our hypothesis, there was evidence that phylogeny rather than performance level influenced the hens' response. The brown-egg lines appeared to be more tolerant to the calcium depletion, while the white-egg lines were more sensitive. Our findings demonstrate the influence of genetics on the adaptive capacity of chickens and underline the importance of preserving genetic variability to cope with potential future environmental challenges.

\section{Abstract}

In modern laying hybrids, calcium ( $\mathrm{Ca}$ ) homeostasis is immensely challenged by daily eggshell calcification. However, excessive mobilization of $\mathrm{Ca}$ from bones may lead to osteoporosis, which then manifests in a high incidence of poor bone quality. The aim of this study was to characterize the hens' adaptation response to an alternating dietary Ca restriction. The animal model consisted of four purebred layer lines, differing in laying performance (high vs. moderately performing lines) and phylogenetic origin (white- vs. brown-egg lines). According to the resource allocation theory, hens selected for high egg production were assumed to show a different response pattern to cope with this nutritive challenge compared to moderately performing lines. Data collected included egg number, egg quality traits, body weight and bone characteristics. The Ca depletion led to a temporary drop in egg production and shell quality and a loss of bone stability due to Ca mobilization. The white-egg lines response was more pronounced, whereas the brown-egg lines were less sensitive towards reduced Ca supply. Our study shows that the hens' responsiveness to coping with a nutritive Ca depletion is not ultimately linked to genetic selection for increased egg production but rather to phylogenetic origin.

Keywords: bone strength; egg production; eggshell quality; calcium depletion; laying hens; phylogeny; recovery 


\section{Introduction}

While various functional traits have now been introduced into the selection index of laying hens, the main focus of the breeding companies remains the number of saleable eggs [1]. In female birds, there is a competitive situation, as calcium ( $\mathrm{Ca}$ ) is needed for eggshell formation and maintaining bone stability. Since up to three grams of $\mathrm{Ca}$ are required for each eggshell calcification process [2], modern laying hybrids' demand for $\mathrm{Ca}$ is particularly high and their $\mathrm{Ca}$ homeostasis is stressed continually [3]. The required $\mathrm{Ca}$ is provided by increased intestinal absorption and stimulated bone resorption in an approximate relation of 1:0.6 [4, 5]. With the onset of sexual maturity, the formation of medullary bone, which serves as a labile Ca source that can be replenished quickly [6], develops under the influence of estradiol-17 $\beta$. At the same time, there is a decrease of cancellous bone volume $[7,8]$. This enables laying hens to meet the temporarily high demand of Ca during the periods of eggshell formation by elevated mobilisation from the bones [9]. However, if this process exceeds physiological dimensions, continuous demineralisation leads to progressive loss of not only medullary but also structural bone tissue resulting in osteoporotic bones susceptible to fractures $[9,10]$. High incidences of bone damage have been demonstrated $[11,12]$ indicating major animal welfare problems and economic losses $[10,13,14]$.

It has been reported that selection for high production efficiency in livestock species might be associated with undesirable side effects such as deficiencies in physiological and functional traits [15], due to an imbalance in resource allocation [16]. Accordingly, chicken layer lines selected for high egg production might have a reduced capacity to compensate for unfavourable physiological conditions, e.g. limited mineral resources, compared to moderately performing genotypes [17-19]. Differences in adaptation responses can also be attributed to phylogenetic origin, as brown- and white-egg layer lines evolved separately over a long period of time and underwent genomic changes, which may have had effects on genetic characteristics even before directional (artificial) selection for high performance began [20, 21].

In the current study, we investigated the effect of a repeated dietary Ca restriction on performance traits and bone stability in four genetically divergent chicken layer lines. To address the potential implications of both the performance level and the phylogenetic origin, the animal model consisted of two brown-egg and two white-egg chicken layer lines. Within each phylogenetic group, the two lines differed in terms of egg-laying performance [22-24]. By characterizing the lines' adaptation responses to dietary Ca restriction, we aimed to test line-specific responses and assess whether genetic lines reacted differently, depending on phylogenetic origin or performance level, or both. In addition, repeated Ca reductions allowed us to study if the lines' responses were temporary and recovery occurred after supplementing feed with Ca again, or if changes were rather permanent.

We assumed that the long-term selected breeding lines for high egg production would respond by retaining their laying performance at the expense of eggshell quality and bone stability. In contrast, the moderately performing lines were supposed to respond with a decrease in performance in favour of bone health. 


\section{Materials and Methods}

\subsection{Ethical Note}

The experiment was performed in accordance with German Animal Welfare Law and approved by the Lower Saxony State Office for Consumer Protection and Food Safety (LAVES) (33.1942502-04-15/1988).

\subsection{Animals and Housing}

The experiment included four purebred chicken layer lines (Gallus gallus domesticus) differing in terms of egg production performance and phylogenetic origin, two white-egg layers and two brown-egg layers. The high performing lines WLA and BLA originate from a commercial breeding program (Lohmann Tierzucht $\mathrm{GmbH}$, Cuxhaven, Germany) and achieve an annual egg production of about 316 eggs [22]. The moderately performing lines R11 and L68 are maintained as resource populations without any selection at the Institute of Farm Animal Genetics of the Friedrich-Loeffler-Institut (Neustadt, Germany) and achieve a laying performance of 226 (R11) and 216 (L68) eggs per year. Besides performance divergence, the animal model included a phylogenetic dimension, as the two white-egg lines (WLA and R11) are both of White Leghorn type and are closely related, but distinct from the brown-egg ones (BLA and L68), which originated from Rhode Island Red and New Hampshire breeds, respectively. The latter breed was derived from the Rhode Island Red, explaining the close phylogenetic relationship of both [21].

All chicks were hatched on the same day. The chicks were tagged with wing bands at hatch for identification and sorted by sex. They were reared in a floor system under standard conditions. Information on the light program is given in the Supplementary Table S3.1. From the beginning of the 24th week of age, the birds were exposed to a light-dark cycle of $14 \mathrm{~h} \mathrm{~L}: 10 \mathrm{~h} \mathrm{D}$. Customary complete feeds for chicks (until 6 weeks of age; $11.8 \mathrm{MJ}$ $\mathrm{AME}_{\mathrm{N}} / \mathrm{kg}$ dry matter (DM), $210.0 \mathrm{~g} / \mathrm{kg}$ crude protein, $40.0 \mathrm{~g} / \mathrm{kg}$ crude fat, $35.0 \mathrm{~g} / \mathrm{kg}$ crude fiber, $60.0 \mathrm{~g} / \mathrm{kg}$ crude ash, $9.5 \mathrm{~g} / \mathrm{kg} \mathrm{Ca}, 6.5 \mathrm{~g} / \mathrm{kg}$ phosphorous) and pullets (from 7 to 17 weeks of age; $11.4 \mathrm{MJ} A M E_{\mathrm{N}} / \mathrm{kg} D M, 155.0 \mathrm{~g} / \mathrm{kg}$ crude protein, $40.0 \mathrm{~g} / \mathrm{kg}$ crude fat, 45.0 $\mathrm{g} / \mathrm{kg}$ crude fiber, $50.0 \mathrm{~g} / \mathrm{kg}$ crude ash, $8.5 \mathrm{~g} / \mathrm{kg} \mathrm{Ca}, 5.5 \mathrm{~g} / \mathrm{kg}$ phosphorous) were offered ad libitum. At 16 weeks of age, 132 pullets (33 birds per layer line) were transferred to six $8 \mathrm{~m}^{2}$ floor pens each littered with wood-shavings and equipped with nipple drinkers, two feeding troughs and four nest boxes. Each pen was occupied in equal proportions with 22 randomly chosen hens of WLA/L68 or BLA/R11 combination. The lines were combined to meet the limited number of nest boxes in the pens, as brown-egg lines use the nests earlier during the day than white-egg lines [25]. Furthermore, combining white-egg and brown-egg lines enabled a separate recording of the egg data for each chicken line even when kept together in the same floor pen. In this way, four Ca restricted pens and two control pens were formed resulting in two temporarily Ca deficient (DEF) and one control group (CON) per chicken layer line.

\subsection{Experimental Procedure}

The experiment lasted from the beginning of the 31st to the end of the 51st week of age. Two customary wheat-soya-based diets for layers were fed ad libitum, which only varied in 
terms of $\mathrm{Ca}$ content. The ingredients and chemical composition of the layer diets are listed in Supplementary Table S3.2. With regard to nutritional recommendations for high performing laying hens [26], the diets' Ca content can be classified as deficient ( $\mathrm{Ca}-, 1.09 \%)$ and adequate $(\mathrm{Ca}+, 4.26 \%)$. The $\mathrm{Ca}+$ diet was fed to all hens from 18 to 30 weeks of age. While the $\mathrm{Ca}+$ diet was fed to the control groups continuously during the whole experiment, the Ca deficient groups were provided with both the $\mathrm{Ca}+$ and the $\mathrm{Ca}$ - diet, alternatingly. In the latter case, a 21-day period of $\mathrm{Ca}$ depletion ( $\mathrm{Ca}$-) was followed by a 44-day recovery phase $(\mathrm{Ca}+)$ twice, followed by a third period of $\mathrm{Ca}$ restriction $(\mathrm{Ca}-)$. This resulted in a preliminary period (Pre, week 18-30), three periods of Ca depletion (D1, week 31-33; D2, week 40-42; D3, week 49-51) with two intermediate recovery periods (R1, week 34-39; R2, week 43-48). Figure 3.1 gives an overview on the experimental periods and the related procedures.

Data collection included traits on production performance and bone stability. Pen-level egg production, including eggshell breakages and defects, was recorded daily. The total laying rate and rate of broken eggs were calculated on a daily basis by dividing the number of eggs by the number of hens. Feed consumption ( $\mathrm{g}$ ) was recorded weekly on pen-level as the difference between the feed weighed in the feeding trough and the refusals. However, due to technical obstacles, feed consumption is only available from period D2 onwards. Immediately prior to changing the diet, the body weight (g) was measured using a digital table scale (CPA 16001S, Sartorius, Göttingen, Germany). Egg quality measurements included all eggs laid during $\mathrm{Ca}$ depletion periods (D1, D2 and D3) as well as those eggs laid within the last three consecutive days of the preliminary period (Pre), and the two recovery periods (R1 and R2). Eggshell breaking strength $(\mathrm{N})$ was determined using a testing machine that showed the maximum load that was required to break the eggshell. Egg weight (g) and eggshell weight (g) were recorded using a digital table scale (Type 3709, Sartorius, Göttingen, Germany). For the latter, the eggs were emptied with a spoon and the shells were dried for $30 \mathrm{~s}$ in a microwave (800 watt). Eggshell thickness $(\mathrm{mm})$ was measured near the equator using a caliper with an accuracy of $0.01 \mathrm{~mm}$ after removing the shell membranes.

At the end of the 51st week of age, the hens were euthanized by carbon dioxide inhalation. Keel bones, tibiotarsi and humeri of the birds were extracted and the adherent tissue removed. The bones were vacuum-packed and stored frozen $\left(-20^{\circ} \mathrm{C}\right)$ until further examination. After measuring the bone weight $(\mathrm{g})$, length $(\mathrm{mm})$ and thickness $(\mathrm{mm})$ of the left tibiotarsus and the left humerus, their radio density was determined given as millimetres of aluminum equivalent ( $\mathrm{mm} \mathrm{Al} \mathrm{eq)} \mathrm{[27].} \mathrm{The} \mathrm{diaphyseal} \mathrm{cortical} \mathrm{bone} \mathrm{proportion} \mathrm{("cortical} \mathrm{area")} \mathrm{of} \mathrm{the}$ left tibiotarsus cut surface was assessed planimetrically [28]. The right long bones were used for assessing bone breaking strength $(\mathrm{N})$ via a three-point bending test as described by Jansen et al. [22]. At slaughter, the keel bones were visually examined for the presence of fractures, indicated by fracture lines or callus formation. 
A

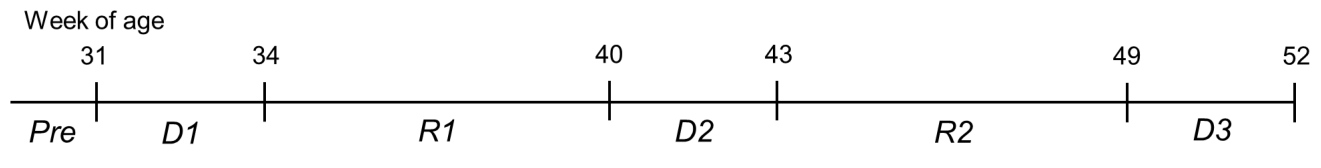

B

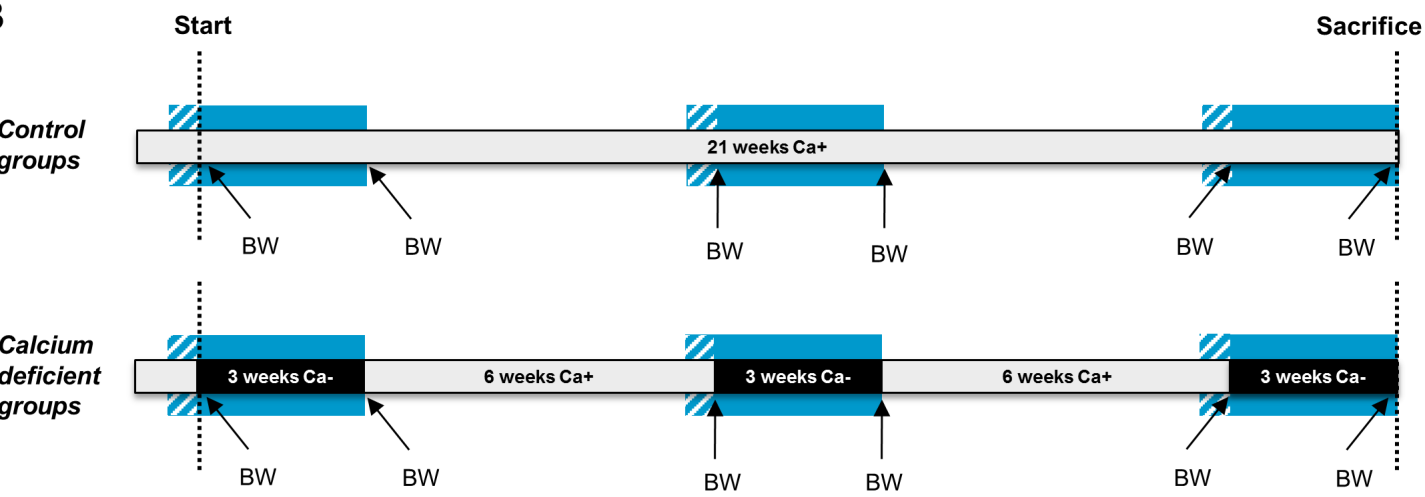

$=$ Periods of adequate calcium supply $(\mathrm{Ca}+)$

$=$ Periods of low calcium supply $(\mathrm{Ca}-)$

Z = Egg quality analysis (of all eggs laid within the last three consecutive days of the respective week of age)

= Egg quality analysis (of all eggs laid within the respective experimental period)

BW = Body weight measurement (directly prior to each change of diet)

Figure 3.1: Schematic illustration of the experimental periods and related procedures. (A) Age of the animals in weeks and experimental periods (Pre: preliminary period; D1: first calcium depletion period; R1: first recovery period; D2: second calcium depletion period; R2: second recovery period; D3: third calcium depletion period). (B) Dietary calcium supply and experimental procedures. Control groups were fed with adequate calcium diet $(\mathrm{Ca}+)$ continuously. Calcium deficient groups were fed alternatingly with low calcium diet ( $\mathrm{Ca}-$ ) (black sections) and adequate $\mathrm{Ca}+$ feed. Egg quality analysis was performed on all eggs laid within the last three consecutive days of periods Pre, R1 and R2 (blue striped sections), as well as during the entire phases of Ca- (blue sections). Body weighing (BW) was performed directly prior to each change of diet.

\subsection{Statistical Analysis}

Data analysis was carried out using SAS 9.4 (SAS Institute Inc. Cary, NC, USA, 2017). For each layer line, the sample size was $n=22$ (DEF groups) and $n=11$ (CON groups).

Both the total laying rate and the rate of broken eggs were analyzed within the layer lines, applying a univariate regression approach using the MIXED procedure, modelling the linear relationship between the laying rate or rate of broken eggs and the day of depletion according to the following model:

$$
\gamma_{i}=\beta_{0}+\beta_{1} x_{i}+\varepsilon_{i}
$$

where $\gamma_{i}$ is the trait under consideration; $\beta_{0}$ is the intercept; $\beta_{1}$ is the slope; $x_{i}$ is the independent variable "day of depletion"; and $\varepsilon_{i}$ is the random error variance.

Concerning egg quality traits, we first examined whether there were significant differences between the dietary groups of the layer lines in the preliminary (Pre) or recovery phases 
(R1, R2). For the depletion periods (D1, D2, D3), an analysis of covariance was applied in order to fit regression curves considering the time during the depletion as a covariate term up to 4 polynomial degrees and the fixed effect of dietary treatment as well as significant interactions between the dietary treatment and the covariate (day of depletion) up to degree 4 of polynomials [29]. For the analysis of the eggshell weight data, the egg weight was considered as a covariate. In a backward selection approach, the Wald F-statistics were used to determine the significance of fixed effects. Egg quality data were analyzed with the MIXED procedure of SAS. Least squares means (LSM) were estimated by applying the LSMEANS statement. Significant differences between LSM were tested using Tukey's HSD (honestly significant difference) test. Statistical significance was set at $p<0.05$. Standard errors of LSM were calculated as described by Littell et al. [29].

The impact of time of measurement, dietary treatment and their interaction on the body weight was analyzed within layer line using the GLIMMIX procedure according to the following model:

$$
\gamma_{i j k l}=\mu+T_{i}+D_{j}+T_{i} \times D_{j}+S_{k}+\varepsilon_{i j k l}
$$

where $\gamma_{i j k l}$ is the trait under consideration; $\mu$ is the general mean; $T_{i}$ is the fixed effect of time of measurement ( $i=1$ to 6 ); $D_{j}$ is the fixed effect of the $\operatorname{diet}(j=1,2) ; T_{i} \times D_{i}$ is the fixed effect of interaction between time of measurement and diet; $S_{k}$ is the random effect of sire $(k=1$ to 66$)$; and $\varepsilon_{i j k l}$ is the random error variance. Tukey's HSD-Test was performed for multiple comparisons of means. Statistical significance was set at $p<0.05$.

Bone analysis took place at the end of the study. At this point, the impact of layer line, dietary treatment and their interaction on the bone characteristics were analyzed using the GLIMMIX procedure according to the following model:

$$
\gamma_{i j k l}=\mu+L L_{i}+D_{j}+L L_{i} \times D_{j}+S_{k}+\varepsilon_{i j k l}
$$

where $\gamma_{i j k l}$ is the trait under consideration; $\mu$ is the general mean; $L L_{i}$ is the fixed effect of layer line ( $i=1$ to 4$) ; D_{j}$ is the fixed effect of the $\operatorname{diet}(j=1,2) ; L L_{i} \times D_{j}$ is the interaction between layer line and diet; $S_{k}$ is the random effect of sire ( $k=1$ to 66$)$; and $\varepsilon_{i j k l}$ is the random error variance. Tukey's HSD-Test was performed for multiple comparisons of means. Statistical significance was set at $p<0.05$.

The results of the keel bone examination have been dichotomized, differentiating between "at least one fracture was present" (score 1) and "no fractures were present" (score 0). The effect of the dietary treatment on the fracture occurrence was analyzed by means of Fisher's exact test separately for each layer line using the FREQ procedure.

\section{Results}

\subsection{Laying Performance}

Figure 3.2 illustrates the total laying rate of the dietary groups of the four layer lines. In addition, the linear relationship between the total laying rate and the day of the respective depletion period is indicated. At 19 (BLA) and 20 (WLA) weeks, laying maturity was reached earlier in the high performing lines than in the moderately performing ones, whose first eggs 
were laid at week 21 (L68) and 23 (R11). The DEF groups of WLA, R11 and BLA showed a marked decline in egg production among all depletion periods. Highly significant, negative regression coefficients $\left(\beta_{1}\right)$ between time of progressive Ca depletion and the laying rate were found in these lines, resulting in average values across the three depletion phases of $\beta_{1}=-1.94$ (WLA), $\beta_{1}=-1.75$ (R11) and $\beta_{1}=-1.93$ (BLA). In the case of the line WLA, for example, this means that per day of $C$ a depletion, the laying rate decreased by $1.94 \%$. After reconversion to adequate Ca supply, the initial performance level was regained consistently in these lines, as the intercept $\left(\beta_{0}\right)$ of the regression curves varied only a little between the depletion periods (Figure 3.2). This indicates a recovery in laying performance. Since both dietary groups of the moderately performing brown-egg line L68 declined more or less equally in the course of the experimental period, there was not such a strong response to Ca depletion in this line as there was for the other lines. The corresponding regression coefficients were not significant.

Figure 3.2 also shows the rate of broken eggs, i.e., eggshell breakages and defects, and the linear relationship between this variable and the day of the depletion period. Increased incidences of eggshell breakages and defects were observed in the DEF groups of all lines. In this instance, the high performing white-egg line WLA showed a considerably higher incidence, as reflected by average regression coefficients of $\beta_{1}=2.48$ (WLA), $\beta_{1}=0.91$ (R11), $\beta_{1}=0.80$ $(\mathrm{BLA})$ and $\beta_{1}=0.56(\mathrm{~L} 68)$. In all lines, however, the rate of broken eggs declined to the initial level of below $1.5 \%$ within two weeks of the recovery phases. 
WLA

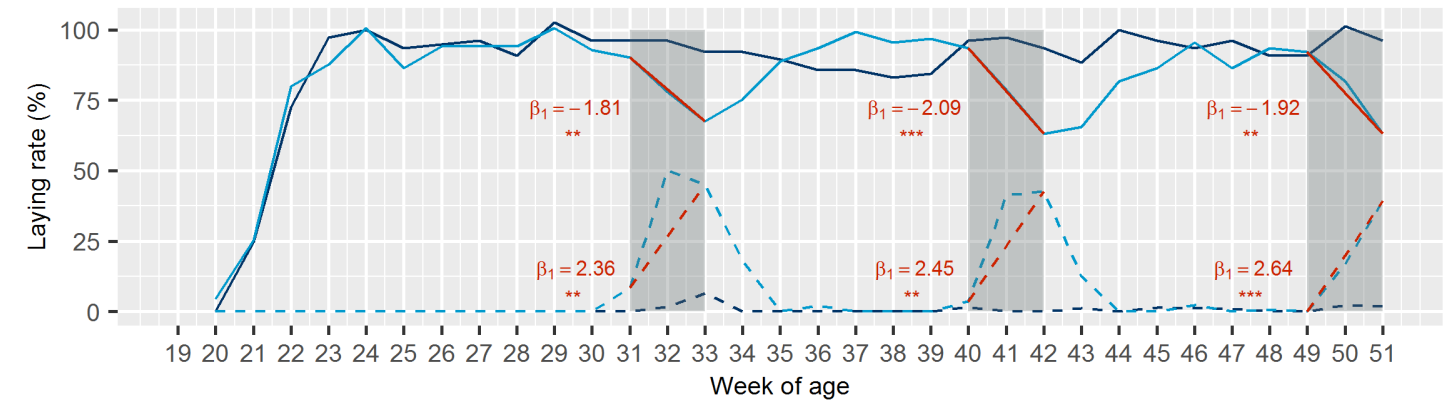

R11

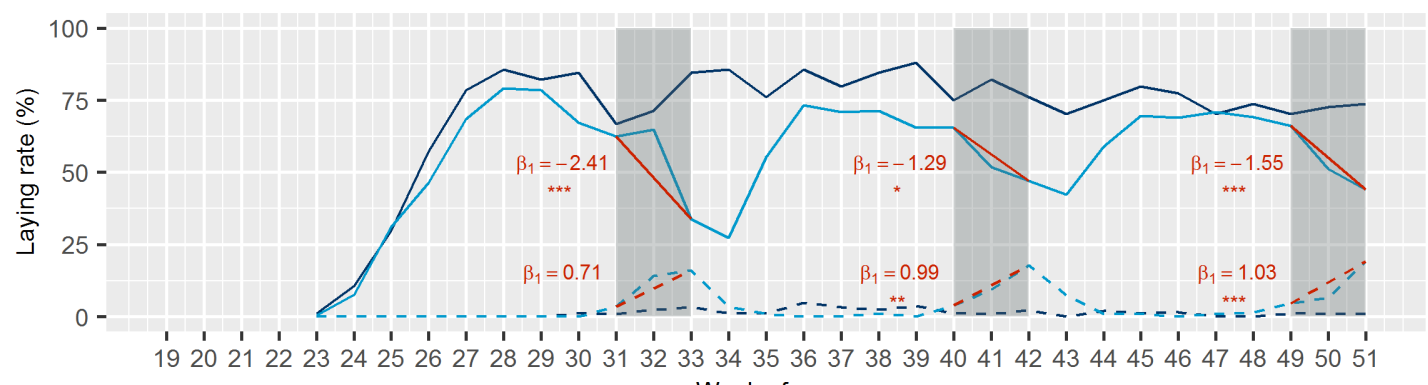

BLA

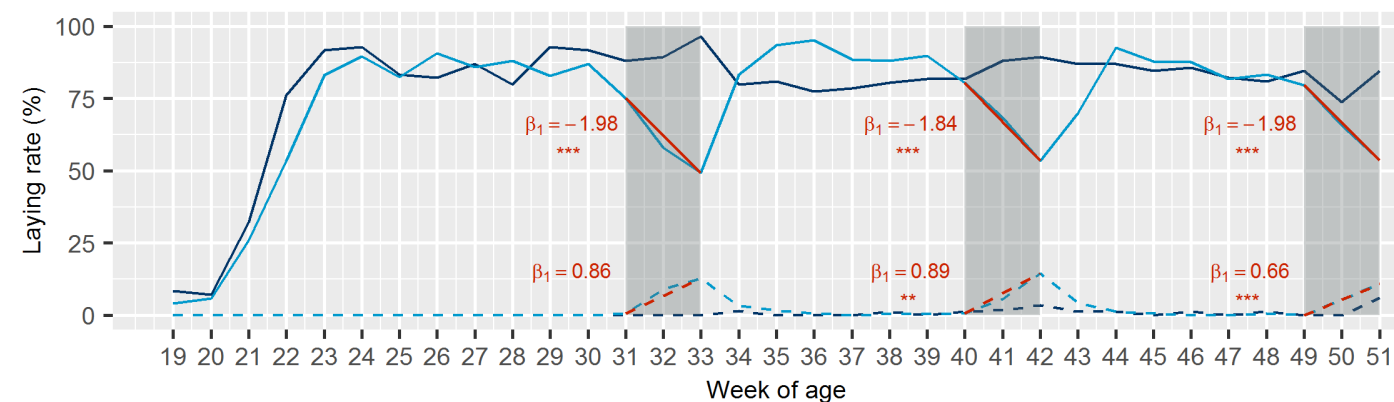

L68

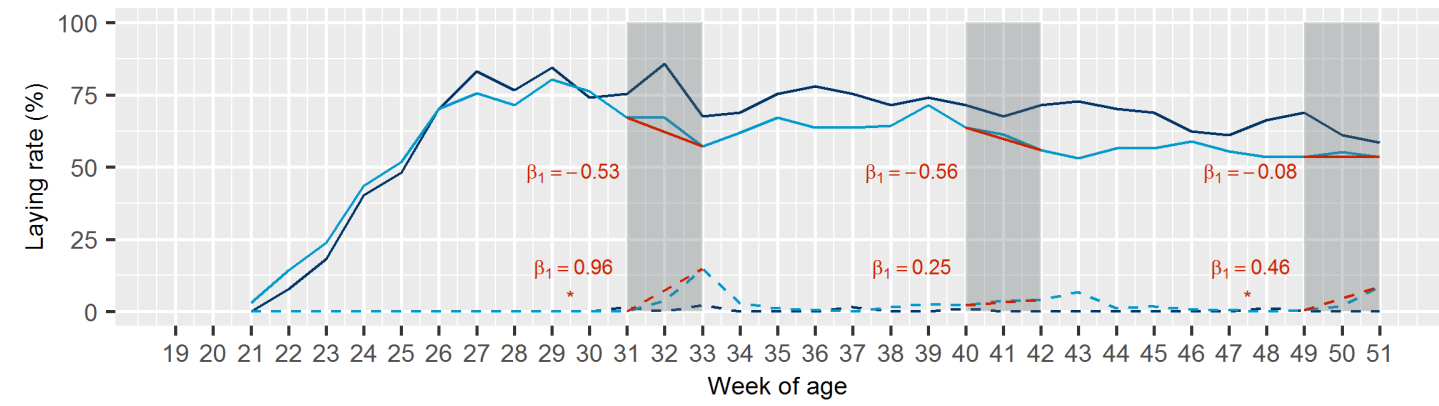

— CON Total — DEF Total - - CON Broken - - DEF Broken

Figure 3.2: Total laying rate (solid lines) and laying rate of broken eggs (dashed lines) in control $(\mathrm{CON})$ and calcium ( $\mathrm{Ca}$ ) deficient (DEF) groups of four layer lines (white-egg layers (WLA, R11), brown-egg layers (BLA, L68)). Grey-shaded sections represent the periods of $\mathrm{Ca}$ depletion. Linear regression curves and the corresponding coefficients $\left(\beta_{1}\right)$ between day of depletion and total laying rate or laying rate of broken eggs are given in red. Significant regression coefficients are marked with asterisks $(* p<0.05$; ** $p<0.01$; $\left.{ }^{* * *} p<0.001\right)$. DEF groups: $n=22$; CON groups: $n=11$. 


\subsection{Egg Quality}

The progression of egg quality traits during the periods of Ca depletion is shown in Figure 3.3 (egg weight), Figure 3.4 (eggshell thickness) and Figure 3.5 (eggshell breaking strength). Taking all periods into account, significant differences between DEF and CON groups of line WLA were observed consistently and mostly earlier than in all other layer lines. While the DEF group of line WLA responded significantly for most traits within the first three days, the dietary groups of line R11 only tended to differ in terms of eggshell breaking strength and thickness. The only significant differences found in line R11 were in egg weight in periods D1 and D3. However, these differences were rather minor. In Ca deficient BLA hens, a significant egg weight decline was observed from the ninth day on (except in D3), whereas for the other traits, a significant response occurred even within the first five days. Although Ca depletion also caused a decrease in egg quality in line L68, a more pronounced decline was observed in its high performing counterpart BLA. These observations are supported by the results on the eggshell weight shown in Supplementary Figure S3.1.

D1

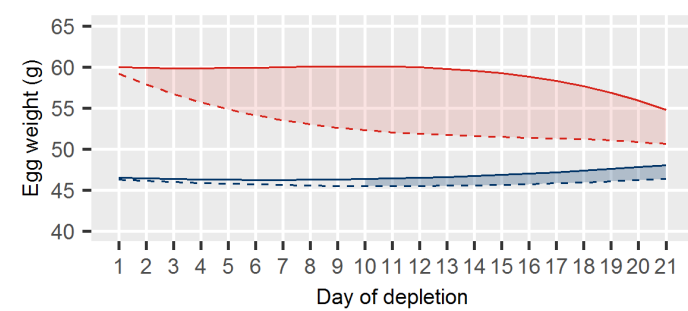

D2

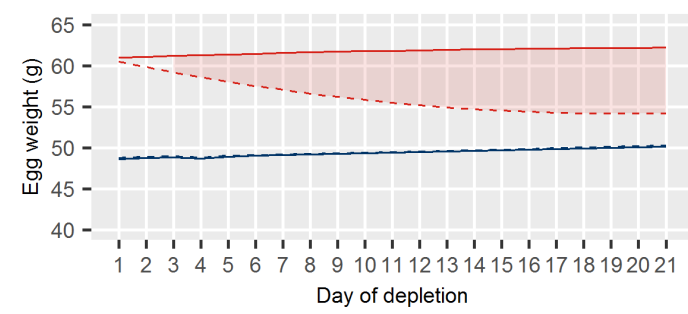

D3

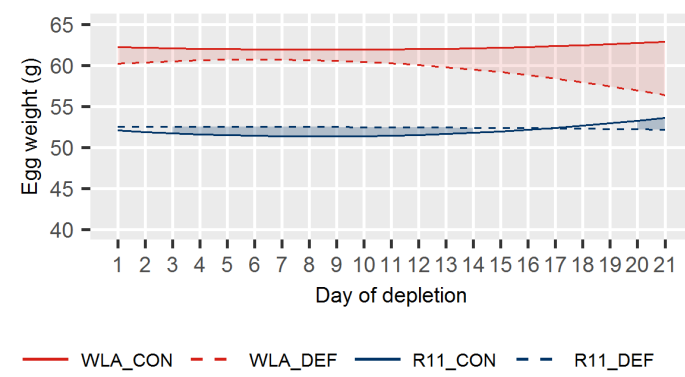

D1

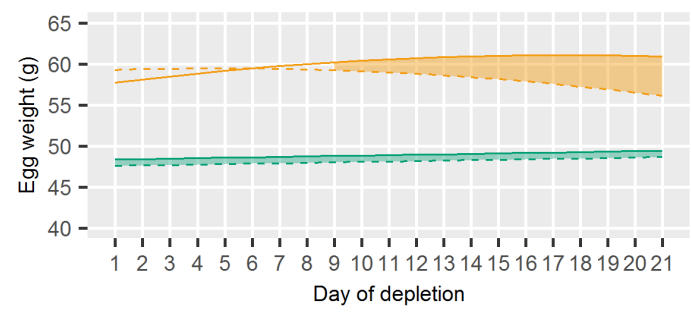

D2

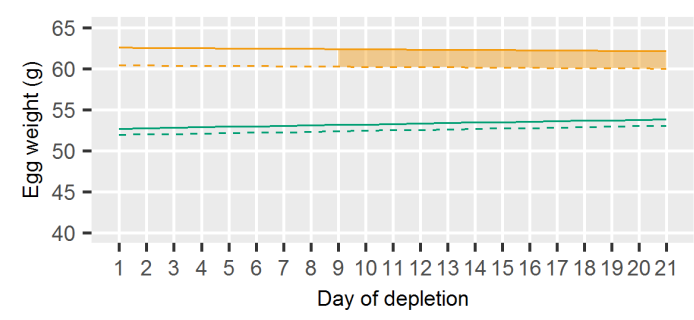

D3

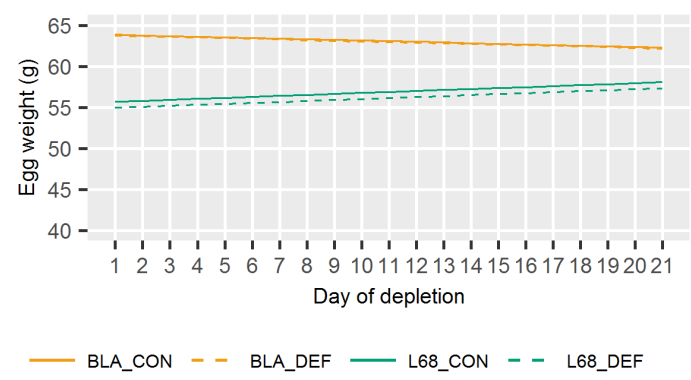

Figure 3.3: Least squares means for egg weight in control (CON) and calcium (Ca) deficient (DEF) groups of four layer lines (WLA, R11, BLA, L68) during periods of Ca depletion (D1, D2, D3). The filled in areas indicate when both dietary groups of the lines differ significantly at $p<0.05$. 
D1

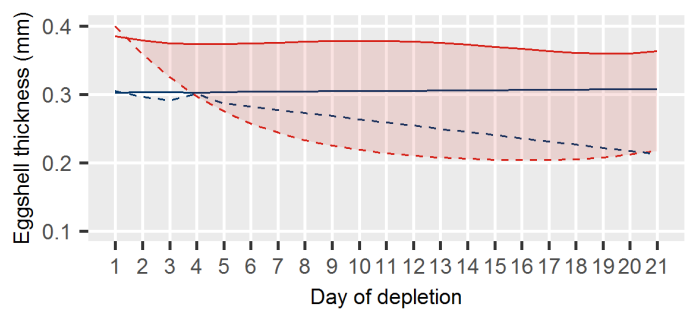

D2

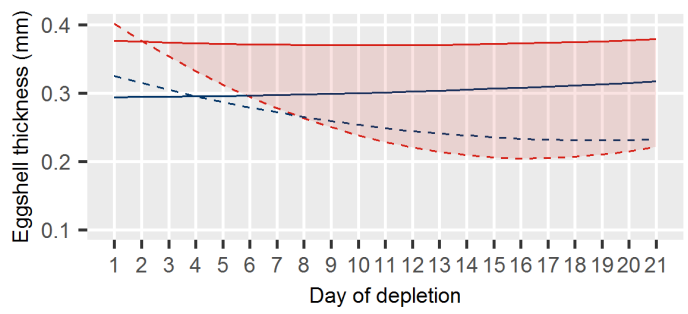

D3

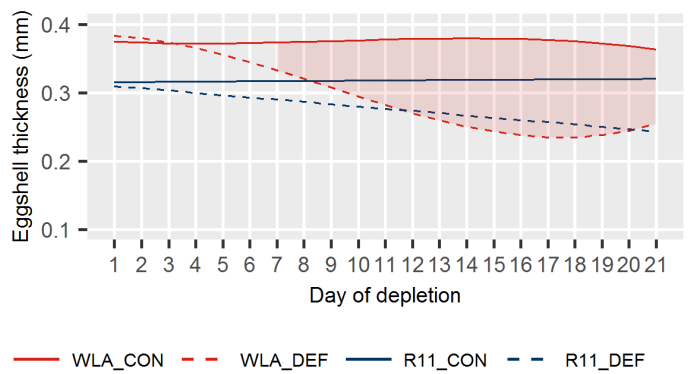

D1

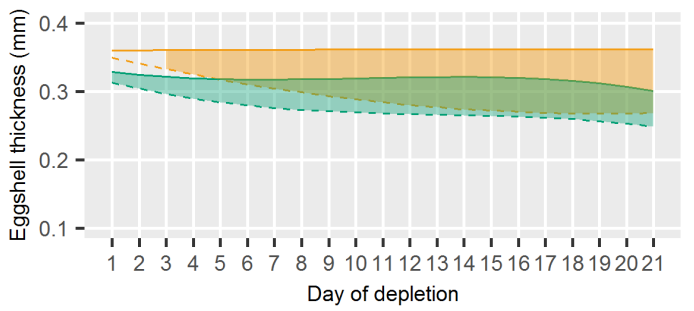

D2

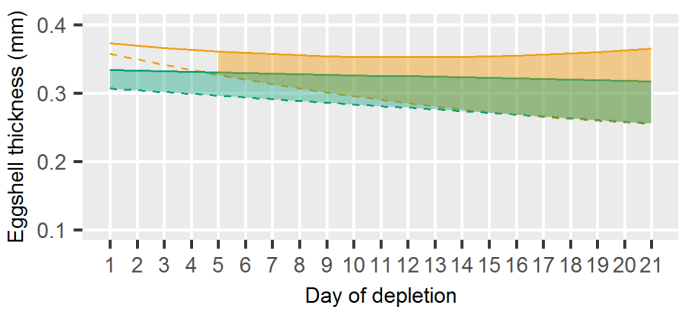

D3

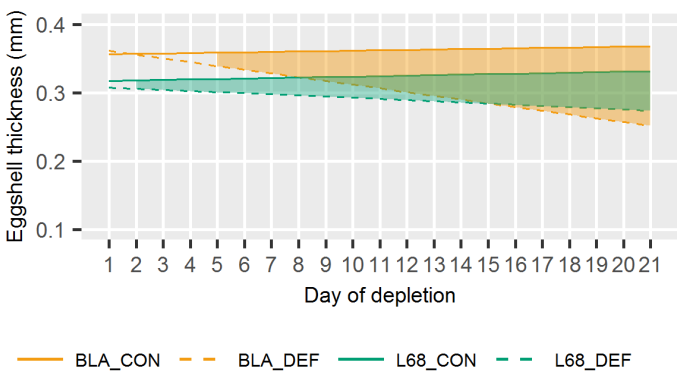

Figure 3.4: Least squares means for eggshell thickness in control (CON) and calcium ( $\mathrm{Ca}$ ) deficient (DEF) groups of four layer lines (WLA, R11, BLA, L68) during periods of Ca depletion (D1, D2, D3). The filled in areas indicate when both dietary groups of the lines differ significantly at $p<0.05$. 
D1

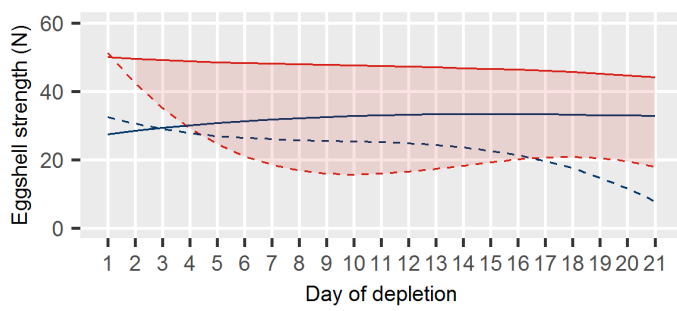

D2

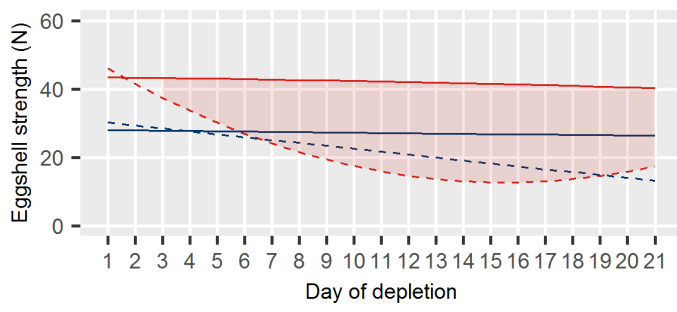

D3

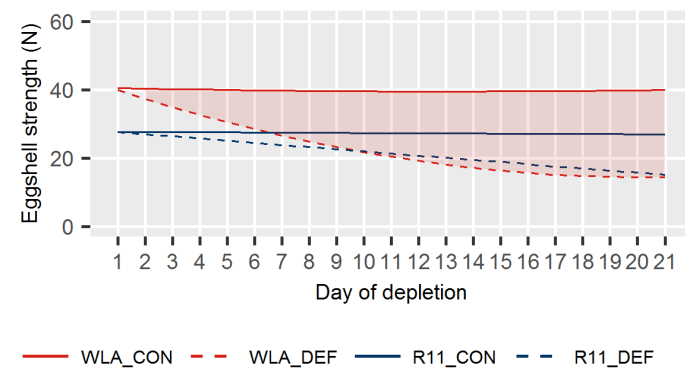

D1

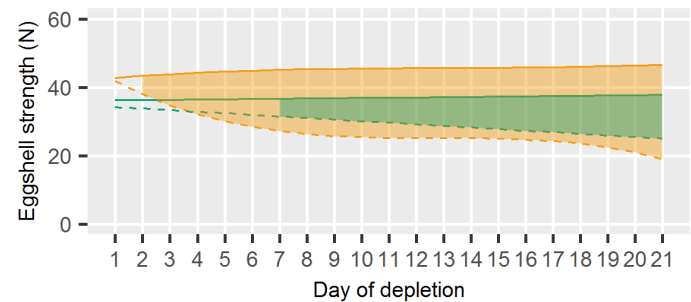

$\mathrm{D} 2$

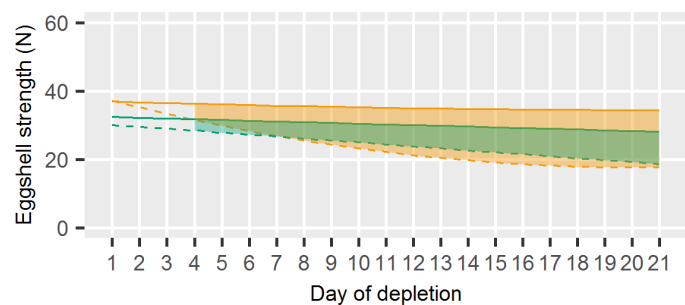

D3

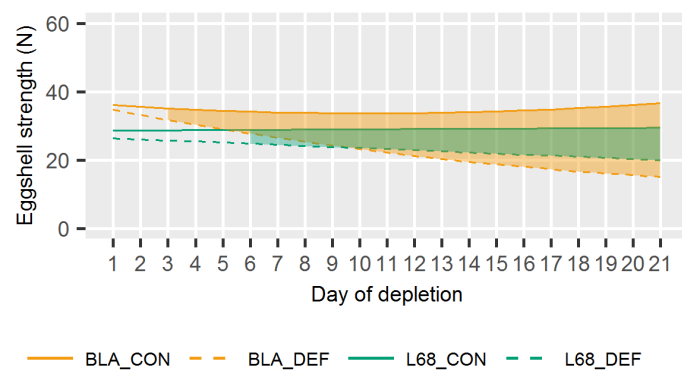

Figure 3.5: Least squares means for eggshell breaking strength in control (CON) and calcium ( $\mathrm{Ca}$ ) deficient (DEF) groups of four layer lines (WLA, R11, BLA, L68) during periods of Ca depletion (D1, D2, D3). The filled in areas indicate when both dietary groups of the lines differ significantly at $p<0.05$.

No significant differences in egg quality were observed between the two dietary groups within each of the layer lines WLA, R11 and BLA at the end of the periods with a sufficient Ca supply, i.e., at the end of the periods Pre, R1 and R2 (Supplementary Table S3.4). Thus, egg quality during periods D2 and D3 has not been affected by prior depletions, suggesting a recovery from restricted Ca supply. Only in line L68, rather small but significant differences in eggshell weight and eggshell thickness were observed in period R1. Whether this represents an aftereffect of period D1 cannot be ruled out, but it seems rather unlikely, since no differences occurred in both the Pre and R2 periods. 


\subsection{Body Weight}

Figure 3.6 illustrates the body weight prior and after the depletion periods according to model (2). Within layer lines and over all time points, the ANOVA revealed a significant dietary effect on the body weight (WLA: $p<0.001$; R11: $p<0.0001$; L68: $p=0.0381$ ). In contrast, no dietary effect was found for line $\operatorname{BLA}(p=0.7457)$. Significant body weight reduction was only observed in the DEF groups of the white-egg lines, whereas no weight changes were evident in the brown-egg lines. While the dietary groups of line R11 differed only in period D1, the DEF group of line WLA had a significant weight reduction in all depletion periods suggesting a distinct response to the $\mathrm{Ca}$ depletion. However, the lines fully recovered from this, as no significant differences between the body weight values at the end of the periods Pre, R1 and R2 were found.
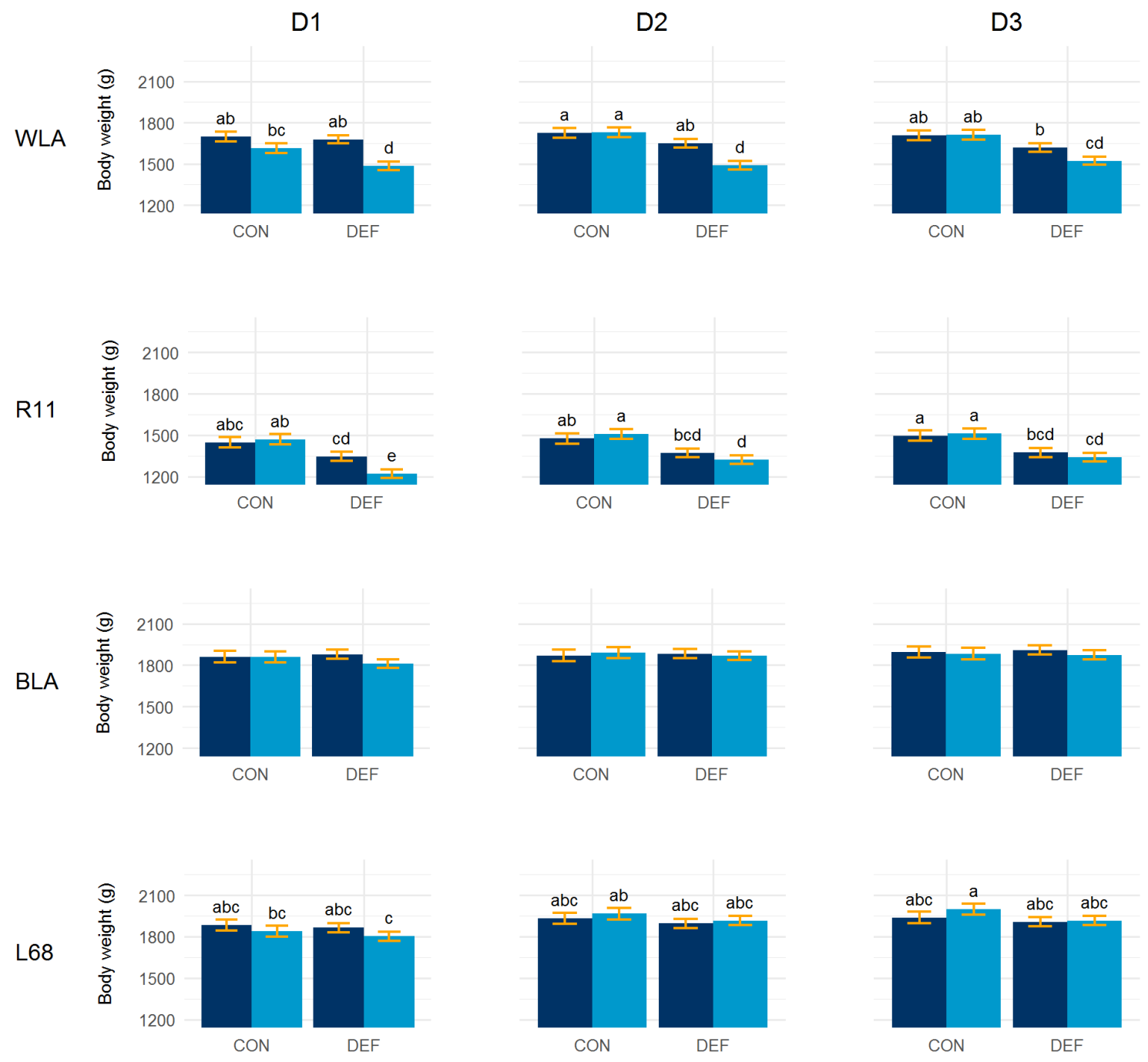

Prior Ca depletion

After Ca depletion

Figure 3.6: Least squares means \pm standard errors for body weight prior and after calcium $(\mathrm{Ca})$ depletion during the three restriction periods (D1, D2, D3), in control (CON) and Ca deficient (DEF) groups of four layer lines (WLA, R11, BLA, L68). DEF groups: $n=22$; CON groups: $n=11$. ${ }^{\mathrm{a}, \mathrm{b}, \mathrm{c}, \mathrm{d}, \mathrm{e}}$ means with different letters within layer lines differ significantly at $p<0.05$. 


\subsection{Feed Consumption}

The feed consumption for the WLA/L68 or BLA/R11 combination is shown in the Supplementary Table S3.3. Overall, the feed consumption ranged between $100 \mathrm{~g}$ and $120 \mathrm{~g}$ per animal and day. Apart from certain general fluctuations, the descriptive analysis suggested a reduced feed consumption of the DEF groups during all depletion periods, and this was reversed in the following recovery phases.

\subsection{Bone Characteristics}

The LSM of examined bone characteristics are shown in Figure 3.7. All bone parameters were significantly influenced by the layer line $(p<0.0001)$. The breaking strength, radio density, weight and cortical area of the tibiotarsus $(p<0.0001)$ as well as the breaking strength $(p<0.0001)$ and radio density $(p=0.0193)$ of the humerus were significantly influenced by the dietary treatment. The layer line by diet interaction was only significant for the breaking strength $(p=0.0218)$ and cortical area $(p=0.0018)$ of the tibiotarsus. With the exception of the humerus in line L68, bone breaking strength was significantly decreased in the DEF groups of all layer lines. The comparison of means further showed that radio density was only affected in the tibiotarsus, where the DEF groups possessed significantly lower bone density. The DEF groups of the white-egg lines WLA and R11 showed significantly declined cortical area of the tibiotarsus, while for both brown layers the difference was rather small and not significant. The $\mathrm{Ca}$ deficit led to a slight weight reduction of the tibiotarsus in all lines, which was only significant in line L68.

Results of post mortem examination of the keel bones are shown in the Supplementary Figure S3.2. Only in the DEF group of line R11 was the proportion of hens with at least one fracture significantly higher than in the CON group. The dietary groups of the other lines did not differ significantly regarding the occurrence of keel bone fractures. 
A

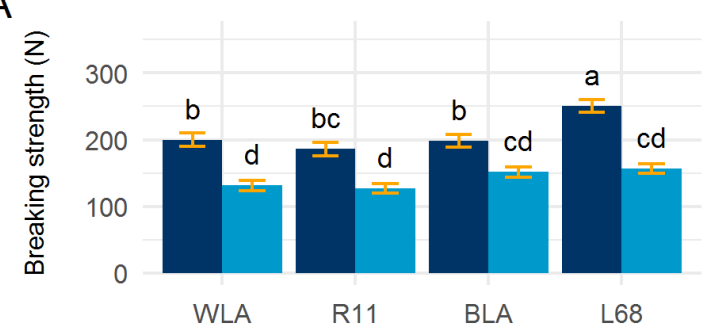

C

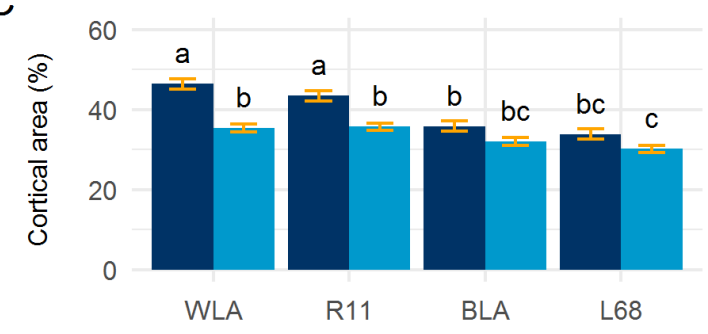

$\mathrm{E}$

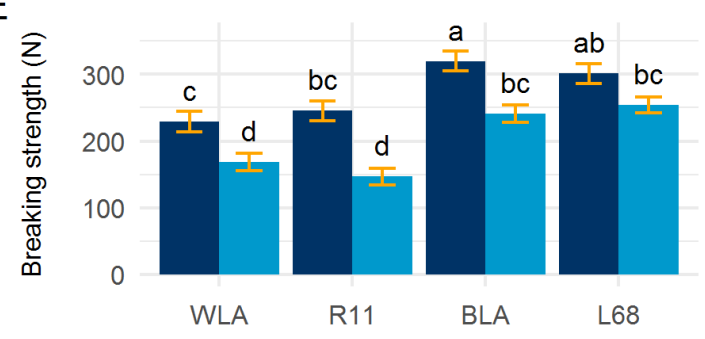

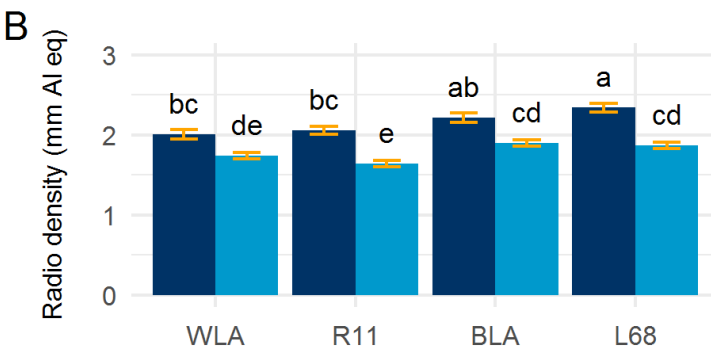

D

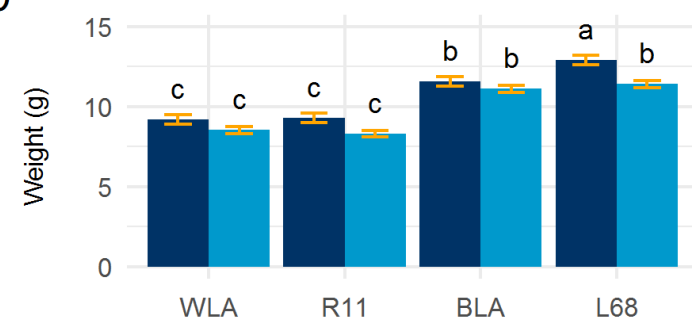

$\mathrm{F}$

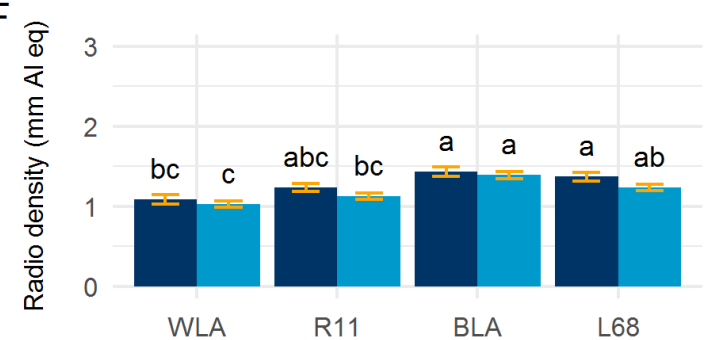

CON DEF

Figure 3.7: Least squares means \pm standard errors for $(\mathbf{A})$ bone breaking strength, $(\mathbf{B})$ radio density, (C) cortical area and (D) weight of the tibiotarsus; (E) bone breaking strength and $(\mathbf{F})$ radio density of the humerus in control (CON) and calcium deficient (DEF) groups of four layer lines (WLA, R11, BLA, L68). DEF groups: $n=22$; CON groups: $n=11$. $\mathrm{a}, \mathrm{b}, \mathrm{c}, \mathrm{d}, \mathrm{e}$ means with different letters differ significantly at $p<0.05$.

\section{Discussion}

Considerable response to $\mathrm{Ca}$ depletion was observed among the layer lines. Our results support the findings of previous studies, in which dietary Ca restriction led to marked and sudden reduction of egg production [30-32]. Consistent with the literature, we also found that hypocalcaemia resulted in progressive reduction of eggshell production [32-34]. In line with Jiang et al. [35], our study showed that decreased eggshell quality leading to increasing incidence of egg breakages and defects was most likely the result of an inadequate Ca supply.

In contrast to Gilbert and Blair [30] and Luck and Scanes [36], who fed a diet of 0.05\% Ca for six weeks and $0.03 \%$ Ca for three weeks, respectively, no evidence of cessation of laying activity was observed. A possible explanation for this might be that only drastically reduced Ca contents cause a suspension, while minor depletions, like in our case, merely lead to a performance decline $[30,37]$.

Although all lines showed a certain performance depression, there were differences between 
the layer lines. Here, the white-egg lines seem to have been more sensitive to the Ca depletion, as they showed not only a greater drop in egg production, but also a higher proportion of defective eggs reflecting impaired eggshell quality. Conversely, despite the same dietary stress, the brown-egg lines retained a higher proportion of intact eggs, possibly because their skeletal system was a relatively larger Ca reservoir compared to the white-egg lines. Moreover, there was evidence that within the phylogenetic groups, a greater decline in egg production and quality occurred in the high performing lines. For example, eggshell quality traits were more decreased in the high performing WLA and BLA lines than in their moderately performing counterparts.

We observed substantial recovery in all layer lines after returning to the adequate Ca supply. Our results therefore indicate that the physiological stress induced by the administration of $1.09 \%$ Ca provoked adaptation response but did not cause permanent impairment of the hens' performance. This is in accordance with previous studies, as Summers et al. [31] found significantly heavier eggs with stabilized eggshells after changing from a previous 28-day supply of $1.50 \%$ Ca to $2.96 \%$ Ca. Immediate improvement, namely increased eggshell strength and laying performance, was also reported for repeated eight-week periods of Ca depletions [32].

The Ca deficiency led to a decrease in body weight and tended to reduce feed consumption. While a tendency of lower feed intake was observed in all DEF groups, significant body weight reduction only occurred in the white-egg lines. This may reflect phylogenetic differences. There seems to be a consensus that Ca deficiency leads to reduced feed intake [31, 32, 38]. In contrast, reports on body weight are inconsistent. Different studies have shown a decreasing [34], increasing [39] or even missing effect of diet on body weight [40]. Irrespective of the underlying mechanism, the body weight of the WLA and R11 hens recovered each time after reconversion to adequate Ca supply.

We observed a significant decrease in bone breaking strength and, to some extent, radio density, which is in accordance with previous studies [32, 38, 41]. However, our investigations revealed layer-line-specific differences. This especially applied to the white-egg lines, both of which showed a significant degradation of cortical bone tissue. While the medullary $\mathrm{Ca}$ reserves were sufficient to buffer temporary $\mathrm{Ca}$ fluctuations, structural bone, i.e., cortical and trabecular bone, was demineralized during prolonged Ca reduction [4, 42]. Cortical bone resorption therefore suggests that the medullary Ca reservoir was insufficient in the WLA and R11 lines. The lines BLA and L68, on the other hand, had larger and thicker bones [22], which probably also had a higher absolute medullary content that provided sufficient $\mathrm{Ca}$ so that no cortical bone had to be resorbed. Therefore, the brown-egg lines probably had a higher capacity to tolerate $\mathrm{Ca}$ depletion thus reflecting a phylogenetic component. That the bone breaking strength was equally impaired in both phylogenetic groups emphasized that medullary bone contributed to overall fracture resistance $[8,43]$.

Taken together, $\mathrm{Ca}$ depletion caused both decreased eggshell production and increased bone demineralization. Given the ongoing debate about mismatched resource allocation, according to which, egg production is prioritized [19,44], our results may reflect the hens' attempt to maintain reproductive performance at the expense of bone stability. Contrary to our assumptions, this was the case for all layer lines. However, the response to the Ca deficit was differently pronounced, which possibly represented the line-specific adaptation potential of the layer lines examined here. For this, lines WLA and L68 responded most differently, as the Ca restriction had the most striking effects on WLA hens. On the other hand, only 
minor effects were observed for line L68, but this may have been caused by a lower Ca demand in general. Despite this line-specificity, there is evidence that the hens responded differently depending on their phylogenetic origin.

While the present study phenotypically focuses mainly on egg production traits and bone characteristics, further studies at the molecular level may help to characterize the adaptation response and explain the differences between the layer lines observed in the current experiment. Here, the description of blood parameters relevant for $\mathrm{Ca}$ homeostasis, such as ionized $\mathrm{Ca}$, total blood Ca, vitamin D3 and phosphorus, and the expression level of epithelial Ca transport proteins may be used for a more comprehensive characterization of the adaptation response. In a follow-up study, the use of single cage housing instead of a floor management system would allow the administration of $\mathrm{Ca}$ restrictions adapted to the egg production of the individual layer lines. Moreover, cage housing would avoid the hens eating eggs, which, although not observed in the present study, could lead to a bias in the data.

\section{Conclusions}

In this study, we characterized the adaptation response of genetically divergent chicken layer lines to repeated transient periods of calcium ( $\mathrm{Ca}$ ) depletion. It could be shown that laying hens apparently compensate for a temporary lack of $\mathrm{Ca}$ in the characteristics studied, albeit in different ways. Contrary to our hypothesis, our results did not indicate a major influence from selection for high egg numbers on the response to Ca depletion. Although layer-line-specific responses were observed, overall, the phylogenetic origin tended to be one of the determining factors with the brown-egg lines showing a higher tolerance to the $\mathrm{Ca}$ deficit. This was probably due to a more favorable body constitution in which the skeletal system was able to provide a higher amount of $\mathrm{Ca}$ without severe health restrictions. It seems essential to maintain the hens' adaptability to cope with changing or disadvantageous environmental conditions. This inevitably requires the preservation of genetic variation for adaptive performance.

Author Contributions: Conceptualization, C.H., M.R.W. and S.W.; formal analysis, S.J., U.B. and A.R.S.; funding acquisition, M.R.W. and S.W.; investigation, S.J. and M.B.; resources, I.H.; supervision, M.R.W. and S.W.; writing-original draft preparation, S.J.; writing-review and editing, S.J., M.B., U.B., C.H., I.H., S.P., A.R.S., A.W., M.R.W. and S.W. All authors have read and agreed to the published version of the manuscript.

Funding: This research was funded by the H. Wilhelm Schaumann Foundation, Hamburg (Germany).

Acknowledgments: The authors like to thank the experimental research station of the Friedrich-Loeffler-Institut for taking care of the animals. The assistance in data collection by the technical and laboratory staff of the abovementioned institutes is greatly appreciated. We thank Daniel Mörlein (Chair Quality of Animal Products, University of Göttingen) for providing of measuring devices.

Conflicts of Interest: The authors declare no conflict of interest. 


\section{References}

[1] Preisinger, R. Innovative layer genetics to handle global challenges in egg production. $\mathrm{Br}$. Poult. Sci. 2018. 59, 1-6.

[2] Roberts, J. R. Factors affecting egg internal quality and egg shell quality in laying hens. J. Poult. Sci. 2004. 41, 161-177.

[3] Bar, A. Calcium transport in strongly calcifying laying birds: Mechanisms and regulation. Comp. Biochem. Physiol. 2009. 152A, 447-469.

[4] Dacke, C. G., Arkle, S., Cook, D. J., Wormstone, I. M., Jones, S., Zaidi, M., Bascal, Z. A. Medullary bone and avian calcium regulation. J. Exp. Biol. 1993. 184, 63-88.

[5] Kim, W. K., Donalson, L. M., Bloomfield, S. A., Hogan, H. A., Kubena, L. F., Nisbet, D. J., Ricke, S. C. Molt Performance and bone density of cortical, medullary, and cancellous bone in laying hens during feed restriction or alfalfa-based feed molt. Poult. Sci. 2007. 86, 1821-1830.

[6] Whitehead, C. C. Overview of bone biology in the egg-laying hen. Poult. Sci. 2004. 83, 193-199.

[7] Wilson, S., Thorp, B. H. Estrogen and cancellous bone loss in the fowl. Calcif. Tissue Int. 1998. 62, 506-511.

[8] Whitehead, C. C., Fleming, R. H. Osteoporosis in cage layers. Poult. Sci. 2000. 79, 1033-1041.

[9] Fleming, R. H., McCormack, H. A., McTeir, L., Whitehead, C. C. Relationships between genetic, environmental and nutritional factors influencing osteoporosis in laying hens. $\mathrm{Br}$. Poult. Sci. 2006. 47, 742-755.

[10] Webster, A. B. Welfare implications of avian osteoporosis. Poult. Sci. 2004. 83, 184-192.

[11] Petrik, M. T., Guerin, M. T., Widowski, T. M. On-farm comparison of keel fracture prevalence and other welfare indicators in conventional cage and floor-housed laying hens in Ontario, Canada. Poult. Sci. 2015. 94, 579-585.

[12] Sandilands, V. The laying hen and bone fractures. Vet. Rec. 2011. 169, 411.

[13] Nasr, M. A. F., Nicol, C. J., Murrell, J. C. Do laying hens with keel bone fractures experience pain? PLoS One 2012. 7, e42420.

[14] Riber, A. B., Casey-Trott, T. M., Herskin, M. S. The influence of keel bone damage on welfare of laying hens. Front. Vet. Sci. 2018. 5, 6.

[15] Rauw, W. M., Kanis, E., Noordhuizen-Stassen, E. N., Grommers, F. J. Undesirable side effects of selection for high production efficiency in farm animals: a review. Livest. Prod. Sci. 1998. $56,15-33$.

[16] Glazier, D. S. Resource allocation patterns in Resource allocation theory applied to farm animal production. (Ed.: Rauw, W. M.). CABI Publishing. Wallingford, Oxfordshire, UK. 2008, pp. 22-43.

[17] Van der Waaij, E. H. A resource allocation model describing consequences of artificial selection under metabolic stress. J. Anim. Sci. 2004. 82, 973-981.

[18] Mirkena, T., Duguma, G., Haile, A., Tibbo, M., Okeyo, A. M., Wurzinger, M., Sölkner, J. Genetics of adaptation in domestic farm animals: A review. Livest. Sci. 2010. 132, 1-12.

[19] Huber, K. Invited review: resource allocation mismatch as pathway to disproportionate growth in farm animals - prerequisite for a disturbed health. Animal 2018. 12, 528-536.

[20] Tixier-Boichard, M., Bed'hom, B., Rognon, X. Chicken domestication: From archeology to genomics. C. R. Biol. 2011. 334, 197-204. 
[21] Malomane, D. K., Simianer, H., Weigend, A., Reimer, C., Schmitt, A. O., Weigend, S. The SYNBREED chicken diversity panel: a global resource to assess chicken diversity at high genomic resolution. BMC Genomics 2019. 20, 345.

[22] Jansen, S., Baulain, U., Habig, C., Weigend, A., Halle, I., Scholz, A. M., Simianer, H., Sharifi, A. R., Weigend, S. Relationship between bone stability and egg production in genetically divergent chicken layer lines. Animals 2020. 10, 850.

[23] Lieboldt, M.-A., Halle, I., Frahm, J., Schrader, L., Baulain, U., Henning, M., Preisinger, R., Dänicke, S., Weigend, S. Phylogenic versus selection effects on growth development, egg laying and egg quality in purebred laying hens. Eur. Poult. Sci. 2015. 79.

[24] Dudde, A., Weigend, S., Krause, E. T., Jansen, S., Habig, C., Schrader, L. Chickens in motion: Effects of egg production level and pen size on the motor abilities and bone stability of laying hens (Gallus gallus forma domestica). Appl. Anim. Behav. Sci. 2020. 227, 104998.

[25] Icken, W., Cavero, D., Schmutz, M., Preisinger, R. New phenotypes for new breeding goals in layers. Worlds Poult. Sci. J. 2012. 68, 387-400.

[26] NRC. Nutrient Requirements of Poultry. 9th. Natl. Acad. Press. Washington, DC, USA. 1994, p. 176.

[27] Eusemann, B. K., Patt, A., Schrader, L., Weigend, S., Thöne-Reineke, C., Petow, S. The role of egg production in the etiology of keel bone damage in laying hens. Front. Vet. Sci. 2020. 7, 81 .

[28] Habig, C., Baulain, U., Henning, M., Scholz, A. M., Sharifi, A. R., Janisch, S., Simianer, H., Weigend, S. How bone stability in laying hens is affected by phylogenetic background and performance level. Eur. Poult. Sci. 2017. 81.

[29] Littell, R. C., Milliken, G. A., Stroup, W. W., Wolfinger, R. D., Schabenberger, O. SAS for Mixed Models. 2nd Ed. SAS Institute Inc. Cary, NC, USA. 2006.

[30] Gilbert, A. B., Blair, R. A comparison of the effects of two low-calcium diets on egg production in the domestic fowl. Br. Poult. Sci. 1975. 16, 547-552.

[31] Summers, J. D., Grandhi, R., Leeson, S. Calcium and phosphorus requirements of the laying hen. Poult. Sci. 1976. 55, 402-413.

[32] Mehring Jr, A. L., Titus, H. W. The effects of low levels of calcium in the diet of laying chickens. Poult. Sci. 1964. 43, 1405-1414.

[33] Clunies, M., Emslie, J., Leeson, S. Effect of dietary calcium level on medullary bone calcium reserves and shell weight of Leghorn hens. Poult. Sci. 1992. 71, 1348-1356.

[34] Keshavarz, K. The effect of variation of calcium intake on production performance and shell quality. Poult. Sci. 1986. 65, 2120-2125.

[35] Jiang, S., Cui, L., Shi, C., Ke, X., Luo, J., Hou, J. Effects of dietary energy and calcium levels on performance, egg shell quality and bone metabolism in hens. Vet. J. 2013. 198, 252-258.

[36] Luck, M. R., Scanes, C. G. The relationship between reproductive activity and blood calcium in the calcium-deficient hen. Br. Poult. Sci. 1979. 20, 559-564.

[37] Bar, A., Rosenberg, J., Hurwitz, S. The lack of relationships between vitamin D3 metabolites and calcium-binding protein in the eggshell gland of laying birds. Comp. Biochem. Physiol. 1984. 78B, 75-79.

[38] Ruschkowski, S. R., Hart, L. E. lonic and endocrine characteristics of reproductive failure in calcium-deficient and vitamin D-deficient laying hens. Poult. Sci. 1992. 71, 1722-1732.

[39] Roland, D. A., Farmer, M., Marple, D. Calcium and its relationship to excess feed consumption, body weight, egg Size, fat deposition, shell quality, and fatty liver hemorrhagic syndrome. Poult. Sci. 1985. 64, 2341-2350. 
[40] Schreiweis, M. A., Orban, J. I., Ledur, M. C., Hester, P. Y. The use of densitometry to detect differences in bone mineral density and content of live White Leghorns fed varying levels of dietary calcium. Poult. Sci. 2003. 82, 1292-1301.

[41] Elaroussi, M. A., Forte, L. R., Eber, S. L., Biellier, H. V. Calcium homeostasis in the laying hen.: 1. age and dietary calcium effects. Poult. Sci. 1994. 73, 1581-1589.

[42] Zambonin Zallone, A., Mueller, W. J. Medullary bone of laying hens during calcium depletion and repletion. Calcif. Tissue Res. 1969. 4, 136-146.

[43] Dacke, C. G., Sugiyama, T., Gay, C. V. The role of hormones in the regulation of bone turnover and eggshell calcification in Sturkie's Avian Physiology. (Ed.: Scanes, C. G.). Academic Press. San Diego, CA, USA. 2015, pp. 549-575.

[44] Glazier, D. S. Trade-offs in Resource allocation theory applied to farm animal production. (Ed.: Rauw, W. M.). CABI Publishing. Wallingford, Oxfordshire, UK. 2008, pp. 44-60. 


\section{Supplementary Materials}

D1

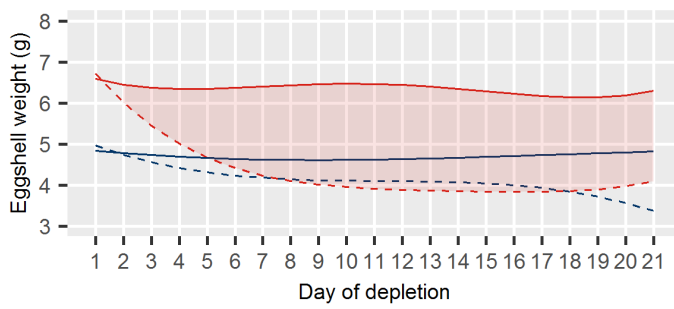

D2

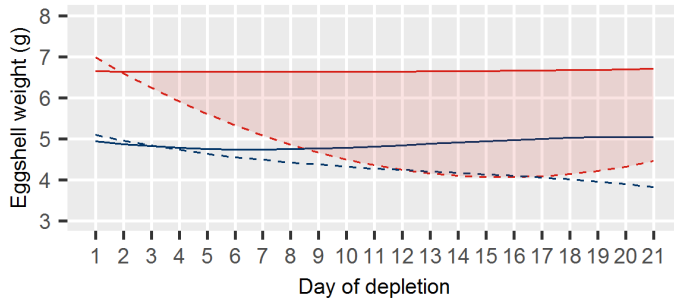

D3

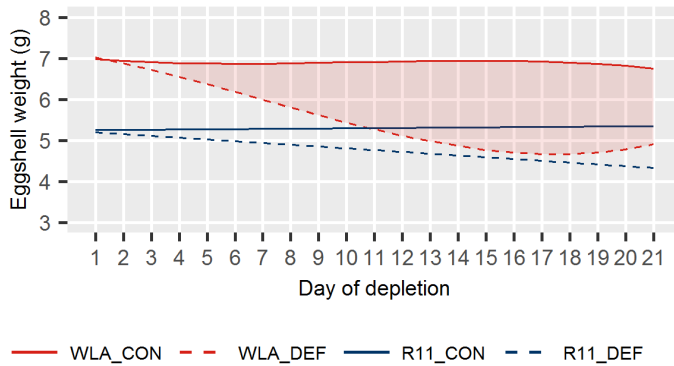

D1

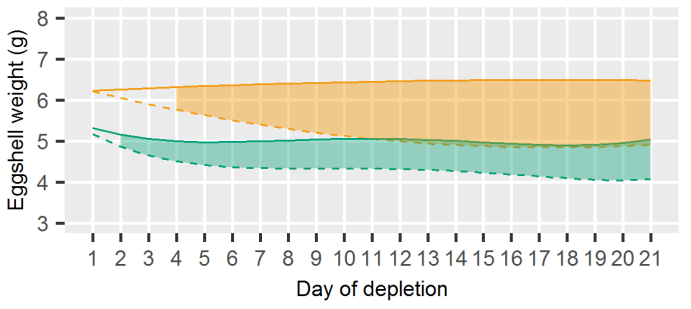

D2

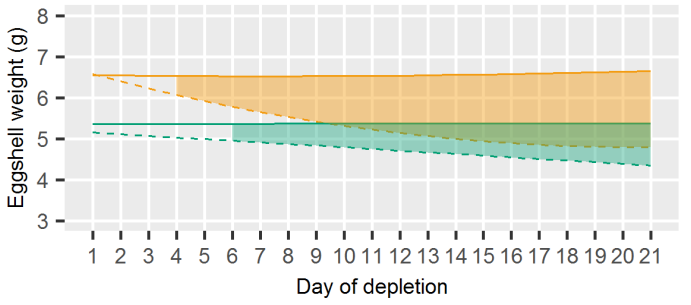

D3

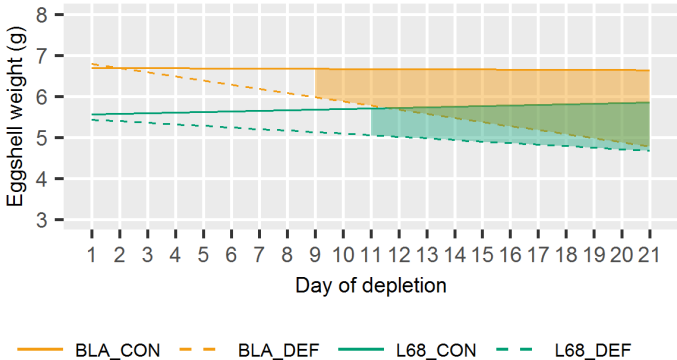

Figure S3.1: Least squares means for eggshell weight in control (CON) and calcium deficient (DEF) groups of four layer lines (WLA, R11, BLA, L68) during periods of calcium depletion (D1, D2, D3). The filled in areas indicate when both dietary groups of the lines differ significantly at $p<0.05$. 


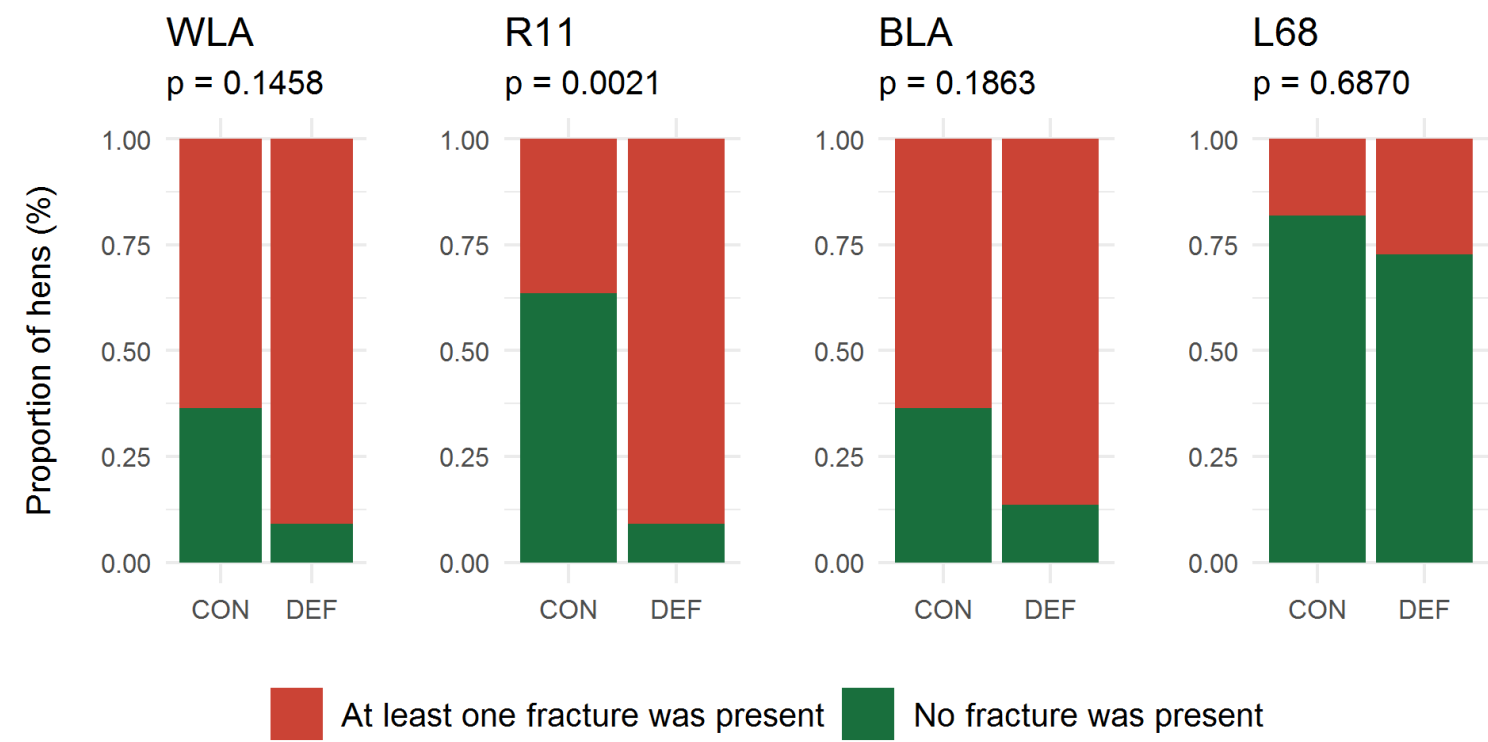

Figure S3.2: Occurrence of keel bone fractures in control (CON) and calcium deficient (DEF) groups of four layer lines (WLA, R11, BLA, L68). Each bar represents the total amount of examined keel bones of one layer line $\times$ diet combination (Fisher's exact test, $p<0.05)$.

Table S3.1: Light program.

\begin{tabular}{ccccc}
\hline $\begin{array}{c}\text { Week of } \\
\text { age }\end{array}$ & \multicolumn{2}{c}{ Time } & $\begin{array}{c}\text { Day length } \\
\text { [h] }\end{array}$ & $\begin{array}{c}\text { Light intensity } \\
\text { [Lux] }\end{array}$ \\
\hline Day 1 & - & - & 24.0 & 20.0 \\
1 & $4: 00 \mathrm{am}$ & $7: 00 \mathrm{pm}$ & 15.0 & 20.0 \\
2 & $4: 30 \mathrm{am}$ & $7: 00 \mathrm{pm}$ & 14.5 & 20.0 \\
3 & $5: 30 \mathrm{am}$ & $7: 00 \mathrm{pm}$ & 13.5 & 20.0 \\
4 & $6: 00 \mathrm{am}$ & $7: 00 \mathrm{pm}$ & 13.0 & 20.0 \\
5 & $7: 00 \mathrm{am}$ & $7: 00 \mathrm{pm}$ & 12.0 & 20.0 \\
6 & $7: 00 \mathrm{am}$ & $6: 00 \mathrm{pm}$ & 11.0 & 10.0 \\
7 & $7: 00 \mathrm{am}$ & $5: 00 \mathrm{pm}$ & 10.0 & 10.0 \\
8 & $7: 30 \mathrm{am}$ & $4: 30 \mathrm{pm}$ & 9.0 & 10.0 \\
9 & $7: 30 \mathrm{am}$ & $3: 30 \mathrm{pm}$ & 8.0 & 10.0 \\
10 & $7: 30 \mathrm{am}$ & $3: 30 \mathrm{pm}$ & 8.0 & 10.0 \\
11 & $7: 30 \mathrm{am}$ & $3: 30 \mathrm{pm}$ & 8.0 & 10.0 \\
12 & $7: 30 \mathrm{am}$ & $3: 30 \mathrm{pm}$ & 8.0 & 10.0 \\
13 & $7: 30 \mathrm{am}$ & $3: 30 \mathrm{pm}$ & 8.0 & 10.0 \\
14 & $7: 30 \mathrm{am}$ & $3: 30 \mathrm{pm}$ & 8.0 & 10.0 \\
15 & $7: 30 \mathrm{am}$ & $3: 30 \mathrm{pm}$ & 8.0 & 10.0 \\
16 & $7: 30 \mathrm{am}$ & $3: 30 \mathrm{pm}$ & 8.0 & 10.0 \\
17 & $7: 00 \mathrm{am}$ & $3: 30 \mathrm{pm}$ & 8.5 & 10.0 \\
18 & $6: 30 \mathrm{am}$ & $3: 30 \mathrm{pm}$ & 9.0 & 10.0 \\
19 & $6: 30 \mathrm{am}$ & $4: 00 \mathrm{pm}$ & 9.5 & 10.0 \\
20 & $5: 30 \mathrm{am}$ & $4: 00 \mathrm{pm}$ & 10.5 & 10.0 \\
21 & $4: 30 \mathrm{am}$ & $4: 00 \mathrm{pm}$ & 11.5 & 10.0 \\
22 & $4: 00 \mathrm{am}$ & $4: 30 \mathrm{pm}$ & 12.5 & 10.0 \\
23 & $3: 30 \mathrm{am}$ & $5: 00 \mathrm{pm}$ & 13.5 & 10.0 \\
$24-52$ & $3: 30 \mathrm{am}$ & $5: 30 \mathrm{pm}$ & 14.0 & 10.0 \\
\hline
\end{tabular}


Table S3.2: Ingredients and nutrient composition of the layer diets.

\begin{tabular}{|c|c|c|c|}
\hline & Diet & $\begin{array}{l}\text { Adequate Calcium diet } \\
(\mathrm{Ca}+)\end{array}$ & $\begin{array}{c}\text { Low Calcium diet } \\
(\mathrm{Ca}-)\end{array}$ \\
\hline \multicolumn{4}{|l|}{ Ingredients (\%) } \\
\hline Wheat & & 39.74 & 36.81 \\
\hline Wheat bran & & - & 11.00 \\
\hline Corn & & 20.00 & 25.00 \\
\hline Soybean toasted & & 10.63 & - \\
\hline Soybean meal toasted & & 8.00 & 10.71 \\
\hline High protein soybean meal toasted & & 5.00 & 5.00 \\
\hline Lucerne pellets & & 2.44 & 5.58 \\
\hline Soybean oil & & 2.00 & 2.00 \\
\hline Calcium phosphate & & 2.46 & 1.79 \\
\hline Calcium carbonate & & 8.15 & 0.53 \\
\hline Sodium chloride & & 0.42 & 0.40 \\
\hline DL-Methionine & & 0.16 & 0.15 \\
\hline Lysine HCL & & - & 0.02 \\
\hline Premix $^{1}$ & & 1.00 & 1.00 \\
\hline \multicolumn{4}{|c|}{ Nutrient composition (on dry matter basis) } \\
\hline Crude protein $(\%)^{2}$ & & 17.10 & 16.60 \\
\hline Crude fat $(\%)^{2}$ & & 6.40 & 5.00 \\
\hline Starch $(\%)^{2}$ & & 38.20 & 42.70 \\
\hline Sucrose $(\%)^{2}$ & & 3.30 & 3.40 \\
\hline $\mathrm{AME}_{\mathrm{N}} / \mathrm{kg} \mathrm{DM}(\mathrm{MJ})^{3,4}$ & & 11.60 & 11.90 \\
\hline Calcium $(\%)^{2}$ & & 4.26 & 1.09 \\
\hline
\end{tabular}

1 Premix - hens: feed additives (per kg premix): Vitamin A, 1,000,000 IU; Vitamin D3, 250,000 IU; Vitamin E, 2,000 mg; Vitamin B1, $250 \mathrm{mg}$; Vitamin B2, $700 \mathrm{mg}$; Vitamin B6, $400 \mathrm{mg}$; Vitamin B12, 2,000 $\mu$ g; Vitamin K3, $400 \mathrm{mg}$; Nicotin amide, 4,000 mg; Calcium-D-pantothenate, 1,000 mg; Folic acid, $60 \mathrm{mg}$; Biotin, 2,500 $\mu \mathrm{g}$; Choline chloride, 40,000 mg; Fe, $4,000 \mathrm{mg} ; \mathrm{Cu}, 1,000 \mathrm{mg} ; \mathrm{Mn}, 10,000 \mathrm{mg} ; \mathrm{Zn}, 8,000 \mathrm{mg}$; I, $120 \mathrm{mg}$; Se, $25 \mathrm{mg}$; Co, $20.5 \mathrm{mg}$; Butylated hydroxy toluene $(\mathrm{BHT}), 12,500 \mathrm{mg}$; Beta-carotene, $400 \mathrm{mg}$; Canthaxanthin, $400 \mathrm{mg} ;{ }^{2}$ Analyzed; ${ }^{3}$ Calculated; ${ }^{4}$ Apparent metabolizable energy concentrations corrected to zero nitrogen balance $\left(\mathrm{AME}_{\mathrm{N}}\right)$, calculated according to the energy estimation equation of the World's Poultry Association (Vogt, 1986).

Table S3.3: Mean $(\bar{x})$ daily feed consumption (g) during periods of calcium depletion (D2, D3) and recovery $(\mathrm{R} 1, \mathrm{R} 2)$ in control (CON) and calcium deficient (DEF) groups of combinations of two layer lines each.

\begin{tabular}{lccccc}
\hline & \multicolumn{2}{c}{ WLA / L68 combination } & & \multicolumn{2}{c}{ BLA / R11 combination } \\
\cline { 2 - 3 } \cline { 5 - 6 } Period & CON & DEF & & CON & DEF \\
\hline D1 & 115.50 & 113.20 & & 121.80 & 101.20 \\
R1 & 115.80 & 114.90 & & 110.30 & 115.50 \\
D2 & 104.30 & 104.40 & & 110.70 & 101.00 \\
R2 & 119.30 & 123.90 & & 118.10 & 123.40 \\
D3 & 117.20 & 112.10 & & 121.20 & 107.90 \\
\hline
\end{tabular}


Table S3.4: Least squares means \pm standard errors for egg quality traits during the last three consecutive days of preliminary (Pre), first (R1) and second recovery period (R2) in control (CON) and calcium deficient (DEF) groups of four layer lines (WLA, R11, BLA, L68).

\begin{tabular}{|c|c|c|c|c|c|c|c|c|}
\hline \multirow[b]{2}{*}{ Period } & \multicolumn{2}{|c|}{ WLA } & \multicolumn{2}{|c|}{ R11 } & \multicolumn{2}{|c|}{ BLA } & \multicolumn{2}{|c|}{ L68 } \\
\hline & CON & DEF & CON & DEF & CON & DEF & CON & DEF \\
\hline \multicolumn{9}{|c|}{ Egg weight (g) } \\
\hline Pre & $59.16 \pm 0.87$ & $58.19 \pm 0.62$ & $46.13 \pm 0.42$ & $45.91 \pm 0.34$ & $58.83 \pm 0.86$ & $59.83 \pm 0.59$ & $47.72 \pm 0.69$ & $47.62 \pm 0.45$ \\
\hline $\mathrm{R} 1$ & $60.12 \pm 0.78$ & $60.65 \pm 0.50$ & $49.34 \pm 0.41$ & $49.18 \pm 0.30$ & $61.57 \pm 1.23$ & $60.36 \pm 0.83$ & $52.68 \pm 0.79$ & $51.47 \pm 0.49$ \\
\hline $\mathrm{R} 2$ & $59.43 \pm 0.80$ & $53.68 \pm 3.23$ & $51.79 \pm 1.00$ & $52.48 \pm 0.72$ & $62.30 \pm 2.45$ & $63.00 \pm 1.72$ & $51.79 \pm 1.00$ & $52.48 \pm 0.72$ \\
\hline \multicolumn{9}{|c|}{ Eggshell weight (g) } \\
\hline Pre & $6.65 \pm 0.12$ & $6.68 \pm 0.08$ & $4.63 \pm 0.08$ & $4.71 \pm 0.06$ & $6.20 \pm 0.13$ & $6.32 \pm 0.09$ & $4.77 \pm 0.17$ & $4.73 \pm 0.12$ \\
\hline $\mathrm{R} 1$ & $6.94 \pm 0.16$ & $7.08 \pm 0.11$ & $5.01 \pm 0.07$ & $5.28 \pm 0.06$ & $6.52 \pm 0.14$ & $6.63 \pm 0.10$ & $5.42 \pm 0.10^{\mathrm{a}}$ & $5.14 \pm 0.06^{b}$ \\
\hline $\mathrm{R} 2$ & $7.11 \pm 0.16$ & $7.14 \pm 0.11$ & $5.40 \pm 0.15$ & $5.60 \pm 0.11$ & $6.61 \pm 0.49$ & $6.87 \pm 0.35$ & $5.40 \pm 0.15$ & $5.60 \pm 0.11$ \\
\hline \multicolumn{9}{|c|}{ Eggshell thickness (mm) } \\
\hline Pre & $0.39 \pm 0.01$ & $0.39 \pm 0.01$ & $0.32 \pm 0.01$ & $0.31 \pm 0.01$ & $0.36 \pm 0.01$ & $0.37 \pm 0.01$ & $0.32 \pm 0.01$ & $0.31 \pm 0.01$ \\
\hline R1 & $0.39 \pm 0.01$ & $0.37 \pm 0.01$ & $0.32 \pm 0.01$ & $0.32 \pm 0.01$ & $0.36 \pm 0.01$ & $0.36 \pm 0.01$ & $0.33 \pm 0.01^{a}$ & $0.31 \pm 0.01^{b}$ \\
\hline $\mathrm{R} 2$ & $0.38 \pm 0.01$ & $0.39 \pm 0.01$ & $0.33 \pm 0.01$ & $0.33 \pm 0.01$ & $0.36 \pm 0.01$ & $0.37 \pm 0.01$ & $0.33 \pm 0.01$ & $0.33 \pm 0.01$ \\
\hline \multicolumn{9}{|c|}{ Eggshell breaking strength (N) } \\
\hline Pre & $49.26 \pm 1.89$ & $50.70 \pm 1.35$ & $34.36 \pm 1.30$ & $34.60 \pm 0.98$ & $44.12 \pm 1.72$ & $45.95 \pm 1.15$ & $38.05 \pm 2.67$ & $37.29 \pm 1.85$ \\
\hline $\mathrm{R} 1$ & $42.96 \pm 2.86$ & $43.70 \pm 1.91$ & $28.70 \pm 1.59$ & $29.89 \pm 1.26$ & $38.33 \pm 1.47$ & $38.78 \pm 0.99$ & $30.28 \pm 2.00$ & $29.91 \pm 1.26$ \\
\hline $\mathrm{R} 2$ & $37.97 \pm 2.41$ & $38.14 \pm 1.73$ & $25.64 \pm 3.18$ & $27.39 \pm 2.27$ & $31.60 \pm 2.67$ & $34.00 \pm 1.86$ & $25.64 \pm 3.18$ & $27.39 \pm 2.27$ \\
\hline
\end{tabular}

a,b Means with no common superscript differed significantly within each parameter, experimental period and layer line (Tukey's HSD-test, $p<0.05)$. 


\section{Identification and Functional Annotation of Genes Related to Bone Stability in Laying Hens Using Genome-wide Association Analyses}

Simon Jansen ${ }^{1}$, Ulrich Baulain ${ }^{1}$, Christin Habig ${ }^{1}$, Faisal Ramzan ${ }^{2}$, Jens Schauer ${ }^{1}$, Armin O. Schmitt ${ }^{2,3}$, Armin M. Scholz ${ }^{4}$, A. Reza Sharifi ${ }^{3,5}$, Annett Weigend ${ }^{1}$ and Steffen Weigend ${ }^{1,3}$

1 Institute of Farm Animal Genetics, Friedrich-Loeffler-Institut, 31535 Neustadt, Germany.

2 Breeding Informatics Group, Department of Animal Sciences, University of Göttingen, 37075 Göttingen, Germany.

3 Center for Integrated Breeding Research, University of Göttingen, 37075 Göttingen, Germany.

4 Livestock Center of the Faculty of Veterinary Medicine, Ludwig-Maximilians-University Munich, 85764 Oberschleißheim, Germany.

5 Animal Breeding and Genetics Group, Department of Animal Sciences, University of Göttingen, 37075 Göttingen, Germany.

Parts of this chapter have been published in Genes 2021, 12 (5): 702 https://doi.org/10.3390/genes12050702 


\section{Abstract}

Skeletal disorders, including fractures and osteoporosis, in laying hens cause major welfare and economic problems. Although genetics have been shown to play a key role in bone integrity, little is yet known about the underlying genetic architecture of the traits. This study aimed to identify genes associated with bone breaking strength and bone mineral density of the tibiotarsus and the humerus in laying hens. Potentially informative single nucleotide polymorphisms (SNP) were identified using both genome-wide association studies (GWAS) and Random Forests classification. We then searched for genes known to be related to bone stability in close proximity to the SNPs and identified 16 potential candidates. Some of them had human orthologues. Based on our findings, we can support the assumption that multiple genes determine bone strength, with each of them having a rather small effect, as illustrated by our SNP effect estimates. Furthermore, the enrichment analysis showed that some of these candidates are involved in metabolic pathways critical for bone integrity. In conclusion, the identified candidates represent genes that may play a role in the bone integrity of chickens. Although further studies are needed to determine causality, the genes reported here are promising in terms of alleviating bone disorders in laying hens.

Keywords: bone mineral density; bone breaking strength; gene set enrichment analysis; osteoporosis; Random Forests; single nucleotide polymorphism; skeletal integrity

\section{Introduction}

The very high incidence of skeletal disorders in laying hens, including brittle and fractured bones, is undoubtedly one of the most serious problems facing the egg production industry [1, 2]. Bone demineralisation associated with eggshell calcification favours the loss of structural bone tissue and ultimately predisposes the birds to osteoporosis in the course of the laying period [3, 4]. Besides dramatic effects on animal welfare [5-7], bone weakness also has an economic impact $[4,8]$. According to a widespread assumption, the reduction in bone stability is primarily the result of selection for high laying performance [9-11]. However, the role of genetic selection on egg production is now seen in a more differentiated view, with recent studies pointing to factors other than egg number alone [12-14].

In the urgently needed improvement of the skeletal health of laying hens, genetics play an important role alongside husbandry and feeding of the birds $[3,15,16]$. To date, a number of quantitative trait loci (QTL) have been mapped to skeletal traits in chickens [17-22]. Dunn et al. [23] discovered a QTL on chromosome 1 that was recently fine-mapped leading to the identification of a promising region around the cystathionine beta synthase gene associated with osteoporosis [24]. The discovery of candidate positions for bone integrity is inevitably linked to technical advances in genotyping and bioinformatics. Today, testing hundreds of thousands of single nucleotide polymorphisms (SNP) by means of genome-wide association studies (GWAS) has become common practice $[15,25,26]$.

Despite its widespread use, GWAS has some potential pitfalls. In addition to population stratification, these include the identification of gene loci with small effect sizes, which rarely 
reach the statistical significance level due to their low strength of association [27]. At this point, machine learning algorithms represent a promising advance. Several studies have demonstrated their potential in identifying genes with small effect sizes $[28,29]$. The Random Forests (RF) models in particular seem to have a great potential for analysing a large number of loci simultaneously and identifying corresponding associations [29-31]. Recently, this approach has been used to identify genes associated with eggshell strength [27].

The aim of the current study was to identify genomic positions associated with bone stability traits, i.e., breaking strength and mineral density of the tibiotarsus and the humerus, in laying hens. The animal model used comprised four layer lines that differed in their phylogenetic origin (brown-egg vs. white-egg layers) and their egg production level (high vs. moderately performing lines) [32]. Jansen et al. [14] have recently reported promising heritability estimates for bone traits in this set of populations, supporting the assumption of an inherited component of hens' susceptibility to osteoporosis. In the study reported here, we applied genome-wide association approaches to take a deeper look into the underlying genetic architecture of these hens. In addition to mixed linear model analysis, this also includes the adoption of RF-based feature selection in order to find potentially important SNPs. Subsequently, we performed a series of functional analyses including gene set enrichment analysis. Furthermore, SNP effects were estimated to confirm candidate genes known from the literature to be associated with bone metabolism.

\section{Materials and Methods}

\subsection{Ethical Note}

The present experiment was performed in accordance with the German Animal Welfare Law and approved by the Lower Saxony State Office for Consumer Protection and Food Safety (LAVES) (33.19-42502-04-15/1988).

\subsection{Population and Experimental Setup}

The population consisted of four purebred chicken layer lines (Gallus gallus domesticus), which are phylogenetically distinct (brown vs. white-egg lines). Within each of these phylogenetic groups, the two lines differed in terms of egg-laying rate (high vs. moderate performing lines) [32, 33]. The set of populations was previously subjected to phenotypic analysis and the estimation of genetic parameters [14]. The data set only comprised hens whose total egg number was within the line specific threefold interquartile range and who laid at least one egg from 67 to 69 weeks of age [14]. For the statistical analyses done in this study, we combined the four chicken lines into one set as described below.

For the current research, we used the bone breaking strength (BBS) and bone mineral density (BMD) measurements previously reported by Jansen et al. [14]. Briefly, BBS and BMD of the tibiotarsus and humerus were determined by the three-point bending test and dual-energy X-ray absorptiometry, respectively, using dissected bones after the hens were sacrificed at 69 weeks of age.

The experimental setup is shown in Figure 4.1. We applied two alternate approaches to identify genomic positions potentially associated with the given phenotypes: (i) GWAS and 
(ii) the machine learning-based approach of Random Forests. Subsequent functional analyses included gene set enrichment analysis and retrospective SNP effects analysis.

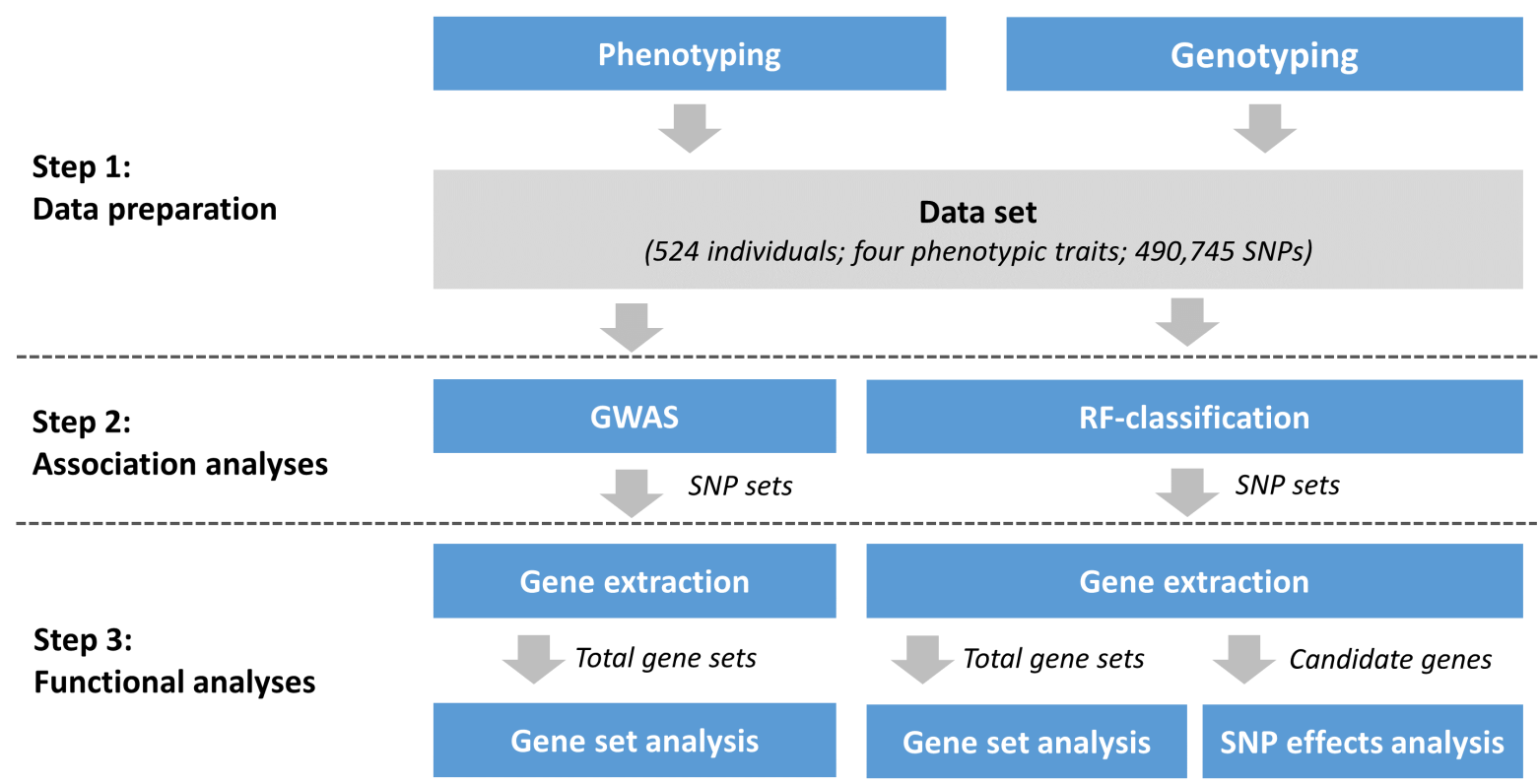

Figure 4.1: Schematic illustration of the study design. The data set included 524 laying hens phenotyped for bone stability traits. The corresponding genotypes included 490,745 SNP markers. Association analyses were performed applying both genome-wide association studies (GWAS) and Random Forests (RF) classification. Genes harbouring significant SNPs were extracted and screened for links to bone stability. Gene set analyses were performed considering all genes obtained from the GWAS or RF classification. Retrospectively, SNP effects were estimated for a subset of candidate genes identified in gene sets obtained from the RF classifier.

\subsection{Genotyping}

Initially deoxyribonucleic acid (DNA) samples from the hens and sires were extracted from blood samples. The hens were genotyped for 51,837 SNPs with a custom-made SNP array (Affymetrix Inc., Santa Clara, CA, USA). From the same chicken lines, in total 80 sires were genotyped for 580,961 SNP markers using the Affymetrix ${ }^{\circledR}$ Axiom ${ }^{\circledR}$ Genome-Wide Chicken Genotyping Array [34]. Quality control was applied to both data sets using the SNP \& Variation Suite (SVS) v8.9 [35]. We only considered SNPs from autosomal chromosomes 1 to 28. The genotypes were filtered for a SNP call rate of $\geq 99 \%$ and an animal call rate of $\geq 95 \%$. Furthermore, missing genotypes were imputed in a two-step procedure using BEAGLE 5.0 [36]. Initially, missing markers within the sire data set were imputed using the default settings. After this, the female genotypes were imputed from 37,606 SNPs left after quality control to 497,041 SNPs. Here, the sire genotypes served as a reference population and the effective population size was set to $n e=5,000$. After imputation, 524 hens and 497,041 SNPs remained, of which 490,745 SNPs were finally annotated using the genome assembly GRCg6a (galGal6) [37], with duplicated SNPs and those with ambiguous chromosome annotation being removed. 


\subsection{Association Analyses}

\subsubsection{Genome-wide Association Study}

For each of the phenotypic traits, i.e. BBS and BMD of the tibiotarsus and the humerus, a GWAS was performed in SVS applying a single-locus mixed linear model analysis. The statistical model was as follows:

$$
\gamma=X \beta+Z u+\varepsilon
$$

where $\gamma$ is a $n \times 1$ vector of phenotypic values for $n$ individuals; $X$ is a $n \times f$ matrix of fixed effects; $\beta$ is a $f \times 1$ vector of corresponding coefficients of the fixed effects; $Z$ is a $n \times t$ matrix of random additive genetic effects; $u$ is a $t \times 1$ vector of random additive genetic effects; and $\varepsilon$ is a vector of random residuals. The model considered the identity by state (IBS) kinship matrix and included the generation as fixed effect. For the latter, a considerable influence on the bone properties has been previously shown [14]. Multiple testing correction was performed by applying the false discovery rate (FDR) approach [38]. For the latter, cut-off for significance was set at $p \leq 0.05$, so that less than or equal to $5 \%$ of the significant SNPs are false positives.

\subsubsection{Random Forests Classification}

As an alternative to the GWAS, we applied the machine learning algorithm of Random Forests (RF) to identify SNPs associated with bone characteristics. Briefly, the RF algorithm constructs a multitude of classifying decision trees assigning importance values to each SNP, thus determining those SNPs that explain variation in the response variable [29]. As shown by Ramzan et al. [27], we performed SNP selection by applying the Boruta algorithm, which works as a wrapper around the classification algorithm [39]. This algorithm is based on the idea that an unimportant attribute is not more useful for classification than a random one. Hence, if an attribute shows lower importance than a random attribute, it can be deemed irrelevant. The second idea is that importance measures get more accurate with less irrelevant attributes, such that iteratively removing unimportant attributes increases the accuracy of the importance measure. The procedure of the algorithm is as follows: The data set is first expanded by adding shuffled copies of the original values of each SNP, called shadow attributes. RF classification is then applied iteratively, assigning a value to each SNP, which is considered as the importance of the SNP. At each iteration, SNPs whose importance is less than the best of their shadow attributes are removed.

We used the Python (v3.8.3) [40] implementation from Homola [41] that specifies the proportion of the shadow attributes by which a SNP has to be better in order to be selected as important. Embedded in the Boruta algorithm, the RF classification itself was carried out with the 'RandomForestRegressor' from the Scikit-learn package [42] using default settings. The parameter perc was set to 99 , representing a threshold of $99 \%$, as no SNP has been confirmed as important at the $100 \%$ level. RF classification was performed separately for each bone trait. The input file consisted of the SNP genotypes, coded as ' 0 ' (AA), '1' (AB), or '2' (BB), and the phenotypic values of the respective bone trait. To account for possible confounding effects due to population stratification, residuals representing adjusted phenotypes were analysed instead 
of the raw values [29]. The following model was used to estimate the residuals:

$$
\gamma_{i j k l}=\mu+G_{i}+L L_{j}+S_{k}+\varepsilon_{i j k l}
$$

where $\gamma_{i j k l}$ is the observation for a bone trait; $\mu$ is the general mean; $G_{i}$ is the fixed effect of generation $(i=1,2) ; L L_{j}$ is the fixed effect of layer line $(j=1$ to 4$) ; S_{k}$ is the random effect of sire ( $k=1$ to 145 ); and $\varepsilon_{i j k l}$ is the residual error. Tukey's HSD (honestly significant difference) test was performed for multiple comparisons of means. The model was computed using JMP v14.0 (SAS Institute Inc., Cary, NC, USA, 2018). Normal distribution of the residuals was assumed (Figure S4.1).

The output of the RF classification was a list of confirmed SNPs, i.e. markers that are more than coincidentally associated with a given bone trait.

\subsection{Functional Analyses}

\subsubsection{Gene Extraction}

All steps of the functional analyses were carried out using $R$ v4.0.3 [43]. Extraction of genes associated with SNPs identified by the association analyses from the Ensembl database v102 [44] was performed using BioMart [45]. All protein-coding genes that are located within $5 \mathrm{~kb}$ upstream and downstream of the respective SNPs were considered for the gene lists. Information on the biological functions of these genes was obtained from both the NCBI [46] and Ensembl databases, as well as from the literature. The gene lists were then screened for genes known to be associated with bone stability traits. In this way, we identified a number of genes that were henceforth regarded as candidate genes.

\subsubsection{SNP Effects Analysis}

The genotypic effect was analysed for those SNPs located in intragenic or in flanking genomic regions of candidate genes, which have previously been shown to be significantly associated with a bone trait (see Table 4.1). SNP effects for each locus were analysed as described by Wiedemann et al. [47]. For this purpose, the actual SNP genotypes were coded as ' 0 ' (AA), ' 1 ' $(A B)$, or '2' $(B B)$, with the $B$ allele representing the minor allele. The minor allele was considered the effect allele, whereas the major allele was termed 'other allele'. All models were computed with the $\mathrm{R}$ package Ime4 [48].

A linear regression model adjusted for fixed factors was applied to estimate the allele substitution effects by single marker regression (SMR):

$$
\gamma_{i j k l m}=\mu+G_{i}+L L_{j}+b_{1} S N P_{k}+S_{l}+\varepsilon_{i j k l m}
$$

where $\gamma_{i j k l m}$ is the observation for a bone trait; $\mu$ is the overall mean effect; $G_{i}$ is the fixed effect of generation $(i=1,2) ; L L_{j}$ is the fixed effect of layer line ( $j=1$ to 4$) ; b_{1}$ is the regression coefficient of the SNP genotype $\left(S N P_{k}\right) ; S_{l}$ is the random effect of sire $(l=1$ to $145)$; and $\varepsilon_{i j k l m}$ is the residual error. Standardised allele substitution effects were calculated according to model (3) after both the dependent variable and the SNP genotypes coded as ' 0 ', ' 1 ', or ' 2 ' were standardised to have a mean of 0 and a standard deviation of 1 . 
To calculate the additive and dominance effects, a dominant-recessive model (DRM) was applied considering the SNP genotype as a fixed class variable. The statistical model was as follows:

$$
\gamma_{i j k l m}=\mu+G_{i}+L L_{j}+S N P_{k}+S_{l}+\varepsilon_{i j k l m}
$$

where $\gamma_{i j k l m}$ is the observation for a bone trait; $\mu$ is the overall mean effect; $G_{i}$ is the fixed effect of generation $(i=1,2) ; L L_{j}$ is the fixed effect of layer line ( $j=1$ to 4$) ; S N P_{k}$ is the fixed effect of SNP genotype ( $k=1$ to 3 ); $S_{l}$ is the random effect of sire ( $l=1$ to 145 ); and $\varepsilon_{i j k l m}$ is the residual error. Least squares means (LSM) for the different genotypes were estimated with the emmeans package [49]. Significant differences between LSM were tested using a $t$-test and adjusted by the Bonferroni method. Additive and dominance effects were estimated by contrasting the respective genotypes according to the following formulas.

$$
\begin{gathered}
a=\frac{\mu_{A A}-\mu_{B B}}{2} \\
d=\mu_{A B}-\frac{\mu_{A A}+\mu_{B B}}{2}
\end{gathered}
$$

where $a$ is the additive effect; $d$ is the dominance effect; $\mu_{A A}$ and $\mu_{B B}$ are the phenotypic mean values of the homozygous genotypes; and $\mu_{A B}$ is the phenotypic mean value of the heterozygous genotype.

\subsubsection{Gene Set Analysis}

With the gene sets including all genes extracted, we performed gene set analysis (GSA) using $\mathrm{g}:$ Profiler2 [50]. This involved the Gene Ontology (GO) (Ensembl v102) and the Kyoto Encyclopedia of Genes and Genomes (KEGG) [51] (FTP release 2020-09-07) databases. The GSA was carried out considering all known genes obtained from Ensembl for the calculation of statistical significance and applying the default g:SCS algorithm [52] for computing the multiple testing correction. Only GO- and pathway terms with significant enrichment $(p<0.05)$ were considered for further analyses. Tree maps of the GO terms were generated using rrvgo [53].

\section{Results}

\subsection{Association Analyses}

\subsubsection{Genome-wide Association Study}

The GWAS results are illustrated as Manhattan plots representing the $-\log _{10} p$-values on a genomic scale (Figure 4.2). The corresponding quantile-quantile (QQ) plots, also shown in Figure 4.2, revealed separation of the observed $p$-values from the distribution under the null hypothesis, when they are less than 0.01 (BBS) or 0.001 (BMD). Estimated genomic inflation factors $(\lambda)$ ranged from $\lambda=0.96$ to $\lambda=0.99$, suggesting a negligible population stratification (Figure 4.2).

In the case of tibiotarsus BBS, 28 significant SNPs were identified. These markers were located on GGA (Gallus gallus chromosome) $1(n=12), 5(n=9), 6(n=3), 8(n=3)$, and $20(n=1)$ (Figure 4.2A). The strongest association signal, $p=7.21 \times 10^{-8}$, was observed 
for SNP AX-76915891, located on GGA 6 (3,171,707 bp). No significant association was identified for humerus BBS (Figure 4.2B). Analysis of tibiotarsus BMD resulted in 75 significant associations, with a peak of 41 SNPs found at GGA 1 (Figure 4.2C). The remaining loci were distributed across the whole genome with two additional signals at GGA $7(n=11)$ and $18(n=9)$. SNP $A X-75843394$ located at GGA $15(7,814,261$ bp $)$ showed the strongest association with tibiotarsus BMD $\left(p=1.30 \times 10^{-11}\right)$. Only one single locus, namely SNP AX-75572283 located at GGA $10(12,023,052 \mathrm{bp})$, was significantly associated with humerus $\operatorname{BMD}\left(p=6.81 \times 10^{-9}\right)($ Figure $4.2 \mathrm{D})$.

\subsubsection{Random Forests Classification}

Lists of confirmed SNPs were obtained from the RF classifier for each of the phenotypic traits. For the tibiotarsus, 358 (BBS) and 374 (BMD) SNPs were confirmed as important, whereas for the humerus 188 (BBS) and 178 (BMD) markers were identified, respectively. There were no confirmed SNPs on GGA 16 for any of the four traits studied (Figure S4.2). In the case of the tibiotarsus, the majority of SNPs were located on GGA 1. In general, there were fewer markers for the humerus, with no markers found on GGA 28. Comparing the two bone types, more than twice as many SNPs were identified for the tibiotarsus, which is consistent with observations from GWAS.

\subsection{Candidate Genes}

\subsubsection{Extracted Gene Sets}

We identified 16 (BBS) and 39 (BMD) genes within an interval of $5 \mathrm{~kb}$ upstream and downstream of SNPs that were found to be significant for the tibiotarsus in GWAS. In contrast, gene sets for the humerus included no (BBS) or only one (BMD) gene. The gene lists obtained from the RF classifier contained a considerably higher number of genes. While 240 (BBS) and 220 (BMD) genes were assigned to the SNPs in the case of the tibiotarsus, 115 (BBS) and 113 (BMD) genes were mapped for the humerus.

Venn diagrams were used to find overlaps and differences between the genes identified for the BBS and BMD of the two bone types. Accordingly, Figure 4.3A and Figure 4.3B depict the genes that were unique or common among the traits within the lists obtained from GWAS and RF classifier analyses, respectively. The corresponding detailed gene lists are given in Table S4.1 (GWAS) and Table S4.2 (RF). It was found that within both methods, the overlaps of loci between the individual traits were rather small. In particular, within the GWAS only one gene in common for BBS and BMD was identified for the tibiotarsus, namely the CNKSR2 gene. Despite the higher number of genes derived from the RF classifier, the relative proportion of overlaps was not substantially higher than for GWAS. It ranged from an overlap of $1.7 \%$ (six genes) between BBS of tibiotarsus and humerus up to an overlap of $6.7 \%$ (31 genes) between BBS and BMD within the tibiotarsus. In both methods of association analyses, no gene was found in all bone and trait combinations. Rather, they were mainly unique genes.

Based on the information on their biological functions and from the literature review, we reduced the gene lists to genes that are known to be related to bone stability. In the case of the gene sets obtained from the RF classifier, we found 16 genes with an already described association (Table 4.1). These genes are located on GGA 1 (MCF2L), GGA 2 (MPP7, CALCR, 
A
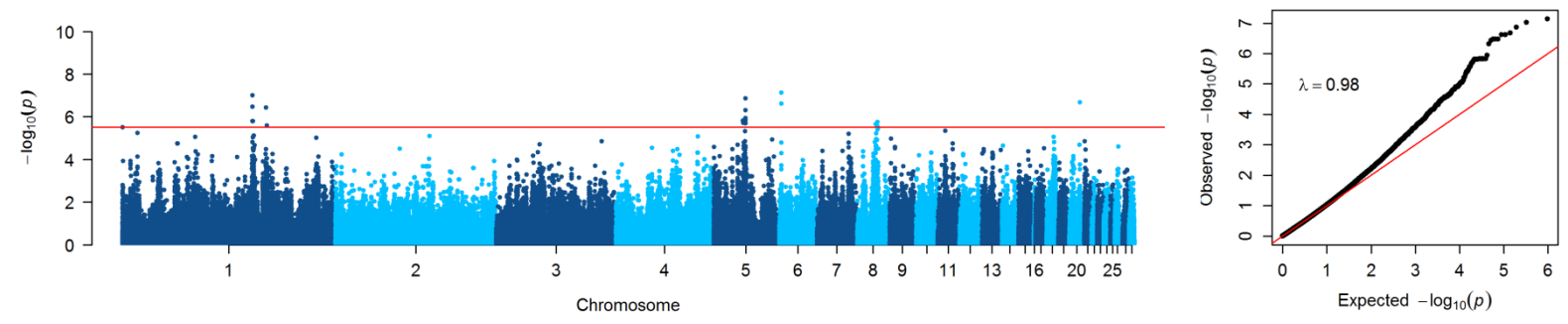

B
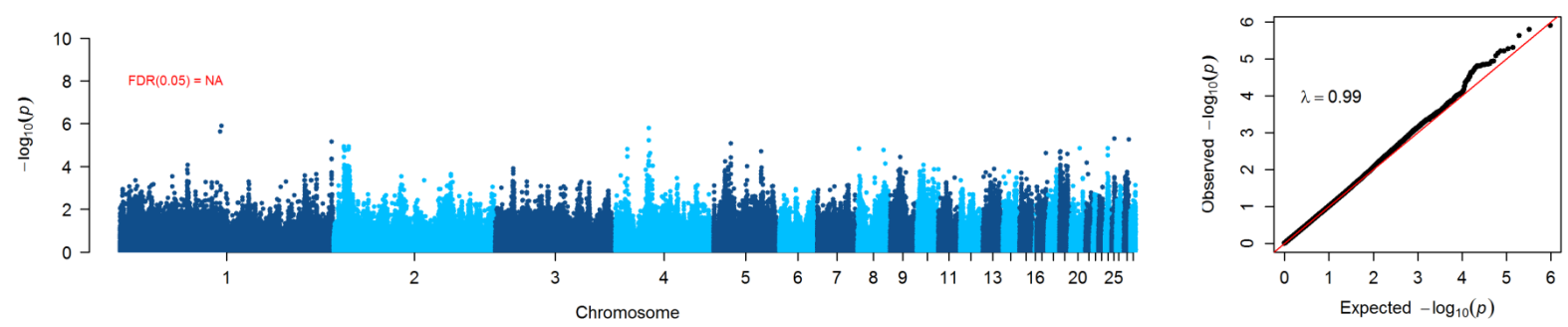

C
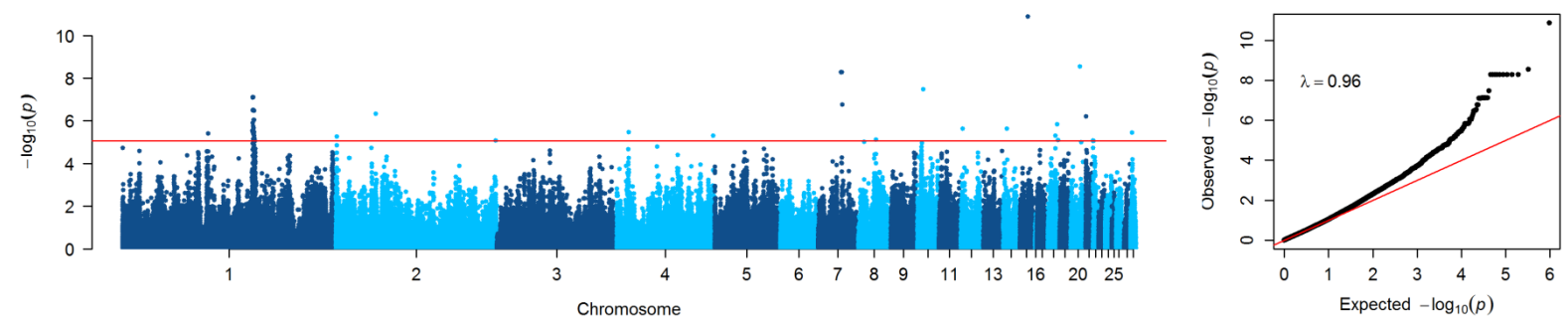

D
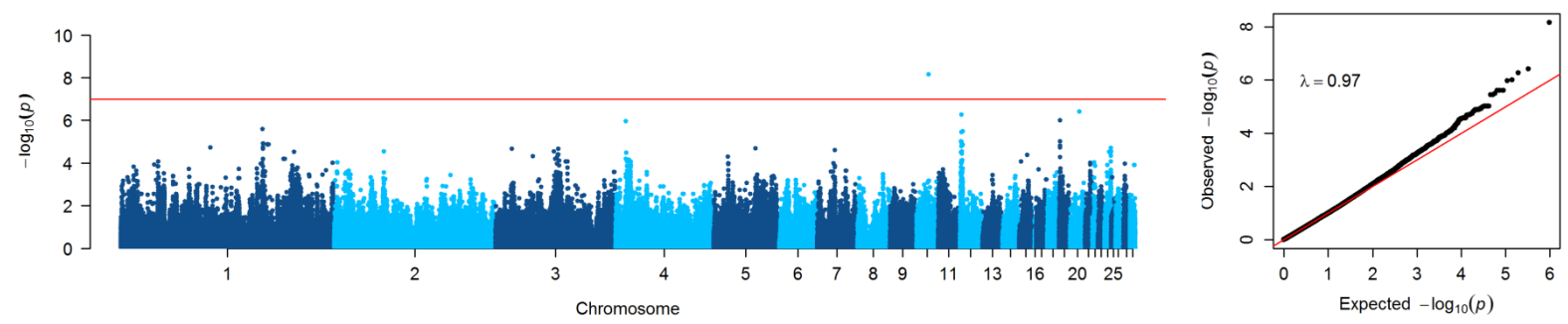

Figure 4.2: Manhattan plots (left) and quantile-quantile (QQ) plots (right) of the genome-wide association values for the bone breaking strengths of the tibiotarsus $(\mathbf{A})$ and humerus (B), and the bone mineral densities of the tibiotarsus (C) and humerus (D). For the Manhattan plots, $-\log _{10} p$-values for the markers (y-axis) are plotted against their genomic position on each chromosome. The red lines indicate a false discovery rate $\leq 0.05$. For the $Q Q$-plots, the $y$-axis shows the observed $-\log _{10} p$-values and the $\mathrm{x}$-axis represents the expected $-\log _{10} p$-values. The corresponding genomic inflation factors $(\lambda)$ are shown in the top left of the plots. 
A

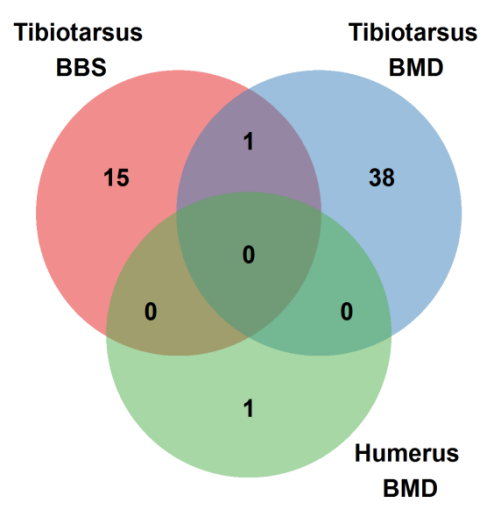

B

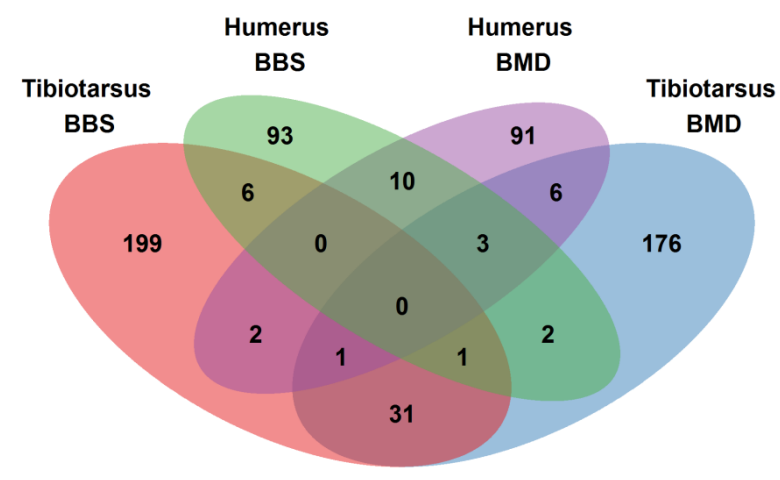

Figure 4.3: Venn diagrams showing the overlap of genes for the bone breaking strengths (BBS) and bone mineral densities (BMD) of the tibiotarsus and humerus derived from the genome-wide association study (A) and the Random Forests classifier (B).

and SFRP4), GGA 3 (ACTR2, TGFB2, and CCDC170), GGA 5 (SOX6), GGA 8 (TMCO1, PODN), GGA 10 (SMAD6), GGA 11 (GPATCH1), GGA 12 (ASPN), GGA 18 (SOX9), and GGA 27 (WNT9B, WNT3). In contrast, there was no evidence of an association to bone stability in the gene sets from the GWAS.

\subsubsection{SNP Effects Analysis}

To reveal the biological significance of the candidate genes, we analysed their associations with the corresponding phenotypic bone traits. To this end, we performed SNP effects analyses of all markers detected by the RF classifier and then assigned to genes (Table 4.1). Since the SNPs $A X-77091655$ (PODN) and AX-76772658 (SOX6) were associated with two traits each and, in addition, two further markers were assigned to the WNT3 gene, SNP effects were estimated for 19 SNP and bone trait combinations.

Results from the SMR model are shown in Table 4.2. Analysis of variance revealed significant effects of SNP genotypes on the respective bone traits. Only the SNPs AX-77276717 (TGFB2) and $A X-75711229$ (ASPN) had no significant effect. Locus AX-76099065 (SFRP4) had the greatest effect on tibiotarsus $B M D$, with the substitution of allele $G$ for allele $A$ leading to a reduction of $0.016 \mathrm{~g} / \mathrm{cm}^{2}$. In contrast, increasing the number of the copies of the effect alleles at loci $A X-76351898$ and $A X-76351899$, both assigned to the WNT3 gene, would yield an increase in humerus BMD of $0.016 \mathrm{~g} / \mathrm{cm}^{2}$. Of all loci significantly associated with BBS, the SNP AX-76491534 (CCDC170) showed the largest effect, whereby substitution of one copy of allele A with allele $\mathrm{G}$ would result in a $15.63 \mathrm{~N}$ decrease of tibiotarsus BBS. The counterpart is the SNP AX-76351785 (WNT9B) in which the T allele would presumably cause an increase of $11.51 \mathrm{~N}$ of humerus BBS. This is also the largest effect among all significant SNPs, with a change of 0.21 expressed in SD units.

Results obtained from the DRM are shown in Table 4.3. Comparison of the genotypic values (LSM) revealed significant differences among the genotypes. This applies to all loci studied, with exception of the SNPs AX-77276717 (TGFB2) and AX-80813610 (CALCR), 
where only a tendency towards a higher value for the homozygote genotype of the effect allele was observed. For the other loci, the effects indicated by the direction of the beta coefficients $(\mathrm{SMR})$ were also reflected in the genotypic values. A significantly higher LSM was found for the homozygote genotype of the effect allele of the SNP AX-75711229 (ASPN). However, this estimate might be biased as the corresponding genotype had a frequency of only 0.01 (Table 4.1) and no significant allele substitution effect was detected for this locus (Table 4.2).

Significant additive effects of the respective other allele (major allele) were accounted for all loci with exception of the SNPs AX-77276717 (TGFB2) and AX-76772658 (SOX6) (Table 4.3). The estimates ranged from -0.02 to $0.017 \mathrm{~g} / \mathrm{cm}^{2}$ for the BMD-related SNPs and from -16.70 to $15.70 \mathrm{~N}$ for the markers associated with the BBS. Effects of complete dominance were observed for the SNPs AX-76044166 (MPP7), AX-75711229 (ASPN), AX75597497 (SMAD6) and AX-76099065 (SFRP4), with one copy of the major allele masking the recessive allele, thus leading to full trait expression. In contrast, complete dominance in favour of the effect allele was seen for the SNP AX-77113061 (TMCO1).

\subsection{Gene Set Analysis}

GSA was performed for all gene sets obtained from the RF classifier and for those of the tibiotarsus obtained from the GWAS. We restricted the results to the GO biological process (BP) category, as we sought to determine overarching biological objectives to which the gene products of the extracted genes contribute. Furthermore, the genes were grouped according to their KEGG pathways. Full lists of significantly enriched GO terms, including those from the cellular component and molecular function categories, are given in Table S4.3 (GWAS) and Table S4.4. The GWAS-derived genes for the tibiotarsal BBS were significantly associated with GO:0009266 (response to temperature stimulus), while in the case of BMD GO:0008150 (biological_process) and GO:0003674 (molecular_function) were enriched. However, these terms were not linked to bone stability in the GO hierarchy.

A large number of genes obtained from the RF classifier were involved in common processes. The analysis reported 81 (BBS) and 51 (BMD) significantly enriched BPs for the tibiotarsus and 33 (BBS) and 42 (BMD) BPs for the humerus, respectively (Table S4.4). Of these, Figure 4.4 (tibiotarsus) and Figure 4.5 (humerus) show the top 15 significantly enriched GO BP terms with the highest $-\log _{10} p$-values and all significantly enriched KEGG pathways obtained from the RF classifier. Although certain BPs overlapped between the bone and trait combinations, no relation to the skeletal system was evident in the enriched BPs. Visualizing the results using tree maps to investigate redundancy based on semantic similarity between different GO terms also did not yield any biologically relevant findings (Figures S4.3, S4.4). However, the literature points to the involvement of Wnt- and MAPK signalling pathways in the pathogenesis of osteoporosis [25]. GSA revealed the Wnt signaling pathway (KEGG:04310) to be significantly enriched in both BMD gene sets (Figures 4.4B, 4.5B). In addition, significant enrichment for the MAPK signaling pathway (KEGG:04010) was identified in the genes for BMD of the tibiotarsus. 


\section{Chapter 4}

Table 4.1: General information for 17 loci associated with the bone breaking strengths (BBS) or bone mineral densities (BMD) of the tibiotarsus (Tib) and humerus (Hum) selected for the SNP effects analysis.

\begin{tabular}{|c|c|c|c|c|c|c|c|c|c|c|c|}
\hline SNP & Trait & Location & $\mathrm{GGA}^{1}$ & Position ${ }^{2}$ & Genotypes & $\mathrm{N}$ individuals & $\begin{array}{l}\text { Genotype } \\
\text { frequencies }\end{array}$ & $\mathrm{EA} / \mathrm{OA}^{3}$ & EA frequency & Candidate gene & Reference ${ }^{4}$ \\
\hline AX-75268181 & Tib_BMD & intragenic & 1 & $139,001,157$ & $\mathrm{CC} / \mathrm{CT} / \mathrm{TT}$ & 392 / 96 / 36 & $0.75 / 0.18 / 0.07$ & $\mathrm{~T} / \mathrm{C}$ & 0.16 & $M C F 2 L$ & [54] \\
\hline AX-76044166 & Tib_BBS & intragenic & 2 & $15,440,861$ & $\mathrm{AA} / \mathrm{AG} / \mathrm{GG}$ & $421 / 63$ / 40 & $0.80 / 0.12 / 0.08$ & $G / A$ & 0.14 & MPP7 & [55] \\
\hline$A X-80813610$ & Tib_BMD & downstream & 2 & $23,056,581$ & $\mathrm{CC} / \mathrm{CG} / \mathrm{GG}$ & 339 / 113 / 72 & $0.65 / 0.22 / 0.13$ & $\mathrm{G} / \mathrm{C}$ & 0.25 & $C A L C R$ & [56] \\
\hline AX-76099065 & Tib_BMD & intragenic & 2 & $46,101,680$ & $\mathrm{GG} / \mathrm{GA} / \mathrm{AA}$ & $392 / 77 / 55$ & $0.75 / 0.15 / 0.10$ & $A / G$ & 0.18 & SFRP4 & {$[57]$} \\
\hline$A X-76601713$ & Tib_BBS & intragenic & 3 & $10,617,925$ & $\mathrm{AA} / \mathrm{AG} / \mathrm{GG}$ & $265 / 102 / 157$ & $0.51 / 0.19 / 0.30$ & $G / A$ & 0.40 & ACTR2 & [15] \\
\hline AX-77276717 & Tib_BBS & intragenic & 3 & $19,498,104$ & GG / GA / AA & $322 / 145 / 57$ & $0.61 / 0.28 / 0.11$ & $A / G$ & 0.25 & TGFB2 & [58] \\
\hline AX-76491534 & Tib_BBS & intragenic & 3 & $49,027,160$ & $\mathrm{AA} / \mathrm{AG} / \mathrm{GG}$ & 432 / 62 / 30 & $0.82 / 0.12 / 0.06$ & $G / A$ & 0.12 & $C C D C 170$ & [59] \\
\hline AX-76772658 & $\begin{array}{l}\text { Tib_BBS / } \\
\text { Hum_BBS }\end{array}$ & intragenic & 5 & $11,438,677$ & $\mathrm{TT} / \mathrm{TC} / \mathrm{CC}$ & 219 / 199 / 109 & $0.41 / 0.38 / 0.21$ & $\mathrm{C} / \mathrm{T}$ & 0.40 & sox6 & {$[60]$} \\
\hline AX-77113061 & Tib_BMD & upstream & 8 & $5,889,886$ & $\mathrm{GG} / \mathrm{AG} / \mathrm{AA}$ & $202 / 156 / 166$ & $0.38 / 0.30 / 0.32$ & $A / G$ & 0.47 & TMCO1 & {$[61]$} \\
\hline AX-77091655 & $\begin{array}{c}\text { Hum_BBS / } \\
\text { Hum_BMD }\end{array}$ & upstream & 8 & $24,931,025$ & $\mathrm{CC} / \mathrm{CA} / \mathrm{AA}$ & 286 / 139 / 99 & $0.54 / 0.27 / 0.19$ & $\mathrm{~A} / \mathrm{C}$ & 0.32 & PODN & [15] \\
\hline AX-75597497 & Hum_BBS & downstream & 10 & $19,108,829$ & $\mathrm{AA} / \mathrm{AG} / \mathrm{GG}$ & $376 / 124$ / 24 & $0.72 / 0.24 / 0.04$ & $\mathrm{G} / \mathrm{A}$ & 0.16 & SMAD6 & [62] \\
\hline AX-75677174 & Tib_BMD & intragenic & 11 & $10,044,055$ & $\mathrm{CC} / \mathrm{CT} / \mathrm{TT}$ & 377 / 107 / 40 & $0.72 / 020 / 0.08$ & $\mathrm{~T} / \mathrm{C}$ & 0.18 & GPATCH1 & [55] \\
\hline AX-75711229 & Tib_BBS & intragenic & 12 & $3,804,145$ & $\mathrm{GG} / \mathrm{AG} / \mathrm{AA}$ & $459 / 58 / 7$ & $0.88 / 0.11 / 0.01$ & $A / G$ & 0.07 & $A S P N$ & {$[63]$} \\
\hline AX-75913642 & Tib_BBS & upstream & 18 & $8,793,585$ & $\mathrm{GG} / \mathrm{AG} / \mathrm{AA}$ & $451 / 61$ / 12 & $0.86 / 0.12 / 0.02$ & $A / G$ & 0.08 & SoX9 & {$[64]$} \\
\hline AX-76351785 & Hum_BBS & intragenic & 27 & $3,497,444$ & $\mathrm{CC} / \mathrm{CT} / \mathrm{TT}$ & 316 / 138 / 70 & $0.61 / 0.26 / 0.13$ & $\mathrm{~T} / \mathrm{C}$ & 0.26 & WNT9B & {$[65]$} \\
\hline AX-76351898 & Hum_BMD & downstream & 27 & $3,518,924$ & $\mathrm{GG} / \mathrm{GA} / \mathrm{AA}$ & 483 / 31 / 10 & $0.92 / 0.06 / 0.02$ & $A / G$ & 0.05 & WNT3 & [55] \\
\hline AX-76351899 & Hum_BMD & downstream & 27 & $3,519,091$ & $\mathrm{TT} / \mathrm{TC} / \mathrm{CC}$ & $483 / 31 / 10$ & $0.92 / 0.06 / 0.02$ & $\mathrm{C} / \mathrm{T}$ & 0.05 & WNT3 & [55] \\
\hline
\end{tabular}

${ }^{1}$ GGA, Gallus gallus chromosome; ${ }^{2}$ Physical position (bp) according to the GRCg6a (galGal6) genome assembly; ${ }^{3}$ EA, effect allele (minor allele); OA, other allele (major allele);

${ }^{4}$ References from the literature suggesting an association of the gene with bone stability traits. 
Table 4.2: SNP effects analysis - Part 1: Analysis of variance table and allele substitution effect obtained from the single marker regression model.

\begin{tabular}{|c|c|c|c|c|c|c|c|c|c|c|c|c|}
\hline \multirow{2}{*}{ SNP } & \multirow{2}{*}{ Trait ${ }^{1}$} & \multirow{2}{*}{$\begin{array}{l}\text { Candidate } \\
\text { gene }\end{array}$} & \multicolumn{2}{|c|}{ Generation } & \multicolumn{2}{|c|}{ Layer line } & \multicolumn{2}{|c|}{ SNP genotype } & \multicolumn{4}{|c|}{ Allele substitution effect ${ }^{2}$} \\
\hline & & & F-statistics & $p$-value & F-statistics & $p$-value & F-statistics & $p$-value & Beta $\left(\mathrm{SE}^{3}\right)$ & $\begin{array}{l}\text { Standardised } \\
\text { beta }{ }^{4}\left(\mathrm{SE}^{3}\right)\end{array}$ & $t$-value & $p$-value \\
\hline AX-76044166 & Tib_BBS & $M P P 7$ & 80.92 & $<0.0001$ & 46.34 & $<0.0001$ & 4.05 & 0.0448 & $8.22(4.09)$ & $0.10(0.05)$ & 2.01 & 0.0448 \\
\hline AX-76601713 & Tib_BBS & ACTR2 & 86.02 & $<0.0001$ & 106.86 & $<0.0001$ & 13.33 & 0.0003 & $-10.19(2.79)$ & $-0.18(0.05)$ & -3.65 & 0.0003 \\
\hline AX-77276717 & Tib_BBS & TGFB2 & 81.07 & $<0.0001$ & 102.16 & $<0.0001$ & 3.32 & 0.0696 & $4.67(2.57)$ & $0.06(0.04)$ & 1.82 & 0.0696 \\
\hline AX-76491534 & Tib_BBS & $C C D C 170$ & 91.49 & $<0.0001$ & 84.86 & $<0.0001$ & 12.58 & 0.0004 & $-15.63(4.41)$ & $-0.17(0.05)$ & -3.55 & 0.0004 \\
\hline AX-76772658 & Tib_BBS & SoX6 & 81.50 & $<0.0001$ & 117.84 & $<0.0001$ & 10.71 & 0.0012 & $7.63(2.33)$ & $0.12(0.04)$ & 3.27 & 0.0012 \\
\hline AX-75711229 & Tib_BBS & $A S P N$ & 79.24 & $<0.0001$ & 84.23 & $<0.0001$ & 2.08 & 0.1503 & $6.66(4.62)$ & $0.05(0.04)$ & 1.44 & 0.1503 \\
\hline AX-75913642 & Tib_BBS & soxg & 83.08 & $<0.0001$ & 111.94 & $<0.0001$ & 9.67 & 0.0019 & $-12.87(4.14)$ & $-0.11(0.04)$ & -3.11 & 0.0019 \\
\hline AX-76772658 & Hum_BBS & sox6 & 36.26 & $<0.0001$ & 52.59 & $<0.0001$ & 5.67 & 0.0177 & $-5.32(2.23)$ & $-0.10(0.04)$ & -2.38 & 0.0177 \\
\hline AX-77091655 & Hum_BBS & PODN & 39.91 & $<0.0001$ & 41.64 & $<0.0001$ & 8.35 & 0.0041 & $6.69(2.31)$ & $0.13(0.04)$ & 2.89 & 0.0041 \\
\hline AX-75597497 & Hum_BBS & SMAD6 & 36.38 & $<0.0001$ & 53.40 & $<0.0001$ & 4.62 & 0.0321 & $-7.13(3.32)$ & $-0.10(0.05)$ & -2.15 & 0.0321 \\
\hline AX-76351785 & Hum_BBS & WNT9B & 37.27 & $<0.0001$ & 67.22 & $<0.0001$ & 21.57 & $<0.0001$ & $11.51(2.48)$ & $0.21(0.04)$ & 4.64 & $<0.0001$ \\
\hline AX-75268181 & Tib_BMD & $M C F 2 L$ & 4.30 & 0.0401 & 106.46 & $<0.0001$ & 13.53 & 0.0003 & $-0.015(0.004)$ & $-0.15(0.05)$ & -3.67 & 0.0003 \\
\hline AX-80813610 & Tib_BMD & $C A L C R$ & 4.24 & 0.0415 & 56.10 & $<0.0001$ & 4.86 & 0.0298 & $0.008(0.004)$ & $0.10(0.05)$ & 2.21 & 0.028 \\
\hline$A X-76099065$ & Tib_BMD & SFRP4 & 4.31 & 0.0400 & 65.23 & $<0.0001$ & 8.55 & 0.0036 & $-0.016(0.006)$ & $-0.18(0.06)$ & -2.92 & 0.0036 \\
\hline AX-77113061 & Tib_BMD & TMCO1 & 4.45 & 0.0369 & 99.26 & $<0.0001$ & 5.27 & 0.0221 & $0.008(0.003)$ & $0.11(0.05)$ & 2.30 & 0.0221 \\
\hline AX-75677174 & Tib_BMD & GPATCH1 & 4.27 & 0.0406 & 61.13 & $<0.0001$ & 10.84 & 0.0011 & $0.013(0.004)$ & $0.13(0.04)$ & 3.29 & 0.0011 \\
\hline AX-77091655 & Hum_BMD & PODN & 20.70 & $<0.0001$ & 51.56 & $<0.0001$ & 11.53 & 0.0008 & $0.007(0.002)$ & $0.14(0.04)$ & 3.39 & 0.0008 \\
\hline AX-76351898 & Hum_BMD & WNT3 & 19.82 & $<0.0001$ & 77.58 & $<0.0001$ & 13.81 & 0.0002 & $0.016(0.004)$ & $0.15(0.04)$ & 3.72 & 0.0002 \\
\hline AX-76351899 & Hum_BMD & WNT3 & 19.82 & $<0.0001$ & 77.58 & $<0.0001$ & 13.81 & 0.0002 & $0.016(0.004)$ & $0.15(0.04)$ & 3.72 & 0.0002 \\
\hline
\end{tabular}

${ }^{1}$ BBS, bone breaking strength; BMD, bone mineral density; Tib, tibiotarsus; Hum, humerus; ${ }^{2}$ Allele substitution effect per copy of the effect allele (minor allele); ${ }^{3}$ SE, standard error; ${ }^{4}$ Standardised regression coefficients expressed in SD unit. 
Table 4.3: SNP effects analysis - Part 2: Genotypic values (least squares means) and additive and dominance effects obtained from the dominantrecessive model.

\begin{tabular}{|c|c|c|c|c|c|c|c|c|c|c|c|}
\hline \multirow{2}{*}{ SNP } & \multirow{2}{*}{ Trait 1} & \multirow{2}{*}{$\begin{array}{l}\text { Candidate } \\
\text { gene }\end{array}$} & \multicolumn{3}{|c|}{ Genotypic values } & \multicolumn{3}{|c|}{ Homozygous additive allele effect ${ }^{5}$} & \multicolumn{3}{|c|}{ Dominance effect 5} \\
\hline & & & $\mathrm{AA}^{2,3}\left(\mathrm{SE}^{4}\right)$ & $\mathrm{AB}^{2,3}\left(\mathrm{SE}^{4}\right)$ & $\mathrm{BB}^{2,3}\left(\mathrm{SE}^{4}\right)$ & Estimate $\left(\mathrm{SE}{ }^{4}\right)$ & t-value & $\mathrm{p}$-value & Estimate (SE) & $t$-value & $p$-value \\
\hline AX-76044166 & Tib_BBS & MPP7 & $155.33(2.26)^{a, b}$ & $145.80(5.85)^{b}$ & $172.76(7.25)^{a}$ & $-8.71(4.05)$ & -2.15 & 0.0320 & $-18.20(5.45)$ & -3.35 & 0.0009 \\
\hline AX-76601713 & Tib_BBS & ACTR2 & $162.77(3.08)^{a}$ & $156.79(3.81)^{a}$ & $143.10(3.79)^{b}$ & $9.83(2.82)$ & 3.49 & 0.0005 & $3.86(4.03)$ & 0.96 & 0.3392 \\
\hline AX-77276717 & Tib_BBS & TGFB2 & $153.42(2.25)^{\mathrm{a}}$ & $157.05(3.06)^{a}$ & $163.72(5.10)^{a}$ & $-5.15(2.83)$ & -1.82 & 0.0694 & $-1.52(3.73)$ & -0.41 & 0.6843 \\
\hline AX-76491534 & Tib_BBS & $C C D C 170$ & $159.13(2.19)^{a}$ & $144.04(6.28)^{a, b}$ & $127.83(8.09)^{b}$ & $15.70(4.42)$ & 3.54 & 0.0004 & $0.56(5.88)$ & 0.096 & 0.9239 \\
\hline AX-76772658 & Tib_BBS & sox6 & $149.06(2.65)^{b}$ & $158.53(2.58)^{a}$ & $163.29(3.90)^{\mathrm{a}}$ & $-7.11(2.43)$ & -2.93 & 0.0035 & $2.36(3.13)$ & 0.75 & 0.4520 \\
\hline AX-75711229 & Tib_BBS & $A S P N$ & $155.14(1.94)^{b}$ & $154.78(5.29)^{b}$ & $188.53(13.11)^{a}$ & $-16.70(6.62)$ & -2.52 & 0.0120 & $-17.10(8.02)$ & -2.13 & 0.0340 \\
\hline AX-75913642 & Tib_BBS & soxg & $157.50(1.93)^{\mathrm{a}}$ & $148.13(4.83)^{a, b}$ & $124.13(10.37)^{b}$ & $16.70(5.31)$ & 3.14 & 0.0018 & $7.40(6.44)$ & 1.15 & 0.2506 \\
\hline AX-76772658 & Hum_BBS & sox6 & $127.04(2.51)^{\mathrm{a}}$ & $116.24(2.46)^{b}$ & $119.38(3.71)^{a, b}$ & $3.83(2.31)$ & 1.66 & 0.0984 & $-6.96(3.02)$ & -2.31 & 0.0215 \\
\hline AX-77091655 & Hum_BBS & PODN & $118.01(2.31)^{b}$ & $120.73(3.04)^{b}$ & $132.21(3.73)^{a}$ & $-7.10(2.31)$ & -3.07 & 0.0023 & $-4.38(3.44)$ & -1.27 & 0.2043 \\
\hline AX-75597497 & Hum_BBS & SMAD6 & $122.16(2.08)^{a}$ & $123.48(3.64)^{a}$ & $98.16(6.97)^{b}$ & $12.0(3.71)$ & 3.23 & 0.0013 & $13.30(4.61)$ & 2.88 & 0.0040 \\
\hline AX-76351785 & Hum_BBS & WNT9B & $115.73(2.19)^{c}$ & $124.86(3.05)^{b}$ & $139.61(4.34)^{\mathrm{a}}$ & $-11.90(2.54)$ & -4.70 & $<0.0001$ & $-2.81(3.49)$ & -0.80 & 0.4215 \\
\hline AX-75268181 & Tib_BMD & $M C F 2 L$ & $0.263(0.003)^{a}$ & $0.253(0.005)^{a}$ & $0.228(0.008)^{b}$ & $0.017(0.004)$ & 3.92 & 0.0001 & $0.008(0.006)$ & 1.35 & 0.1768 \\
\hline$A X-80813610$ & Tib_BMD & $C A L C R$ & $0.256(0.003)^{a}$ & $0.258(0.005)^{a}$ & $0.273(0.006)^{a}$ & $-0.009(0.004)$ & -2.24 & 0.0257 & $-0.007(0.005)$ & -1.27 & 0.2051 \\
\hline AX-76099065 & Tib_BMD & SFRP4 & $0.261(0.003)^{a, b}$ & $0.265(0.008)^{a}$ & $0.235(0.009)^{b}$ & $0.013(0.006)$ & 2.32 & 0.0206 & $0.018(0.006)$ & 2.71 & 0.0071 \\
\hline AX-77113061 & Tib_BMD & TMCO1 & $0.246(0.005)^{a}$ & $0.267(0.004)^{a}$ & $0.266(0.004)^{a}$ & $-0.01(0.004)$ & -2.82 & 0.0050 & $0.011(0.004)$ & 2.51 & 0.0125 \\
\hline AX-75677174 & Tib_BMD & GPATCH1 & $0.254(0.003)^{b}$ & $0.269(0.005)^{a}$ & $0.278(0.007)^{a}$ & $-0.012(0.004)$ & -3.05 & 0.0024 & $0.004(0.005)$ & 0.56 & 0.5739 \\
\hline AX-77091655 & Hum_BMD & PODN & $0.164(0.002)^{b}$ & $0.167(0.003)^{b}$ & $0.178(0.003)^{a}$ & $-0.007(0.002)$ & -3.53 & 0.0005 & $-0.004(0.003)$ & -1.25 & 0.2117 \\
\hline AX-76351898 & Hum_BMD & WNT3 & $0.166(0.002)^{b}$ & $0.176(0.006)^{b}$ & $0.206(0.010)^{a}$ & $-0.02(0.005)$ & -3.84 & 0.0001 & $-0.009(0.007)$ & -1.29 & 0.1991 \\
\hline AX-76351899 & Hum_BMD & WNT3 & $0.166(0.002)^{b}$ & $0.176(0.006)^{b}$ & $0.206(0.010)^{a}$ & $-0.02(0.005)$ & -3.84 & 0.0001 & $-0.009(0.007)$ & -1.29 & 0.1991 \\
\hline
\end{tabular}


A

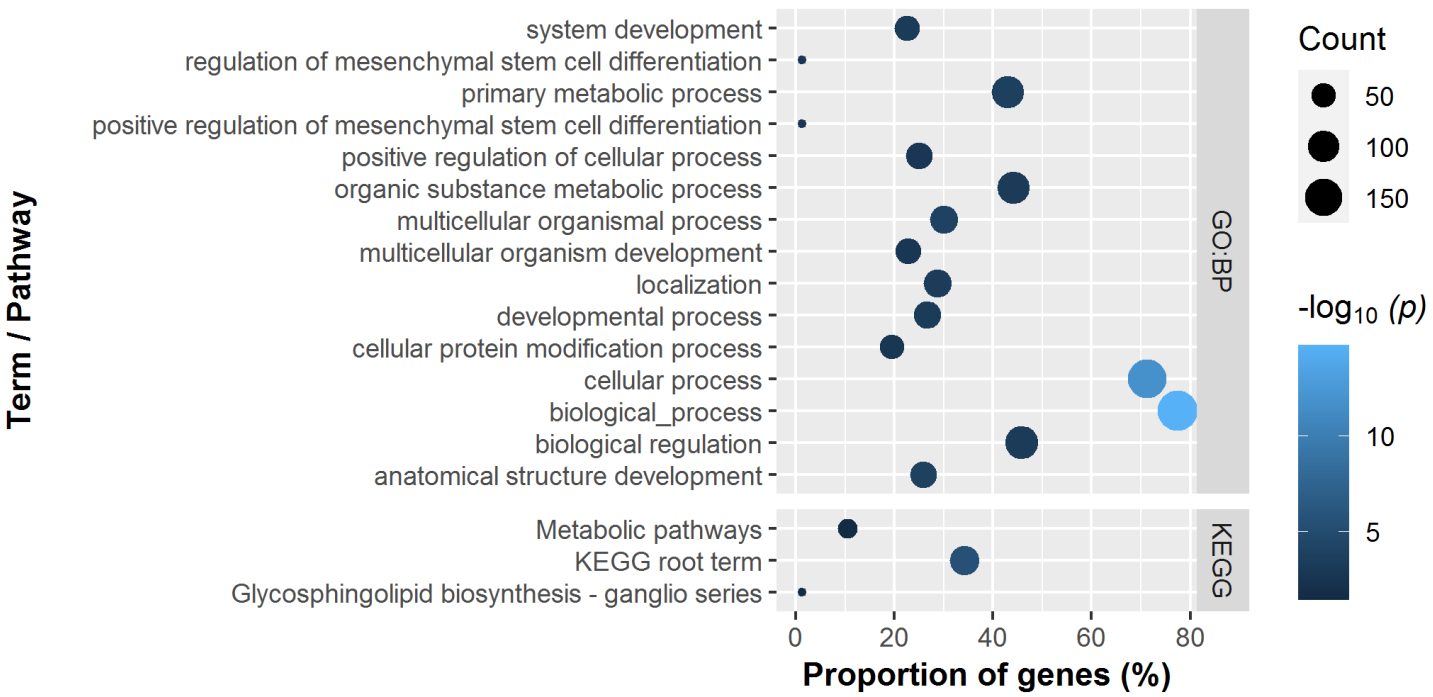

B

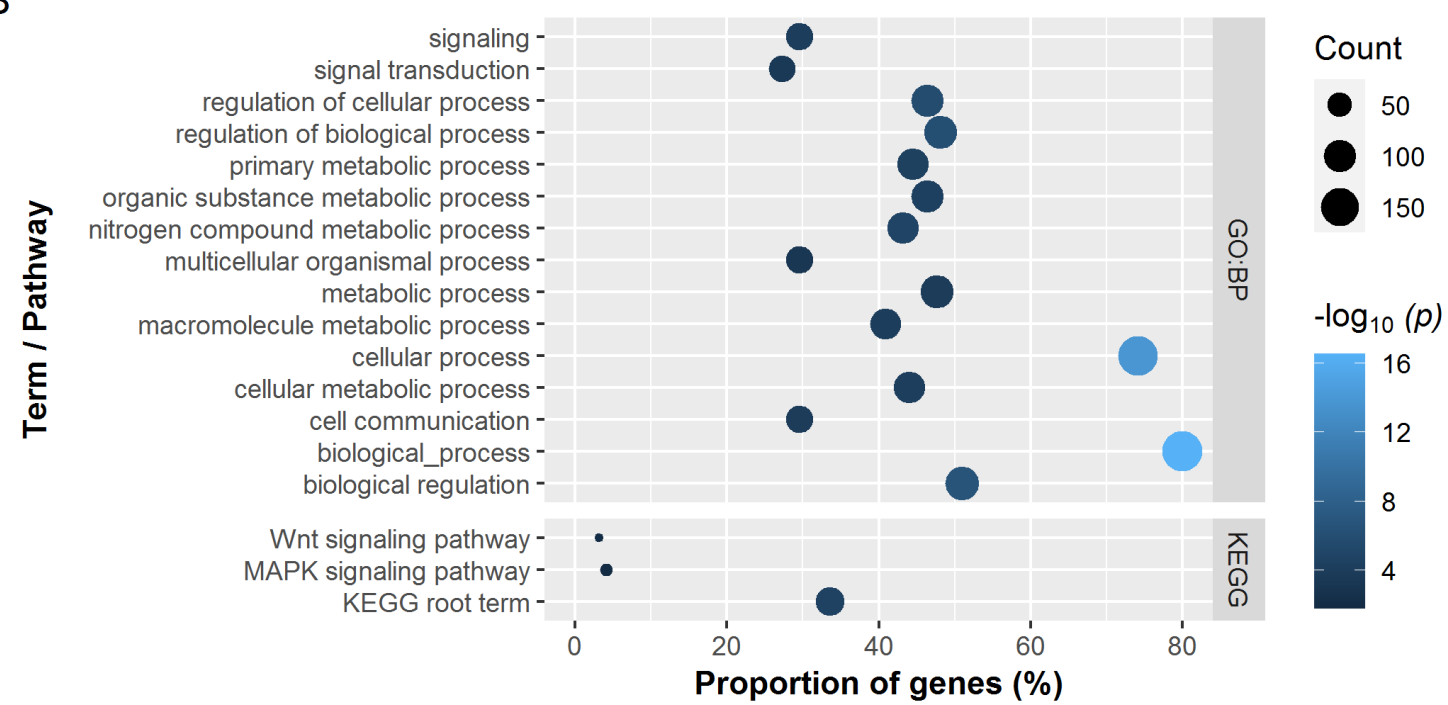

Figure 4.4: Significantly enriched Gene Ontology terms of the category biological processes (GO:BP; top 15 with the highest - $\log _{10}$ p-values) and KEGG pathways for the bone breaking strength $(\mathbf{A})$ and bone mineral density $(\mathbf{B})$ of the tibiotarsus. The dot size represents the absolute number of genes enriched in the term. The proportion of enriched genes in all queried genes is represented on the x-axis. The colour represents the $-\log _{10}$ transformed adjusted $p$-values. 
A

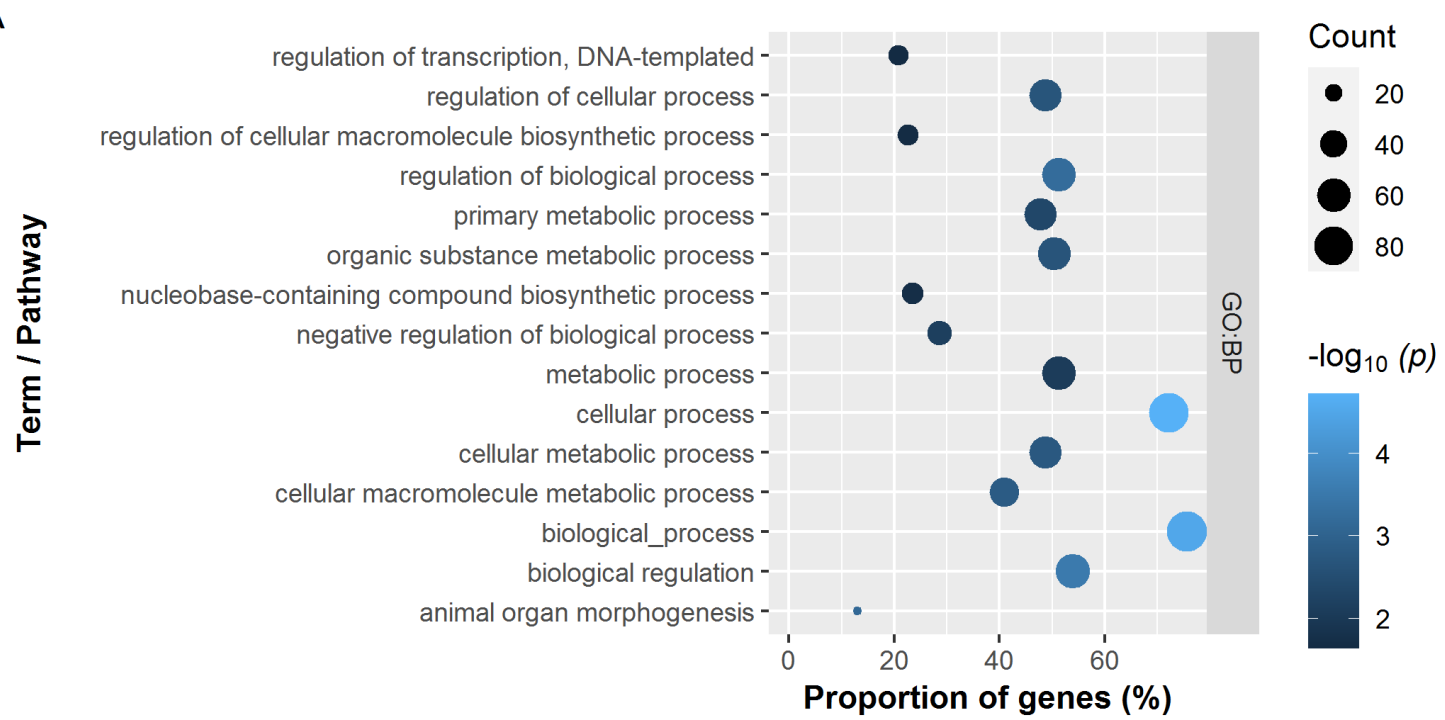

B

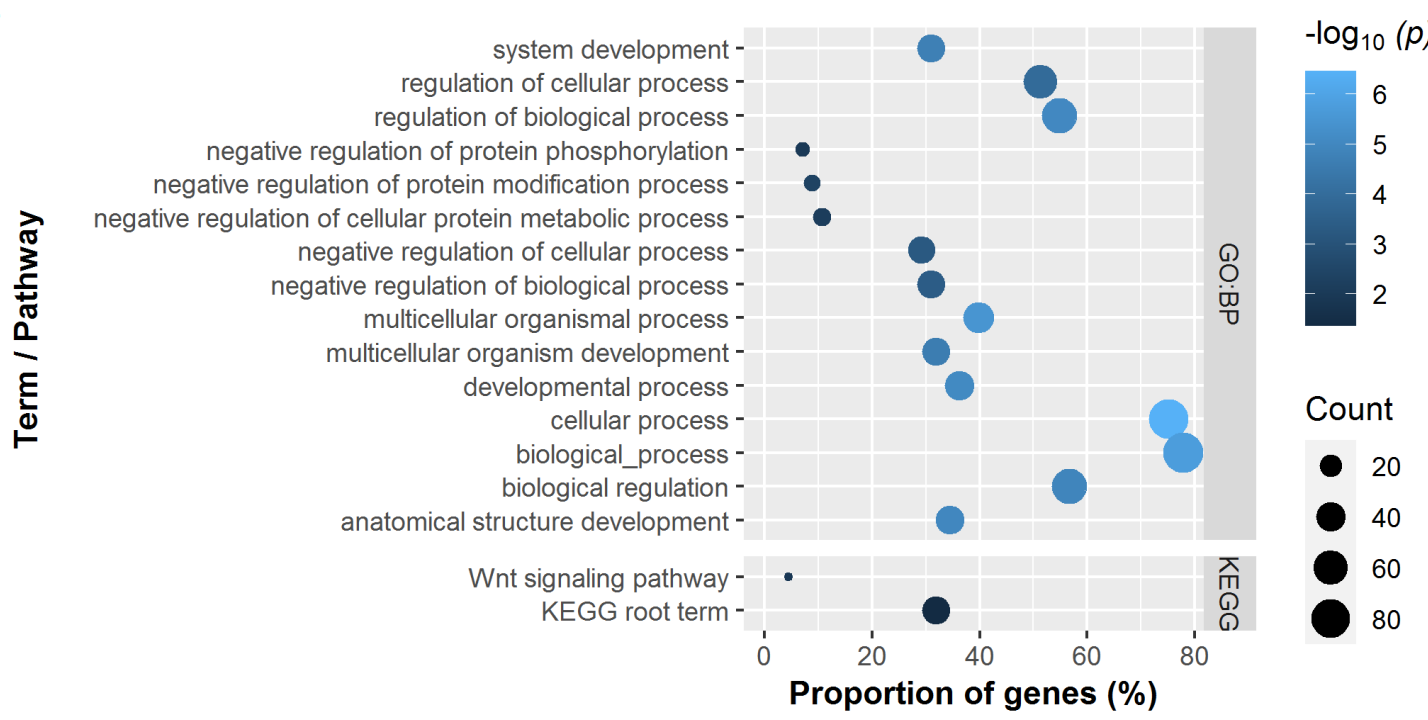

Figure 4.5: Significantly enriched Gene Ontology terms of the category biological processes (GO:BP; top 15 with the highest $-\log _{10} p$-values) and KEGG pathways for the bone breaking strength $(\mathbf{A})$ and bone mineral density $(\mathbf{B})$ of the humerus. The dot size represents the absolute number of genes enriched in the term. The proportion of enriched genes in all queried genes is represented on the $x$-axis. The colour represents the $-\log _{10}$ transformed adjusted $p$-values.

\section{Discussion}

The objective of the present study was to identify genomic positions potentially associated with skeletal integrity in a laying hen population. There is solid evidence that osteoporosis is a polygenic disorder, i.e. determined by multiple functional genes acting conjointly rather than a few major genes $[15,25]$. For this reason, in addition to GWAS, we applied RF classification, an approach known to be able to detect genes with modest effects $[29,30]$. To our knowledge, this is the first study applying a machine learning approach to bone data in chickens. As both methods have advantages and promising candidate genes have so far been identified by means of GWAS $[15,25]$, we ran both in parallel rather than considering them complementary and 
only examining loci that both methods have in common [29]. RF classification led to the identification of a higher number of SNPs compared to GWAS. Consequently, the methods also differed considerably in the number of genes extracted, with only very little overlap. No genes functionally related to the skeleton were found in GWAS. Although a large number of genes were adjacent to the SNPs from the RF classifier, only 16 candidate genes related to skeletal disorders were identified; of these, many had human orthologues. However, for the vast majority of genes, no involvement in bone metabolism has been suspected so far, which is in line with previous reports $[15,66]$. From the 16 identified candidates discussed below, we first focus on genes that have previously been linked to BBS or BMD $(n=10)$, followed by genes for which an association with osteoarthritis is suggested $(n=3)$. Finally, genes are discussed that are functionally related to the Wnt signalling pathway $(n=3)$.

Ten of our candidate genes can be grouped as having previously been associated with BBS or BMD traits in the literature. Of these, the membrane palmitoylated protein 7 gene (MPP7) was associated with vertebral BMD in humans [55]. Its strong functional role in osteoblast biology was demonstrated by means of in vivo and in vitro studies [67]. Based on these reports, we consider MPP7 to be a good candidate for bone disorders in chickens. In our study, the calcitonin receptor gene (CALCR) was identified as a strong candidate for BMD. Calcitonin plays a role in calcium homeostasis and is primarily an inhibitor of bone resorption [68]. Our observations are in line with previous reports, as CALCR polymorphisms were associated with site-specific BMD in humans $[56,69]$, and alpha-calcitonin gene-related peptide deficient mice were shown to have a lower bone mass [70]. One of the candidates for BBS located on GGA 3 is the actin related protein 2 gene (ACTR2), which was recently identified by Raymond et al. [15] as being associated with BBS in laying hens. ACTR2 is functionally linked to bone via its importance for cilia formation, as cilia are known to play an integral role in skeletal development $[15,71]$. Although no significant effect of the variant corresponding to the transforming growth factor beta 2 gene (TGFB2) was observed in our study, TGFB2 is considered a very promising candidate for skeletal integrity in the chicken. As a cytokine, the protein encoded by TGFB2 has important functions in many biological processes related to bone remodelling $[19,58]$. Analyses in different chicken populations including broilers and layers suggest TGFB2 to be associated with various bone characteristics $[19,21,58]$. In this context, the SMAD family member 6 gene (SMAD6) has to be mentioned, which we identified as a candidate for BBS. Its protein acts as a regulator of the TGF-beta family and inhibits bone morphogenetic protein pathways, which are integral parts of osteoblast and chondrocyte differentiation $[72,73]$. A study on mice revealed their essential role in bone formation, as SMAD3 knockout resulted in osteopenia [62]. The coiled coil domain containing 170 gene ( $C C D C 170)$ is our third candidate for BBS located on GGA 3. The region around this locus has been linked to BMD in humans $[59,65]$. However, since the function of the protein is yet unclear, it has been speculated whether associations attributed to CCDC170 do not rather belong to the adjacent estrogen receptor 1 gene [59]. In a follow-up study, CCDC170 polymorphisms were in turn associated with osteoporosis-relevant phenotypes [74]. Only one of our candidates was located on GGA 5. The corresponding variant is located in the intron of the SRY-box 6 gene (SOX6), which encodes a transcription factor known to affect developmental processes and skeletal formation in humans $[60,65]$. In addition, the gene was linked with BMD of the femoral neck [75], and skeletal abnormalities have previously been observed in SOX6 knockout mice, suggesting an integral role in cartilage formation [76]. We identified the transmembrane and coiled-coil domains 1 gene (TMCO1), located on GGA 8, as a candidate for BMD. TMCO1 plays an important role in bone formation mediating calcium homeostasis within the endoplasmic reticulum [61]. Disruption of the endoplasmic reticulum of an osteoblast can lead to severe bone disorders [77]. Recently, Li et al. [61] demonstrated that TMCO1 deficiency 
leads to reduced bone formation and osteoblast differentiation in humans and mice. In addition to SOX6, the podocan gene $(P O D N)$ is another candidate that was associated with two traits, namely $\mathrm{BBS}$ and BMD of the humerus. $P O D N$ encodes a proteoglycan that was shown to bind type 1 collagen, suggesting a potential role in growth regulation [78]. At this point, the great influence of collagen on mechanical properties of bones should be mentioned, which is assumed to apply equally to humans [79] and chickens [80]. That PODN could be a promising candidate for bone integrity in laying hens is supported by findings of Raymond et al. [15]. Although the G-patch domain containing 1 gene (GPATCH1), identified as BMD candidate, is considered a candidate gene for osteoporosis in humans [55], functional information is limited and its role in skeletal pathophysiology is not yet clear.

For a group of three candidates, the literature suggests a functional relationship with osteoarthritis, a pathological condition of cartilage degradation [81]. Osteoarthritis and osteoporosis are closely related and characterised by subchondral bone loss and excessive bone resorption [20, 81, 82]. It is assumed that both diseases are partly determined by common genes [83]. One of the candidates found in our study is the MCF.2 cell line derived transforming sequence like gene (MCF2L), shown to be expressed in cartilage tissue, and linked to joint osteoarthritis in humans [54, 84]. In addition, Mao et al. [85] recently pointed out the relevance of $M C F 2 L$ for osteoporosis, which underlines the link between both disorders. The asporin gene $(A S P N)$, also known as biglycan $(B G N)$, is assumed to regulate chondrogenesis. While the results of Mishra et al. [63] point to a functional role of ASPN in osteoarthritis, other studies reported only a marginal relationship or contradict such an association $[86,87]$. Given these contradictory results and the fact that the association with ASPN was not significant in our study, we consider $A S P N$ a suggestive candidate that requires further investigation. The SRY-box 9 gene (SOX9) is our third candidate linked to osteoarthritis [88]. SOX9 is considered a pivotal player in chondrogenesis, as its protein, the transcription factor SOX9, was shown to stimulate chondrocyte differentiation [64, 89]. In addition, SOX9 mediates the Wnt signalling pathway, abnormalities of which are correlated with cartilage degradation [64].

The remaining candidates, i.e. the SFRP4, WNT3, and WNT9B genes, are functionally linked to the Wnt signalling pathway, which plays a key role in various basic developmental processes [90]. The secreted frizzled related protein 4 gene (SFRP4) encodes a protein that primarily antagonizes Wnt polypeptides [90] and is one of the BMD candidates. A mutation in SFRP4 was shown to cause pathological reduction of cortical bone tissue in mice and humans [57]. The Wnt signalling pathway is crucial for bone metabolism and to date, several Wnt genes are known to be associated with traits such as bone mass and BMD $[55,91]$. This also includes the Wnt family member 3 gene (WNT3), which was identified in this study [55, 88]. The Wnt family member 9B gene (WNT9B), located adjacent to WNT3 on GGA 27, was identified as a candidate for BBS. Although its role in skeletal biology is less explored than that of other Wnt genes, we consider WNT9B a susceptibility gene for bone strength due to its association with femur BMD [65]. The high importance of the Wnt signalling pathway for bone strength is supported by the significant enrichment that was shown in the GSA for this functional pathway. Furthermore, the mitogen-activated protein kinase (MAPK) signalling pathway was enriched, which is also very important for skeletal development and, in particular, for chondrogenesis [92]. These observations are in accordance with recent results from pathway analyses [25, 93].

Taken together, we identified a number of genetic loci associated with the bone traits studied. Based on these findings, we can confirm the assumption that bone stability is determined by multiple genes, each of which has a rather small effect size. The genes presented here represent suggestive susceptibility genes of bone integrity in chickens, some of which are nonetheless very promising based on what is known so far. Follow-up studies will 
be required to determine causalities and further uncover the biological significance of these genes. Here, the use of an F2 mapping population for high-resolution mapping of loci is recommended [94]. Considering the animal model, a follow-up study should also investigate the influence of phylogenetic origin on bone phenotypic plasticity, which was not done here, as we focused on finding loci that are significant for laying hens across phylogenetically divergent layer lines.

\section{Conclusions}

In this study, association analyses were performed to identify loci related with bone integrity in laying hens. In the subsequent functional analyses, a set of 16 promising candidate genes was identified, although in some cases rather small SNP effect estimates were observed. Some of the genes were shown to be involved in pivotal pathways that regulate bone metabolism. Our results strongly support genetics as a crucial factor that contributes significantly to the regulation of bone strength and thus offers great opportunities to improve bone health in laying hens. Further functional analyses on the candidate genes identified at a suggestive level have to follow in order to confirm their biological significance.

Author Contributions: Conceptualisation, S.J., U.B. and S.W; data curation, A.W.; formal analysis, S.J., U.B. and J.S.; funding acquisition, S.W.; investigation, S.J., C.H. and A.W.; resources, A.M.S.; supervision, A.R.S and S.W.; visualisation, S.J.; writing - original draft preparation, S.J.; writing - review and editing, S.J., U.B., C.H., F.R., J.S., A.O.S., A.M.S., A.R.S., A.W. and S.W. All authors have read and agreed to the final version of the manuscript.

Funding: This research was funded by the AdaptHuhn Initiative of the Friedrich-Loeffler-Institut.

Acknowledgments: We like to thank Torsten Pook (Animal Breeding and Genetics Group, University of Göttingen) for performing the imputation of the chicken genotypes. Furthermore, we greatly appreciate the support in data collection and DNA preparation provided by the technical staff of the Institute of Farm Animal Genetics.

Conflicts of Interest: The authors declare no conflict of interest. 


\section{References}

[1] Sandilands, V. The laying hen and bone fractures. Vet. Rec. 2011. 169, 411.

[2] Petrik, M. T., Guerin, M. T., Widowski, T. M. On-farm comparison of keel fracture prevalence and other welfare indicators in conventional cage and floor-housed laying hens in Ontario, Canada. Poult. Sci. 2015. 94, 579-585.

[3] Fleming, R. H., McCormack, H. A., McTeir, L., Whitehead, C. C. Relationships between genetic, environmental and nutritional factors influencing osteoporosis in laying hens. $\mathrm{Br}$. Poult. Sci. 2006. 47, 742-755.

[4] Cransberg, P. H., Parkinson, G. B., Wilson, S., Thorp, B. H. Sequential studies of skeletal calcium reserves and structural bone volume in a commercial layer flock. Br. Poult. Sci. 2001. 42, 260-265.

[5] McCoy, M. A., Reilly, G. A. C., Kilpatrick, D. J. Density and breaking strength of bones of mortalities among caged layers. Res. Vet. Sci. 1996. 60, 185-186.

[6] Nasr, M. A. F., Nicol, C. J., Murrell, J. C. Do laying hens with keel bone fractures experience pain? PLoS One 2012. 7, e42420.

[7] Webster, A. B. Welfare implications of avian osteoporosis. Poult. Sci. 2004. 83, 184-192.

[8] Nasr, M. A. F., Murrell, J., Nicol, C. J. The effect of keel fractures on egg production, feed and water consumption in individual laying hens. Br. Poult. Sci. 2013. 54, 165-170.

[9] Eusemann, B. K., Patt, A., Schrader, L., Weigend, S., Thöne-Reineke, C., Petow, S. The role of egg production in the etiology of keel bone damage in laying hens. Front. Vet. Sci. 2020. $7,81$.

[10] Habig, C., Baulain, U., Henning, M., Scholz, A. M., Sharifi, A. R., Janisch, S., Simianer, H., Weigend, S. How bone stability in laying hens is affected by phylogenetic background and performance level. Eur. Poult. Sci. 2017. 81.

[11] Hocking, P. M., Bain, M., Channing, C. E., Fleming, R., Wilson, S. Genetic variation for egg production, egg quality and bone strength in selected and traditional breeds of laying fowl. Br. Poult. Sci. 2003. 44, 365-373.

[12] Gebhardt-Henrich, S. G., Fröhlich, E. K. Early onset of laying and bumblefoot favor keel bone fractures. Animals 2015. 5, 1192-1206.

[13] Dunn, I. C., De Koning, D.-J., McCormack, H. A., Fleming, R. H., Wilson, P. W., Andersson, B., Schmutz, M., Benavides, C., Dominguez-Gasca, N., Sanchez-Rodriguez, E., et al. No evidence that selection for egg production persistency causes loss of bone quality in laying hens. Genet. Sel. Evol. 2021. 53, 11.

[14] Jansen, S., Baulain, U., Habig, C., Weigend, A., Halle, I., Scholz, A. M., Simianer, H., Sharifi, A. R., Weigend, S. Relationship between bone stability and egg production in genetically divergent chicken layer lines. Animals 2020. 10, 850.

[15] Raymond, B., Johansson, A. M., McCormack, H. A., Fleming, R. H., Schmutz, M., Dunn, I. C., De Koning, D. J. Genome-wide association study for bone strength in laying hens. J. Anim. Sci. 2018. 96, 2525-2535.

[16] Bishop, S. C., Fleming, R. H., McCormack, H. A., Flock, D. K., Whitehead, C. C. Inheritance of bone characteristics affecting osteoporosis in laying hens. Br. Poult. Sci. 2000. 41, 33-40.

[17] Rubin, C. J., Brändström, H., Wright, D., Kerje, S., Gunnarsson, U., Schutz, K., Fredriksson, R., Jensen, P., Andersson, L., Ohlsson, C., et al. Quantitative trait loci for BMD and bone strength in an intercross between domestic and wildtype chickens. J. Bone Miner. Res. 2007. $22,375-384$. 
[18] Zhou, H., Deeb, N., Evock-Clover, C. M., Mitchell, A. D., Ashwell, C. M., Lamont, S. J. Genome-wide linkage analysis to identify chromosomal regions affecting phenotypic traits in the chicken. III. Skeletal integrity. Poult. Sci. 2007. 86, 255-266.

[19] Bennett, A. K., Hester, P. Y., Spurlock, D. M. Relationships of a transforming growth factorbeta2 single nucleotide polymorphism and messenger ribonucleic acid abundance with bone and production traits in chickens. Poult. Sci. 2007. 86, 829-834.

[20] Johnsson, M., Gustafson, I., Rubin, C.-J., Sahlqvist, A.-S., Jonsson, K. B., Kerje, S., Ekwall, O., Kämpe, O., Andersson, L., Jensen, P., et al. A sexual ornament in chickens is affected by pleiotropic alleles at HAO1 and BMP2, selected during domestication. PLoS Genetics 2012. 8, e1002914.

[21] Schreiweis, M. A., Hester, P. Y., Moody, D. E. Identification of quantitative trait loci associated with bone traits and body weight in an F2 resource population of chickens. Genet. Sel. Evol. 2005. 37, 677.

[22] Podisi, B. K., Knott, S. A., Dunn, I. C., Burt, D. W., Hocking, P. M. Bone mineral density QTL at sexual maturity and end of lay. Br. Poult. Sci. 2012. 53, 763-769.

[23] Dunn, I. C., Fleming, R. H., McCormack, H. A., Morrice, D., Burt, D. W., Preisinger, R., Whitehead, C. C. A QTL for osteoporosis detected in an F2 population derived from White Leghorn chicken lines divergently selected for bone index. Anim. Genet. 2007. 38, 45-49.

[24] De Koning, D.-J., Dominguez-Gasca, N., Fleming, R. H., Gill, A., Kurian, D., Law, A., McCormack, H. A., Morrice, D., Sanchez-Rodriguez, E., Rodriguez-Navarro, A. B., et al. An eQTL in the cystathionine beta synthase gene is linked to osteoporosis in laying hens. Genet. Sel. Evol. 2020. 52, 13.

[25] Guo, J., Sun, C., Qu, L., Shen, M., Dou, T., Ma, M., Wang, K., Yang, N. Genetic architecture of bone quality variation in layer chickens revealed by a genome-wide association study. Sci. Rep. 2017. 7, 45317.

[26] Rothammer, S., Bernau, M., Kremer-Rücker, P. V., Medugorac, I., Scholz, A. M. Genomewide QTL mapping results for regional DXA body composition and bone mineral density traits in pigs. Arch. Anim. Breed. 2017. 60, 51-59.

[27] Ramzan, F., Klees, S., Schmitt, A. O., Cavero, D., Gültas, M. Identification of age-specific and common key regulatory mechanisms governing eggshell strength in chicken using Random Forests. Genes 2020. 11, 464.

[28] Romagnoni, A., Jégou, S., Van Steen, K., Wainrib, G., Hugot, J.-P., Peyrin-Biroulet, L., Chamaillard, M., Colombel, J.-F., Cottone, M., D'Amato, M., et al. Comparative performances of machine learning methods for classifying Crohn Disease patients using genome-wide genotyping data. Sci. Rep. 2019. 9, 10351.

[29] Brieuc, M. S. O., Waters, C. D., Drinan, D. P., Naish, K. A. A practical introduction to Random Forest for genetic association studies in ecology and evolution. Mol. Ecol. Resour. 2018. 18, 755-766.

[30] Brieuc, M. S. O., Ono, K., Drinan, D. P., Naish, K. A. Integration of Random Forest with population-based outlier analyses provides insight on the genomic basis and evolution of run timing in Chinook salmon (Oncorhynchus tshawytscha). Mol. Ecol. 2015. 24, 2729-2746.

[31] Nguyen, T.-T., Huang, J. Z., Wu, Q., Nguyen, T. T., Li, M. J. Genome-wide association data classification and SNPs selection using two-stage quality-based Random Forests. BMC Genom. 2015. 16, S5.

[32] Lieboldt, M.-A., Halle, I., Frahm, J., Schrader, L., Baulain, U., Henning, M., Preisinger, R., Dänicke, S., Weigend, S. Phylogenic versus selection effects on growth development, egg laying and egg quality in purebred laying hens. Eur. Poult. Sci. 2015. 79. 
[33] Dudde, A., Weigend, S., Krause, E. T., Jansen, S., Habig, C., Schrader, L. Chickens in motion: Effects of egg production level and pen size on the motor abilities and bone stability of laying hens (Gallus gallus forma domestica). Appl. Anim. Behav. Sci. 2020. 227, 104998.

[34] Kranis, A., Gheyas, A. A., Boschiero, C., Turner, F., Yu, L., Smith, S., Talbot, R., Pirani, A., Brew, F., Kaiser, P., et al. Development of a high density 600K SNP genotyping array for chicken. BMC Genomics 2013. 14, 59.

[35] SNP \& Variation Suite ${ }^{T M}$ (Version 8.9). Bozeman, M. T. Golden Helix Inc. https:// goldenhelix.com.

[36] Browning, B. L., Zhou, Y., Browning, S. R. A one-penny imputed genome from nextgeneration reference panels. Am. J. Hum. Genet. 2018. 103, 338-348.

[37] National Center for Biotechnology Information (NCBI). Genome assembly GRCg6a. https: //ncbi.nlm.nih.gov/assembly/GCF_000002315.6. Accessed on 17 June 2020.

[38] Benjamini, Y., Hochberg, Y. Controlling the false discovery rate: A practical and powerful approach to multiple testing. J. R. Stat. Soc. Series B Stat. Methodol. 1995. 57, 289-300.

[39] Kursa, M. B., Rudnicki, W. R. Feature selection with the Boruta package. J. Stat. Softw. 2010. 36.

[40] Python Software Foundation. Python Language Reference, version 3.8.9. https://docs. python.org/3.8/reference/index.html. 2019.

[41] Homola, D. Python implementations of the Boruta all-relevant feature selection method. https://github.com/scikit-learn-contrib/boruta_py. Accessed on 14 October 2020.

[42] Pedregosa, F., Varoquaux, G., Gramfort, A., Michel, V., Thirion, B., Grisel, O., Blondel, M., Prettenhofer, P., Weiss, R., Dubourg, V. Scikit-learn: Machine learning in Python. J. Mach. Learn. Res. 2011. 12, 2825-2830.

[43] R Core Team. R: A language and environment for statistical computing. R Foundation for statistical computing. Vienna, Austria. 2020.

[44] Yates, A. D., Achuthan, P., Akanni, W., Allen, J., Allen, J., Alvarez-Jarreta, J., Amode, M. R., Armean, I. M., Azov, A. G., Bennett, R., et al. Ensembl 2020. Nucleic Acids Res. 2020. 48, 682-688.

[45] Kinsella, R. J., Kähäri, A., Haider, S., Zamora, J., Proctor, G., Spudich, G., Almeida-King, J., Staines, D., Derwent, P., Kerhornou, A., et al. Ensembl BioMarts: a hub for data retrieval across taxonomic space. Database 2011. 2011, bar030.

[46] Brown, G. R., Hem, V., Katz, K. S., Ovetsky, M., Wallin, C., Ermolaeva, O., Tolstoy, I., Tatusova, T., Pruitt, K. D., Maglott, D. R., et al. Gene: a gene-centered information resource at NCBI. Nucleic Acids Res. 2015. 43, 36-42.

[47] Wiedemann, I., Maehlmeyer, A., Jansen, S., Sharifi, A. R., Knorr, C. SNP g.1007A $>$ G within the porcine DNAL4 gene affects sperm motility traits and percentage of midpiece abnormalities. Reprod. Domest. Anim. 2018. 53, 401-413.

[48] Bates, D., Mächler, M., Bolker, B., Walker, S. Fitting linear mixed-effects models using Ime4. J. Stat. Softw. 2015. 67.

[49] Van Lenth, R. emmeans: Estimated marginal means, aka least-squares means. $R$ package version 1.5.3. https : / / CRAN . R - project . org / package $=$ emmeans. Accessed on 08 January 2021.

[50] Raudvere, U., Kolberg, L., Kuzmin, I., Arak, T., Adler, P., Peterson, H., Vilo, J. g:Profiler: a web server for functional enrichment analysis and conversions of gene lists (2019 update). Nucleic Acids Res. 2019. 47, 191-198. 
[51] Kanehisa, M., Furumichi, M., Sato, Y., Ishiguro-Watanabe, M., Tanabe, M. KEGG: integrating viruses and cellular organisms. Nucleic Acids Res. 2021. 49, D545-D551.

[52] Reimand, J., Kull, M., Peterson, H., Hansen, J., Vilo, J. g:Profiler-a web-based toolset for functional profiling of gene lists from large-scale experiments. Nucleic Acids Res. 2007. 35, 193-200.

[53] Sayols, S. rrvgo: a Bioconductor package to reduce and visualize Gene Ontology terms. https://ssayols.github.io/rrvgo. Accessed on 07 February 2021.

[54] Day-Williams, A. G., Southam, L., Panoutsopoulou, K., Rayner, N. W., Esko, T., Estrada, K., Helgadottir, H. T., Hofman, A., Ingvarsson, T., Jonsson, H., et al. A variant in MCF2L is associated with osteoarthritis. Am. J. Hum. Genet. 2011. 89, 446-450.

[55] Estrada, K., Styrkarsdottir, U., Evangelou, E., Hsu, Y.-H., Duncan, E. L., Ntzani, E. E., Oei, L., Albagha, O. M. E., Amin, N., Kemp, J. P., et al. Genome-wide meta-analysis identifies 56 bone mineral density loci and reveals 14 loci associated with risk of fracture. Nat. Genet. 2012. 44, 491-501.

[56] Zhang, H., Tao, X., Wu, J. Association of calcitonin receptor gene polymorphism with bone mineral density in postmenopausal Chinese women: a meta-analysis. Arch. Gynecol. Obstet. 2015. 291, 165-172.

[57] Kiper, P. O. S., Saito, H., Gori, F., Unger, S., Hesse, E., Yamana, K., Kiviranta, R., Solban, N., Liu, J., Brommage, R., et al. Cortical-bone fragility-Insights from sFRP4 deficiency in Pyle's disease. N. Engl. J. Med. 2016. 374, 2553-2562.

[58] Li, H., Deeb, N., Zhou, H., Mitchell, A. D., Ashwell, C. M., Lamont, S. J. Chicken quantitative trait loci for growth and body composition associated with transforming growth factor-beta genes. Poult. Sci. 2003. 82, 347-356.

[59] Mullin, B. H., Walsh, J. P., Zheng, H.-F., Brown, S. J., Surdulescu, G. L., Curtis, C., Breen, G., Dudbridge, F., Richards, J. B., Spector, T. D., et al. Genome-wide association study using family-based cohorts identifies the WLS and CCDC170/ESR1 loci as associated with bone mineral density. BMC Genomics 2016. 17, 136.

[60] Yang, T. L., Guo, Y., Liu, Y. J., Shen, H., Liu, Y. Z., Lei, S. F., Li, J., Tian, Q., Deng, H. W. Genetic variants in the SOX6 gene are associated with bone mineral density in both Caucasian and Chinese populations. Osteoporos. Int. 2012. 23, 781-787.

[61] Li, J., Liu, C., Li, Y., Zheng, Q., Xu, Y., Liu, B., Sun, W., Li, Y., Ji, S., Liu, M., et al. TMCO1-mediated $\mathrm{Ca}(2+)$ leak underlies osteoblast functions via CaMKII signaling. Nat. Commun. 2019. 10, 1589.

[62] Borton, A. J., Frederick, J. P., Datto, M. B., Wang, X. F., Weinstein, R. S. The loss of Smad3 results in a lower rate of bone formation and osteopenia through dysregulation of osteoblast differentiation and apoptosis. J. Bone Miner. Res. 2001. 16, 1754-1764.

[63] Mishra, A., Awasthi, S., Raj, S., Mishra, P., Srivastava, R. N. Identifying the role of ASPN and COMP genes in knee osteoarthritis development. J. Orthop. Surg. Res. 2019. 14, 337.

[64] Szwedowski, D., Szczepanek, J., Paczesny, Ł., Pękała, P., Zabrzyński, J., Kruczyński, J. Genetics in cartilage lesions: Basic science and therapy approaches. Int. J. Mol. Sci. 2020. $21,5430$.

[65] Karasik, D., Rivadeneira, F., Johnson, M. L. The genetics of bone mass and susceptibility to bone diseases. Nat. Rev. Rheumatol. 2016. 12, 323-334.

[66] Johnsson, M., Jonsson, K. B., Andersson, L., Jensen, P., Wright, D. Genetic regulation of bone metabolism in the chicken: Similarities and differences to ammalian systems. PLoS Genetics 2015. 11, e1005250. 
[67] Xiao, S.-M., Kung, A. W. C., Gao, Y., Lau, K.-S., Ma, A., Zhang, Z.-L., Liu, J.-M., Xia, W., $\mathrm{He}$, J.-W., Zhao, L., et al. Post-genome wide association studies and functional analyses identify association of MPP7 gene variants with site-specific bone mineral density. Hum. Mol. Genet. 2012. 21, 1648-1657.

[68] Xie, J., Guo, J., Kanwal, Z., Wu, M., Lv, X., Ibrahim, N. A., Li, P., Buabeid, M. A., Arafa, E.-S. A., Sun, Q. Calcitonin and bone physiology: In vitro, in vivo, and clinical investigations. J. Endocrinol. 2020. 2020, 3236828.

[69] Zofková, I., Zajícková, K., Hill, M., Krepelová, A. Does polymorphism C1377T of the calcitonin receptor gene determine bone mineral density in postmenopausal women? Exp. Clin. Endocrinol. Diabetes 2003. 111, 447-449.

[70] Schinke, T., Liese, S., Priemel, M., Haberland, M., Schilling, A. F., Catala-Lehnen, P., Blicharski, D., Rueger, J. M., Gagel, R. F., Emeson, R. B., et al. Decreased bone formation and osteopenia in mice lacking $\alpha$-Calcitonin gene-related peptide. J. Bone Miner. Res. 2004. 19, 2049-2056.

[71] Goetz, S. C., Anderson, K. V. The primary cilium: a signalling centre during vertebrate development. Nat. Rev. Genet. 2010. 11, 331-344.

[72] Ali, I. H. A., Brazil, D. P. Bone morphogenetic proteins and their antagonists: current and emerging clinical uses. Br. J. Pharmacol. 2014. 171, 3620-3632.

[73] Hata, A., Lagna, G., Massagué, J., Hemmati-Brivanlou, A. Smad6 inhibits BMP/Smad1 signaling by specifically competing with the Smad4 tumor suppressor. Genes Dev. 1998. 12, 186-197.

[74] Hidalgo-Bravo, A., Parra-Torres, A. Y., Casas-Avila, L., Jimenez-Ortega, R. F., RamírezSalazar, E. G., Patiño, N., Rivera-Paredez, B., Salmerón, J., Valdés-Flores, M., VelázquezCruz, R. Association of RMND1/CCDC170-ESR1 single nucleotide polymorphisms with hip fracture and osteoporosis in postmenopausal women. Climacteric 2019. 22, 97-104.

[75] Rivadeneira, F., Styrkarsdottir, U., Estrada, K., Halldorsson, B. V., Hsu, Y.-H., Richards, J. B., Zillikens, M. C., Kavvoura, F. K., Amin, N., Aulchenko, Y. S., et al. Twenty bonemineral-density loci identified by large-scale meta-analysis of genome-wide association studies. Nat. Genetic. 2009. 41, 1199-1206.

[76] Smits, P., Li, P., Mandel, J., Zhang, Z., Deng, J. M., Behringer, R. R., Crombrugghe, B. de, Lefebvre, V. The transcription factors L-Sox5 and Sox6 are essential for cartilage formation. Dev. Cell 2001. 1, 277-290.

[77] Sammels, E., Parys, J. B., Missiaen, L., De Smedt, H., Bultynck, G. Intracellular Ca2+ storage in health and disease: a dynamic equilibrium. Cell calcium 2010. 47, 297-314.

[78] Shimizu-Hirota, R., Sasamura, H., Kuroda, M., Kobayashi, E., Saruta, T. Functional characterization of podocan, a member of a new class in the small leucine-rich repeat protein family. FEBS Letters 2004. 563, 69-74.

[79] Viguet-Carrin, S., Garnero, P., Delmas, P. D. The role of collagen in bone strength. Osteoporos. Int. 2006. 17, 319-336.

[80] Sparke, A. J., Sims, T. J., Avery, N. C., Bailey, A. J., Fleming, R. H., Whitehead, C. C. Differences in composition of avian bone collagen following genetic selection for resistance to osteoporosis. Br. Poult. Sci. 2002. 43, 127-134.

[81] Bultink, I. E., Lems, W. F. Osteoarthritis and osteoporosis: what is the overlap? Curr. Rheumatol. Rep. 2013. 15, 328.

[82] Oliveira, M. C., Vullings, J., Loo, F. A. J. van de. Osteoporosis and osteoarthritis are two sides of the same coin paid for obesity. Nutrition 2020. 70, 110486. 
[83] Cong, Y., Ru, J. Y., Bao, N. R., Guo, T., Zhao, J. N. A single nucleotide polymorphism in the TGF- $\beta 1$ gene ( $r$ 1982073 C>T) may contribute to increased risks of bone fracture, osteoporosis, and osteoarthritis: a meta-analysis. Clin. Rheumatol. 2016. 35, 973-985.

[84] Shepherd, C., Skelton, A. J., Rushton, M. D., Reynard, L. N., Loughlin, J. Expression analysis of the osteoarthritis genetic susceptibility locus mapping to an intron of the MCF2L gene and marked by the polymorphism rs11842874. BMC Med. Genet. 2015. 16, 108.

[85] Mao, J. H., Sui, Y. X., Ao, S., Wang, Y., Liu, Y., Leng, H. miR-140-3p exhibits repressive functions on preosteoblast viability and differentiation by downregulating MCF2L in osteoporosis. In Vitro Cell. Dev. Biol. Anim. 2020. 56, 49-58.

[86] González-Huerta, N. C., Borgonio-Cuadra, V. M., Zenteno, J. C., Cortés-González, S., DuarteSalazar, C., Miranda-Duarte, A. D14 repeat polymorphism of the asporin gene is associated with primary osteoarthritis of the knee in a Mexican Mestizo population. Int. J. Rheum. Dis. 2017. 20, 1935-1941.

[87] Sobhan, M. R., Mehdinejad, M., Jamaladini, M. H., Mazaheri, M., Zare-Shehneh, M., Neamatzadeh, H. Association between aspartic acid repeat polymorphism of the asporin gene and risk of knee osteoarthritis: A systematic review and meta-analysis. Acta Orthop. Traumatol. Turc. 2017. 51, 409-415.

[88] Hsu, Y. H., Kiel, D. P. Clinical review: Genome-wide association studies of skeletal phenotypes: what we have learned and where we are headed. J. Clin. Endocrinol. Metab. 2012. 97, 1958-1977.

[89] Juhász, T., Matta, C., Somogyi, C., Katona, É., Takács, R., Soha, R. F., Szabó, I. A., Cserháti, C., Sződy, R., Karácsonyi, Z., et al. Mechanical loading stimulates chondrogenesis via the PKA/CREB-Sox9 and PP2A pathways in chicken micromass cultures. Cell. Signal. 2014. 26, 468-482.

[90] Kawano, Y., Kypta, R. Secreted antagonists of the Wnt signalling pathway. J. Cell Sci. 2003. $116,2627-2634$.

[91] Johnson, M. L. LRP5 and bone mass regulation: Where are we now? Bonekey Rep 2012. 1, 1.

[92] Zhang, Y., Pizzute, T., Pei, M. A review of crosstalk between MAPK and Wnt signals and its impact on cartilage regeneration. Cell Tissue Res. 2014. 358, 633-649.

[93] Gu, H., Huang, Z., Chen, G., Zhou, K., Zhang, Y., Chen, J., Xu, J., Yin, X. Network and pathway-based analyses of genes associated with osteoporosis. Medicine 2020. 99, e19120.

[94] Yi, G., Shen, M., Yuan, J., Sun, C., Duan, Z., Qu, L., Dou, T., Ma, M., Lu, J., Guo, J., et al. Genome-wide association study dissects genetic architecture underlying longitudinal egg weights in chickens. BMC Genomics 2015. 16, 746. 


\section{Supplementary Materials}

A

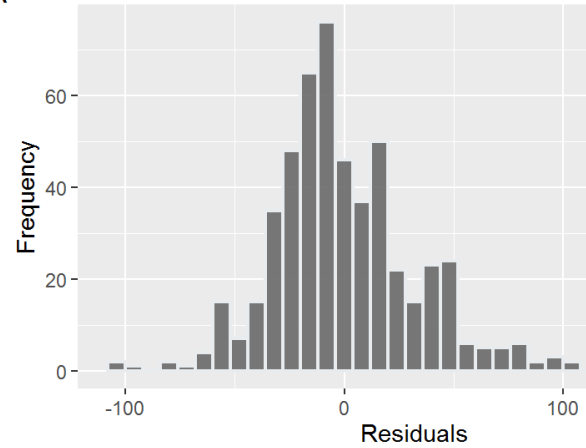

C

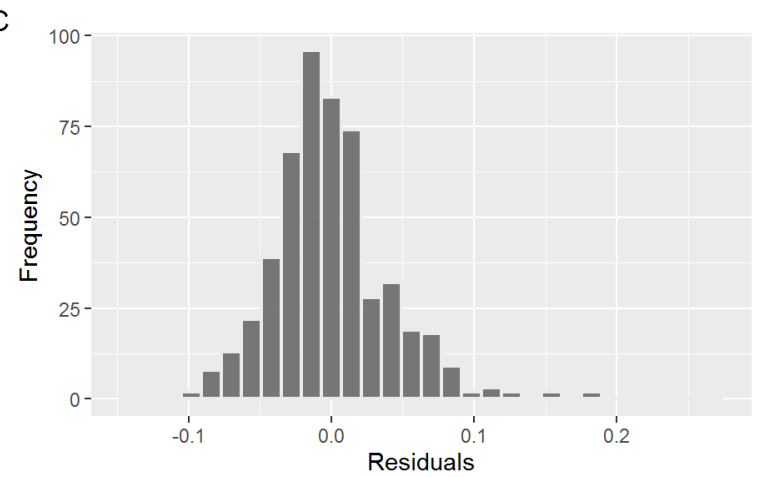

B

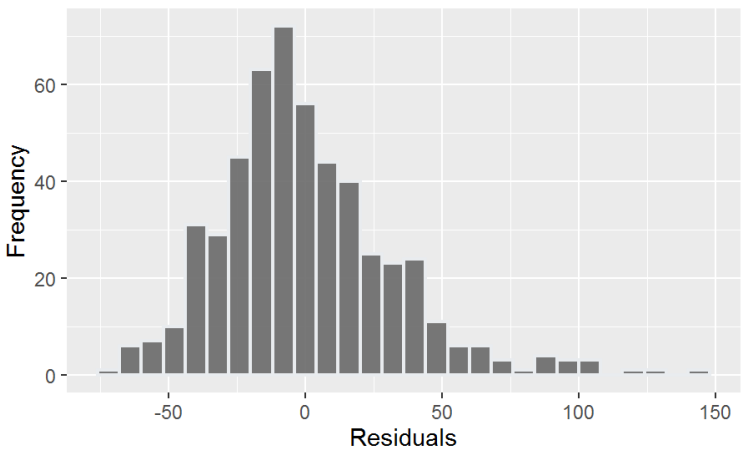

$\mathrm{D}$

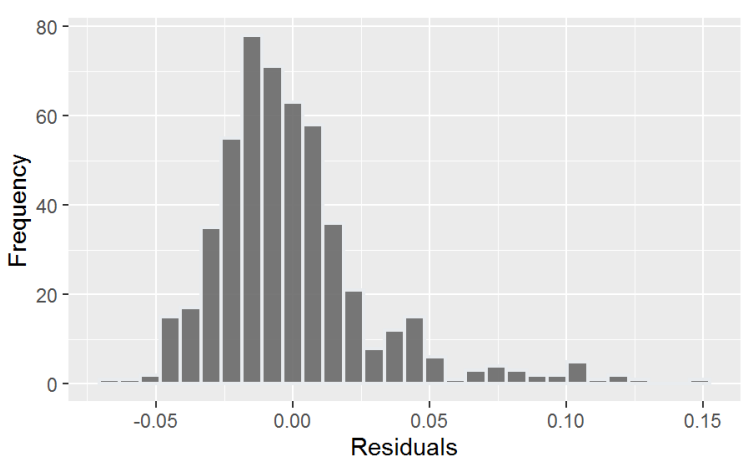

Figure S4.1: Histograms of the residuals for the bone breaking strengths of the tibiotarsus (A) and humerus (B), and the bone mineral densities of the tibiotarsus (C) and humerus (D). 
A

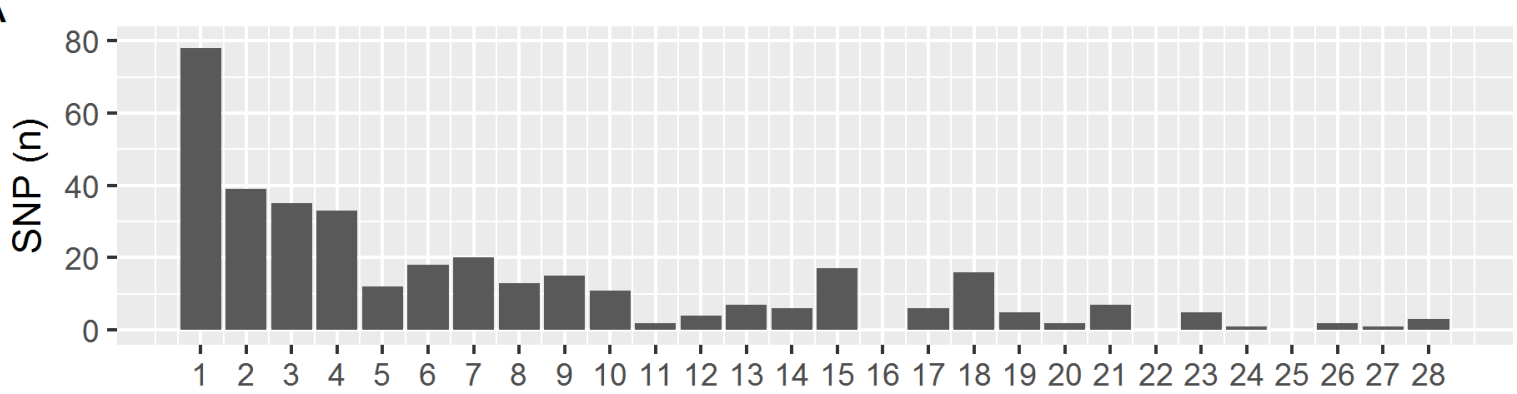

Chromosome

B

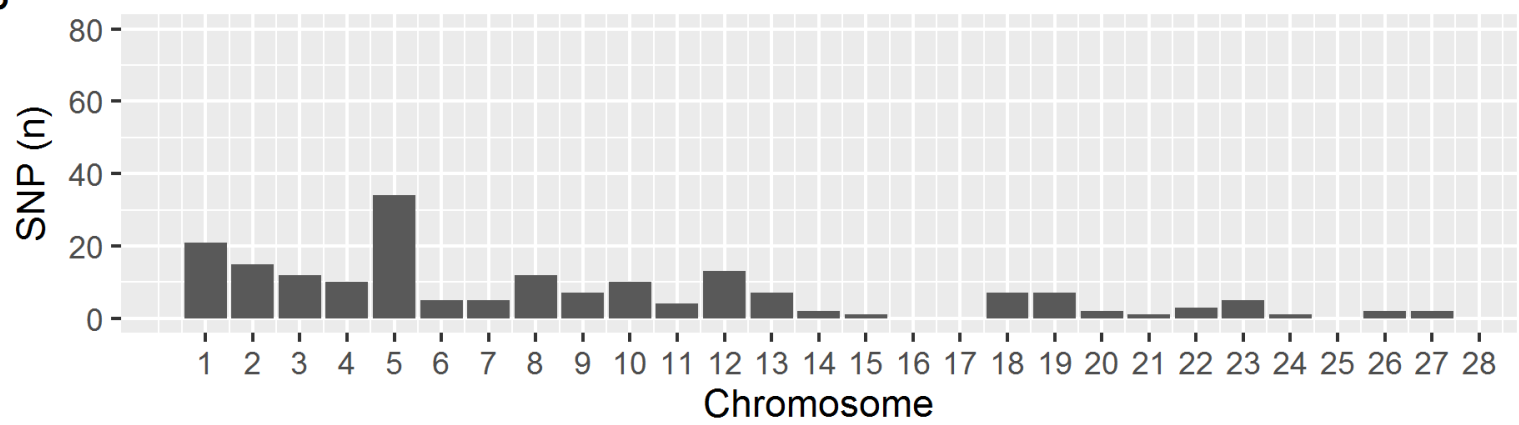

C

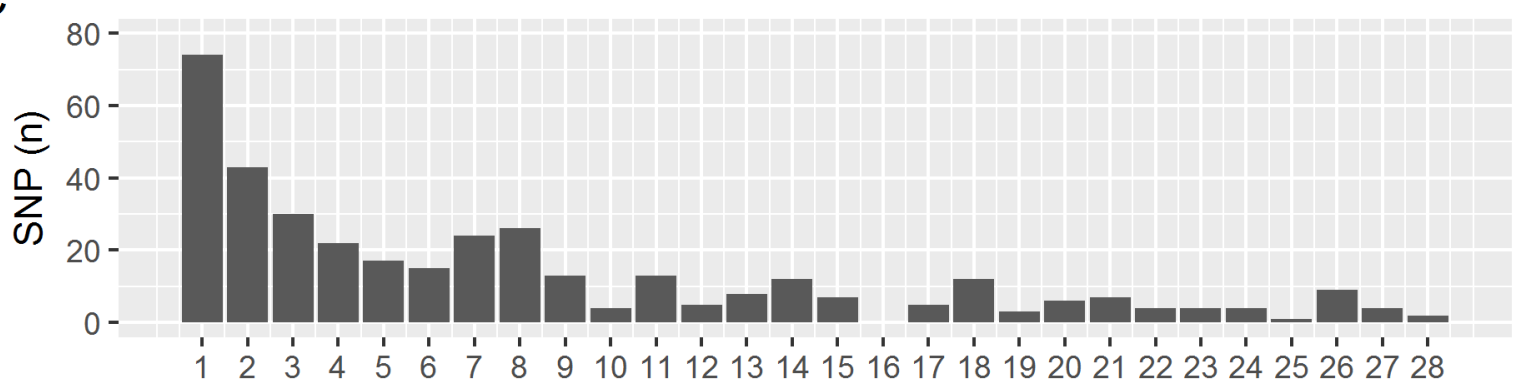

Chromosome

$\mathrm{D}$

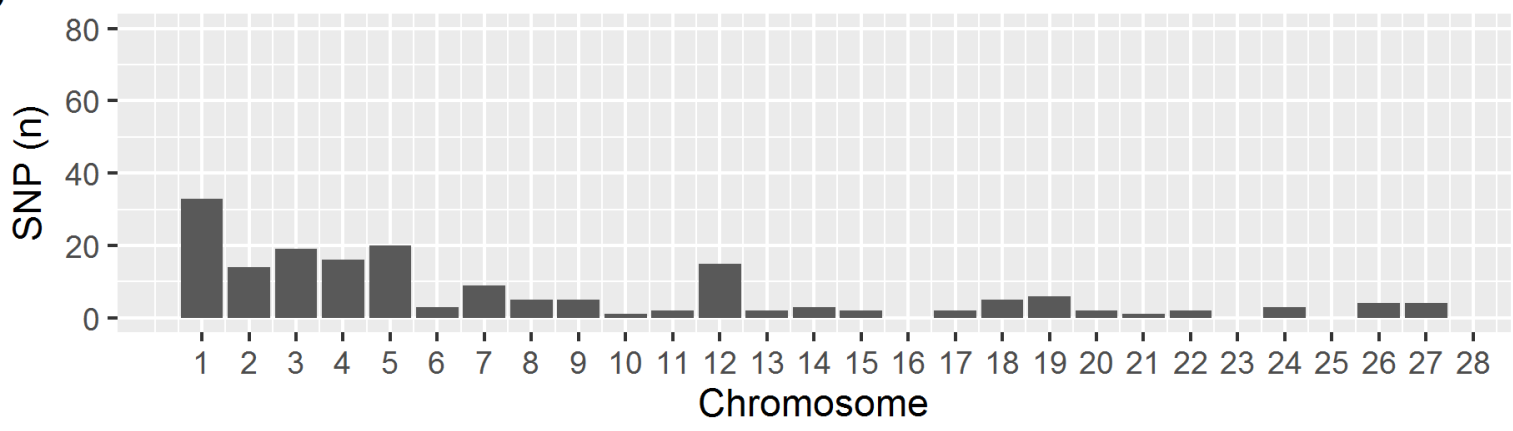

Figure S4.2: Results from the Random Forests classification: Number of annotated SNPs per chromosome for the bone breaking strengths of the tibiotarsus (A) and humerus (B), and the bone mineral densities of the tibiotarsus (C) and humerus (D). 


\section{A}

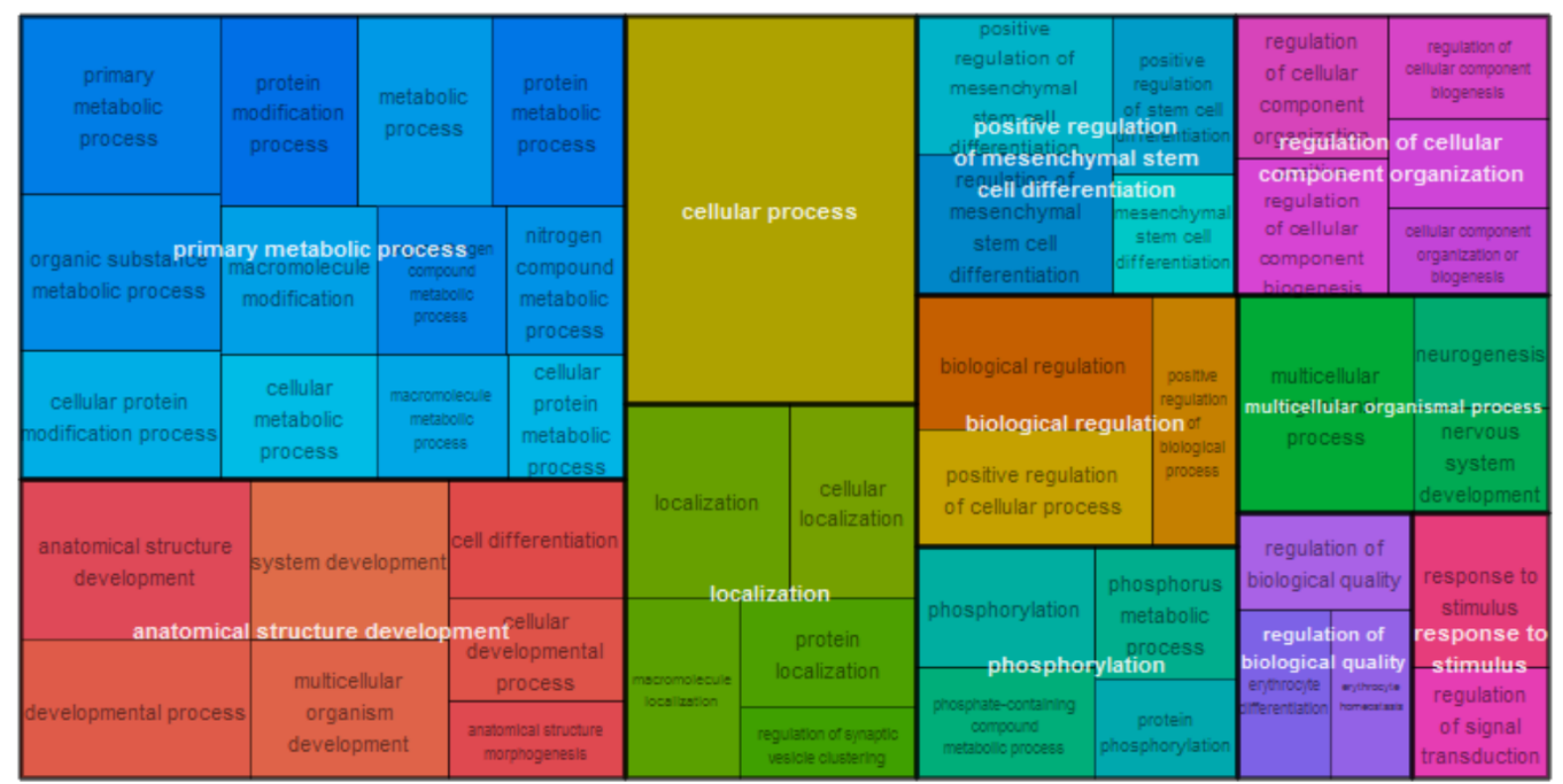

$\mathrm{B}$

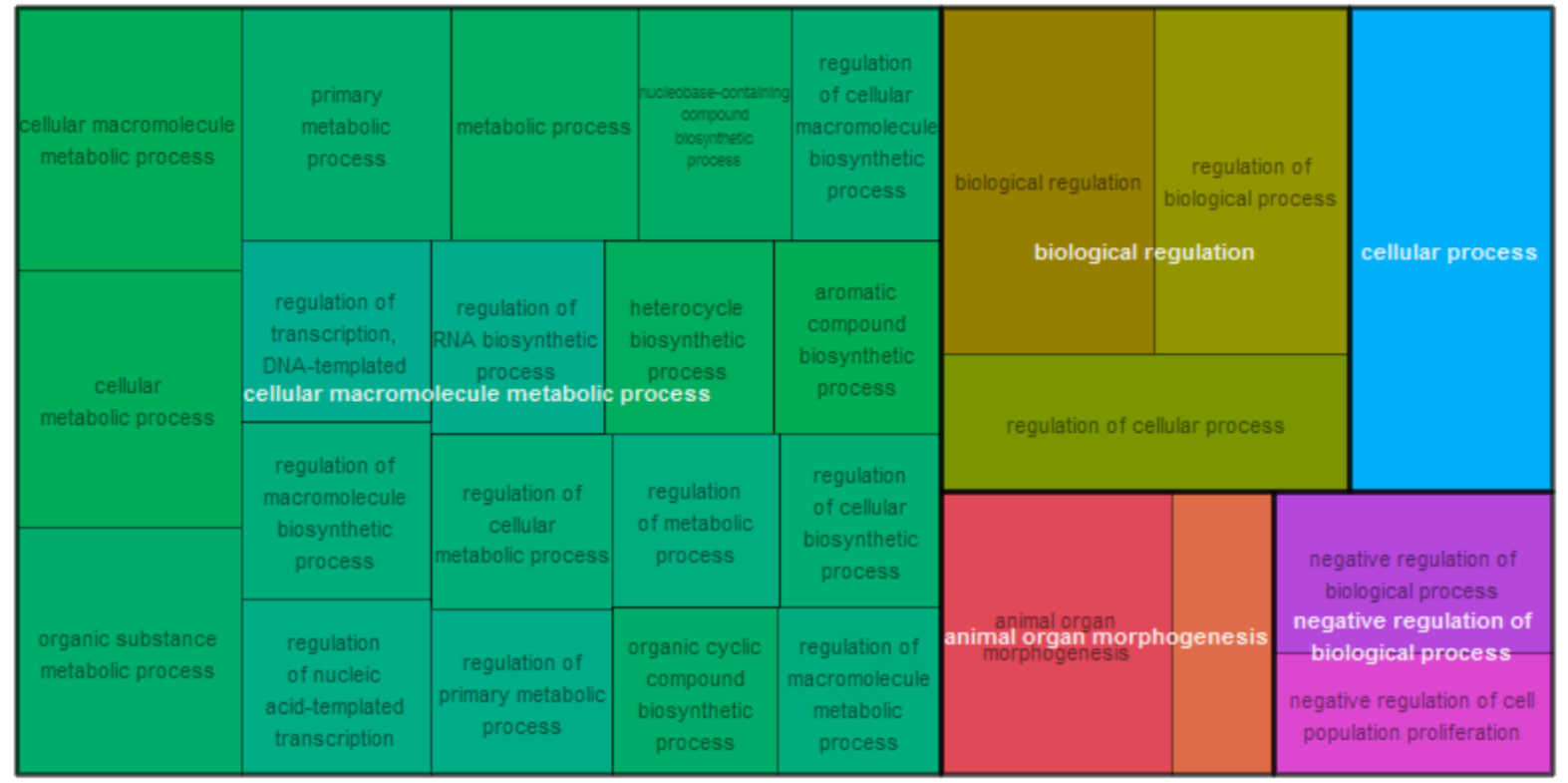

Figure S4.3: Tree maps of significantly enriched Gene Ontology (GO) terms of the category biological processes for genes associated with the bone breaking strengths of the tibiotarsus (A) and humerus (B). Each colour indicates a parent GO term drawn as a box in which the lower-level terms are plotted. The space filled by the terms is proportional to their $-\log _{10} p$-values. 
A

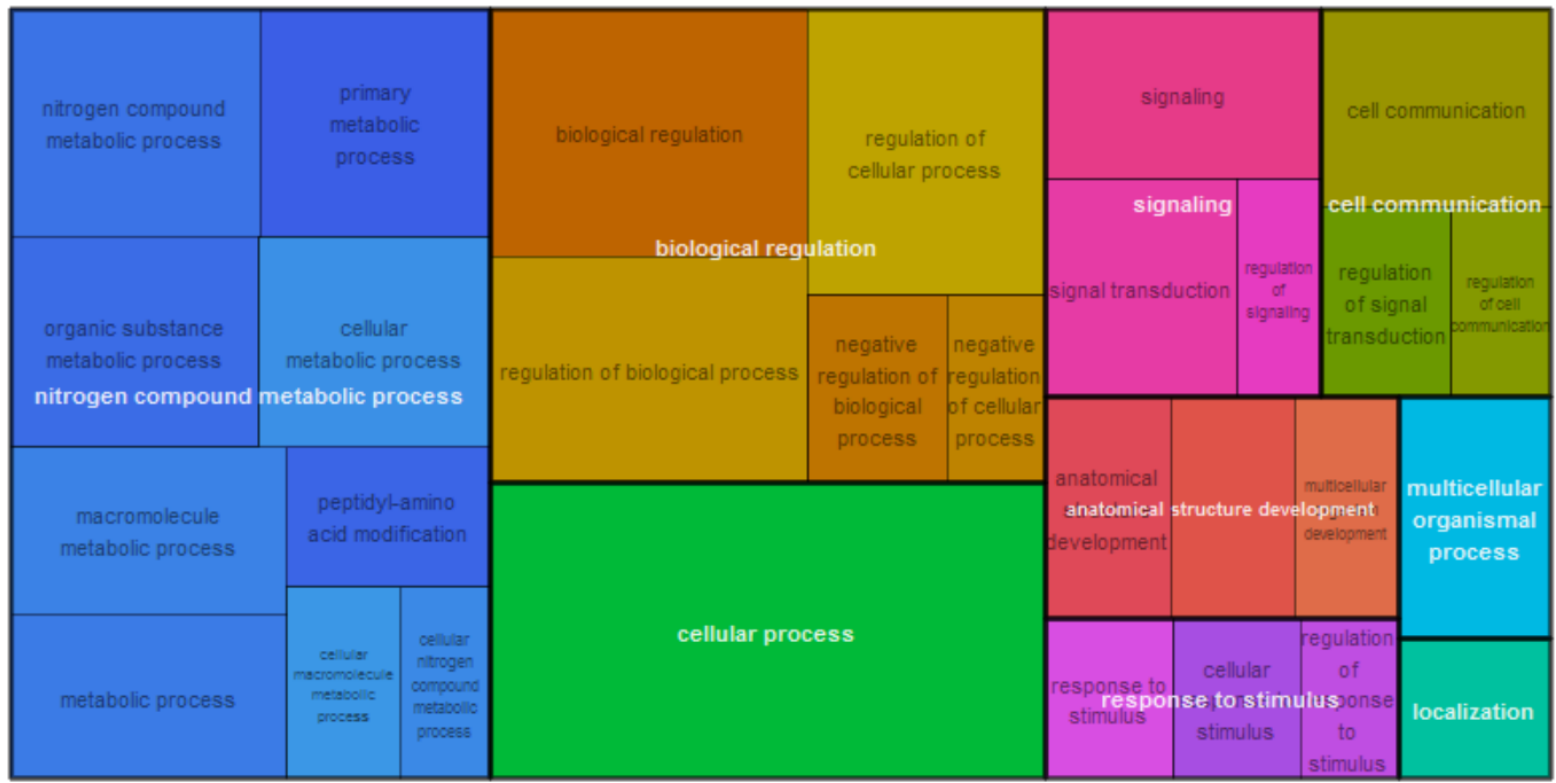

$\mathrm{B}$

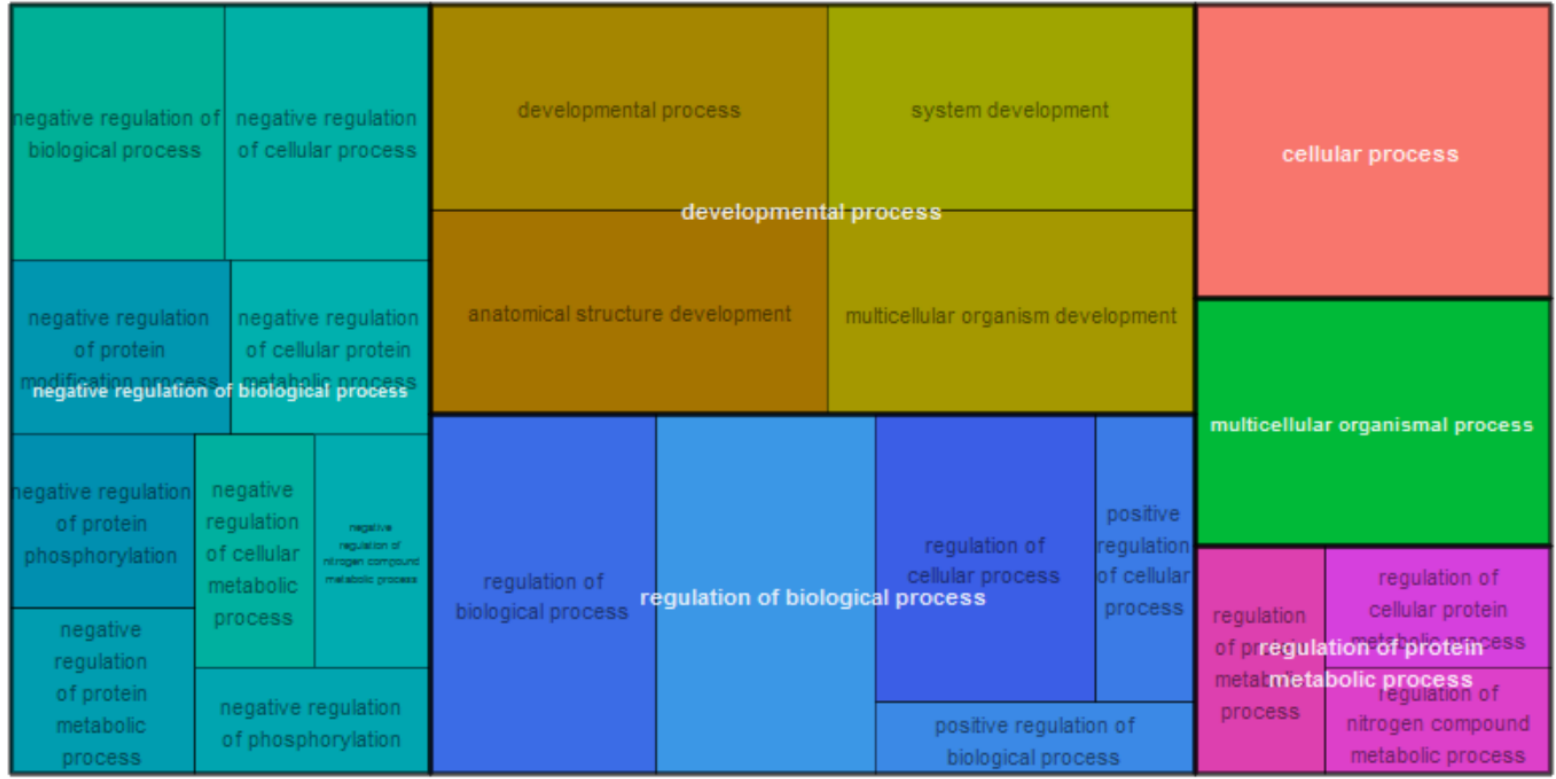

Figure S4.4: Tree maps of significantly enriched Gene Ontology (GO) terms of the category biological processes for genes associated with the bone mineral densities of the tibiotarsus (A) and humerus (B). Each colour indicates a parent GO term drawn as a box in which the lower-level terms are plotted. The space filled by the terms is proportional to their $-\log _{10} p$-values. 
Table S4.1: List of all genes extracted for the bone breaking strengths (BBS) or bone mineral densities (BMD) of the tibiotarsus (Tib) and humerus (Hum) obtained from the genome-wide association studies.

\begin{tabular}{|c|c|c|c|c|}
\hline Ensembl gene id & Chr. & Start & End & Gene name \\
\hline \multicolumn{5}{|l|}{ Unique in Tib_BBS } \\
\hline ENSGALG00000053594 & 1 & 133320865 & 133325014 & - \\
\hline ENSGALG00000016767 & 1 & 133973567 & 134294259 & AFF3 \\
\hline ENSGALG00000037326 & 5 & 27522846 & 27570512 & MAP3K 9 \\
\hline ENSGALG00000009387 & 5 & 27699720 & 27751679 & SYNJ2BP \\
\hline ENSGALG00000009421 & 5 & 28087093 & 28091730 & SRSF5 \\
\hline ENSGALG00000009587 & 5 & 29263703 & 29530569 & GPHN \\
\hline ENSGALG00000009611 & 5 & 29687623 & 29720743 & EIF2AK4 \\
\hline ENSGALG00000009619 & 5 & 29722191 & 29753143 & GPR176 \\
\hline ENSGALG00000001907 & 6 & 2968233 & 3091445 & WAPL \\
\hline ENSGALG00000001934 & 6 & 3059913 & 3082527 & OPN4 \\
\hline ENSGALG00000001977 & 6 & 3104861 & 3175701 & LDB3 \\
\hline ENSGALG00000008939 & 8 & 19243036 & 19264136 & FUBP1 \\
\hline ENSGALG00000008945 & 8 & 19269326 & 19285928 & NEXN \\
\hline ENSGALG00000008951 & 8 & 19297753 & 19332508 & MIGA1 \\
\hline ENSGALG00000006194 & 20 & 9910901 & 9915465 & SLC52A3 \\
\hline \multicolumn{5}{|l|}{ Unique in Tib_BMD } \\
\hline ENSGALG00000050866 & 1 & 79311694 & 79327367 & HSD3B1 \\
\hline ENSGALG00000014766 & 1 & 79328749 & 79338994 & $\mathrm{HAO} 2$ \\
\hline 00016379 & 1 & 5336 & 120468539 & SMS \\
\hline 0000016382 & 1 & 120491889 & 120522883 & MBTPS2 \\
\hline ENSGALG00000019157 & 1 & 120533946 & 120578001 & SMPX \\
\hline ENSGALG00000016406 & 1 & 121157720 & 121225454 & RPS6KA3 \\
\hline 16420 & 1 & 1213 & 121606919 & KBP1 \\
\hline 5426 & 1 & 121 & & MAP3K15 \\
\hline ENSG & 1 & 1216 & 121 & PDHA2 \\
\hline ENSGALG00000016511 & 1 & 121777765 & 121819130 & ADGRG2 \\
\hline ENSGALG00000016518 & 1 & 121822368 & 121859658 & PHKA2 \\
\hline 16522 & 1 & & 121891693 & PPEF1 \\
\hline ENS & 1 & & & $D C 1$ \\
\hline ENSGALG00000016529 & 1 & 121923761 & 122022946 & CDKL5 \\
\hline ENSGALG00000016537 & 1 & 122078244 & 122134183 & SCML2 \\
\hline GALG00000016538 & 1 & 122146582 & 122148228 & RAI2 \\
\hline 5584 & 4 & 82 & 1097 & VSIG10L \\
\hline 28222 & 4 & 10977328 & 10983991 & LOC4222 \\
\hline ENSGALG00000016034 & 4 & 89176735 & 89316390 & ATRN \\
\hline ENSGALG00000038543 & 7 & 20946474 & 21036251 & $\mathrm{KCNH} 7$ \\
\hline 1192 & 7 & & 90 & $\mathrm{IFIH} 1$ \\
\hline 00011099 & 7 & 210 & 211 & FAP \\
\hline ENSGALG00000011132 & 7 & 21626535 & 21764185 & RBMS1 \\
\hline ENSGALG00000011149 & 7 & 21828489 & 21864267 & PLA2R1 \\
\hline ENSGALG00000011172 & 7 & 21930914 & 21996451 & MYO10L \\
\hline 053241 & 7 & 22082731 & 22084314 & LOC4241 \\
\hline ALG00000011250 & 7 & 22086695 & 22105857 & $\mathrm{ASIC} 4$ \\
\hline ENSGALG00000011252 & 7 & 22129021 & 22132591 & LOC4290 \\
\hline ENSGALG00000008733 & 8 & 16810670 & 16822126 & LPAR3 \\
\hline ENSGALG00000038242 & 12 & 1874442 & 2001509 & CACNA \\
\hline ENS & 14 & 3778529 & 3801415 & - \\
\hline ENSGALG00000026119 & 15 & 7779109 & 7810799 & MN1 \\
\hline ENSGALG00000005654 & 15 & 7819084 & 7836307 & PITPNB \\
\hline ENSGALG00000003476 & 18 & 6755211 & 6787645 & ERN1 \\
\hline ENSGALG00000003496 & 18 & & & TEX2 \\
\hline ENSGALG00000033569 & 21 & 508552 & 539804 & - \\
\hline ENSGALG00000039187 & 22 & 405357 & 409427 & GKN2 \\
\hline ENSGALG00000001812 & 28 & 1582029 & 1594481 & ATCAY \\
\hline \multicolumn{5}{|l|}{ Unique in Hum_BMD } \\
\hline ENSGALG00000053663 & 10 & 12005808 & 12033052 & 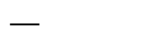 \\
\hline \multicolumn{5}{|c|}{ Common in Tib_BBS and $T$} \\
\hline ENSGALG00000016391 & 1 & 120600351 & 120804008 & CNKSR2 \\
\hline
\end{tabular}


Table S4.2: List of all genes extracted for the bone breaking strengths (BBS) or bone mineral densities (BMD) of the tibiotarsus (Tib) and humerus (Hum) obtained from the Random Forests classification.

\section{Ensembl gene id \\ Unique in Tib_BBS}

GALG0000031975

ENSGALG00000008048

ENSGALG00000027296

ENSGALG0000000808

ENSGALG00000038834

ENSGALG00000008167

ENSGALG00000008154

ENSGALG00000004897

ENSGALG00000009596

ENSGALG00000009601

ENSGALG00000011325

ENSCALO000011327

ENSGALG00000012488

ENSGALG00000012530

ENSGALG00000012532

ENSGALG00000032768

ENSGALG00000047534

ENSGALG00000014106

ENSGALG00000014178

ENSGALG00000014567

ENSGALG00000014568

ENSGALG00000014687

ENSGALG00000015367

ENSGALG00000015378

ENSGALG00000019157

ENSGALG00000016415

ENSGALG00000016522

ENSGALG00000016545

ENSGAL G00000053594

ENSGALG0000001683

ENSGALG00000054981

ENSGALG00000013489

ENSGALG00000006173

ENSGALG00000007408

ENSGALG00000040028

ENSGALG00000050380

ENSGALG0000003264

ENSGALG00000037940

ENSGALG00000044675

ENSGALG00000031700

ENSGALG00000029596

ENSGALG00000036085

ENSGALG00000008779

000873

ENSGALG0000000961

ENSGALG00000009652

ENSGALG00000010538

ENSGALG00000032440

ENSGALG00000010641

ENSGALG00000011560

ENSGALG0000001156

ENSGALG0000001297

ENSGALG00000013754

ENSGALG00000013756

ENSGALG0000015465

ENSGALG00000015465

ENSGALG00000015808

ENSGALG00000016174

ENSGALG00000035016

ENSGALG00000041900

ENSGALG0000001006

ENSGALG00000030065

ENSGALG00000012015

ENSGALG00000033286

ENSGALG00000012222

ENSGALG00000041121

ENSGALG00000014425

ENSGALG00000015623

ENSGALG00000050742

ENSGALG00000006192

ENSGALG00000009387

ENSGALG0000000958

ENSGALG0000000980

ENSGALG00000010117

ENSGALG0000001181

ENSGALG00000011889

ENSGALG00000012017

ENSGALG00000053215

ENSGALG00000001907

ENSGALG0000000193

ENSGALG00000001977

Chr. Star

\section{0}

1584921

1595635

1600797

11833981

13903212

13958935

15836984

30234476

30463434

45339203

45354985

51511486

51519368

5171668

51727168
65833774

65833774

68191397

68564109

77994636

78015335
78020566

78020566

78162527

89486875

120533946

121229301

121300649

121861691

122667268

133320865

138904758

164781979

186228663

6172986

15436178

44367312

44408018

44615726

79940291

127306456

134839746

137356485

148823679

10612572

1211155

1944922

2045857

31481892

33691214

33929665

3395185

44391258

44583493

49020942

52353589

52959497

52959497

72530453

72530453

(2)

83099425

5853920

2475257
32846926

4005345

5609208

5644311

59688409

7498175

75726455

75879121

81930559

12148432

12148432

29263703

29263703

31651198

.

43821392
53231805

53231805

55009316

2282853

2968233

3059913

11585402
1533752

(153752

(599967

604593

2556826

13955809

5848465

30430729

(30606675

45346941

51518776

51518776
51524961

51524961

51725962
51734903

66173568

67956166

68291071
68765156

68765156
78014698

78014698

78020461

89817466

120578001

121238473

121891693

122766511

133325014

138912133
138918510

164862248

186241876

6255970

15577480
44413014

44413014

44413032

54947966

79950017

127363344

135006696

148841111

10632536

12286838

19512091

20827409

31584930

33705352
33952049

33961883

44584053

45261117

49053025

52378280

52388126

7093914

72641635

76467565

83166464

95856597

2530889

33218988

40498128

56195330

56482183

59777549

75225786

75920712

81966939

83290229

12193954

27751679

29530569

3176669

37178495

43876997

53388473

54333650

2284631

3091445

3082527

3175701
11612168

Gene name

UBE2H

CPA2

CPA5
CPA1

MAGI2

KMT2E
SRPK2

GTSE1

TMEM117

NELL2

DUFA

FOXRED2

XN2

OX5

PPFIBP1

SCUBE1

PTPN6
PHB2

PHB2

EPHA1

NECTIN3

ABHD10

EIF1AX

MAP7D2

PPEF1

REPS2

PROZ

PCDH17

CCDC82

XYLB
MPP7

TMPPE

CLASP2 
Table S4.2: (continued)

\begin{tabular}{|c|}
\hline Ensembl gene id \\
\hline ENSGALG00000006194 \\
\hline ENSGALG00000033293 \\
\hline ENSGALG00000041708 \\
\hline ENSGALG00000001329 \\
\hline ENSGALG00000029653 \\
\hline ENSGALG00000032763 \\
\hline ENSGALG00000002499 \\
\hline ENSGALG00000006969 \\
\hline ENSGALG00000001512 \\
\hline ENSGALG00000040017 \\
\hline ENSGALG00000029142 \\
\hline ENSGALG00000053742 \\
\hline ENSGALG00000002085 \\
\hline ENSGALG00000032469 \\
\hline ENSGALG00000002591 \\
\hline \\
\hline Unique in Tib_BMD \\
\hline ENSGALG000000̄33051 \\
\hline ENSGALG00000010177 \\
\hline ENSGALG00000033589 \\
\hline ENSGALG00000037807 \\
\hline ENSGALG00000050127 \\
\hline ENSGALG00000046776 \\
\hline ENSGALG00000050866 \\
\hline ENSGALG00000014766 \\
\hline ENSGALG00000040620 \\
\hline ENSGALG00000015230 \\
\hline ENSGALG00000015511 \\
\hline ENSGALG00000040926 \\
\hline ENSGALG00000016755 \\
\hline ENSGALG00000040621 \\
\hline ENSGALG00000016788 \\
\hline ENSGALG00000016834 \\
\hline ENSGALG00000016872 \\
\hline ENSGALG00000042339 \\
\hline ENSGALG00000025748 \\
\hline ENSGALG00000019042 \\
\hline ENSGALG00000029172 \\
\hline ENSGALG00000052452 \\
\hline ENSGALG00000000681 \\
\hline ENSGALG00000040478 \\
\hline ENSGALG00000000755 \\
\hline ENSGALG00000040783 \\
\hline ENSGALG00000006233 \\
\hline ENSGALG00000041791 \\
\hline ENSGALG00000009500 \\
\hline ENSGALG00000009509 \\
\hline ENSGALG00000030455 \\
\hline ENSGALG00000039092 \\
\hline ENSGALG00000031997 \\
\hline ENSGALG00000039139 \\
\hline ENSGALG00000012681 \\
\hline ENSGALG00000012702 \\
\hline ENSGALG00000013081 \\
\hline ENSGALG00000043570 \\
\hline ENSGALG00000031131 \\
\hline ENSGALG00000031076 \\
\hline ENSGALG00000037955 \\
\hline ENSGALG00000031282 \\
\hline ENSGALG00000035199 \\
\hline ENSGALG00000034099 \\
\hline ENSGALG00000051312 \\
\hline ENSGALG00000009107 \\
\hline ENSGALG00000031582 \\
\hline ENSGALG00000009947 \\
\hline ENSGALG00000010560 \\
\hline ENSGALG00000010561 \\
\hline ENSGALG00000026600 \\
\hline ENSGALG00000032780 \\
\hline ENSGALG00000034030 \\
\hline ENSGALG00000037423 \\
\hline ENSGALG00000015605 \\
\hline ENSGALG00000039001 \\
\hline ENSGALG00000028709 \\
\hline ENSGALG00000047072 \\
\hline ENSGALG00000007151 \\
\hline ENSGALG00000007608 \\
\hline ENSGALG00000009378 \\
\hline ENSGALG00000034741 \\
\hline ENSGALG00000043106 \\
\hline ENSGALG00000010932 \\
\hline ENSGALG00000010963 \\
\hline ENSGALG00000012219 \\
\hline ENSGALG00000014262 \\
\hline ENSGALG00000037228 \\
\hline ENSGALG00000041249 \\
\hline ENSGALG00000038269 \\
\hline ENSGALG00000049638 \\
\hline ENSGALG00000037195 \\
\hline ENSGALG00000007948 \\
\hline ENSGALG00000008553 \\
\hline ENSGALG00000011858 \\
\hline ENSGALG00000011861 \\
\hline ENSGALG00000002942 \\
\hline ENSGALG00000031534 \\
\hline ENSGALG00000003526 \\
\hline ENSGALG00000003533 \\
\hline
\end{tabular}


Table S4.2: (continued)

\begin{tabular}{|c|c|c|c|}
\hline Ensembl gene id & Chr. & Start & End \\
\hline Unique in Hum_BBS & & & \\
\hline ENSGALG00000008144 & 1 & 1619330 & 1638626 \\
\hline ENSGALG00000047442 & 1 & 1926186 & 1938922 \\
\hline ENSGALG00000013069 & 1 & 62167702 & 62186545 \\
\hline ENSGALG00000015379 & 1 & 89826120 & 89837361 \\
\hline ENSGALG00000017047 & 1 & 173658067 & 173691648 \\
\hline ENSGALG00000017165 & 1 & 181692016 & 181714409 \\
\hline ENSGALG00000042992 & 1 & 190815780 & 191167322 \\
\hline ENSGALG00000006443 & 1 & 195587654 & 195590524 \\
\hline ENSGALG00000000868 & 1 & 195591204 & 195602075 \\
\hline ENSGALG00000017493 & 1 & 195602594 & 195605798 \\
\hline ENSGALG00000005710 & 2 & 4568785 & 4637109 \\
\hline ENSGALG00000041154 & 2 & 8624610 & 8627626 \\
\hline ENSGALG00000006652 & 2 & 9990437 & 10275976 \\
\hline ENSGALG00000007351 & 2 & 14995874 & 15011632 \\
\hline ENSGALG00000037769 & 2 & 18124237 & 18368109 \\
\hline ENSGALG00000029235 & 2 & 41858803 & 42075903 \\
\hline ENSGALG00000035505 & 2 & 46604093 & 46670393 \\
\hline ENSGALG00000008725 & 3 & 5496073 & 5630444 \\
\hline ENSGALG00000001661 & 3 & 16081562 & 16095818 \\
\hline ENSGALG00000008614 & 3 & 16096879 & 16112242 \\
\hline ENSGALG00000045514 & 3 & 16135916 & 16149641 \\
\hline ENSGALG00000037576 & 3 & 16155290 & 16157946 \\
\hline ENSGALG00000010050 & 3 & 28348991 & 28495437 \\
\hline ENSGALG00000011571 & 3 & 45283852 & 45353246 \\
\hline ENSGALG00000038782 & 3 & 48204075 & 48212692 \\
\hline ENSGALG00000053107 & 3 & 58190054 & 58231715 \\
\hline ENSGALG00000013651 & 3 & 60217079 & 60270213 \\
\hline ENSGALG00000039756 & 3 & 60319457 & 60834072 \\
\hline ENSGALG00000009830 & 4 & 29651474 & 29681776 \\
\hline ENSGALG00000028643 & 4 & 30838745 & 31010530 \\
\hline ENSGALG00000009948 & 4 & 30847852 & 30924570 \\
\hline ENSGALG00000035482 & 4 & 37267897 & 37308644 \\
\hline ENSGALG00000005716 & 5 & 9248870 & 9478933 \\
\hline ENSGALG00000005986 & 5 & 10457958 & 10515004 \\
\hline ENSGALG00000006035 & 5 & 10693066 & 10768567 \\
\hline ENSGALG00000032558 & 5 & 10855015 & 10936272 \\
\hline ENSGALG00000006873 & 5 & 16064998 & 16084574 \\
\hline ENSGALG00000029260 & 5 & 16217236 & 16252397 \\
\hline ENSGALG00000035023 & 5 & 56658775 & 56665015 \\
\hline ENSGALG00000012220 & 5 & 56665337 & 56672072 \\
\hline ENSGALG00000012228 & 5 & 56940987 & 57248827 \\
\hline ENSGALG00000009495 & 6 & 31834704 & 31906976 \\
\hline ENSGALG00000042374 & 7 & 15549638 & 15673377 \\
\hline ENSGALG00000011630 & 7 & 25779538 & 25958144 \\
\hline ENSGALG00000012470 & 7 & 34907319 & 34912403 \\
\hline ENSGALG00000002182 & 8 & 1987324 & 2069077 \\
\hline ENSGALG00000002216 & 8 & 2565913 & 2621188 \\
\hline ENSGALG00000005203 & 8 & 11872299 & 11926941 \\
\hline ENSGALG00000005580 & 8 & 13738852 & 13781167 \\
\hline ENSGALG00000008835 & 8 & 17017291 & 17029086 \\
\hline ENSGALG00000036909 & 8 & 23047528 & 23885562 \\
\hline ENSGALG00000010540 & 8 & 24366673 & 24408000 \\
\hline ENSGALG00000010543 & 8 & 24411559 & 24454049 \\
\hline ENSGALG00000010570 & 8 & 24612084 & 24622313 \\
\hline ENSGALG00000010805 & 8 & 25639131 & 25696695 \\
\hline ENSGALG00000006395 & 9 & 4871958 & 4876064 \\
\hline ENSGALG00000006392 & 9 & 4879911 & 4889610 \\
\hline ENSGALG00000006317 & 9 & 4943378 & 4951651 \\
\hline ENSGALG00000006305 & 9 & 4951779 & 4957263 \\
\hline ENSGALG00000033618 & 10 & 1858212 & 2010750 \\
\hline ENSGALG00000002883 & 10 & 3662745 & 3799455 \\
\hline ENSGALG00000002925 & 10 & 3810178 & 3840160 \\
\hline ENSGALG00000006516 & 10 & 13083181 & 13104916 \\
\hline ENSGALG00000044204 & 10 & 13568712 & 13577891 \\
\hline ENSGALG00000025898 & 10 & 19113380 & 19141564 \\
\hline ENSGALG00000002798 & 11 & 1901047 & 1949555 \\
\hline ENSGALG00000005377 & 11 & 14060228 & 14531588 \\
\hline ENSGALG00000002335 & 12 & 2360795 & 2623950 \\
\hline ENSGALG00000005909 & 12 & 9596109 & 9612130 \\
\hline ENSGALG00000038684 & 12 & 9789679 & 9901939 \\
\hline ENSGALG00000006526 & 12 & 11683446 & 11738536 \\
\hline ENSGALG00000007168 & 12 & 12285419 & 12348377 \\
\hline ENSGALG00000002203 & 13 & 3919090 & 4012490 \\
\hline ENSGALG00000002191 & 13 & 4053522 & 4055527 \\
\hline ENSGALG00000028602 & 13 & 10211261 & 10285881 \\
\hline ENSGALG00000038848 & 13 & 10514513 & 10519859 \\
\hline ENSGALG00000004398 & 14 & 3830739 & 3870033 \\
\hline ENSGALG00000009205 & 14 & 14438034 & 14559559 \\
\hline ENSGALG00000008201 & 15 & 11611346 & 11627560 \\
\hline ENSGALG00000008206 & 15 & 11628671 & 11631426 \\
\hline ENSGALG00000004333 & 18 & 7950536 & 7974012 \\
\hline ENSGALG00000004413 & 18 & 8903444 & 8963934 \\
\hline ENSGALG00000001042 & 19 & 801748 & 844553 \\
\hline ENSGALG00000035131 & 19 & 859638 & 866958 \\
\hline ENSGALG00000050734 & 19 & 866383 & 869249 \\
\hline ENSGALG00000005084 & 19 & 7313633 & 7334393 \\
\hline ENSGALG00000005103 & 19 & 7353284 & 7364909 \\
\hline ENSGALG00000028801 & 19 & 7369597 & 7400205 \\
\hline ENSGALG00000005295 & 19 & 7797174 & 8098869 \\
\hline ENSGALG00000005774 & 20 & 8729917 & 8777657 \\
\hline ENSGALG00000003398 & 22 & 2737380 & 2757692 \\
\hline ENSGALG00000001604 & 24 & 2597820 & 2619876 \\
\hline ENSGALG00000001097 & 27 & 3494643 & 3509799 \\
\hline
\end{tabular}


Table S4.2: (continued)

\begin{tabular}{|c|c|c|c|c|}
\hline Ensembl gene id & Chr. & Start & End & Gene name \\
\hline \multicolumn{5}{|c|}{ Common in Tib_BBS and Tib_BMD } \\
\hline ENSGALG00000019361 & 1 & 32828666 & 32879723 & TAFA2 \\
\hline ENSGALG00000016391 & 1 & 120600351 & 120804008 & CNKSR2 \\
\hline ENSGALG00000016420 & 1 & 121385060 & 121606919 & SH3KBP1 \\
\hline ENSGALG00000043118 & 1 & 132986041 & 133096377 & ATP10A \\
\hline ENSGALG00000016767 & 1 & 133973567 & 134294259 & AFF3 \\
\hline ENSGALG00000008574 & 1 & 194436252 & 194446714 & CLNS1A \\
\hline ENSGALG00000031450 & 1 & 194597369 & 194675601 & MYO7A \\
\hline ENSGALG00000006153 & 2 & 5782448 & 5801847 & EXOG \\
\hline ENSGALG00000049653 & 2 & 6621972 & 6760289 & $\mathrm{KMT} 2 \mathrm{C}$ \\
\hline ENSGALG00000038265 & 2 & 33231086 & 33475464 & CREB5 \\
\hline ENSGALG00000013086 & 2 & 80659236 & 80730292 & IKZF1 \\
\hline ENSGALG00000037014 & 2 & 146916969 & 147397126 & TSNARE1 \\
\hline ENSGALG00000011473 & 3 & 42691591 & 42928349 & RPS6KA2 \\
\hline ENSGALG00000016451 & 3 & 97177532 & 97270178 & ROCK2 \\
\hline ENSGALG00000007028 & 4 & 8732666 & 8906442 & - \\
\hline ENSGALG00000011078 & 4 & 45807324 & 45891224 & PTPN13 \\
\hline ENSGALG00000011109 & 4 & 45932534 & 46032124 & MAPK10 \\
\hline ENSGALG00000052375 & 4 & 57098783 & 57108321 & - \\
\hline ENSGALG00000009172 & 7 & 15434552 & 15516341 & OSBPL6 \\
\hline ENSGALG00000030350 & 9 & 5719637 & 5755791 & - \\
\hline ENSGALG00000003767 & 11 & 6241053 & 6411630 & NKD1 \\
\hline ENSGALG00000002229 & 13 & 3572457 & 3637749 & FBXW11 \\
\hline ENSGALG00000003548 & 14 & 1552022 & 1586667 & BAIAP2L1 \\
\hline ENSGALG00000051488 & 15 & 9238928 & 9263621 & SFI1 \\
\hline ENSGALG00000027897 & 15 & 11471568 & 11477474 & DTX1 \\
\hline ENSGALG00000008150 & 15 & 11476814 & 11485534 & RASAL1 \\
\hline ENSGALG00000003476 & 18 & 6755211 & 6787645 & ERN1 \\
\hline ENSGALG00000003496 & 18 & 6791861 & 6805476 & TEX2 \\
\hline ENSGALG00000021636 & 19 & 4027300 & 4254453 & CUX1 \\
\hline ENSGALG00000004878 & 21 & 6417028 & 6426299 & - \\
\hline ENSGALG00000052799 & 21 & 6426944 & 6443949 & - \\
\hline \multicolumn{5}{|c|}{ Common in Tib_BBS and Hum_BBS } \\
\hline ENSGALG00000007125 & 2 & 13147629 & 13581750 & PARD3 \\
\hline ENSGALG00000014485 & 4 & 76025150 & 76382215 & LDB2 \\
\hline ENSGALG00000006074 & 5 & 11366630 & 11601652 & sox6 \\
\hline ENSGALG00000011801 & 5 & 53184725 & 53226447 & ESR2 \\
\hline ENSGALG00000004741 & 21 & 5956010 & 6053651 & EPHB2 \\
\hline ENSGALG00000031440 & 23 & 2911566 & 3132209 & PTPRU \\
\hline
\end{tabular}

\begin{tabular}{|c|c|c|c|c|}
\hline Ensembl gene id & Chr. & Start & End & Gene name \\
\hline \multicolumn{5}{|c|}{ Common in Tib_BBS and Hum_BMD } \\
\hline ENSGALG00000034989 & 18 & 7450622 & 7589963 & CEP112 \\
\hline ENSGALG00000001122 & 19 & 1102760 & 1225316 & CALN1 \\
\hline \multicolumn{5}{|c|}{ Common in Tib_BMD and Hum_BMD } \\
\hline ENSGALG00000020292 & 4 & 10827137 & 10859217 & GABRE \\
\hline ENSGALG00000043448 & 4 & 80649049 & 80786524 & ABLIM2 \\
\hline ENSGALG00000039221 & 5 & 16259485 & 16322745 & LOC423110 \\
\hline ENSGALG00000011677 & 7 & 26448702 & 26481703 & HSPBAP1 \\
\hline ENSGALG00000008456 & 17 & 2470501 & 2727279 & CACNA1B \\
\hline ENSGALG00000041473 & 17 & 6893819 & 6935800 & DDX31 \\
\hline \multicolumn{5}{|c|}{ Common in Tib_BMD and Hum_BBS } \\
\hline ENSGALG00000016312 & 1 & 119273945 & 119465002 & POLA1 \\
\hline ENSGALG00000021395 & 18 & 7924961 & 7946282 & ABCA9 \\
\hline \multicolumn{5}{|c|}{ Common in Hum_BBS and Hum_BMD } \\
\hline ENSGALG00000043771 & 1 & 1110497 & 1128266 & DENND6B \\
\hline ENSGALG00000013095 & 1 & 63109353 & 63163425 & DERA \\
\hline ENSGALG00000017062 & 1 & 174375172 & 174843962 & NBEA \\
\hline ENSGALG00000027853 & 4 & 87427085 & 87823826 & CTNNA2 \\
\hline ENSGALG00000006608 & 5 & 14310133 & 14525237 & - \\
\hline ENSGALG00000006647 & 5 & 14360355 & 14381768 & DUSP8 \\
\hline ENSGALG00000002015 & 6 & 3338993 & 3346509 & SNCG \\
\hline ENSGALG00000021869 & 8 & 24907072 & 24927370 & PODN \\
\hline ENSGALG00000003699 & 13 & 11388767 & 11649631 & EBF1 \\
\hline ENSGALG00000001153 & 19 & 1512994 & 2173032 & AUTS2 \\
\hline \multicolumn{5}{|c|}{ Common in Tib_BBS, Tib_BMD and Hum_BMD } \\
\hline ENSGALG00000009400 & 5 & $2783904 \overline{7}$ & 27917728 & SLC8A3 \\
\hline \multicolumn{5}{|c|}{ Common in Tib_BBS, Tib_BMD and Hum_BBS } \\
\hline ENSGALG00000007025 & $\overline{1}$ & 15633800 & 15729892 & CPNE8 \\
\hline \multicolumn{5}{|c|}{ Common in Tib_BMD, Hum_BMD and Hum_BBS } \\
\hline ENSGALG00000015768 & 3 & 75547294 & 75651254 & ANKRD6 \\
\hline ENSGALG00000026258 & 11 & 14531508 & 14691257 & MAF \\
\hline ENSGALG00000001433 & 18 & 3121259 & 3232611 & B3GNTL1 \\
\hline
\end{tabular}

Table S4.3: List of all enriched terms / pathways obtained from the genome-wide association studies.

\begin{tabular}{cllllll}
\hline Source & Term ID & Term name & $p$-value & Term size & Query size & Intersection \\
\hline Enrichend in Tib_BBS & & & & & \\
GO:BP & GO:0009266 & response to temperature stimulus & $2.62 \times 10^{-6}$ & 88 & 16 & 3 \\
& & & & & \\
Enrichend in Tib_BMD & & $4.46 \times 10^{-2}$ & 12167 & 39 & 32 \\
GO:BP GO:0008150 & biological_process & $3.46 \times 10^{-3}$ & 12467 & 39 & 32 \\
GO:MF $\quad$ GO:0003674 & molecular_function &
\end{tabular}


Table S4.4: List of all enriched terms / pathways obtained from the Random Forests classification.

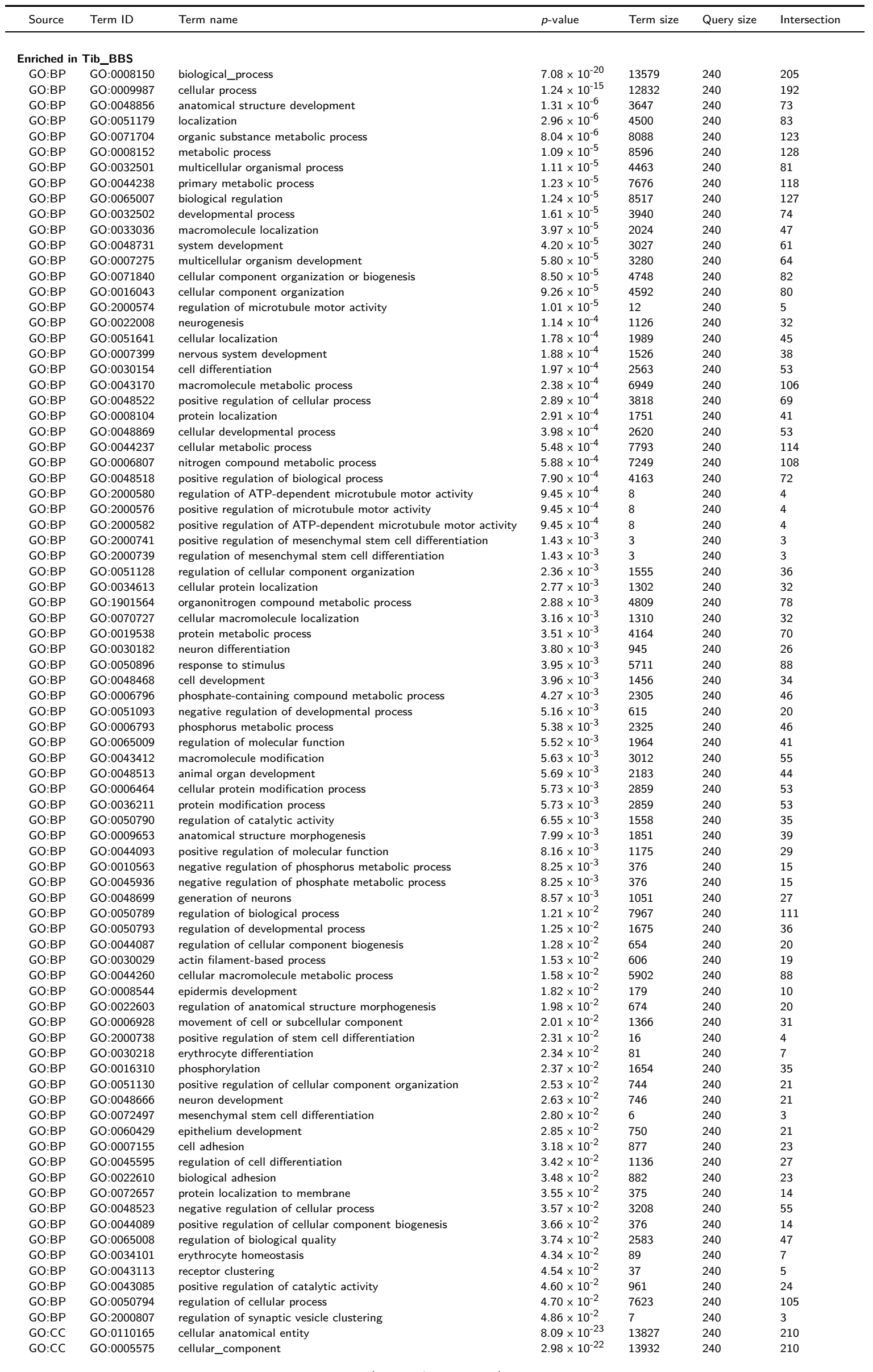

(continued on next page) 
Table S4.4: (continued)

\begin{tabular}{|c|c|c|c|c|c|c|}
\hline Source & Term ID & Term name & $p$-value & Term size & Query size & Intersection \\
\hline GO:CC & GO:0043226 & organelle & $1.24 \times 10^{-14}$ & 9149 & 240 & 154 \\
\hline $\mathrm{GO}: \mathrm{CC}$ & GO:0005622 & intracellular & $1.49 \times 10^{-14}$ & 10264 & 240 & 165 \\
\hline $\mathrm{GO}: \mathrm{CC}$ & GO:0043229 & intracellular organelle & $8.04 \times 10^{-13}$ & 8849 & 240 & 147 \\
\hline $\mathrm{GO}: \mathrm{CC}$ & GO:0005737 & cytoplasm & $3.01 \times 10^{-9}$ & 7503 & 240 & 124 \\
\hline GO:CC & GO:0043227 & membrane-bounded organelle & $1.20 \times 10^{-8}$ & 7921 & 240 & 127 \\
\hline GO:CC & GO:0043231 & intracellular membrane-bounded organelle & $2.91 \times 10^{-8}$ & 7375 & 240 & 120 \\
\hline GO:CC & GO:0032991 & protein-containing complex & $7.20 \times 10^{-6}$ & 4028 & 240 & 74 \\
\hline GO:CC & GO:0016020 & membrane & $5.30 \times 10^{-5}$ & 6623 & 240 & 102 \\
\hline GO:CC & GO:0005634 & nucleus & $1.15 \times 10^{-4}$ & 4975 & 240 & 82 \\
\hline $\mathrm{GO}: \mathrm{CC}$ & GO:0005856 & cytoskeleton & $1.40 \times 10^{-4}$ & 1685 & 240 & 39 \\
\hline GO:CC & GO:0043228 & non-membrane-bounded organelle & $2.96 \times 10^{-4}$ & 3206 & 240 & 59 \\
\hline GO:CC & GO:0043232 & intracellular non-membrane-bounded organelle & $2.96 \times 10^{-4}$ & 3206 & 240 & 59 \\
\hline $\mathrm{GO}: \mathrm{CC}$ & GO:0070161 & anchoring junction & $3.32 \times 10^{-4}$ & 426 & 240 & 17 \\
\hline $\mathrm{GO}: \mathrm{CC}$ & GO:0030054 & cell junction & $5.87 \times 10^{-4}$ & 1250 & 240 & 31 \\
\hline $\mathrm{GO}: \mathrm{CC}$ & GO:0015630 & microtubule cytoskeleton & $2.46 \times 10^{-3}$ & 894 & 240 & 24 \\
\hline GO:CC & GO:0005886 & plasma membrane & $2.53 \times 10^{-3}$ & 3349 & 240 & 58 \\
\hline GO:CC & GO:0098590 & plasma membrane region & $2.94 \times 10^{-3}$ & 667 & 240 & 20 \\
\hline $\mathrm{GO}: \mathrm{CC}$ & GO:0071944 & cell periphery & $3.57 \times 10^{-3}$ & 3468 & 240 & 59 \\
\hline GO:CC & GO:0005911 & cell-cell junction & $1.94 \times 10^{-2}$ & 315 & 240 & 12 \\
\hline GO:CC & GO:0005829 & cytosol & $2.01 \times 10^{-2}$ & 2391 & 240 & 43 \\
\hline $\mathrm{GO}: \mathrm{CC}$ & GO:0043005 & neuron projection & $3.16 \times 10^{-2}$ & 791 & 240 & 20 \\
\hline GO:CC & GO:0042995 & cell projection & $3.35 \times 10^{-2}$ & 1399 & 240 & 29 \\
\hline GO:CC & GO:0032391 & photoreceptor connecting cilium & $4.09 \times 10^{-2}$ & 28 & 240 & 4 \\
\hline GO:CC & GO:0120025 & plasma membrane bounded cell projection & $4.32 \times 10^{-2}$ & 1349 & 240 & 28 \\
\hline GO:CC & GO:0070013 & intracellular organelle lumen & $4.49 \times 10^{-2}$ & 3121 & 240 & 51 \\
\hline $\mathrm{GO}: \mathrm{CC}$ & GO:0043233 & organelle lumen & $4.49 \times 10^{-2}$ & 3121 & 240 & 51 \\
\hline GO:CC & GO:0031974 & membrane-enclosed lumen & $4.49 \times 10^{-2}$ & 3121 & 240 & 51 \\
\hline GO:MF & GO:0003674 & molecular_function & $6.54 \times 10^{-21}$ & 13343 & 240 & 204 \\
\hline GO:MF & GO:0005488 & binding & $8.39 \times 10^{-19}$ & 10509 & 240 & 176 \\
\hline GO:MF & GO:0005515 & protein binding & $5.77 \times 10^{-14}$ & 6570 & 240 & 125 \\
\hline GO:MF & GO:0043167 & ion binding & $6.88 \times 10^{-8}$ & 4187 & 240 & 82 \\
\hline GO:MF & GO:0046872 & metal ion binding & $5.68 \times 10^{-7}$ & 2430 & 240 & 56 \\
\hline GO:MF & GO:0043169 & cation binding & $1.53 \times 10^{-6}$ & 2497 & 240 & 56 \\
\hline GO:MF & GO:0003824 & catalytic activity & $8.16 \times 10^{-5}$ & 4943 & 240 & 83 \\
\hline GO:MF & GO:0140096 & catalytic activity, acting on a protein & $2.16 \times 10^{-4}$ & 1872 & 240 & 42 \\
\hline GO:MF & GO:0016740 & transferase activity & $3.11 \times 10^{-3}$ & 1933 & 240 & 40 \\
\hline GO:MF & GO:0005509 & calcium ion binding & $5.43 \times 10^{-3}$ & 553 & 240 & 18 \\
\hline GO:MF & GO:0042802 & identical protein binding & $7.55 \times 10^{-3}$ & 1239 & 240 & 29 \\
\hline GO:MF & GO:0005524 & ATP binding & $8.01 \times 10^{-3}$ & 1177 & 240 & 28 \\
\hline GO:MF & GO:0032559 & adenyl ribonucleotide binding & $1.39 \times 10^{-2}$ & 1214 & 240 & 28 \\
\hline GO:MF & GO:0030554 & adenyl nucleotide binding & $1.49 \times 10^{-2}$ & 1219 & 240 & 28 \\
\hline GO:MF & GO:0016773 & phosphotransferase activity, alcohol group as acceptor & $1.90 \times 10^{-2}$ & 608 & 240 & 18 \\
\hline GO:MF & GO:0016301 & kinase activity & $2.02 \times 10^{-2}$ & 669 & 240 & 19 \\
\hline GO:MF & GO:0016772 & transferase activity, transferring phosphorus-containing groups & $3.96 \times 10^{-2}$ & 827 & 240 & 21 \\
\hline GO:MF & GO:0019899 & enzyme binding & $4.69 \times 10^{-2}$ & 1513 & 240 & 31 \\
\hline KEGG & KEGG:00000 & KEGG root term & $2.85 \times 10^{-6}$ & 4773 & 240 & 82 \\
\hline KEGG & KEGG:00604 & Glycosphingolipid biosynthesis - ganglio series & $1.57 \times 10^{-2}$ & 15 & 240 & 3 \\
\hline KEGG & KEGG:01100 & Metabolic pathways & $3.60 \times 10^{-2}$ & 1280 & 240 & 25 \\
\hline \multicolumn{7}{|c|}{ Enriched in Tib_BMD } \\
\hline GO:BP & GO:0008150 & biological_process & $1.12 \times 10^{-21}$ & 13579 & 220 & 193 \\
\hline $\mathrm{GO}: \mathrm{BP}$ & GO:0009987 & cellular process & $6.60 \times 10^{-16}$ & 12832 & 220 & 179 \\
\hline GO:BP & GO:0065007 & biological regulation & $1.19 \times 10^{-10}$ & 8517 & 220 & 131 \\
\hline GO:BP & GO:0050794 & regulation of cellular process & $7.11 \times 10^{-9}$ & 7623 & 220 & 118 \\
\hline GO:BP & GO:0050789 & regulation of biological process & $1.08 \times 10^{-8}$ & 7967 & 220 & 121 \\
\hline $\mathrm{GO}: \mathrm{BP}$ & GO:0007154 & cell communication & $1.86 \times 10^{-5}$ & 4259 & 220 & 73 \\
\hline $\mathrm{GO}: \mathrm{BP}$ & GO:0008152 & metabolic process & $2.80 \times 10^{-5}$ & 8596 & 220 & 118 \\
\hline GO:BP & GO:0023052 & signaling & $3.47 \times 10^{-5}$ & 4234 & 220 & 72 \\
\hline GO:BP & GO:0032501 & multicellular organismal process & $5.87 \times 10^{-5}$ & 4463 & 220 & 74 \\
\hline GO:BP & GO:0044238 & primary metabolic process & $5.91 \times 10^{-5}$ & 7676 & 220 & 108 \\
\hline GO:BP & GO:0071704 & organic substance metabolic process & $6.25 \times 10^{-5}$ & 8088 & 220 & 112 \\
\hline GO:BP & GO:0006807 & nitrogen compound metabolic process & $1.02 \times 10^{-4}$ & 7249 & 220 & 103 \\
\hline $\mathrm{GO}: \mathrm{BP}$ & GO:0007165 & signal transduction & $1.73 \times 10^{-4}$ & 3878 & 220 & 66 \\
\hline GO:BP & GO:0051179 & localization & $1.89 \times 10^{-4}$ & 4500 & 220 & 73 \\
\hline GO:BP & GO:0043170 & macromolecule metabolic process & $4.35 \times 10^{-4}$ & 6949 & 220 & 98 \\
\hline GO:BP & GO:0044237 & cellular metabolic process & $6.01 \times 10^{-4}$ & 7793 & 220 & 106 \\
\hline GO:BP & GO:0032502 & developmental process & $1.58 \times 10^{-3}$ & 3940 & 220 & 64 \\
\hline GO:BP & GO:0050896 & response to stimulus & $2.09 \times 10^{-3}$ & 5711 & 220 & 83 \\
\hline GO:BP & GO:0060255 & regulation of macromolecule metabolic process & $2.18 \times 10^{-3}$ & 4242 & 220 & 67 \\
\hline GO:BP & GO:0010467 & gene expression & $2.44 \times 10^{-3}$ & 3901 & 220 & 63 \\
\hline GO:BP & GO:0048856 & anatomical structure development & $2.61 \times 10^{-3}$ & 3647 & 220 & 60 \\
\hline GO:BP & GO:0051716 & cellular response to stimulus & $3.52 \times 10^{-3}$ & 4937 & 220 & 74 \\
\hline GO:BP & GO:0048519 & negative regulation of biological process & $3.56 \times 10^{-3}$ & 3508 & 220 & 58 \\
\hline GO:BP & GO:0019222 & regulation of metabolic process & $3.75 \times 10^{-3}$ & 4578 & 220 & 70 \\
\hline GO:BP & GO:0007275 & multicellular organism development & $4.67 \times 10^{-3}$ & 3280 & 220 & 55 \\
\hline GO:BP & GO:0034641 & cellular nitrogen compound metabolic process & $5.19 \times 10^{-3}$ & 4437 & 220 & 68 \\
\hline GO:BP & GO:0051171 & regulation of nitrogen compound metabolic process & $5.33 \times 10^{-3}$ & 3903 & 220 & 62 \\
\hline GO:BP & GO:0080090 & regulation of primary metabolic process & $5.44 \times 10^{-3}$ & 3994 & 220 & 63 \\
\hline GO:BP & GO:0006810 & transport & $7.19 \times 10^{-3}$ & 3327 & 220 & 55 \\
\hline GO:BP & GO:0010468 & regulation of gene expression & $7.37 \times 10^{-3}$ & 3074 & 220 & 52 \\
\hline $\mathrm{GO}: \mathrm{BP}$ & GO:0051234 & establishment of localization & $8.22 \times 10^{-3}$ & 3428 & 220 & 56 \\
\hline GO:BP & GO:0048523 & negative regulation of cellular process & $1.15 \times 10^{-2}$ & 3208 & 220 & 53 \\
\hline GO:BP & GO:0048869 & cellular developmental process & $1.16 \times 10^{-2}$ & 2620 & 220 & 46 \\
\hline GO:BP & GO:0050793 & regulation of developmental process & $1.19 \times 10^{-2}$ & 1675 & 220 & 34 \\
\hline
\end{tabular}


Table S4.4: (continued)

\begin{tabular}{|c|c|c|c|c|c|c|}
\hline Source & Term ID & Term name & $p$-value & Term size & Query size & Intersection \\
\hline GO:BP & GO:0018193 & peptidyl-amino acid modification & $1.36 \times 10^{-2}$ & 907 & 220 & 23 \\
\hline GO:BP & GO:0071840 & cellular component organization or biogenesis & $1.39 \times 10^{-2}$ & 4748 & 220 & 70 \\
\hline GO:BP & GO:0030154 & cell differentiation & $1.49 \times 10^{-2}$ & 2563 & 220 & 45 \\
\hline GO:BP & GO:0006725 & cellular aromatic compound metabolic process & $1.59 \times 10^{-2}$ & 4036 & 220 & 62 \\
\hline GO:BP & GO:0016043 & cellular component organization & $1.72 \times 10^{-2}$ & 4592 & 220 & 68 \\
\hline GO:BP & GO:0051239 & regulation of multicellular organismal process & $1.92 \times 10^{-2}$ & 1945 & 220 & 37 \\
\hline GO:BP & GO: 1901360 & organic cyclic compound metabolic process & $1.96 \times 10^{-2}$ & 4153 & 220 & 63 \\
\hline GO:BP & GO:0010646 & regulation of cell communication & $2.21 \times 10^{-2}$ & 2195 & 220 & 40 \\
\hline GO:BP & GO:0048731 & system development & $2.28 \times 10^{-2}$ & 3027 & 220 & 50 \\
\hline GO:BP & GO:0046483 & heterocycle metabolic process & $2.41 \times 10^{-2}$ & 3999 & 220 & 61 \\
\hline GO:BP & GO:0006139 & nucleobase-containing compound metabolic process & $2.43 \times 10^{-2}$ & 3910 & 220 & 60 \\
\hline GO:BP & GO:0023051 & regulation of signaling & $2.61 \times 10^{-2}$ & 2211 & 220 & 40 \\
\hline GO:BP & GO:2000026 & regulation of multicellular organismal development & $3.01 \times 10^{-2}$ & 1303 & 220 & 28 \\
\hline $\mathrm{GO}: \mathrm{BP}$ & GO:0044260 & cellular macromolecule metabolic process & $3.02 \times 10^{-2}$ & 5902 & 220 & 81 \\
\hline GO:BP & GO:0048468 & cell development & $3.29 \times 10^{-2}$ & 1456 & 220 & 30 \\
\hline GO:BP & GO:0016070 & RNA metabolic process & $3.85 \times 10^{-2}$ & 3173 & 220 & 51 \\
\hline GO:BP & GO:0031323 & regulation of cellular metabolic process & $3.92 \times 10^{-2}$ & 4153 & 220 & 62 \\
\hline $\mathrm{GO}: \mathrm{CC}$ & GO:0110165 & cellular anatomical entity & $1.68 \times 10^{-23}$ & 13827 & 220 & 196 \\
\hline GO:CC & GO:0005575 & cellular_component & $5.91 \times 10^{-23}$ & 13932 & 220 & 196 \\
\hline GO:CC & GO:0005622 & intracellular & $3.80 \times 10^{-13}$ & 10264 & 220 & 151 \\
\hline GO:CC & GO:0043226 & organelle & $1.72 \times 10^{-8}$ & 9149 & 220 & 130 \\
\hline GO:CC & GO:0043229 & intracellular organelle & $1.12 \times 10^{-7}$ & 8849 & 220 & 125 \\
\hline GO:CC & GO:0005737 & cytoplasm & $4.96 \times 10^{-7}$ & 7503 & 220 & 110 \\
\hline $\mathrm{GO}: \mathrm{CC}$ & GO:0016020 & membrane & $1.25 \times 10^{-5}$ & 6623 & 220 & 97 \\
\hline GO:CC & GO:0043227 & membrane-bounded organelle & $1.34 \times 10^{-5}$ & 7921 & 220 & 110 \\
\hline GO:CC & GO:0043231 & intracellular membrane-bounded organelle & $4.29 \times 10^{-5}$ & 7375 & 220 & 103 \\
\hline GO:CC & GO:0005634 & nucleus & $1.81 \times 10^{-4}$ & 4975 & 220 & 76 \\
\hline GO:CC & GO:0005886 & plasma membrane & $2.93 \times 10^{-4}$ & 3349 & 220 & 57 \\
\hline GO:CC & GO:0071944 & cell periphery & $4.04 \times 10^{-4}$ & 3468 & 220 & 58 \\
\hline GO:CC & GO:0043025 & neuronal cell body & $3.34 \times 10^{-3}$ & 197 & 220 & 10 \\
\hline GO:CC & GO:0005829 & cytosol & $1.14 \times 10^{-2}$ & 2391 & 220 & 41 \\
\hline GO:CC & GO:0031224 & intrinsic component of membrane & $1.19 \times 10^{-2}$ & 4422 & 220 & 64 \\
\hline GO:CC & GO:0044297 & cell body & $1.35 \times 10^{-2}$ & 232 & 220 & 10 \\
\hline $\mathrm{GO}: \mathrm{CC}$ & GO:0043232 & intracellular non-membrane-bounded organelle & $1.71 \times 10^{-2}$ & 3206 & 220 & 50 \\
\hline GO:CC & GO:0043228 & non-membrane-bounded organelle & $1.71 \times 10^{-2}$ & 3206 & 220 & 50 \\
\hline $\mathrm{GO}: \mathrm{CC}$ & GO:0016604 & nuclear body & $1.97 \times 10^{-2}$ & 516 & 220 & 15 \\
\hline GO:CC & GO:0045092 & interleukin-18 receptor complex & $2.08 \times 10^{-2}$ & 2 & 220 & 2 \\
\hline GO:CC & GO:0016021 & integral component of membrane & $2.64 \times 10^{-2}$ & 4352 & 220 & 62 \\
\hline GO:CC & GO:0031981 & nuclear lumen & $3.50 \times 10^{-2}$ & 2859 & 220 & 45 \\
\hline GO:CC & GO:0000118 & histone deacetylase complex & $3.86 \times 10^{-2}$ & 56 & 220 & 5 \\
\hline $\mathrm{GO}: \mathrm{CC}$ & GO:0017053 & transcription repressor complex & $3.86 \times 10^{-2}$ & 56 & 220 & 5 \\
\hline GO:CC & GO:0016581 & NuRD complex & $4.98 \times 10^{-2}$ & 13 & 220 & 3 \\
\hline $\mathrm{GO}: \mathrm{CC}$ & GO:0090545 & CHD-type complex & $4.98 \times 10^{-2}$ & 13 & 220 & 3 \\
\hline GO:MF & GO:0003674 & molecular_function & $2.32 \times 10^{-20}$ & 13343 & 220 & 189 \\
\hline GO:MF & GO:0005488 & binding & $3.35 \times 10^{-12}$ & 10509 & 220 & 152 \\
\hline GO:MF & GO:0005515 & protein binding & $1.93 \times 10^{-5}$ & 6570 & 220 & 97 \\
\hline GO:MF & GO:0043167 & ion binding & $2.41 \times 10^{-4}$ & 4187 & 220 & 68 \\
\hline GO:MF & GO:0003824 & catalytic activity & $6.97 \times 10^{-4}$ & 4943 & 220 & 75 \\
\hline GO:MF & GO:0043168 & anion binding & $1.47 \times 10^{-3}$ & 2194 & 220 & 42 \\
\hline GO:MF & GO:0097159 & organic cyclic compound binding & $1.51 \times 10^{-3}$ & 4401 & 220 & 68 \\
\hline GO:MF & GO:0005524 & ATP binding & $1.78 \times 10^{-3}$ & 1177 & 220 & 28 \\
\hline GO:MF & GO:0016740 & transferase activity & $2.63 \times 10^{-3}$ & 1933 & 220 & 38 \\
\hline GO:MF & GO:0032559 & adenyl ribonucleotide binding & $3.21 \times 10^{-3}$ & 1214 & 220 & 28 \\
\hline GO:MF & GO:0030554 & adenyl nucleotide binding & $3.46 \times 10^{-3}$ & 1219 & 220 & 28 \\
\hline GO:MF & GO:1901363 & heterocyclic compound binding & $4.02 \times 10^{-3}$ & 4342 & 220 & 66 \\
\hline GO:MF & GO:0036094 & small molecule binding & $4.04 \times 10^{-3}$ & 1969 & 220 & 38 \\
\hline GO:MF & GO:0017076 & purine nucleotide binding & $4.56 \times 10^{-3}$ & 1525 & 220 & 32 \\
\hline GO:MF & GO:0032553 & ribonucleotide binding & $4.56 \times 10^{-3}$ & 1525 & 220 & 32 \\
\hline GO:MF & GO:0035639 & purine ribonucleoside triphosphate binding & $5.61 \times 10^{-3}$ & 1467 & 220 & 31 \\
\hline GO:MF & GO:1901265 & nucleoside phosphate binding & $8.30 \times 10^{-3}$ & 1722 & 220 & 34 \\
\hline GO:MF & GO:0000166 & nucleotide binding & $8.30 \times 10^{-3}$ & 1722 & 220 & 34 \\
\hline GO:MF & GO:0004674 & protein serine/threonine kinase activity & $9.36 \times 10^{-3}$ & 342 & 220 & 13 \\
\hline GO:MF & GO:0032555 & purine ribonucleotide binding & $1.01 \times 10^{-2}$ & 1512 & 220 & 31 \\
\hline GO:MF & GO:0097367 & carbohydrate derivative binding & $1.80 \times 10^{-2}$ & 1711 & 220 & 33 \\
\hline GO:MF & GO:0016301 & kinase activity & $2.46 \times 10^{-2}$ & 669 & 220 & 18 \\
\hline GO:MF & GO:0016772 & transferase activity, transferring phosphorus-containing groups & $4.06 \times 10^{-2}$ & 827 & 220 & 20 \\
\hline GO:MF & GO:0140096 & catalytic activity, acting on a protein & $4.48 \times 10^{-2}$ & 1872 & 220 & 34 \\
\hline GO:MF & GO:0042008 & interleukin- 18 receptor activity & $4.95 \times 10^{-2}$ & 2 & 220 & 2 \\
\hline KEGG & KEGG:00000 & KEGG root term & $2.33 \times 10^{-5}$ & 4773 & 220 & 74 \\
\hline KEGG & KEGG:04310 & Wnt signaling pathway & $9.00 \times 10^{-4}$ & 135 & 220 & 7 \\
\hline KEGG & KEGG:04010 & MAPK signaling pathway & $1.78 \times 10^{-2}$ & 249 & 220 & 9 \\
\hline \multicolumn{7}{|c|}{ Enriched in Hum_BBS } \\
\hline GO:BP & GO:0008150 & biological_process & $6.01 \times 10^{-9}$ & 13579 & 115 & 99 \\
\hline GO:BP & GO:0009987 & cellular process & $5.59 \times 10^{-7}$ & 12832 & 115 & 93 \\
\hline GO:BP & GO:0065007 & biological regulation & $7.94 \times 10^{-5}$ & 8517 & 115 & 69 \\
\hline GO:BP & GO:0050789 & regulation of biological process & $9.47 \times 10^{-5}$ & 7967 & 115 & 66 \\
\hline GO:BP & GO:0044260 & cellular macromolecule metabolic process & $1.96 \times 10^{-4}$ & 5902 & 115 & 54 \\
\hline GO:BP & GO:0071704 & organic substance metabolic process & $4.91 \times 10^{-4}$ & 8088 & 115 & 65 \\
\hline GO:BP & GO:0044237 & cellular metabolic process & $7.73 \times 10^{-4}$ & 7793 & 115 & 63 \\
\hline GO:BP & GO:0044238 & primary metabolic process & $1.12 \times 10^{-3}$ & 7676 & 115 & 62 \\
\hline GO:BP & GO:0048519 & negative regulation of biological process & $2.26 \times 10^{-3}$ & 3508 & 115 & 37 \\
\hline GO:BP & GO:0009887 & animal organ morphogenesis & $3.77 \times 10^{-3}$ & 727 & 115 & 15 \\
\hline GO:BP & GO:0060255 & regulation of macromolecule metabolic process & $4.55 \times 10^{-3}$ & 4242 & 115 & 41 \\
\hline
\end{tabular}

(continued on next page) 
Table S4.4: (continued)

\begin{tabular}{|c|c|c|c|c|c|c|}
\hline Source & Term ID & Term name & $p$-value & Term size & Query size & Intersection \\
\hline GO:BP & GO:0018130 & heterocycle biosynthetic process & $4.77 \times 10^{-3}$ & 2721 & 115 & 31 \\
\hline GO:BP & GO:0019438 & aromatic compound biosynthetic process & $5.00 \times 10^{-3}$ & 2727 & 115 & 31 \\
\hline $\mathrm{GO}: \mathrm{BP}$ & GO:0050794 & regulation of cellular process & $5.53 \times 10^{-3}$ & 7623 & 115 & 60 \\
\hline GO:BP & GO:0006807 & nitrogen compound metabolic process & $5.62 \times 10^{-3}$ & 7249 & 115 & 58 \\
\hline GO:BP & GO:0008152 & metabolic process & $5.65 \times 10^{-3}$ & 8596 & 115 & 65 \\
\hline $\mathrm{GO}: \mathrm{BP}$ & GO:0080090 & regulation of primary metabolic process & $7.16 \times 10^{-3}$ & 3994 & 115 & 39 \\
\hline GO:BP & GO:1901362 & organic cyclic compound biosynthetic process & $8.69 \times 10^{-3}$ & 2800 & 115 & 31 \\
\hline GO:BP & GO:0034654 & nucleobase-containing compound biosynthetic process & $9.73 \times 10^{-3}$ & 2670 & 115 & 30 \\
\hline GO:BP & GO:0019222 & regulation of metabolic process & $1.26 \times 10^{-2}$ & 4578 & 115 & 42 \\
\hline GO:BP & GO:0031323 & regulation of cellular metabolic process & $1.87 \times 10^{-2}$ & 4153 & 115 & 39 \\
\hline GO:BP & GO:0006355 & regulation of transcription, DNA-templated & $1.90 \times 10^{-2}$ & 2190 & 115 & 26 \\
\hline GO:BP & GO:0006357 & regulation of transcription by RNA polymerase II & $2.25 \times 10^{-2}$ & 1546 & 115 & 21 \\
\hline $\mathrm{GO}: \mathrm{BP}$ & GO:2000112 & regulation of cellular macromolecule biosynthetic process & $2.52 \times 10^{-2}$ & 2509 & 115 & 28 \\
\hline GO:BP & GO:1903506 & regulation of nucleic acid-templated transcription & $2.72 \times 10^{-2}$ & 2235 & 115 & 26 \\
\hline $\mathrm{GO}: \mathrm{BP}$ & GO:2001141 & regulation of RNA biosynthetic process & $2.72 \times 10^{-2}$ & 2235 & 115 & 26 \\
\hline GO:BP & GO:0051171 & regulation of nitrogen compound metabolic process & $2.87 \times 10^{-2}$ & 3903 & 115 & 37 \\
\hline GO:BP & GO:0006366 & transcription by RNA polymerase II & $3.22 \times 10^{-2}$ & 1583 & 115 & 21 \\
\hline $\mathrm{GO}: \mathrm{BP}$ & GO:0008285 & negative regulation of cell population proliferation & $3.44 \times 10^{-2}$ & 388 & 115 & 10 \\
\hline GO:BP & GO:0006351 & transcription, DNA-templated & $3.69 \times 10^{-2}$ & 2274 & 115 & 26 \\
\hline GO:BP & GO:0010556 & regulation of macromolecule biosynthetic process & $4.12 \times 10^{-2}$ & 2576 & 115 & 28 \\
\hline $\mathrm{GO}: \mathrm{BP}$ & GO:0043170 & macromolecule metabolic process & $4.45 \times 10^{-2}$ & 6949 & 115 & 54 \\
\hline GO:BP & GO:0044271 & cellular nitrogen compound biosynthetic process & $4.52 \times 10^{-2}$ & 3190 & 115 & 32 \\
\hline $\mathrm{GO}: \mathrm{CC}$ & GO:0005575 & cellular_component & $8.98 \times 10^{-8}$ & 13932 & 115 & 97 \\
\hline $\mathrm{GO}: \mathrm{CC}$ & GO:0110165 & cellular anatomical entity & $2.04 \times 10^{-7}$ & 13827 & 115 & 96 \\
\hline $\mathrm{GO}: \mathrm{CC}$ & GO:0005622 & intracellular & $5.15 \times 10^{-6}$ & 10264 & 115 & 78 \\
\hline $\mathrm{GO}: \mathrm{CC}$ & GO:0043226 & organelle & $2.77 \times 10^{-5}$ & 9149 & 115 & 71 \\
\hline $\mathrm{GO}: \mathrm{CC}$ & GO:0043229 & intracellular organelle & $4.59 \times 10^{-5}$ & 8849 & 115 & 69 \\
\hline GO:CC & GO:0043227 & membrane-bounded organelle & $5.88 \times 10^{-5}$ & 7921 & 115 & 64 \\
\hline $\mathrm{GO}: \mathrm{CC}$ & GO:0043231 & intracellular membrane-bounded organelle & $6.61 \times 10^{-5}$ & 7375 & 115 & 61 \\
\hline $\mathrm{GO}: \mathrm{CC}$ & GO:0005737 & cytoplasm & $3.26 \times 10^{-4}$ & 7503 & 115 & 60 \\
\hline $\mathrm{GO}: \mathrm{CC}$ & GO:0005634 & nucleus & $1.07 \times 10^{-2}$ & 4975 & 115 & 42 \\
\hline GO:CC & GO:0005794 & Golgi apparatus & $4.12 \times 10^{-2}$ & 963 & 115 & 14 \\
\hline GO:MF & GO:0003674 & molecular_function & $2.14 \times 10^{-13}$ & 13343 & 115 & 103 \\
\hline GO:MF & GO:0005488 & binding & $4.88 \times 10^{-10}$ & 10509 & 115 & 87 \\
\hline GO:MF & GO:0043167 & ion binding & $7.49 \times 10^{-6}$ & 4187 & 115 & 45 \\
\hline GO:MF & GO:0005515 & protein binding & $7.71 \times 10^{-5}$ & 6570 & 115 & 57 \\
\hline GO:MF & GO:0046872 & metal ion binding & $2.46 \times 10^{-4}$ & 2430 & 115 & 30 \\
\hline GO:MF & GO:0003824 & catalytic activity & $3.91 \times 10^{-4}$ & 4943 & 115 & 46 \\
\hline GO:MF & GO:0043169 & cation binding & $4.37 \times 10^{-4}$ & 2497 & 115 & 30 \\
\hline GO:MF & GO:0003682 & chromatin binding & $2.37 \times 10^{-3}$ & 429 & 115 & 11 \\
\hline GO:MF & GO:0042578 & phosphoric ester hydrolase activity & $8.18 \times 10^{-3}$ & 319 & 115 & 9 \\
\hline GO:MF & GO:0019103 & pyrimidine nucleotide binding & $8.56 \times 10^{-3}$ & 2 & 115 & 2 \\
\hline GO:MF & GO:0016787 & hydrolase activity & $2.80 \times 10^{-2}$ & 2184 & 115 & 24 \\
\hline \multicolumn{7}{|c|}{ Enriched in Hum_BMD } \\
\hline $\mathrm{GO}: \mathrm{BP}$ & GO:0008150 & biological_process & $3.04 \times 10^{-7}$ & 13579 & 113 & 95 \\
\hline $\mathrm{GO}: \mathrm{BP}$ & GO:0009987 & cellular process & $1.39 \times 10^{-6}$ & 12832 & 113 & 91 \\
\hline GO:BP & GO:0032502 & developmental process & $3.80 \times 10^{-5}$ & 3940 & 113 & 43 \\
\hline $\mathrm{GO}: \mathrm{BP}$ & GO:0048856 & anatomical structure development & $4.20 \times 10^{-5}$ & 3647 & 113 & 41 \\
\hline GO:BP & GO:0032501 & multicellular organismal process & $5.47 \times 10^{-5}$ & 4463 & 113 & 46 \\
\hline GO:BP & GO:0007275 & multicellular organism development & $8.04 \times 10^{-5}$ & 3280 & 113 & 38 \\
\hline GO:BP & GO:0065007 & biological regulation & $8.81 \times 10^{-5}$ & 8517 & 113 & 68 \\
\hline GO:BP & GO:0048731 & system development & $1.10 \times 10^{-4}$ & 3027 & 113 & 36 \\
\hline GO:BP & GO:0050789 & regulation of biological process & $1.10 \times 10^{-4}$ & 7967 & 113 & 65 \\
\hline $\mathrm{GO}: \mathrm{BP}$ & GO:0050794 & regulation of cellular process & $1.39 \times 10^{-4}$ & 7623 & 113 & 63 \\
\hline GO:BP & GO:0048519 & negative regulation of biological process & $1.45 \times 10^{-3}$ & 3508 & 113 & 37 \\
\hline GO:BP & GO:0048523 & negative regulation of cellular process & $4.51 \times 10^{-3}$ & 3208 & 113 & 34 \\
\hline GO:BP & GO:0051246 & regulation of protein metabolic process & $2.87 \times 10^{-2}$ & 1861 & 113 & 23 \\
\hline GO:BP & GO:0051179 & localization & $3.36 \times 10^{-2}$ & 4500 & 113 & 40 \\
\hline GO:BP & GO:0032268 & regulation of cellular protein metabolic process & $3.62 \times 10^{-2}$ & 1753 & 113 & 22 \\
\hline GO:BP & GO:0031400 & negative regulation of protein modification process & $4.09 \times 10^{-2}$ & 401 & 113 & 10 \\
\hline GO:BP & GO:0098885 & modification of postsynaptic actin cytoskeleton & $4.84 \times 10^{-2}$ & 2 & 113 & 2 \\
\hline $\mathrm{GO}: \mathrm{CC}$ & GO:0005575 & cellular_component & $3.96 \times 10^{-14}$ & 13932 & 113 & 104 \\
\hline $\mathrm{GO}: \mathrm{CC}$ & GO:0110165 & cellular anatomical entity & $1.59 \times 10^{-13}$ & 13827 & 113 & 103 \\
\hline $\mathrm{GO}: \mathrm{CC}$ & GO:0005622 & intracellular & $3.21 \times 10^{-9}$ & 10264 & 113 & 83 \\
\hline GO:CC & GO:0005737 & cytoplasm & $2.56 \times 10^{-6}$ & 7503 & 113 & 64 \\
\hline $\mathrm{GO}: \mathrm{CC}$ & GO:0043226 & organelle & $3.53 \times 10^{-6}$ & 9149 & 113 & 72 \\
\hline $\mathrm{GO}: \mathrm{CC}$ & GO:0043229 & intracellular organelle & $6.28 \times 10^{-6}$ & 8849 & 113 & 70 \\
\hline GO:CC & GO:0005813 & centrosome & $1.99 \times 10^{-3}$ & 452 & 113 & 11 \\
\hline $\mathrm{GO}: \mathrm{CC}$ & GO:0005815 & microtubule organizing center & $1.06 \times 10^{-2}$ & 542 & 113 & 11 \\
\hline $\mathrm{GO}: \mathrm{CC}$ & GO:0098793 & presynapse & $1.17 \times 10^{-2}$ & 280 & 113 & 8 \\
\hline $\mathrm{GO}: \mathrm{CC}$ & GO:0043227 & membrane-bounded organelle & $1.36 \times 10^{-2}$ & 7921 & 113 & $\begin{array}{l}0 \\
57\end{array}$ \\
\hline $\mathrm{GO}: \mathrm{CC}$ & GO:0005856 & cytoskeleton & $2.11 \times 10^{-2}$ & 1685 & 113 & 20 \\
\hline GO:CC & GO:0043231 & intracellular membrane-bounded organelle & $3.40 \times 10^{-2}$ & 7375 & 113 & 53 \\
\hline GO:MF & GO:0003674 & molecular_function & $6.12 \times 10^{-8}$ & 13343 & 113 & 94 \\
\hline GO:MF & GO:0005488 & binding & $3.00 \times 10^{-6}$ & 10509 & 113 & 79 \\
\hline GO:MF & GO:0005515 & protein binding & $6.97 \times 10^{-4}$ & 6570 & 113 & 54 \\
\hline GO:MF & GO:0008641 & ubiquitin-like modifier activating enzyme activity & $6.14 \times 10^{-3}$ & 11 & 113 & 3 \\
\hline KEGG & KEGG:04310 & Wnt signaling pathway & $1.29 \times 10^{-2}$ & 135 & 113 & 5 \\
\hline KEGG & KEGG:00000 & KEGG root term & $4.06 \times 10^{-2}$ & 4773 & 113 & 36 \\
\hline
\end{tabular}




\section{General Discussion}

The aim of this work was to characterise the influence of genetics on the differentiation of bone stability and to evaluate its potential for improving bone health in laying hens. Studies were carried out at the phenotypic and genomic level. After the general introduction in Chapter 1, the two following chapters of this thesis focused on the possible effects of the hens' phylogenetic background and laying performance on skeletal traits. At this, Chapter 2 examined the relationship between bone strength and laying performance in hens in a normal metabolic state and performed genetic parameter estimations, while Chapter 3 focused on the influence of the two factors mentioned above on bone properties in a state of nutritive calcium deficiency. Finally, Chapter 4 dealt with the identification and functional annotation of candidate genes associated with bone quality measures.

Taking into account the results of the second and third chapters, this general discussion will first address the question of whether the phylogenetic origin and egg production level are two main determinants of bone stability. Subsequently, the second part of the discussion will focus on the potential of genetics to improve skeletal health in laying hens. To this end, the genetic parameter estimations from the second chapter and the outcomes from the genomic analyses presented in the fourth chapter are discussed in a broader context. In addition to the overarching discussion of the main results achieved, important methodological aspects are addressed in the following and an outlook for future research is given. At the end, the main conclusions of this thesis are drawn.

\subsection{Phylogenetic Origin and Egg Production Level - Two Main Determinants?}

\section{The Four-Line Animal Model}

As shown in the literature review, the two factors of phylogenetic origin and performance level are generally considered to have a high influence on hens' bone stability. However, our understanding of the interaction of these two factors is sparse, and this is where this work ties in. The experiments of this thesis were carried out applying the four-line animal model, which is characterised by a two-dimensional divergence with respect to these factors (see Figure 1.2). The model was developed as a part of a multidisciplinary collaboration at the Friedrich-LoefflerInstitut that aimed to investigate the adaptability of laying hens to changing environmental conditions. It was first introduced by Lieboldt et al. [1] describing the growth and performance of the four chicken lines. Since then, a number of studies have been conducted applying this model to investigate behavioural [2-4], nutritional [5, 6], parasitological [7] and immunological objectives [8,9]. Another group of studies dealt with bone characteristics $[10,11]$ and keel bone damages [12-14]. The experiments underlying this thesis complement these studies on skeletal integrity. 
The most striking advantage of the four-line animal model is that it allows the two factors of phylogenetic origin and performance level to be addressed within one study. This enables to investigate potential influences of both factors on a trait simultaneously. Moreover, it covers a broad spectrum of laying hen genetics as the lines cluster with regard to their phylogenetic origin $[15,16]$. However, considering the studies mentioned above, it becomes clear that disentangling these factors can be difficult. It seems that the most distinct demarcation of the lines with regard to one of the two dimensions can be observed when examining performance parameters [1, 10]. In contrast, the results for other traits are sometimes contradictory or ambiguous, which could indicate, for example, the effect of behavioural differences not accounted for by this model $[10-12,14]$.

Another critical point is that despite the phylogenetic relationships $[15,16]$, all lines in the model represent distinct strains which have evolved separately. To study selection effects in the true sense, the two lines of a phylogenetic group would have to have descended from the same founder and have been divergently selected over several generations. One such long-term study is that of Dunnington and Siegel [17], in which White Plymouth Rock chickens were divergently selected for eight-week body weight over 38 generations. In laying hens, we are only aware of shorter experiments, such as that of Bishop et al. [18], in which White Leghorn chickens were divergently selected for bone quality over five generations. However, given the clear divergence in productivity between WLA and R11 or BLA and L68 shown in Chapter 2, it seems justified to infer indications of different levels of productivity.

In summary, the four-line animal model is a very effective way of accounting for phylogenetic and performance effects within the same experiment, which is advantageous given the often limited experimental capacity.

\section{Effects of Egg Production}

One of the most important issues in relation to bone health in laying hens concerns the influence of egg production level on skeletal integrity. There is an ongoing discussion about whether and to what extent bone stability is influenced by hens' productivity. A common hypothesis is that the susceptibility to osteoporosis occurs because of physiological adaptations that have evolved for egg production in modern laying hens [19]. Accordingly, bone weakness is thought to be the result of gradual but persistent structural bone resorption to meet the calcium requirements for eggshell formation $[14,20]$. In this context, it is frequently claimed that there is a negative correlation between bone stability and egg number and that this is the result of intensive selection for laying performance $[19,21]$.

There are indeed results suggesting this conclusion and given the large number of studies in which traditional or low performing lines were inferior to modern laying hybrids in terms of bone health, this presumed negative correlation seems conclusive [22-26]. However, most of these studies drew their conclusions from comparisons of mean values obtained for different strains kept under similar conditions. Provided we only contrast differentially productive lines, our results from Chapter 2 also strongly suggest that bone fragility is mainly caused by high laying rates. This is supported by previous studies on the same four lines, where a correlation between poor bone quality and high performance was suggested based on line comparisons [10, 11]. One difficulty with this approach is that possible effects of the lines genetic background 
remain unconsidered, which can lead to an oversimplification of the differences in skeletal traits between genotypes [22].

Another argument pointing to a negative influence of high egg production relates to nonreproductive hens. Compared to birds in reproductive state, hens that do not lay eggs showed higher amounts of cortical and medullary tissue in the long bones [27] as well as an icreased keel bone density and a significantly lower risk of keel bone fractures $[13,28]$. Furthermore, a link between laying activity and fracture susceptibility is suspected because males usually have higher bone quality than females and are virtually non-osteoporotic $[19,29,30]$. However, increased bone strength can also be expected in hens with very low egg production [31, 32], as structural bone formation resumes when laying activity ceases [22]. Failure to account for non-laying and very low performing individuals during data analysis can lead to bias [18]. In the present study (Chapter 2), this was taken into account by excluding hens from the data set that either did not show continuous laying activity in the last three weeks before slaughter or whose total egg count did not exceed a certain line specific threshold. In retrospect, this approach seems to have been justified because, as shown in Figure 5.1, the inclusion of those birds that did not meet the specified criteria would inevitably have led to a distortion of the results. Figure 5.1 depicts the phenotypic correlation between total egg number and bone characteristics of the tibiotarsus, calculated either based on the full data set containing all hens sampled $(n=576)$ or based on the truncated one containing only those meeting the egg-laying criteria $(n=524)$. It can be clearly seen that in the case of the complete data set there is partial evidence of phenotypic correlations, apparently due to the effect of a few individuals that laid poorly and at the same time had high bone quality. These data points have a kind of leverage effect that can lead to a strong shift in the correlation. Our observations are supported by findings from [33], who also observed that a few chickens with particularly low laying performance and high bone index values cause a strong negative correlation between these traits. By excluding hens with less than 230 and 250 eggs laid, the phenotypic correlation declined from -0.36 to -0.06 and -0.05 , respectively. It has been argued that in these chickens, as the number of eggs decreases, the periods during which bone formation could potentially take place increase, finally resulting in higher bone strength [33].

Discarding outliers seems to be a crucial step in calculating valid correlations from which biological inferences can be drawn. Exclusion of non-layers can simply be done visually at dissection based on the presence of active ovarian follicles, however, data curation as in Chapter 2 necessarily requires individual performance records, which can be difficult to collect. In addition to cage housing, transponder-based nest boxes offer a way of recording these data $[34,35]$. Such a system was used in our second study presented in Chapter 3. However, as some hens did not use these nests at all or did not use them consistently, the manually recorded laying performance at pen level was used at the end for reasons of data validity. 
A

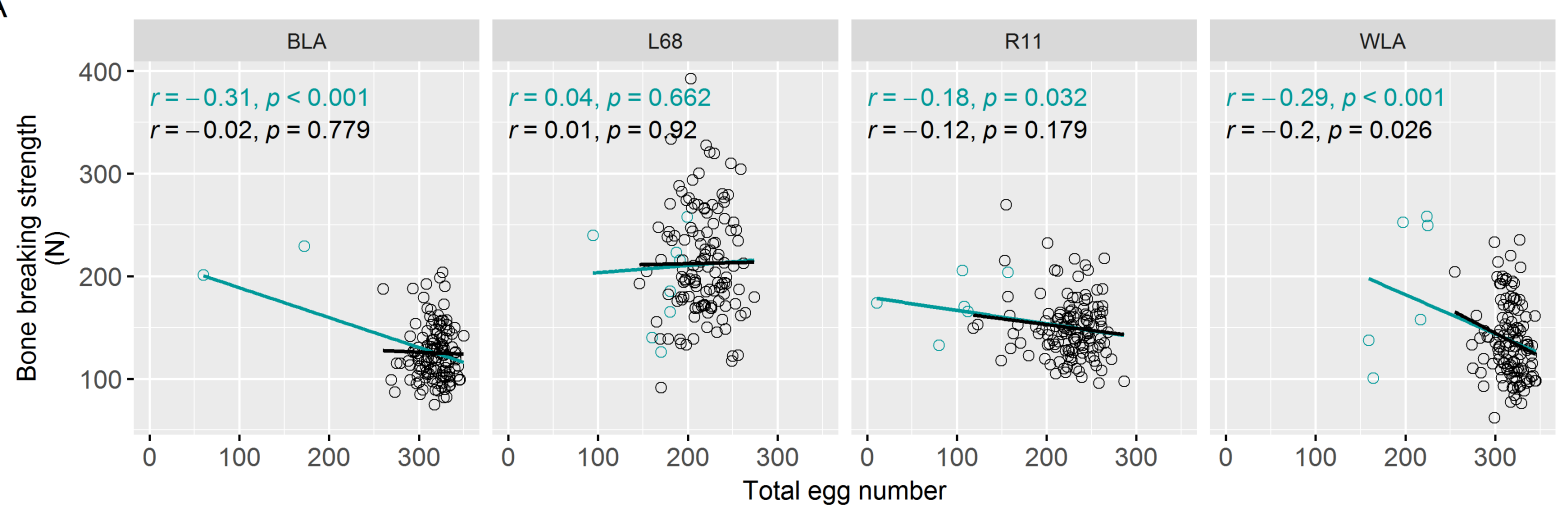

B

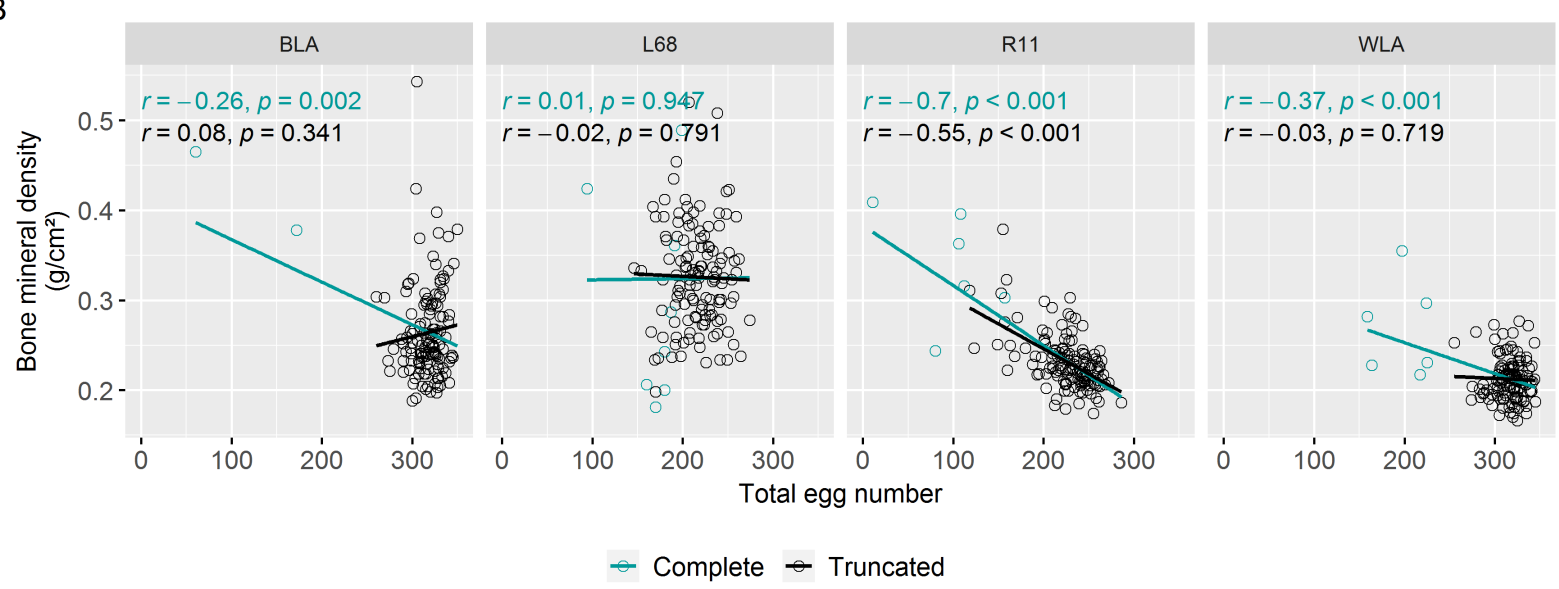

Figure 5.1: Linear relationship between total egg number and bone breaking strength $(\mathbf{A})$ or bone mineral density (B) of the tibiotarsus in four different chicken layer lines (BLA, L68, R11, WLA). Two phenotypic correlations are given for each trait $\times$ line combination, either based on the complete dataset $(n=576)$ (cyan) or on the truncated one in which non-layers and very low performing hens were excluded $(n=524)$ (black). Pearson's correlation coefficients; correlations are considered significantly different from zero at $p<0.05$.

Even when considering these methodological aspects, i.e. testing within lines and excluding low producing hens, there is no evidence in the literature that validly support the hypothesis of a direct relationship between egg number and bone stability $[19,21]$. Rather, it has been repeatedly observed that high laying performance or sufficient eggshell strength and bone stability can coexist $[19,36-40]$. Furthermore, skeletal problems were observed long before intensive selection for laying performance began [21, 41]. Certainly, the hypothesis is most likely to be questioned given the lack of phenotypic relationship. Based on the phenotypic correlations between egg production and bone strength, which were 0.0 and -0.16 , respectively, Rennie et al. [22] concluded that there could be at most a minimal link between these traits. Bishop et al. [18], who also observed no significant difference in mean egg number between the lines divergently selected for high and low bone stability, supported this. Furthermore, both, Jendral et al. [42] and Alfonso-Carrillo et al. [43] reported an absence of correlation between bone quality traits and egg production. Gebhardt-Henrich and Fröhlich [44] focused on keel bone damages and observed no relationship between the total egg number and fractures. Recently, Dunn et al. [19] investigated two phylogenetically unrelated lines and negated any phenotypic correlations between bone quality and post-peak egg production. These results are 
particularly interesting because the layer lines constituting the four-line animal model originate from the same breeds that were studied by Dunn et al. [19], namely White Leghorn and Rhode Island Red. In fact, their observations are very much in line with our findings from Chapter 2. Within the layer lines, we observed no significant effect of total eggshell production on either bone breaking strength or bone mineral density. Here our results could be even more meaningful, as we refer to the trait of eggshell production, which might be biologically closer to the pivot point of calcium supply than the egg number without simultaneous consideration of shell quality. Regression analyses showed a solitary effect of eggshell production on bone mineral density in line R11, which was recently confirmed for keel bone mineral density [14]. However, the effect size was rather small in both studies and was not significant at all in the other layer lines.

Taken together, it can be concluded that there is no strong correlation between the number of eggs laid or, given our own results, the amount of eggshell produced and bone stability. However, according to Toscano et al. [20] obviously there is a link of some kind between bone health and physiological adaptations to laying activity, so other factors than egg number, either causative or predisposing, should be considered. One of these factors is the laying persistency, as osteoporosis is caused by prolonged structural bone loss, so the duration of continuous laying could be a decisive factor [22, 33, 45]. Another promising factor is the development of medullary bone content, which can prevent cortical bone resorption by ensuring adequate calcium supply for eggshell formation [19, 43]. Recently, indications for a positive genetic correlation between late egg production and medullary bone mineralisation have been found [19]. Furthermore, the age at the onset of laying seems to be of particular importance for bone stability [20]. In this respect, the earlier switch to medullary bone formation associated with selection of hens for early sexual maturity and high peak production may have prevented both, the accumulation of sufficient amounts of medullary bone [43] and complete ossification of the skeleton $[19,20]$. A number of studies has observed effects of age at first egg suggesting a negative impact of early puberty on skeletal integrity $[19,29,44,46,47]$. As puberty is a trait with clear genetic determination [20], age at onset of laying seems to be most promising in terms of identifying possible links between laying activity and bone health. However, it is beyond the scope of the present study to investigate this in more detail. Therefore, follow-up studies are needed to further characterise the implications of this factor.

\section{Effects of Phylogeny}

In addition to the influence of productivity on laying hen skeleton, the question of the role of phylogenetic origin on bone health is also of particular importance. As reviewed in Chapter 1.4, the literature points to a strong phylogenetic effect on bone stability. Our results are supportive of this assumption in that marked phenotypic differences in production and bone characteristics were found between the groups of brown and white-egg layer lines in the present analyses (Chapter 2).

So far, however, little is known about what causes the differences in bone integrity, leaving the white-egg lines more susceptible to bone weakness $[13,48,49]$. Results from Habig et al. [49], who studied the same four lines, suggested a higher bone turnover in the high performing brown-egg line, while white-egg layers were assumed to have depleted bone calcium reserves and therefore rely more on dietary calcium intake. According to Dudde et al. [11] phylogenetic 
effects on bone stability may also reflect the brown-egg strains genetic heritage, as they are partly originating from Malay chickens, which are typical game birds in which robust individuals may have been favoured. Overall, it seems that brown-egg layers are basically in a more favourable situation, i.e. due to their physical constitution they are better equipped to cope with the physiological adaptations that have evolved for high egg laying activity. This constitutional aspect includes the tendency of the brown-egg laying hens to have a higher body weight, as observed in Chapter 2 and Chapter 3, which is associated with a higher mechanical load on the bones likely leading to a higher bone stability $[13,50,51]$.

Constitutional advantages of the brown-egg lines seem to be particularly rewarding in metabolic challenging situations. In the case of the present work, such a situation was induced by repeated transient periods of nutritional calcium deprivation (Chapter 3), which are known to trigger adaptive response [52]. The results showed that the hens reacted differently depending on their phylogenetic origin, whereas the genetic selection for increased egg production only played a minor role. White-egg lines showed a higher drop of egg production and quality as well as a higher level of bone degradation, suggesting that medullary reserves were unable to buffer temporary calcium fluctuations in these lines. The brown-egg strains, in contrast, showed a higher tolerance to the calcium deprivation, likely reflecting advantageous physical constitution in which the skeletal system was able to provide a higher amount of calcium without severe bone health restrictions.

In summary, phylogeny is a crucial factor for bone stability. That was confirmed by the results of this thesis. However, compared to the question of productivity effects, which has been extensively studied so that quite valid statements can be made on this, there is still a large gap in knowledge regarding phylogenetic influences on bone health. Currently, the phylogenetic component in bone stability seems to be primarily based on a more favourable physical constitution of the brown-egg chicken lines, but further studies addressing the exact mechanisms are needed.

\subsection{Potential of Genetics to Improve Bone Stability}

\section{Quantitative Genetic Properties of Skeletal Traits}

Given the considerable variation within and between different chicken breeds or lines, genetic determination of bone stability is considered high [25, 53, 54]. Hence, enormous potential is seen in animal breeding to improve the bone health of laying hens $[18,55]$.

The heredity of a desired trait is a critical factor and, in principle, bone quality traits in chickens are assumed to be weakly to moderately heritable $[47,53,56]$. Our results of the genetic parameters estimated in Chapter 2 are consistent with this range of inheritance. Average values of $h^{2}=0.38$ and $h^{2}=0.40$ were observed across the lines for bone breaking strength of the tibiotarsus and humerus, respectively. For bone mineral density, heritability estimates were $h^{2}=0.60$ for the tibiotarsus and $h^{2}=0.48$ for the humerus. These values are in line with those reported by others $[18,19]$ and indicate a moderate heritability of these traits. However, as shown in Table 2.4, we found a relatively large variation in the estimators among the four lines. This could be due to methodological reasons, as our sample size was rather small with an average of $n=131$ observations per line. Small sample size may also explain why in two cases no heritability estimation was possible due to a lack of convergence 
of the model. On the other hand, the variation in these estimates may reflect distinct breeding history of the four lines and/or diverse genetic composition $[16,19,57]$. It is probably a combination of biological and methodological effects.

The close phenotypic relationship between bone breaking strength and bone mineral density found in Chapter 2, was corresponding with a close and even more pronounced genetic relation as reflected in mean genetic correlations of $r_{\mathrm{g}}=0.61$ (tibiotarsus) and $r_{\mathrm{g}}=0.71$ (humerus), respectively. In this work, the genetic correlations were limited to bone traits. However, since the main goal of layer breeding will remain the number of saleable eggs, estimates of the genetic correlation between bone and performance traits in these four lines must follow to complete the picture. In view of the large number of studies reporting the absence or at most weak correlations $[19,22,43,53,58,59]$, it can be assumed that the two areas of skeletal properties and egg production and quality are relatively independent of each other. This would allow genetic selection for improved bone stability without unfavourable effects on hen productivity $[19,56]$. Furthermore, when selecting for improved bone strength, attention should be paid to body weight. An increase would have a negative effect on feed efficiency, but the body weight is positively correlated with bone stability at both phenotypic and genotypic levels $[32,43,50,60,61]$. Nevertheless, body weight independent selection for bone strength is possible $[18,53]$.

In order to select for a desired trait, it is important to accurately phenotype this trait in a large number of animals in addition to heritability [59]. In experimental settings, extensive and elaborate dissections and post mortem analyses are acceptable in order to capture the biology of the bone most precisely $[19,56,62]$. This includes virtually all the methods we have employed throughout the present studies, including the dual energy $\mathrm{X}$-ray absorptiometry and threepoint bending test measurement. However, other requirements are placed on phenotyping in commercial settings, as bone traits of interest must be assessable on large scale, i.e. populations of thousands of birds, rapidly and at low cost [63]. Furthermore, as post mortem analyses always require the rearing of a high number of possible selection candidates from each individual, the aim is to measure the trait on the selection candidate themselves [56, 64]. In this regard, the keel bone palpation and the radiography of the humerus are two traits under consideration that show reasonable heritabilities and can be assessed with sufficient accuracy on the living bird [47, 65]. According to Preisinger [64], both traits will be included in the balanced selection approach of commercial layer breeding programs.

\section{Application of Genomic Methods}

The introduction and continuous development of DNA marker technology has led to major advances in assessing genetic variability and identifying the genetic basis of diseases and traits $[56,65,66]$. After replacing microsatellites with single nucleotide polymorphisms (SNP) as genetic markers, the development of high-density SNP arrays followed, which are now used as a state-of-the-art technique for genetic analysis in animal breeding [66]. As described in Chapter 1.4 and Chapter 4, a number of potential genomic regions that may be related with bone health in laying hens have been identified through genome-wide analyses using microsatellite or SNP markers.

In the third study, presented in Chapter 4, we performed genome-wide association analyses, which aimed at identifying genomic regions associated with the bone phenotypes we previously 
collected in Chapter 2. Since bone characteristics are assumed to be polygenic, i.e. regulated by multiple functional genes, each of which has a rather small effect $[32,67]$, Random Forests (RF) classification was used for SNP identification in parallel to the traditional single-locus mixed linear model analysis. With an average of 275 identified SNPs, a considerably higher number of markers were classified as potentially informative in the RF classification compared to the mixed linear model analysis, in which an average of only 26 SNPs were identified across all bone and trait combinations. This reflects the great potential of RF classification to identify loci with modest effects [68-70], many of which probably did not reach the significance threshold in the traditional approach and thus remained unnoticed given many small signals in the corresponding Mahattan plots (Figure 4.2). RF classification seems to be more robust in terms of population stratification bias, as least in our case. Although the four-line animal model has advantages because it includes a broad diversity of different lines, population stratification is a challenge. The RF algorithm includes random shuffling of loci and phenotypes and irratic exclusion of SNPs, which seems to have solved this problem better than single marker regression. For future studies on these bone phenotypes, the combination of RF classification with other methods should be considered in order to increase the power to detect relevant genotype-phenotype associations [71]. Recently, Ramzan et al. [72] successfully performed a two-step analysis of egg quality data in which the detection of quantitative trait loci (QTL) was followed by RF classification to prioritise SNPs within these QTLs.

The need for follow-up studies also arises from the fact that the four layer lines were combined for the present analysis in order to obtain a sufficient sample size. Hence, the focus was on finding loci that might be significant for laying hens in general. However, considering the four-line animal model (see Chapter 1.6), a subsequent study should investigate the influence of phylogenetic origin and egg production level on bone phenotypic plasticity. Here, for example, F2 mapping populations could be generated within the white and brownegg lines, which show higher variability for the purpose of high-resolution mapping of loci. In addition, genomic regions of high monomorphism could be compared within phylogenetic groups, with such regions occurring only in highly selected lines possibly representing selection signatures. Subsequently, such an investigation for runs of homozygosity could be performed on phylogenetically divergent lines. A higher rate of homozygosity is to be expected especially in white-egg layers due to their overall lower genetic diversity [16].

Following the association analyses, sixteen candidate genes known from the literature to be functionally related to bone metabolism were identified in close proximity to significant SNPs. Their biological importance is suspected because they were partly involved in the Wnt signaling and MAPK signaling pathways, which are critical for bone stability. Although some of these genes are quite promising according to the current state of knowledge, they are all still suggestive genes for bone integrity in laying hens, whose biological significance and, most importantly, causality have yet to be proven in follow-up studies. Given the polygenic nature of complex traits such as bone stability, identification of causative genes is generally a challenging and tedious endeavour [56, 61, 73]. However, according to Johnsson [56], new interventions for increased bone health can be derived from biological insights drawn from causal genes. At this point, functional genomics approaches such as RNA sequencing could be used to gain deeper insights into bone plasticity, e.g. of phylogenetically divergent lines.

Practical application of genomic information in poultry breeding takes place in markerassisted selection (MAS), i.e. selection based on phenotypic information combined with genetic 
information obtained from SNP markers associated with QTLs [66]. It was initially thought that by identifying QTLs associated with genes related to bone properties, MAS for resistance to osteoporosis could be established [53]. However, unlike for major genes, conventional MAS does not seem feasible for complex traits such as bone strength [56]. Genomic selection, on the other hand, which is an advanced form of MAS that takes into account all markers across the entire genome $[66,74]$, appears promising in terms of improving bone health $[56,65,75]$. Various advantages led to the rapid adoption of genomic selection by poultry breeders [76]. This includes that by applying genomic selection, males and females can be selected for any traits soon after hatch thus enabling increasing selection pressure and making difficult measurements more practical [21, 59, 65]. Fulton [76] recently concluded that genomic selection is a valuable instrument that can significantly improve the efficiency and accuracy of breeding programs when combined with genetic selection methods.

\subsection{General Conclusions}

In this dissertation, the influence of genetics on the differentiation of bone stability traits in purebred chicken layer lines was characterised, focusing on effects of phylogenetic origin and egg laying performance. Furthermore, the potential of genetics for improving bone health was addressed. The main conclusions of this thesis can be summarised as follows:

i. No significant effect of total eggshell production on either bone breaking strength or bone mineral density was observed within the layer lines, suggesting that a high egg laying rate in itself does not necessarily pose a risk for bone weakness. Instead, a causal or predisposing effect of the age at onset of laying in combination with medullary bone quality is suspected.

ii. There were considerable differences in performance and bone characteristics between the phylogenetic groups, pointing to a strong effect of phylogenetic origin on bone stability. Our results suggest that the white-egg lines are more susceptible to bone weakness.

iii. The phylogenetic effect was particularly evident in the state of metabolic challenge, in which brown-egg lines proved more resilient and showed a less pronounced response to calcium deficiency. Our findings support the hypothesis of a more favourable physical constitution of brown-egg hens, possibly making them better adapted to high laying activity and more stable with regard to a varying calcium supply.

iv. The quantitive genetic analyses revealed a moderate inheritance of bone breaking strength and bone mineral density, suggesting that bone health could be improved through genetic selection. As there was no correlation between egg production and bone strength, selection for higher skeletal integrity seems to be possible, but effects of selection for extended laying persistence need to be monitored with regard to bone stability. 
v. Genomic analyses identified a number of promising candidate genes for bone stability, all of which have a rather small effect confirming the assumption that skeletal traits are influenced by multiple genes. Functional analyses consolidated the evidence for a biological significance of these genomic regions for the chicken. To our knowledge, this is the first study applying a machine learning approach to bone data in chickens.

\subsection{References}

[1] Lieboldt, M.-A., Halle, I., Frahm, J., Schrader, L., Baulain, U., Henning, M., Preisinger, R., Dänicke, S., Weigend, S. Phylogenic versus selection effects on growth development, egg laying and egg quality in purebred laying hens. Eur. Poult. Sci. 2015. 79.

[2] Dudde, A., Schrader, L., Weigend, S., Matthews, L. R., Krause, E. T. More eggs but less social and more fearful? Differences in behavioral traits in relation to the phylogenetic background and productivity level in laying hens. Appl. Anim. Behav. Sci. 2018. 209, 65-70.

[3] Dudde, A., Krause, E. T., Matthews, L. R., Schrader, L. More than eggs - relationship between productivity and learning in laying hens. Front. Psychol. 2018. 9, 2000.

[4] Krause, E. T., Schrader, L. High, low, or familiar? Nest site preferences of experienced laying hens. Br. Poult. Sci. 2018. 59, 359-364.

[5] Lieboldt, M.-A., Halle, I., Frahm, J., Schrader, L., Weigend, S., Preisinger, R., Dänicke, S. Effects of long-term graded L-arginine supply on growth development, egg laying and egg quality in four genetically diverse purebred layer lines. J. Poult. Sci. 2015. 53, 8-21.

[6] Höhne, A., Schrader, L., Weigend, S., Petow, S. Ghrelin plasma concentration does not covary with energy demand in adult laying hens. Domest. Anim. Endocrinol. 2017. 61, 77-83.

[7] Schares, G., Herrmann, D. C., Maksimov, P., Matzkeit, B., Conraths, F. J., Moré, G., Preisinger, R., Weigend, S. Chicken line-dependent mortality after experimental infection with three type IIxIII recombinant Toxoplasma gondii clones. Exp. Parasitol. 2017. 180, 101-111.

[8] Blohm, U., Weigend, S., Preisinger, R., Beer, M., Hoffmann, D. Immunological competence of different domestic chicken breeds against avian influenza infection. Avian Dis. 2016. 60, 262-268.

[9] Polasky, C., Weigend, S., Schrader, L., Berndt, A. Non-specific activation of CD8 $\alpha-$ characterised $\gamma \delta \mathrm{T}$ cells in PBL cultures of different chicken lines. Vet. Immunol. Immunopathol. 2016. 179, 1-7.

[10] Habig, C., Baulain, U., Henning, M., Scholz, A. M., Sharifi, A. R., Janisch, S., Simianer, H., Weigend, S. How bone stability in laying hens is affected by phylogenetic background and performance level. Eur. Poult. Sci. 2017. 81.

[11] Dudde, A., Weigend, S., Krause, E. T., Jansen, S., Habig, C., Schrader, L. Chickens in motion: Effects of egg production level and pen size on the motor abilities and bone stability of laying hens (Gallus gallus forma domestica). Appl. Anim. Behav. Sci. 2020. 227, 104998.

[12] Eusemann, B. K., Baulain, U., Schrader, L., Thöne-Reineke, C., Patt, A., Petow, S. Radiographic examination of keel bone damage in living laying hens of different strains kept in two housing systems. PLoS One 2018. 13, e0194974.

[13] Eusemann, B. K., Patt, A., Schrader, L., Weigend, S., Thöne-Reineke, C., Petow, S. The role of egg production in the etiology of keel bone damage in laying hens. Front. Vet. Sci. 2020. 7,81 . 
[14] Habig, C., Henning, M., Baulain, U., Jansen, S., Scholz, A. M., Weigend, S. Keel Bone Damage in Laying Hens-Its Relation to Bone Mineral Density, Body Growth Rate and Laying Performance. Animals 2021. 11, 1546.

[15] Lyimo, C. M., Weigend, A., Msoffe, P. L., Eding, H., Simianer, H., Weigend, S. Global diversity and genetic contributions of chicken populations from African, Asian and European regions. Anim. Genet. 2014. 45, 836-848.

[16] Malomane, D. K., Simianer, H., Weigend, A., Reimer, C., Schmitt, A. O., Weigend, S. The SYNBREED chicken diversity panel: a global resource to assess chicken diversity at high genomic resolution. BMC Genomics 2019. 20, 345.

[17] Dunnington, E. A., Siegel, P. B. Long-term divergent selection for eight-week body weight in white Plymouth rock chickens. Poult. Sci. 1996. 75, 1168-1179.

[18] Bishop, S. C., Fleming, R. H., McCormack, H. A., Flock, D. K., Whitehead, C. C. Inheritance of bone characteristics affecting osteoporosis in laying hens. Br. Poult. Sci. 2000. 41, 33-40.

[19] Dunn, I. C., De Koning, D.-J., McCormack, H. A., Fleming, R. H., Wilson, P. W., Andersson, B., Schmutz, M., Benavides, C., Dominguez-Gasca, N., Sanchez-Rodriguez, E., et al. No evidence that selection for egg production persistency causes loss of bone quality in laying hens. Genet. Sel. Evol. 2021. 53, 11.

[20] Toscano, M. J., Dunn, I. C., Christensen, J.-P., Petow, S., Kittelsen, K., Ulrich, R. Explanations for keel bone fractures in laying hens: Are there explanations in addition to elevated egg production? Poult. Sci. 2020. 99, 4183-4194.

[21] Dunn, I. C., Andersson, B., Fleming, R. H., De Koning, D. J., McCormack, H. M., RodriguezNavarro, A. B., Schmutz, M., Wilson, P. W. Quality of the laying hen skeleton; insights and solutions from genetics in Proceedings of The 17th International Conference on Production Diseases in Farm Animals. (Eds.: Bruckmaier, R. M., Gross, J. J.). Bern University. Bern, Switzerland. 2019, p. 50.

[22] Rennie, J. S., Fleming, R. H., McCormack, H. A., McCorquodale, C. C., Whitehead, C. C. Studies on effects of nutritional factors on bone structure and osteoporosis in laying hens. Br. Poult. Sci. 1997. 38, 417-424.

[23] Budgell, K. L., Silversides, F. G. Bone breakage in three strains of end-of-lay hens. Can. J. Anim. Sci. 2004. 84, 745-747.

[24] Hocking, P. M., Sandercock, D. A., Wilson, S., Fleming, R. H. Quantifying genetic (co)variation and effects of genetic selection on tibial bone morphology and quality in 37 lines of broiler, layer and traditional chickens. Br. Poult. Sci. 2009. 50, 443-450.

[25] Silversides, F. G., Singh, R., Cheng, K. M., Korver, D. R. Comparison of bones of 4 strains of laying hens kept in conventional cages and floor pens. Poult. Sci. 2012. 91, 1-7.

[26] Stratmann, A., Frohlich, E. K., Gebhardt-Henrich, S. G., Harlander-Matauschek, A., Wurbel, H., Toscano, M. J. Genetic selection to increase bone strength affects prevalence of keel bone damage and egg parameters in commercially housed laying hens. Poult. Sci. 2016. 95, 975-984.

[27] Kim, W. K., Donalson, L. M., Herrera, P., Woodward, C. L., Kubena, L. F., Nisbet, D. J., Ricke, S. C. Effects of different bone preparation methods (fresh, dry, and fat-free dry) on bone parameters and the correlations between bone breaking strength and the other bone parameters. Poult. Sci. 2004. 83, 1663-1666.

[28] Eusemann, B. K., Sharifi, A. R., Patt, A., Reinhard, A.-K., Schrader, L., Thöne-Reineke, C., Petow, S. Influence of a sustained release deslorelin acetate implant on reproductive physiology and associated traits in laying hens. Front. Physiol. 2018. 9, 1846. 
[29] Kittelsen, K. E., Jensen, P., Christensen, J. P., Toftaker, I., Moe, R. O., Vasdal, G. Prevalence of Keel Bone Damage in Red Jungle Fowls (Gallus gallus)—A Pilot Study. Animals 2020. 10, 1655.

[30] Kittelsen, K. E., Moe, R. O., Hansen, T. B., Toftaker, I., Christensen, J. P., Vasdal, G. A Descriptive Study of Keel Bone Fractures in Hens and Roosters from Four Non-Commercial Laying Breeds Housed in Furnished Cages. Animals 2020. 10, 2192.

[31] Whitehead, C. C., Fleming, R. H. Osteoporosis in cage layers. Poult. Sci. 2000. 79, 1033-1041.

[32] Raymond, B., Johansson, A. M., McCormack, H. A., Fleming, R. H., Schmutz, M., Dunn, I. C., De Koning, D. J. Genome-wide association study for bone strength in laying hens. J. Anim. Sci. 2018. 96, 2525-2535.

[33] Whitehead, C. C. Overview of bone biology in the egg-laying hen. Poult. Sci. 2004. 83, 193-199.

[34] Icken, W., Cavero, D., Schmutz, M., Preisinger, R. New phenotypes for new breeding goals in layers. Worlds Poult. Sci. J. 2012. 68, 387-400.

[35] Icken, W., Thurner, S., Heinrich, A., Kaiser, A., Cavero, D., Wendl, G., Fries, R., Schmutz, M., Preisinger, R. Higher precision level at individual laying performance tests in noncage housing systems. Poult. Sci. 2013. 92, 2276-2282.

[36] Rowland, L. O., Fry, J. L., Christmas, R. B., O'Steen, A. W., Harms, R. H. Differences in tibia strength and bone ash among strains of layers. Poult. Sci. 1972. 51, 1612-1615.

[37] Riczu, C. M., Saunders-Blades, J. L., Yngvesson, A. K., Robinson, F. E., Korver, D. R. Endof-cycle bone quality in white- and brown-egg laying hens. Poult. Sci. 2004. 83, 375-383.

[38] Schreiweis, M. A., Orban, J. I., Ledur, M. C., Moody, D. E., Hester, P. Y. Effects of ovulatory and egg laying cycle on bone mineral density and content of live white leghorns as assessed by dual-energy X-ray absorptiometry. Poult. Sci. 2004. 83, 1011-1019.

[39] Nasr, M. A. F., Murrell, J., Wilkins, L. J., Nicol, C. J. The effect of keel fractures on eggproduction parameters, mobility and behaviour in individual laying hens. Anim. Welfare 2012. $21,127-135$.

[40] Candelotto, L., Stratmann, A., Gebhardt-Henrich, S. G., Rufener, C., Braak, T. van de, Toscano, M. J. Susceptibility to keel bone fractures in laying hens and the role of genetic variation. Poult. Sci. 2017. 96, 3517-3528.

[41] Warren, D. C. Physiologic and genetic studies of crooked keels in chickens. Kansas Agricultural Experiment Station Technical Bulletin 1937. 44, 5-32.

[42] Jendral, M. J., Korver, D. R., Church, J. S., Feddes, J. J. R. Bone mineral density and breaking strength of White Leghorns housed in conventional, modified, and commercially available colony battery cages. Poult. Sci. 2008. 87, 828-837.

[43] Alfonso-Carrillo, C., Benavides-Reyes, C., Mozos, J. de los, Dominguez-Gasca, N., SanchezRodríguez, E., Garcia-Ruiz, A. I., Rodriguez-Navarro, A. B. Relationship between bone quality, egg production and eggshell quality in laying hens at the end of an extended production cycle (105 weeks). Animals 2021. 11, 623.

[44] Gebhardt-Henrich, S. G., Fröhlich, E. K. Early onset of laying and bumblefoot favor keel bone fractures. Animals 2015. 5, 1192-1206.

[45] Bain, M. M., Nys, Y., Dunn, I. C. Increasing persistency in lay and stabilising egg quality in longer laying cycles. What are the challenges? Br. Poult. Sci. 2016. 57, 330-338.

[46] Hocking, P. M., Bain, M., Channing, C. E., Fleming, R., Wilson, S. Genetic variation for egg production, egg quality and bone strength in selected and traditional breeds of laying fowl. Br. Poult. Sci. 2003. 44, 365-373. 
[47] Andersson, B., Icken, W., Kaufmann, F., Schmutz, M. Genetic aspects of keel bone deformities and fractures determined by palpation in laying hens. Lohmann Information 2017. $51,36-41$.

[48] Rayan, G. N., El-Attar, A. H., Fathi, M. M. Eggshell and bone quality in two different genetic groups of aged layer breeders. Braz. J. Poultry Sci. 2020. 22, 1-7.

[49] Habig, C., Weigend, A., Baulain, U., Petow, S., Weigend, S. Influence of Age and Phylogenetic Background on Blood Parameters Associated With Bone Metabolism in Laying Hens. Front. Physiol. 2021. 12, 592.

[50] Knowles, T. G., Broom, D. M., Gregory, N. G., Wilkins, L. J. Effect of bone strength on the frequency of broken bones in hens. Res. Vet. Sci. 1993. 54, 15-19.

[51] Rodriguez-Navarro, A. B., McCormack, H. M., Fleming, R. H., Alvarez-Lloret, P., RomeroPastor, J., Dominguez-Gasca, N., Prozorov, T., Dunn, I. C. Influence of physical activity on tibial bone material properties in laying hens. J. Struct. Biol. 2018. 201, 36-45.

[52] Zhao, S. C., Teng, X. Q., Xu, D. L., Chi, X., Ge, M., Xu, S. W. Influences of low level of dietary calcium on bone characters in laying hens. Poult. Sci. 2020. 99, 7084-7091.

[53] Whitehead, C. C., Fleming, R. H., Julian, R. J., Sørensen, P. Skeletal problems associated with selection for increased production in Poultry Genetics, Breeding and Biotechnology. (Eds.: Muir, W. M., Aggrey, S. E.). CABI Publishing. Wallingford, Oxfordshire, UK. 2003, pp. 29-52.

[54] Käppeli, S., Gebhardt-Henrich, S. G., Fröhlich, E., Pfulg, A., Schäublin, H., Stoffel, M. H. Effects of housing, perches, genetics, and 25-hydroxycholecalciferol on keel bone deformities in laying hens. Poult. Sci. 2011. 90, 1637-1644.

[55] Toscano, M. Skeletal problems in contemporary commercial laying hens in Advances in Poultry Welfare. (Ed.: Mench, J. A.). Woodhead Publishing. Cambridge, UK. 2018, pp. 151-173.

[56] Johnsson, M. Genetics and genomics of skeletal traits in Advances in poultry genetics and genomics. (Eds.: Aggrey, S. E., Zhou, H., Tixier-Boichard, M., Rhoads, D. D.). Burleigh Dodds Science Publishing. Cambridge, UK. 2020, pp. 307-323.

[57] Tixier-Boichard, M., Bed'hom, B., Rognon, X. Chicken domestication: From archeology to genomics. C. R. Biol. 2011. 334, 197-204.

[58] Fleming, R. H., McCormack, H. A., McTeir, L., Whitehead, C. C. Relationships between genetic, environmental and nutritional factors influencing osteoporosis in laying hens. $\mathrm{Br}$. Poult. Sci. 2006. 47, 742-755.

[59] Thiruvenkadan, A. K., Panneerselvam, S., Prabakaran, R. Layer breeding strategies: an overview. Worlds Poult. Sci. J. 2010. 66, 477-502.

[60] Rubin, C. J., Brändström, H., Wright, D., Kerje, S., Gunnarsson, U., Schutz, K., Fredriksson, R., Jensen, P., Andersson, L., Ohlsson, C., et al. Quantitative trait loci for BMD and bone strength in an intercross between domestic and wildtype chickens. J. Bone Miner. Res. 2007. 22, 375-384.

[61] De Koning, D.-J., Dominguez-Gasca, N., Fleming, R. H., Gill, A., Kurian, D., Law, A., McCormack, H. A., Morrice, D., Sanchez-Rodriguez, E., Rodriguez-Navarro, A. B., et al. An eQTL in the cystathionine beta synthase gene is linked to osteoporosis in laying hens. Genet. Sel. Evol. 2020. 52, 13.

[62] Clark, W. D., Cox, W. R., Silversides, F. G. Bone fracture incidence in end-of-lay highproducing, noncommercial laying hens identified using radiographs. Poult. Sci. 2008. 87, 1964-1970. 
[63] Lay, D. C., Fulton, R. M., Hester, P. Y., Karcher, D. M., Kjaer, J. B., Mench, J. A., Mullens, B. A., Newberry, R. C., Nicol, C. J., O'Sullivan, N. P., et al. Hen welfare in different housing systems. Poult. Sci. 2011. 90, 278-294.

[64] Preisinger, R. Kommerzielle Legehennenzucht: Rückblick und Ausblick. Züchtungskunde 2021. 93, 210-228.

[65] Preisinger, R. Innovative layer genetics to handle global challenges in egg production. $\mathrm{Br}$. Poult. Sci. 2018. 59, 1-6.

[66] Kumar Saxena, V., Kolluri, G. Selection Methods in Poultry Breeding: From Genetics to Genomics in Application of Genetics and Genomics in Poultry Science. (Ed.: Liu, X.). IntechOpen. Rijeka. 2018, pp. 19-32.

[67] Guo, J., Sun, C., Qu, L., Shen, M., Dou, T., Ma, M., Wang, K., Yang, N. Genetic architecture of bone quality variation in layer chickens revealed by a genome-wide association study. Sci. Rep. 2017. 7, 45317.

[68] Brieuc, M. S. O., Ono, K., Drinan, D. P., Naish, K. A. Integration of Random Forest with population-based outlier analyses provides insight on the genomic basis and evolution of run timing in Chinook salmon (Oncorhynchus tshawytscha). Mol. Ecol. 2015. 24, 2729-2746.

[69] Brieuc, M. S. O., Waters, C. D., Drinan, D. P., Naish, K. A. A practical introduction to Random Forest for genetic association studies in ecology and evolution. Mol. Ecol. Resour. 2018. 18, 755-766.

[70] Romagnoni, A., Jégou, S., Van Steen, K., Wainrib, G., Hugot, J.-P., Peyrin-Biroulet, L., Chamaillard, M., Colombel, J.-F., Cottone, M., D'Amato, M., et al. Comparative performances of machine learning methods for classifying Crohn Disease patients using genome-wide genotyping data. Sci. Rep. 2019. 9, 10351.

[71] Sun, S., Dong, B., Quan, Z. Revisiting genome-wide association studies from statistical modelling to machine learning. Brief. Bioinform. 2020, 1-10.

[72] Ramzan, F., Gültas, M., Bertram, H., Cavero, D., Schmitt, A. O. Combining Random Forests and a Signal Detection Method Leads to the Robust Detection of Genotype-Phenotype Associations. Genes 2020. 11, 892.

[73] Boyle, E. A., Li, Y. I., Pritchard, J. K. An Expanded View of Complex Traits: From Polygenic to Omnigenic. Cell 2017. 169, 1177-1186.

[74] Fulton, J. E. Genomic selection for poultry breeding. Anim. Front. 2012. 2, 30-36.

[75] Harlander-Matauschek, A., Rodenburg, T. B., Sandilands, V., Tobalske, B. W., Toscano, M. J. Causes of keel bone damage and their solutions in laying hens. Worlds Poult. Sci. J. 2015. 71, 461-472.

[76] Fulton, J. E. Application of genomic selection in commercial egg-type populations in Advances in poultry genetics and genomics. (Eds.: Aggrey, S. E., Zhou, H., Tixier-Boichard, M., Rhoads, D. D.). Burleigh Dodds Science Publishing. Cambridge, UK. 2020, pp. 403-420. 
6 Appendix 


\title{
6.1 Corrigendum
}

\section{animals}

Correction

\section{Correction: Jansen, S., et al. Relationship between Bone Stability and Egg Production in Genetically Divergent Chicken Layer Lines. Animals 2020, 10, 850}

\author{
Simon Jansen ${ }^{1, *(\mathbb{D})}$, Ulrich Baulain ${ }^{1}$, Christin Habig ${ }^{1}$, Annett Weigend ${ }^{1}$, Ingrid Halle ${ }^{2}$, \\ Armin Manfred Scholz $\left.{ }^{3}{ }^{(}\right)$, Henner Simianer ${ }^{4,5}$, Ahmad Reza Sharifi ${ }^{4,5}$ and Steffen Weigend ${ }^{1,5}$ (D) \\ 1 Institute of Farm Animal Genetics, Friedrich-Loeffler-Institut, 31535 Neustadt, Germany; \\ ulrich.baulain@fli.de (U.B.); christin.habig@fli.de (C.H.); annett.weigend@fli.de (A.W.); \\ steffen.weigend@fli.de (S.W.) \\ 2 Institute of Animal Nutrition, Friedrich-Loeffler-Institut, 38116 Braunschweig, Germany; ingrid.halle@fli.de \\ 3 Livestock Center of the Faculty of Veterinary Medicine, Ludwig-Maximilians-University Munich, \\ 85764 Oberschleissheim, Germany; armin.scholz@lvg.vetmed.uni-muenchen.de \\ 4 Animal Breeding and Genetics Group, Department of Animal Sciences, University of Göttingen, \\ 37075 Göttingen, Germany; hsimian@gwdg.de (H.S.); rsharif@gwdg.de (A.R.S.) \\ 5 Center for Integrated Breeding Research, University of Göttingen, 37075 Göttingen, Germany \\ * Correspondence: simon.jansen@fli.de
}

Received: 3 December 2020; Accepted: 7 December 2020; Published: 9 December 2020

The authors wish to make the following corrections to this paper [1]:

The body weight given as the weight of the 35th week of age is in fact the weight of the 49th week of age. However, the data presented are correct and the changes do not alter their interpretation.

\section{Main Body Paragraphs Correction}

There was an error in the original article. On page 4, Section 2.3. Experimental Procedure, 1st paragraph, the sentence:

"Body weight (g) was measured at hatch and during the experimental period (at week 21, 25, 35 and 69) using a digital table scale (CPA 16001S, Sartorius, Göttingen, Germany) with a weighing accuracy of $0.1 \mathrm{~g} . "$

should be

“Body weight (g) was measured at hatch and during the experimental period (at week 21, 25, 49 and 69) using a digital table scale (CPA 16001S, Sartorius, Göttingen, Germany) with a weighing accuracy of $0.1 \mathrm{~g} . "$

\section{Figures/Tables Correction}

Due to the mistake mentioned above, we need to make the following changes to figures and tables:

Replace Figure 1: 


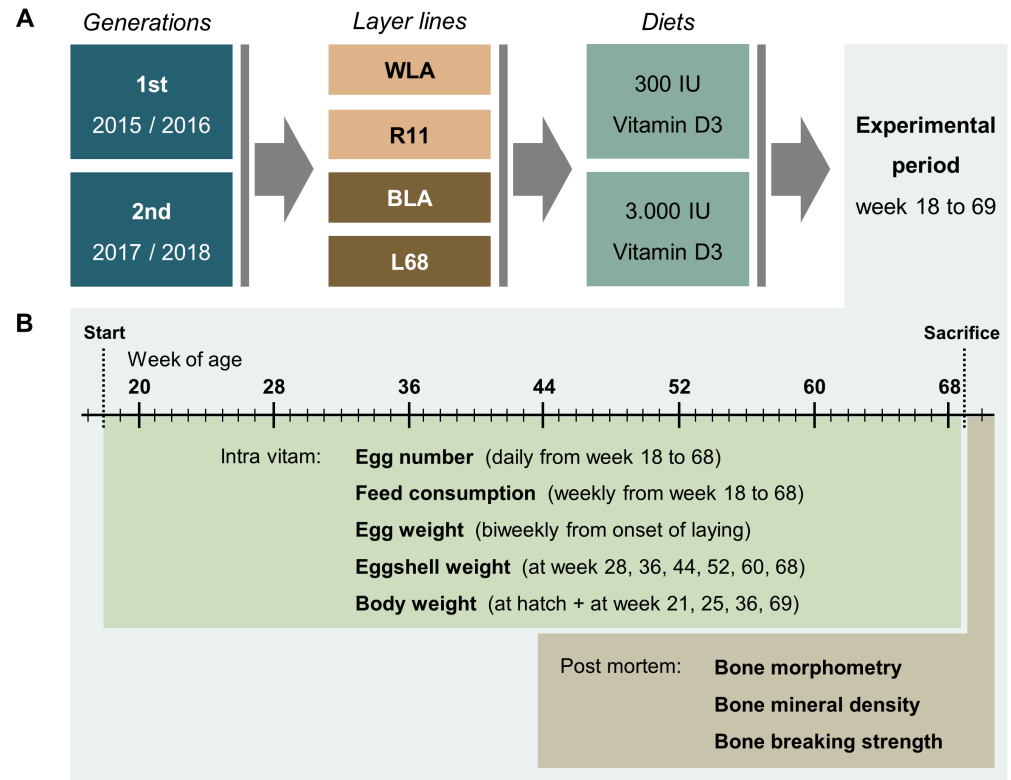

Figure 1. Schematic illustration of the experimental setup (A) and related data collection (B). In two consecutive generations, four chicken layer lines were allocated to a diet containing either 300 or $3000 \mathrm{IU}$ of vitamin D3. During the experimental period, data on egg number, egg quality, feed consumption, and body weight were collected as indicated. Post mortem, bone morphometry, bone mineral density, and bone breaking strength were assessed.

With new Figure 1 below:

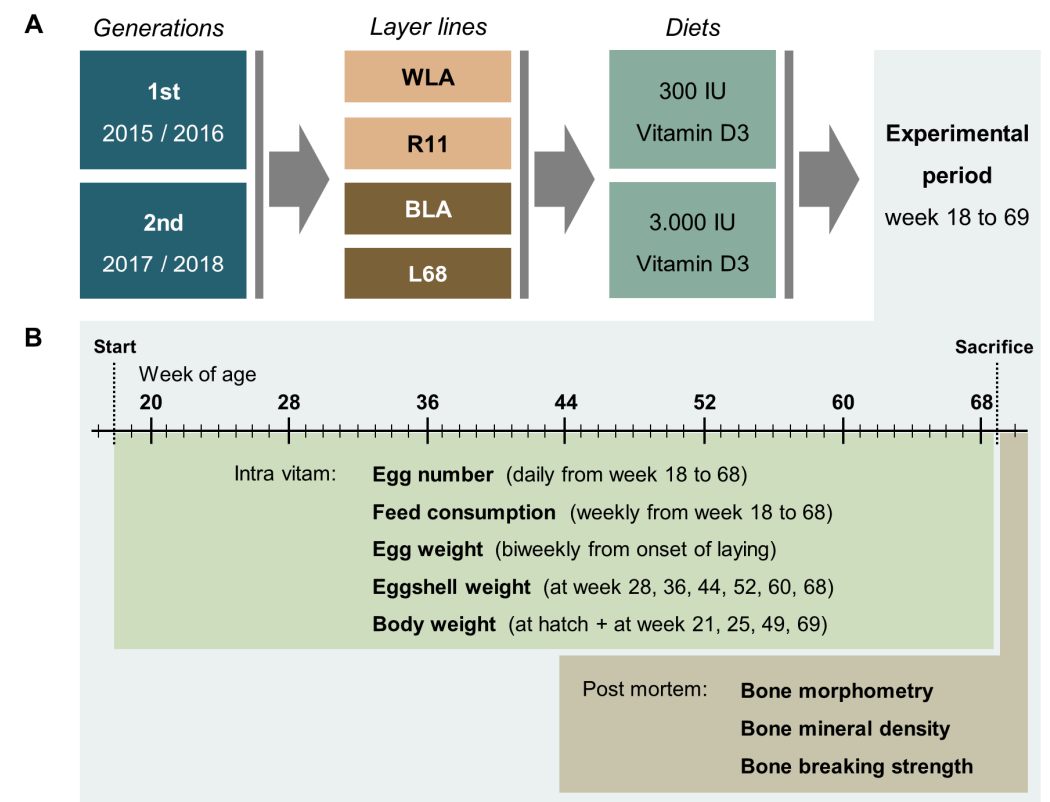

Figure 1. Schematic illustration of the experimental setup (A) and related data collection (B). In two consecutive generations, four chicken layer lines were allocated to a diet containing either 300 or 3000 IU of vitamin D3. During the experimental period, data on egg number, egg quality, feed consumption, and body weight were collected as indicated. Post mortem, bone morphometry, bone mineral density, and bone breaking strength were assessed. 


\section{Change in Supplementary File}

Replace Table S5:

Table S5. Sample sizes for the analysis.

\begin{tabular}{cccccc}
\hline Variable & Total & \multicolumn{4}{c}{ Layer Line } \\
\cline { 3 - 5 } & & WLA & R11 & BLA & L68 \\
\hline Laying maturity & 524 & 129 & 134 & 133 & 128 \\
Total number of eggs & 524 & 129 & 134 & 133 & 128 \\
Egg weight & 524 & 129 & 134 & 133 & 128 \\
Eggshell weight & 524 & 129 & 134 & 133 & 128 \\
Eggshell proportion & 524 & 129 & 134 & 133 & 128 \\
Total eggshell production & 524 & 129 & 134 & 133 & 128 \\
Daily feed consumption & 513 & 128 & 131 & 129 & 125 \\
Feed-to-egg-conversion rate & 513 & 128 & 131 & 129 & 125 \\
Feed-to-eggshell conversion rate & 513 & 128 & 131 & 129 & 125 \\
Bone breaking strength Tibiotarsus & 518 & 126 & 134 & 131 & 127 \\
Bone mineral density Tibiotarsus & 524 & 129 & 134 & 133 & 128 \\
Weight Tibiotarsus & 524 & 129 & 134 & 133 & 128 \\
Length Tibiotarsus & 524 & 129 & 134 & 133 & 128 \\
Thickness Tibiotarsus & 524 & 129 & 134 & 133 & 128 \\
Bone breaking strength Humerus & 516 & 128 & 131 & 132 & 125 \\
Bone mineral density Humerus & 519 & 129 & 134 & 128 & 128 \\
Weight Humerus & 521 & 127 & 134 & 132 & 128 \\
Length Humerus & 523 & 129 & 134 & 132 & 128 \\
Thickness Humerus & 523 & 129 & 134 & 132 & 128 \\
Body weight at hatch & 523 & 129 & 133 & 133 & 128 \\
Body weight at week 21 & 524 & 129 & 134 & 133 & 128 \\
Body weight at week 25 & 524 & 129 & 134 & 133 & 128 \\
Body weight at week 35 & 524 & 129 & 134 & 133 & 128 \\
Body weight at week 69 & 524 & 129 & 134 & 133 & 128 \\
\hline
\end{tabular}

With new Table S5:

Table S5. Sample sizes for the analysis.

\begin{tabular}{cccccc}
\hline Variable & Total & \multicolumn{3}{c}{ Layer Line } \\
\cline { 3 - 5 } & & WLA & R11 & BLA & L68 \\
\hline Laying maturity & 524 & 129 & 134 & 133 & 128 \\
Total number of eggs & 524 & 129 & 134 & 133 & 128 \\
Egg weight & 524 & 129 & 134 & 133 & 128 \\
Eggshell weight & 524 & 129 & 134 & 133 & 128 \\
Eggshell proportion & 524 & 129 & 134 & 133 & 128 \\
Total eggshell production & 524 & 129 & 134 & 133 & 128 \\
Daily feed consumption & 513 & 128 & 131 & 129 & 125 \\
Feed-to-egg-conversion rate & 513 & 128 & 131 & 129 & 125 \\
Feed-to-eggshell conversion rate & 513 & 128 & 131 & 129 & 125 \\
Bone breaking strength Tibiotarsus & 518 & 126 & 134 & 131 & 127 \\
Bone mineral density Tibiotarsus & 524 & 129 & 134 & 133 & 128 \\
Weight Tibiotarsus & 524 & 129 & 134 & 133 & 128 \\
Length Tibiotarsus & 524 & 129 & 134 & 133 & 128 \\
Thickness Tibiotarsus & 524 & 129 & 134 & 133 & 128 \\
Bone breaking strength Humerus & 516 & 128 & 131 & 132 & 125 \\
Bone mineral density Humerus & 519 & 129 & 134 & 128 & 128 \\
Weight Humerus & 521 & 127 & 134 & 132 & 128 \\
Length Humerus & 523 & 129 & 134 & 132 & 128 \\
Thickness Humerus & 523 & 129 & 134 & 132 & 128 \\
Body weight at hatch & 523 & 129 & 133 & 133 & 128 \\
Body weight at week 21 & 524 & 129 & 134 & 133 & 128 \\
Body weight at week 25 & 524 & 129 & 134 & 133 & 128 \\
Body weight at week 49 & 524 & 129 & 134 & 133 & 128 \\
Body weight at week 69 & 524 & 129 & 134 & 133 & 128 \\
\hline
\end{tabular}


And replace Table S6:

Table S6. Least squares means \pm standard errors and level of significance for body weight measured at hatching, and different weeks of age under the effect of layer line (LL), generation (Gen), and their interaction.

\begin{tabular}{|c|c|c|c|c|c|}
\hline \multirow{2}{*}{ Effect } & \multicolumn{5}{|c|}{ Body Weight (g) } \\
\hline & Hatch & Week 21 & Week 25 & Week 35 & Week 69 \\
\hline \multicolumn{6}{|l|}{ Layer line (LL) } \\
\hline WLA & $38.35 \pm 0.37^{\mathrm{a}}$ & $1420.02 \pm 15.79^{b}$ & $1468.38 \pm 16.19^{b}$ & $1497.54 \pm 20.46^{b}$ & $1504.23 \pm 22.26^{c}$ \\
\hline R11 & $33.17 \pm 0.36^{c}$ & $1040.84 \pm 15.60^{c}$ & $1236.40 \pm 15.99^{c}$ & $1309.28 \pm 20.21^{\mathrm{c}}$ & $1362.79 \pm 21.99^{\mathrm{d}}$ \\
\hline BLA & $39.35 \pm 0.37^{a}$ & $1584.15 \pm 15.71^{a}$ & $1663.55 \pm 16.11^{\mathrm{a}}$ & $1821.81 \pm 20.34^{\mathrm{a}}$ & $1838.10 \pm 22.13^{b}$ \\
\hline L68 & $34.84 \pm 0.37^{b}$ & $1568.91 \pm 15.81^{a}$ & $1714.92 \pm 16.21^{\mathrm{a}}$ & $1837.91 \pm 20.48^{a}$ & $1923.44 \pm 22.29^{a}$ \\
\hline \multicolumn{6}{|l|}{ Generation (Gen) } \\
\hline Gen 1 & $35.86 \pm 0.26$ & $1379.01 \pm 11.17$ & $1485.67 \pm 11.45$ & $1567.49 \pm 14.47$ & $1616.21 \pm 15.76$ \\
\hline Gen 2 & $37.00 \pm 0.26$ & $1427.95 \pm 11.07$ & $1555.96 \pm 11.36$ & $1665.79 \pm 14.34$ & $1698.07 \pm 15.59$ \\
\hline \multicolumn{6}{|l|}{$\mathrm{LL} \times \mathrm{Gen}$} \\
\hline WLA $\times$ Gen 1 & $37.77 \pm 0.52$ & $1376.72 \pm 22.36$ & $1415.84 \pm 22.91$ & $1460.33 \pm 28.96$ & $1443.48 \pm 31.51$ \\
\hline WLA $\times$ Gen 2 & $38.93 \pm 0.52$ & $1463.31 \pm 22.32$ & $1520.93 \pm 22.88$ & $1534.75 \pm 28.91$ & $1564.98 \pm 31.45$ \\
\hline R11 × Gen1 & $32.64 \pm 0.51$ & $1027.33 \pm 21.99$ & $1222.77 \pm 22.53$ & $1284.20 \pm 28.49$ & $1338.12 \pm 31.02$ \\
\hline $\mathrm{R} 11 \times \mathrm{Gen} 2$ & $33.69 \pm 0.52$ & $1054.36 \pm 22.14$ & $1250.04 \pm 22.71$ & $1334.37 \pm 28.66$ & $1387.45 \pm 31.17$ \\
\hline BLA × Gen1 & $38.84 \pm 0.52$ & $1549.66 \pm 22.41$ & $1627.91 \pm 22.97$ & $1767.90 \pm 29.03$ & $1804.33 \pm 31.60$ \\
\hline BLA × Gen 2 & $39.87 \pm 0.51$ & $1618.63 \pm 22.02$ & $1699.19 \pm 22.59$ & $1875.73 \pm 28.50$ & $1871.86 \pm 30.98$ \\
\hline L68 × Gen1 & $34.18 \pm 0.52$ & $1562.32 \pm 22.61$ & $1676.16 \pm 23.16$ & $1757.53 \pm 29.31$ & $1878.89 \pm 31.92$ \\
\hline L68 $\times$ Gen 2 & $35.51 \pm 0.51$ & $1575.50 \pm 22.11$ & $1753.67 \pm 22.68$ & $1918.30 \pm 28.62$ & $1968.00 \pm 31.12$ \\
\hline \multicolumn{6}{|c|}{ ANOVA significance level ( $p$ value) } \\
\hline & Layer & & Generation & & $\mathrm{LL} \times \mathrm{Gen}$ \\
\hline Hatch & $<0.0$ & & 0.0019 & & 0.9908 \\
\hline Week 21 & $<0.0$ & & 0.0020 & & 0.3097 \\
\hline Week 25 & $<0.0$ & & $<0.0001$ & & 0.3907 \\
\hline Week 35 & $<0.0$ & & $<0.0001$ & & 0.2486 \\
\hline Week 69 & 0.00 & & $<0.0001$ & & 0.6892 \\
\hline
\end{tabular}

Means within a column with different letters differ significantly (Tukey's HSD-Test, $p<0.05$ ).

With new Table S6:

Table S6. Least squares means \pm standard errors and level of significance for body weight measured at hatching, and different weeks of age under the effect of layer line (LL), generation (Gen), and their interaction.

\begin{tabular}{|c|c|c|c|c|c|}
\hline \multirow{2}{*}{ Effect } & \multicolumn{5}{|c|}{ Body Weight (g) } \\
\hline & Hatch & Week 21 & Week 25 & Week 49 & Week 69 \\
\hline \multicolumn{6}{|l|}{ Layer line (LL) } \\
\hline WLA & $38.35 \pm 0.37^{\mathrm{a}}$ & $1420.02 \pm 15.79^{b}$ & $1468.38 \pm 16.19^{b}$ & $1497.54 \pm 20.46^{b}$ & $1504.23 \pm 22.26^{c}$ \\
\hline R11 & $33.17 \pm 0.36^{c}$ & $1040.84 \pm 15.60^{c}$ & $1236.40 \pm 15.99^{c}$ & $1309.28 \pm 20.21^{c}$ & $1362.79 \pm 21.99^{d}$ \\
\hline BLA & $39.35 \pm 0.37^{a}$ & $1584.15 \pm 15.71^{\mathrm{a}}$ & $1663.55 \pm 16.11^{a}$ & $1821.81 \pm 20.34^{\mathrm{a}}$ & $1838.10 \pm 22.13^{b}$ \\
\hline L68 & $34.84 \pm 0.37^{b}$ & $1568.91 \pm 15.81^{\mathrm{a}}$ & $1714.92 \pm 16.21^{a}$ & $1837.91 \pm 20.48^{a}$ & $1923.44 \pm 22.29^{a}$ \\
\hline \multicolumn{6}{|l|}{ Generation (Gen) } \\
\hline Gen 1 & $35.86 \pm 0.26$ & $1379.01 \pm 11.17$ & $1485.67 \pm 11.45$ & $1567.49 \pm 14.47$ & $1616.21 \pm 15.76$ \\
\hline Gen 2 & $37.00 \pm 0.26$ & $1427.95 \pm 11.07$ & $1555.96 \pm 11.36$ & $1665.79 \pm 14.34$ & $1698.07 \pm 15.59$ \\
\hline \multicolumn{6}{|l|}{$\mathrm{LL} \times \mathrm{Gen}$} \\
\hline WLA $\times$ Gen 1 & $37.77 \pm 0.52$ & $1376.72 \pm 22.36$ & $1415.84 \pm 22.91$ & $1460.33 \pm 28.96$ & $1443.48 \pm 31.51$ \\
\hline WLA $\times$ Gen 2 & $38.93 \pm 0.52$ & $1463.31 \pm 22.32$ & $1520.93 \pm 22.88$ & $1534.75 \pm 28.91$ & $1564.98 \pm 31.45$ \\
\hline R11 × Gen 1 & $32.64 \pm 0.51$ & $1027.33 \pm 21.99$ & $1222.77 \pm 22.53$ & $1284.20 \pm 28.49$ & $1338.12 \pm 31.02$ \\
\hline $\mathrm{R} 11 \times \mathrm{Gen} 2$ & $33.69 \pm 0.52$ & $1054.36 \pm 22.14$ & $1250.04 \pm 22.71$ & $1334.37 \pm 28.66$ & $1387.45 \pm 31.17$ \\
\hline BLA × Gen 1 & $38.84 \pm 0.52$ & $1549.66 \pm 22.41$ & $1627.91 \pm 22.97$ & $1767.90 \pm 29.03$ & $1804.33 \pm 31.60$ \\
\hline BLA × Gen2 & $39.87 \pm 0.51$ & $1618.63 \pm 22.02$ & $1699.19 \pm 22.59$ & $1875.73 \pm 28.50$ & $1871.86 \pm 30.98$ \\
\hline L68 × Gen 1 & $34.18 \pm 0.52$ & $1562.32 \pm 22.61$ & $1676.16 \pm 23.16$ & $1757.53 \pm 29.31$ & $1878.89 \pm 31.92$ \\
\hline L68 $\times$ Gen 2 & $35.51 \pm 0.51$ & $1575.50 \pm 22.11$ & $1753.67 \pm 22.68$ & $1918.30 \pm 28.62$ & $1968.00 \pm 31.12$ \\
\hline \multicolumn{6}{|c|}{ ANOVA significance level ( $p$ value) } \\
\hline & Layer & & Generation & & $\mathrm{LL} \times$ Gen \\
\hline Hatch & $<0.0$ & & 0.0019 & & 0.9908 \\
\hline Week 21 & $<0.0$ & & 0.0020 & & 0.3097 \\
\hline Week 25 & $<0.0$ & & $<0.0001$ & & 0.3907 \\
\hline Week 49 & $<0.0$ & & $<0.0001$ & & 0.2486 \\
\hline Week 69 & 0.00 & & $<0.0001$ & & 0.6892 \\
\hline
\end{tabular}

Means within a column with different letters differ significantly (Tukey's HSD-Test, $p<0.05$ ). 
The authors would like to apologize for any inconvenience caused to the readers by these changes.

\section{Reference}

1. Jansen, S.; Baulain, U.; Habig, C.; Weigend, A.; Halle, I.; Scholz, A.M.; Simianer, H.; Sharifi, A.R.; Weigend, S. Relationship between Bone Stability and Egg Production in Genetically Divergent Chicken Layer Lines. Animals 2020, 10, 850. [CrossRef] [PubMed]

Publisher's Note: MDPI stays neutral with regard to jurisdictional claims in published maps and institutional affiliations.

(C) 2020 by the authors. Licensee MDPI, Basel, Switzerland. This article is an open access article distributed under the terms and conditions of the Creative Commons Attribution (CC BY) license (http://creativecommons.org/licenses/by/4.0/). 


\subsection{Acknowledgements}

I am sincerely grateful to the members of my thesis committee for their support, guidance and supervision throughout the past years. Many thanks to the reviewers of this thesis.

Dr. A. Reza Sharifi, I would like to express my gratitude to you for being my first supervisor. Thank you for the many critical discussions and the great support with the statistical data analysis, for which you have always freed up time.

Prof. Dr. Armin O. Schmitt, thank you very much for being a member of my thesis committee. I very much appreciate your valuable advice and constructive suggestions.

Prof. Dr. Georg Thaller, thank you very much for reviewing this thesis.

In particular, I would like to thank Prof. Dr. Steffen Weigend for leaving this topic to me. Steffen, I am deeply indebted to you for the great mentoring, the many critical discussions, the opportunity to present our results at international conferences and for giving me the freedom to pursue my own ideas. Your great support has guided me through my doctorate!

I would like to thank the head of the Institute of Farm Animal Genetics (ING), FriedrichLoeffler-Institut, for providing the workplace.

Furthermore, I would like to thank all members of the ING and the affiliated experimental research station, who have contributed to this work in many ways. I would like to express my gratitude to my colleagues in the Department of Breeding and Genetic Resources for their warm welcome into the working group, for their support in data collection and their engagement in the research projects on which this thesis is based. I enjoyed the time with you very much, inside and outside the institute.

Many thanks to the staff of the Department of Animal Sciences, University of Göttingen, for their valuable support in data acquisition and analysis.

I would like to thank all co-authors and project partners for the pleasant and successful cooperations. Thanks to the proofreaders for their helpful feedback.

The research in this thesis was funded by the Ministry for Science and Culture of the German State of Lower Saxony and the AdaptHuhn Initiative of the Friedrich-LoefflerInstitut.

Finally, I would like to thank my family and in particular Hannes for their invaluable support on the way to my doctorate. My deep and sincere gratitude to my parents who have enabled me to go this way. I dedicate this thesis to them. 


\subsection{Declarations}

1. Hereby, I declare that this doctoral thesis has not been presented to any other examination body either in its present or a similar form. Furthermore, I also affirm that I have not applied for a doctoral degree at any other university.

2. Hereby, I declare that this dissertation was undertaken independently and without any unauthorised aid.

Göttingen, 18 June 2021

Simon Jansen 